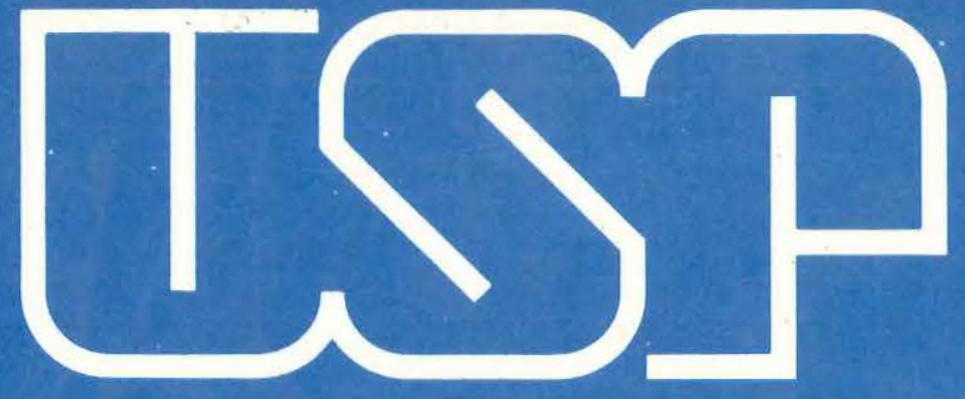

Campus de São Carlos

AVALIAÇÃO DAS PROPRIEDADES MECÂNICAS DE MISTURAS DE FOSFOGESSO E CIMENTO PARA USO NA CONSTRUÇÃO RODOVIÁRIA

MARCELO DE CASTRO TAKEDA

ORIENTADOR: PROF. DR. ALEXANDRE BENETTI PARREIRA

UNIVERSIDADE DE SÃO PAULO

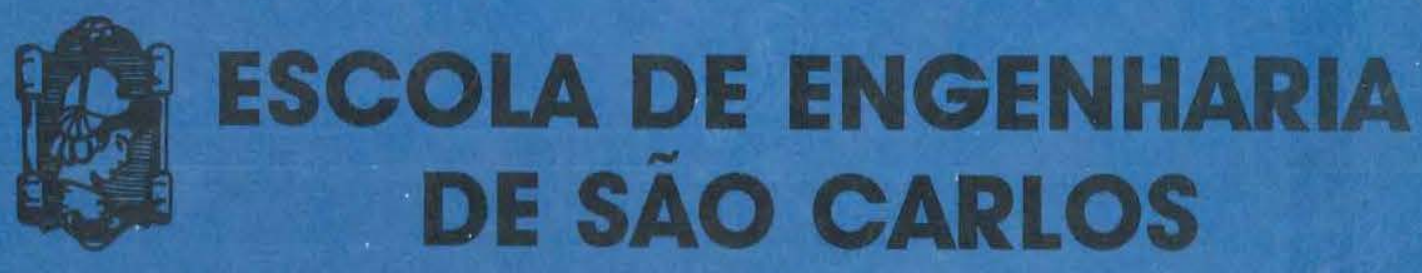




\title{
AVALIAÇÃO DAS PROPRIEDADES MECÂNICAS DE MISTURAS DE FOSFOGESSO E CIMENTO PARA USO NA CONSTRUÇÃO RODOVIÁRIA
}

\author{
Marcelo de CASTRO TAKeda
}

Dissertação apresentada à Escola de Engenharia de São Carlos da Universidade de São Paulo, como parte dos requisitos para a obtenção do título de Mestre em Transportes

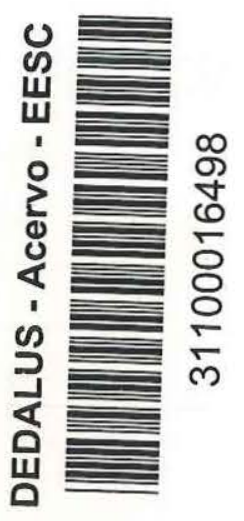

ORIENTADOR: Prof. Dr. Alexandre Benetti Parreira

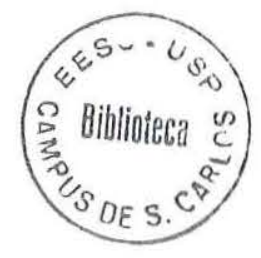

São Carlos 


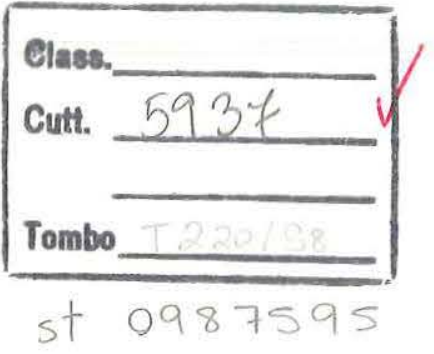

Ficha catalográfica preparada pela Seção de Tratamento da Inform ação do Serviço de Biblioteca - EESC-USP

$\mathrm{T} 136 \mathrm{a}$

Takeda, Marcelo de Castro

Avaliação das propriedades mecânicas de misturas de fosfogesso e cimento para uso na construção rodoviária / Marcelo de Castro Takeda. -- São Carlos, 1998.

Dissertação (Mestrado) -- Escola de Engenharia de São Carlos-Universidade de São Paulo, 1998.

Área: Transportes.

Orientador: Prof. Dr. Alexandre Benetti Parreira.

1. Fosfogesso. 2. Cimento. 3. Resíduo industrial. 4. Pavimentos. I. Título. 
Candidato: Engenheiro MARCELO DE CASTRO TAKEDA

Dissertação defendida e aprovada em 30-7-1998 pela Comissão Julgadora:

$$
\text { Alex B Parreira }
$$

Prof. Doutor ALEXANDRE BENETTI PARREIRA (Orientador) (Escola de Engenharia de São Carlos - Universidade de São Paulo)

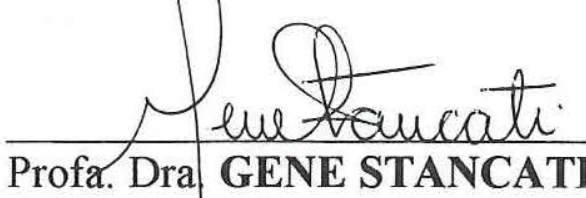

(Escola de Engenharia de São Carlos - Universidade de São Paulo)

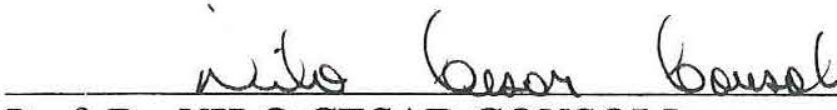

Prof. Dr. NILO CESAR CONSOLI

(Universidade Federal do Rio Grande do Sul)

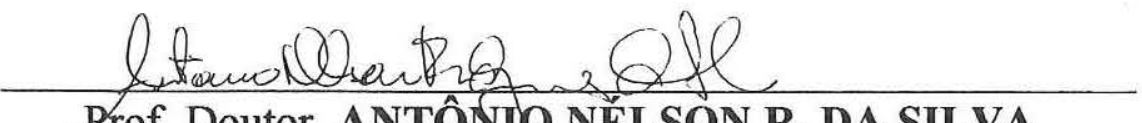

Prof. Doutor ANTÔNIIO NÉLSON R. DA SILVA

Coordenador da Área de Transportes

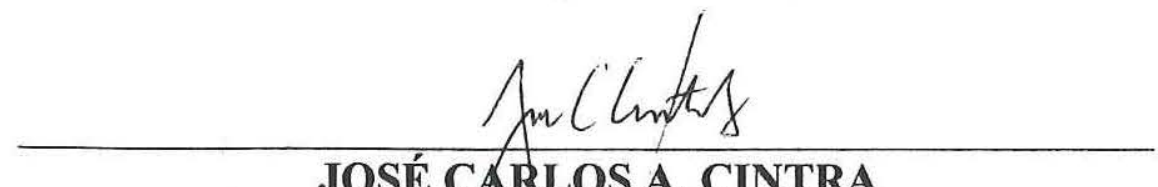

Presidente da Comissão de Pós-Graduação da EESC 
DEDICATÓRIA

Aos meus pais, Luiz e Shirley Aos meus irmãos, Reinaldo e Rogério 


\section{AGRADECIMENTOS}

Aos meus pais e irmãos, por todo apoio e incentivo durante todos os passos da minha vida.

Ao Prof. Dr. Alexandre Benetti Parreira, pelos ensinamentos, orientação e confiança depositados, pessoa a quem aprendi a respeitar e admirar.

À minha namorada Paula, por todo apoio, carinho, amizade, e principalmente a compreensão.

A todos os professores do Departamento de Transportes da Escola de Engenharia de São Carlos - USP, pelos ensinamentos transmitidos.

Ao $\mathrm{CNPq}$ e à FAPESP, pelo apoio financeiro durante a realização da pesquisa;

Aos funcionários, e amigos, do Laboratório de Estradas do Departamento de Transportes da EESC-USP, Gigante, Morasco e Oliveira, pelos ensinamentos e ajuda imprescindível na realização dos ensaios.

Ao José Luís e ao Benedito (Dito), pela ajuda prestada na realização dos ensaios de compressão simples e triaxiais dinâmicos;

À FOSFERTIL, pelo fornecimento do material usado nesta pesquisa;

Ao FIPR, pelo material bibliográfico, de suma importância para o desenvolvimento do trabalho;

A todos os amigos e colegas do Departamento de Transportes, em especial ao Ricardinho, à Sandra Oda, à Satie, à Sueli Ferreira, à Renata, à Cynthia, ao Eric, ao Hilário, ao Cássio, à Ana Rita, ao Rone, ao Ricardo, e ao Nilder, por tornarem mais fácil e feliz essa minha estada em São Carlos. 
LISTA DE FIGURAS VI

LISTA DE TABELAS XII

LISTA DE ABREVIATURAS E SIGLAS XV

LISTA DE SÍMBOLOS XVII

RESUMO XIX ABSTRACT $x x$

CAPÍTULO 1 - INTRODUÇÃO 1

1.1 Natureza do problema 1

1.2 Usos alternativos do fosfogesso 3

1.2.1 Matéria-prima química

1.2.2 Aplicações na agricultura

1.2.3 Materiais de construção 4

1.3 Objetivo 6

1.4 Método experimental _ 6

1.5 Organização do trabalho __ 7

CAPÍTULO 2 - REVISÃO BIBLIOGRÁFICA __ 8

2.1 Introdução __ 8

2.2 Processos de produção do ácido fosfórico __ 9

2.2.1 Processo di-hidratado _ 10

2.2.2 Processo hemi-hidratado_ 10

2.2.3 Processo hemi-di-hidratado___ 11

2.2.4 Processo anidro 12

2.3 Características químicas e físicas do fosfogesso ___ 13

2.3.1 Análise química 13

2.3.2 Análise morfológica 15

2.3.3 Análise Radiológica 18

2.3.4 Análise física — 20

2.4 Características e propriedades do fosfogesso compactado ___ 23 
Página iv

2.4.1 Relação entre massa específica seca e umidade ___ 23

2.4.2 Resistência à compressão simples __ 26

\subsection{Características e propriedades de misturas compactadas contendo}

fosfogesso 30

2.5.1 Fosfogesso e cimento 30

2.5.2 Concreto rolado compactado usando fosfogesso __ 50

2.5.3 Fosfogesso e solo

2.5.4 Fosfogesso e cinza volante___ 60

\section{CAPITULO 3 - MATERIAIS E MÉTODOS__ 64}

3.1 Introdução _ 64

3.2 Caraterísticas dos materiais __ 65

3.2.1 Fosfogesso 65

3.2.1.1 Granulometria 65

3.2.1.2 Massa específica dos sólidos __ 66

3.2.1.3 Limites de Atterberg___ 67

3.2.1.4 Análise química

3.2.2 Cimento _ 69

3.3 Estudo Preliminar $\quad 69$

3.3.1 Preparação dos materiais __ 70

3.3.2 Dosagem e mistura ___ 70

3.3.3 Compactação dos corpos de prova_

3.3.4 Procedimento de cura _ 72

3.3.5 Ensaio de compressão simples__ 72

3.4 Escolha do fosfogesso __ 73

3.5 Estudo Definitivo _ 74

3.5.1 Resumo das situações analisadas _ 75

3.5.2 Ensaio de compressão simples_ 77

3.5.3 Ensaio de compressão triaxial dinâmico __ 79

\section{CAPITULO 4 - APRESENTAÇÃO E DISCUSSÃO DOS RESULTADOS 83}

4.1 Introdução

4.2 Estudo Preliminar__ 83

4.2.1 Temperatura de secagem do fosfogesso

4.2.2 Ensaios de compactação e compressão simples para o fosfogesso $\mathrm{A}$

4.2.3 Estudo do efeito da neutralização do fosfogesso $A$

4.2.4 Ensaios de compactação e compressão simples com o fosfogesso $B$

4.3 Estudo Definitivo 98

4.3.1 Resistência determinada através de ensaios de compressão simples para o fosfogesso B $\quad 98$

4.3.1.1 Influência do teor de cimento __ 101

4.3.1.2 Influência do tempo de cura _-103

4.3.1.3 Influência da energia de compactação __ 104

4.3.1.4 Influência da condição de ensaio: sem imersão e após imersão __ 106

4.3.1.5 Influência da umidade de compactação _ 106

4.3.2 Deformabilidade deteminada através de ensaios de compressão simples para o fosfogesso B

4.3.2.1 Influência do teor de cimento

4.3.2.2 Influência do tempo de cura 113

4.3.2.3 Influência da energia de compactação __ 115 
Página v

4.3.2.4 Influência da condição de ensaio 115

4.3.2.5 Influência da umidade de compactação ___ 117

4.3.3 Deformabilidade deteminada através de ensaios triaxiais dinâmicos. 120

CAPITULO 5 - CONCLUSÕES E SUGESTÕES 128

5.1 Introdução 128

5.2 Conclusões 128

5.3 Sugestões e recomendações para trabalhos futuros 132

REFERÊNCIAS BIBLIOGRÁFICAS 133 ANEXO A 141

ANEXO B 151

ANEXO C 156

ANEXO D 161

ANEXO E 163 
FIGURA 1.1: DEPÓSITO DE FOSFOGESSO (FOSFERTIL-UBERABA, MG) 2

FIGURA 2.1: CRISTAIS ACICULARES (FONTE: MANGIN, 1978). 17

FIGURA 2.2: CRISTAIS TABULARES (FONTE: MANGIN, 1978) 17

FIGURA 2.3: AGREGADOS POLICRISTALINOS (FONTE: MANGIN, 1978) 17

FIGURA 2.4: CURVAS GRANULOMÉTRICAS DOS FOSFOGESSOS PRODUZIDOS NOS ESTADOS AMERICANOS DO TEXAS, FLORIDA E LOUISIANA (FONTE: ADAPTADO DE TAHA \& SEALS, 1991) 22

FIGURA 2.5: COMPARAÇÄO ENTRE A RESISTENCIA A COMPRESSÃO SIMPLES DE 8 FONTES DISTINTAS DE FOSFOGESSO PRODUZIDOS NOS ESTADOS UNIDOS, COMPACTADOS NO PROCTOR MODIFICADO, ENSAIADO NA CONDIÇÃO SECO AO AR (FONTE: ADAPTADO DE CHANG \& MANTELL, 1990). 27

FIGURA 2.6: RELAÇÃO ENTRE UMIDADE, MASSA ESPECIFICA SECA E RESISTENCIA A COMPRESSÄO SIMPLES PARA O FOSFOGESSO DI-HIDRATADO PRODUZIDO PELA INDÚSTRIA GARDINIER, COMPACTADO NA ENERGIA MODIFICADA E ENSAIADO EM CONDIÇŐES SECA AO AR (FONTE: ADAPTADO DE CHANG, CHIN \& HO, 1989 E CHANG \& MANTELL, 1990). 28

FIGURA 2.7: RELAÇÃO ENTRE UMIDADE, MASSA ESPECIFICA SECA E RESISTENCIA A COMPRESSÄO SIMPLES PARA O FOSFOGESSO DI-HIDRATADO PRODUZIDO PELA INDÚSTRIA AGRICO, COMPACTADO NA ENERGIA MODIFICADA E ENSAIADO EM CONDIÇÕES SECA AO AR (FONTE: ADAPTADO DE CHANG, CHIN \& HO, 1989 E CHANG \& MANTELL, 1990). 29

FIGURA 2.8: COMPARAÇÄO ENTRE A RESISTENCIA A COMPRESSÃO DE FOSFOGESSO ESTABILIZADO COM 6\% DE CIMENTO EM FUNÇÃO DO TEMPO DE CURA E PH (FONTE: ADAPTADO DE SAYLAK ET AL., 1988). 32

FIGURA 2.9: DESENVOLVIMENTO DA RESISTENCIA A COMPRESSÃO DO FOSFOGESSO PROVENIENTE DA PILHA 2, ESTABILIZADO COM CIMENTO PORTLAND, EM FUNÇÃO DO PERIODO DE CURA (FONTE: ADAPTADO DE GREGORY ET AL., 1984). 33

FIGURA 2.10: RESISTENCIA A COMPRESSÄO SIMPLES EM FUNÇÄO DO TEMPO DE CURA E TEOR DE CIMENTO (FONTE: ADAPTADO DE TAHA ET AL. 1992) 35

FIGURA 2.11: RESISTENNCIA A COMPRESSÃO SIMPLES DE MISTURAS COMPACTADAS NAS ENERGIAS NORMAL E INTERMEDIARIA, ESTABILIZADAS COM CIMENTO E CURADAS POR 7 DIAS E 28 DIAS (FONTE: ADAPTADO DE TAHA ET AL. 1992). 
Página vii

FIGURA 2.12: RESULTADOS DE ENSAIOS DE EXPANSÃO PARA MISTURAS DE FOSFOGESSO E 10\% DE CIMENTO (FONTE: ADAPTADO DE TAHA ET AL., 1992). 38

FIGURA 2.13: EFEITO DO TIPO E TEOR DE CIMENTO SOBRE A RESISTENCIA A COMPRESSÃO SIMPLES EM MISTURAS DE FOSFOGESSO E CIMENTO SUBMETIDAS A UM PERIODO DE CURA DE 7 DIAS E COMPACTADAS NA ENERGIA NORMAL (FONTE: ADAPTADO DE ONG ET AL., 1994). 41

FIGURA 2.14: EFEITO DO TIPO E TEOR DE CIMENTO SOBRE A RESISTENCIA A COMPRESSÃO SIMPLES EM MISTURAS DE FOSFOGESSO E CIMENTO SUBMETIDAS A UM PERIODO DE CURA DE 7 DIAS E COMPACTADAS NA ENERGIA INTERMEDIÁRIA (FONTE: ADAPTADO DE ONG ET AL., 1994). 41

FIGURA 2.15: COMPARAÇÃO ENTRE OS VALORES DO MÓDULO DE RESILIENNCIA DO FOSFOGESSO ESTABILIZADO COM CIMENTO E MATERIAIS CONVENCIONAIS PARA EXECUÇÃO DE BASES RODOVIARIAS (FONTE: TAHA E SEALS, 1991).

FIGURA 2.16: CURVA TENSÃO X DEFORMAÇÃO T(PICA PARA MISTURAS DE FOSFOGESSO E CIMENTO (FONTE: ADAPTADO DE GERRITY, 1996). 44

FIGURA 2.17: CURVA TENSÃO X DEFORMAÇÃO PARA MISTURAS DE FOSFOGESSO E CIMENTO SUBMETIDO A CARREGAMENTO CICLICO (FONTE: ADAPTADO DE GERRITY, 1996). 44

FIGURA 2.18: CURVAS DE COMPACTAÇÃO PARA MISTURAS DE FOSFOGESSO E SOLO (FONTE: CHANG \& MANTEL 1990). 53

FIGURA 2.19: RESISTENNCIA A COMPRESSÃO SIMPLES EM FUNÇÃO DO TEMPO DE CURA PARA MISTURAS DE FOSFOGESSO E SOLO NA PROPORÇÃO DE 1:2, COMPACTADAS COM TEORES DE UMIDADE VARIÁVEIS (FONTE: ADAPTADO DE CHANG \& MANTELL, 1990). 55

FIGURA 2.20: RESISTENNCIA A COMPRESSÃO SIMPLES EM FUNÇÃO DO TEMPO DE CURA PARA MISTURAS DE FOSFOGESSO DI-HIDRATADO, SOLO E CR-70 (FONTE: ADAPTADO DE FIGUEROA, 1987). 58

FIGURA 2.21: EFEITO DO TEOR DE CR-70 NA RESISTENNCIA A COMPRESSÃO SIMPLES DE MISTURAS DE FOSFOGESSO DI-HIDRATADO E SOLO SOB CONDIÇÕES IMERSAS E SECA AO AR (FONTE: ADAPTADO DE CHANG \& MANTELL, 1990). 59

FIGURA 2.22: DESENVOLVIMENTO DA RESISTENCIA A COMPRESSÃO SIMPLES PARA MISTURAS DE FOSFOGESSO E CINZA VOLANTE EM FUNÇÃO DO TEMPO DE CURA (FONTE: ADAPTADO DE GREGORY ET AL. 1984). 61

FIGURA 2.23:COMPARAÇÃO ENTRE A RESISTENCIA A COMPRESSÃO SIMPLES DE VARIAS MISTURAS DE FOSFOGESSO, CINZA VOLANTE E CAL (FONTE: ADAPTADO DE CHANG \& MANTELL 1990). 63

FIGURA 3.1: CURVAS GRANULOMÉTRICAS DOS FOSFOGESSOS A E B. 66

FIGURA 3.2: COMPACTADOR PARA CORPOS DE PROVA DE DIMENSŐES REDUZIDAS. _ 71

FIGURA 3.3: PRENSA DE MINI-CBR. 72

FIGURA 3.4:PRENSA USADA PARA ENSAIOS DE COMPRESSÃO SIMPLES 78

FIGURA 3.5: PRENSA USADA PARA OS ENSAIOS TRIAXIAIS DINÂMICOS. 80

FIGURA 4.1: CURVAS DE COMPACTAÇÃO PARA MISTURAS DE FOSFOGESSO A E CIMENTO COMPACTADAS NA ENERGIA NORMAL. 
FIGURA 4.2: CURVAS DE COMPACTAÇÃO PARA MISTURAS DE FOSFOGESSO A E CIMENTO COMPACTADAS NA ENERGIA INTERMEDIARIA 86

FIGURA 4.3: RESULTADOS DO ENSAIO DE COMPRESSÃO SIMPLES SOB CONDIÇÕES IMERSAS E NÃO IMERSAS, APÓS 7 DIAS DE CURA, PARA CORPOS DE PROVA COMPACTADOS NA ENERGIA NORMAL. 87

FIGURA 4.4: RESULTADOS DO ENSAIO DE COMPRESSÃO SIMPLES SOB CONDIÇÖES IMERSAS E NÃO IMERSAS, APÓS 7 DIAS DE CURA, PARA CORPOS DE PROVA COMPACTADOS NA ENERGIA INTERMEDIARIA. 88

FIGURA 4.5: CURVAS DE COMPACTAÇÃO PARA MISTURAS DE FOSFOGESSO B E CIMENTO COMPACTADAS NA ENERGIA NORMAL. 92

FIGURA 4.6: CURVAS DE COMPACTAÇÃO PARA MISTURAS DE FOSFOGESSO B E CIMENTO COMPACTADAS NA ENERGIA INTERMEDIARIA. 93

FIGURA 4.7: VARIAÇÃO DA UMIDADE ÓTIMA COM O TEOR DE CIMENTO PARA O FOSFOGESSO B. 95

FIGURA 4.8: VARIAÇÄO DA MASSA ESPECIFICA SECA MAXIMA COM O TEOR DE CIMENTO PARA COMPACTAÇÃO NAS ENERGIAS NORMAL E INTERMEDIÁRIA. 95

FIGURA 4.9: VALORES DE RESISTENCIA A COMPRESSÃO SIMPLES PARA MISTURAS CONTENDO FOSFOGESSO B, COMPACTADAS NA ENERGIA NORMAL E ENSAIADAS APÓS 7 DIAS DE CURA SOB DUAS CONDIÇÖES, IMERSO E NÃO IMERSO. 96

FIGURA 4.10: VALORES DE RESISTENCIA A COMPRESSÃO SIMPLES PARA MISTURAS CONTENDO FOSFOGESSO B, COMPACTADAS NA ENERGIA INTERMEDIARIA E ENSAIADAS APÓS 7 DIAS DE CURA SOB DUAS CONDIÇÖES, IMERSO E NÃO IMERSO.

FIGURA 4.11:RESISTENCIA A COMPRESSÃO SIMPLES EM FUNÇÃO DA ENERGIA DE COMPACTAÇÄO, DO TEMPO DE CURA E DO TEOR DE CIMENTO PARA ENSAIO SEM IMERSÃO PRÉVIA. 100

FIGURA 4.12: RESISTENCIA A COMPRESSÃO SIMPLES EM FUNÇÃO DA ENERGIA DE COMPACTAÇÃO, DO TEMPO DE CURA E DO TEOR DE CIMENTO PARA ENSAIO COM IMERSÄO PRÉVIA. 100

FIGURA 4.13: RESISTENCIA A COMPRESSÃO SIMPLES EM FUNÇÃO DO TEOR DE CIMENTO PARA MISTURAS COMPACTADAS NA ENERGIA NORMAL E ENSAIADAS EM CONDIÇÕES IMERSAS E NÃO IMERSAS. 102

FIGURA 4.14: RESISTENCIA A COMPRESSÃO SIMPLES EM FUNÇÃO DO TEOR DE CIMENTO PARA MISTURAS COMPACTADAS NA ENERGIA INTERMEDIÁRIA E ENSAIADAS EM CONDIÇÕES IMERSAS E NÃO IMERSAS. 103

FIGURA 4.15:RESISTÊNCIA A COMPRESSÃO SIMPLES EM FUNÇÃO DO TEMPO DE CURA, DO TEOR DE CIMENTO E DA CONDIÇÃO DE ENSAIO PARA MISTURAS COMPACTADAS NA ENERGIA NORMAL. 105

FIGURA 4.16: RESISTENNCIA A COMPRESSÃO SIMPLES EM FUNÇÃO DO TEMPO DE CURA, DO TEOR DE CIMENTO E DA CONDIÇÃO DE ENSAIO PARA MISTURAS COMPACTADAS NA ENERGIA INTERMEDIÁRIA. 105

FIGURA 4.17: RESISTENCIA A COMPRESSÃO SIMPLES EM FUNÇÃO DA UMIDADE DE COMPACTAÇÃO PARA MISTURAS COM $10 \%$ DE CIMENTO, SUBMETIDAS A PERIODOS DE CURA DE 7, 28 E 84 DIAS, ENSAIADAS EM CONDIÇÕES IMERSAS E NÃO IMERSAS E COMPACTADAS NA ENERGIA NORMAL. 
FIGURA 4.18: RESISTENNCIA A COMPRESSÃO SIMPLES EM FUNÇÃO DA UMIDADE DE COMPACTAÇÃO PARA MISTURAS COM 15\% DE CIMENTO, SUBMETIDAS A PERIODOS DE CURA DE 7, 28 E 84 DIAS, ENSAIADAS EM CONDIÇÕES IMERSAS E NÃO IMERSAS E COMPACTADAS NA ENERGIA NORMAL. 107

FIGURA 4.19: RESISTENCIA A COMPRESSÃO SIMPLES EM FUNÇÃO DA UMIDADE DE COMPACTAÇÃO PARA MISTURAS COM 7\% DE CIMENTO, SUBMETIDAS A PERIODOS DE CURA DE 7, 28 E 84 DIAS, ENSAIADAS EM CONDIÇÕES IMERSAS E NÃO IMERSAS E COMPACTADAS NA ENERGIA INTERMEDIARIA. 108

FIGURA 4.20: RESISTENCIA A COMPRESSÃO SIMPLES EM FUNÇÃO DA UMIDADE DE COMPACTAÇÃO PARA MISTURAS COM $10 \%$ DE CIMENTO, SUBMETIDAS A PERIODOS DE CURA DE 7, 28 E 84 DIAS, ENSAIADAS EM CONDIÇÕES IMERSAS E NÃO IMERSAS E COMPACTADAS NA ENERGIA INTERMEDIARIA. 108

FIGURA 4.21: EXEMPLO DE UMA CURVA X TENSÃO DEFORMAÇÃO, CORRESPONDENDO AO CORPO DE PROVA 5, COM 7\% DE CIMENTO, COMPACTADO NA Wo COM ENERGIA EQUIVALENTE AO PROCTOR INTERMEDIARIO, SUBMETIDO A 7 DIAS DE CURA E ENSAIADO APÓS IMERSÃO PRÉVIA EM AGUA. 109

FIGURA 4.22: EXEMPLO DE DETERMINAÇÃO DO COEFICIENTE A PARA CALCULO DO EO. DETERMINADA A PARTIR DOS RESULTADOS APRESENTADOS NA FIGURA 4.21.

FIGURA 4.23: MÓDULO TANGENTE INICIAL EM FUNÇÃO DO TEOR DE CIMENTO PARA MISTURAS COMPACTADAS NA ENERGIA NORMAL E ENSAIADAS EM CONDIÇÕES IMERSAS E NÃO IMERSAS. 112

FIGURA 4.24: MÓDULO TANGENTE INICIAL EM FUNÇÃO DO TEOR DE CIMENTO PARA MISTURAS COMPACTADAS NA ENERGIA INTERMEDIARIA E ENSAIADAS EM CONDIÇÕES IMERSAS E NÃO IMERSAS. 113

FIGURA 4.25: MÓDULO TANGENTE INICIAL EM FUNÇÃO DA ENERGIA DE COMPACTAÇÃO, DO TEMPO DE CURA E DO TEOR DE CIMENTO PARA ENSAIO SEM IMERSÃO PRÉVIA. 114

FIGURA 4.26: MÓDULO TANGENTE INICIAL EM FUNÇÃO DA ENERGIA DE COMPACTAÇÃO, DO TEMPO DE CURA E DO TEOR DE CIMENTO PARA ENSAIO COM IMERSÃO PRÉVIA. 115

FIGURA 4.27: MÓDULO TANGENTE INICIAL EM FUNÇÃO DO TEMPO DE CURA, DO TEOR DE CIMENTO E DA CONDIÇÃO DE ENSAIO PARA MISTURAS COMPACTADAS NA ENERGIA NORMAL. 116

FIGURA 4.28: MÓDULO TANGENTE INICIAL EM FUNÇÃO DO TEMPO DE CURA, DO TEOR DE CIMENTO E DA CONDIÇÃO DE ENSAIO PARA MISTURAS COMPACTADAS NA ENERGIA INTERMEDIÁRIA. 117

FIGURA 4.29: MÓDULO TANGENTE INICIAL EM FUNÇÃO DA UMIDADE DE COMPACTAÇÃO PARA MISTURAS COM $10 \%$ DE CIMENTO, SUBMETIDAS A PERIODOS DE CURA DE 7, 28 E 84 DIAS, ENSAIADAS EM CONDIÇŐES IMERSAS E NÃO IMERSAS, E COMPACTADAS NA ENERGIA NORMAL. 118

FIGURA 4.30: MÓDULO TANGENTE INICIAL EM FUNÇÃO DA UMIDADE DE COMPACTAÇÃO PARA MISTURAS COM $15 \%$ DE CIMENTO, SUBMETIDAS A PERIODOS DE CURA DE 7, 28 E 84 DIAS, ENSAIADAS EM CONDIÇÕES IMERSAS E NÄO IMERSAS, E COMPACTADAS NA ENERGIA NORMAL. 118

FIGURA 4.31: MÓDULO TANGENTE INICIAL EM FUNÇÃO DA UMIDADE DE COMPACTAÇÃO PARA MISTURAS COM 7\% DE CIMENTO, SUBMETIDAS A PERIODOS DE CURA 
Página $x$

DE 7, 28 E 84 DIAS, ENSAIADAS EM CONDIÇÕES IMERSAS E NÄO IMERSAS, E COMPACTADAS NA ENERGIA INTERMEDIARIA. 119

FIGURA 4.32: MÓDULO TANGENTE INICIAL EM FUNÇÃO DA UMIDADE DE COMPACTAÇÃO PARA MISTURAS COM $10 \%$ DE CIMENTO, SUBMETIDAS A PERIODOS DE CURA DE 7, 28 E 84 DIAS, ENSAIADAS EM CONDIÇÖES IMERSAS E NÃO IMERSAS, E COMPACTADAS NA ENERGIA INTERMEDIARIA. 119

FIGURA 4.33: VARIAÇÃO DO MÓDULO DE RESILIENNCIA COM A TENSÃO CONFINANTE PARA O CORPO DE PROVA 1. VALORES OBSERVADOS E RETA DE REGRESSÃO. 123

FIGURA 4.34: VARIAÇÃO DO MÓDULO DE RESILIÊNCIA COM A TENSÃO CONFINANTE PARA O CORPO DE PROVA 2. VALORES OBSERVADOS E RETA DE REGRESSÃO. 123

FIGURA 4.35: VARIAÇÃO DO MÓDULO DE RESILIÊNCIA COM A TENSÃO CONFINANTE PARA O CORPO DE PROVA 3. VALORES OBSERVADOS E RETA DE REGRESSÄO. 124

FIGURA 4.36: VARIAÇÃO DO MÓDULO DE RESILIENCIA COM A TENSÄO DESVIO PARA O CORPO DE PROVA 1. VALORES OBSERVADOS E RETA DE REGRESSÃO. 124

FIGURA 4.37: : VARIAÇÃO DO MÓDULO DE RESILIÊNCIA COM A TENSÃO DESVIO PARA O CORPO DE PROVA 2. VALORES OBSERVADOS E RETA DE REGRESSÃO. 124

FIGURA 4.38: VARIAÇÃO DO MÓDULO DE RESILIÊNCIA COM A TENSÃO DESVIO PARA O CORPO DE PROVA 3. VALORES OBSERVADOS E RETA DE REGRESSÃO. 125

FIGURA 4.39: VARIAÇÃO DO MÓDULO DE RESILIENCIA COM A TENSÃO DESVIO PARA OS CORPOS DE PROVA 1,2 E 3 . 125

FIGURA A.1: CURVA DE COMPACTAÇÃO E VALORES DE RESISTENCIA A COMPRESSÃO SIMPLES PARA CORPOS DE PROVA COMPOSTOS COM FOSFOGESSO A E 7\% DE CIMENTO COMPACTADOS NA ENERGIA NORMAL. 142

FIGURA A.2: CURVA DE COMPACTAÇÃO E VALORES DE RESISTENNCIA A COMPRESSÃO SIMPLES PARA CORPOS DE PROVA COMPOSTOS COM FOSFOGESSO A E $10 \%$ DE CIMENTO COMPACTADOS NA ENERGIA NORMAL. 142

FIGURA A.3: CURVA DE COMPACTAÇÃO E VALORES DE RESISTENCIA A COMPRESSÃO SIMPLES PARA CORPOS DE PROVA COMPOSTOS COM FOSFOGESSO A E $12 \%$ DE CIMENTO COMPACTADOS NA ENERGIA NORMAL. 143

FIGURA A.4: CURVA DE COMPACTAÇÃO E VALORES DE RESISTENNCIA A COMPRESSÃO SIMPLES PARA CORPOS DE PROVA COMPOSTOS COM FOSFOGESSO A E $15 \%$ DE CIMENTO COMPACTADOS NA ENERGIA NORMAL. 143

FIGURA A.5: CURVA DE COMPACTAÇÃO E VALORES DE RESISTENNCIA A COMPRESSÃO SIMPLES PARA CORPOS DE PROVA COMPOSTOS COM FOSFOGESSO A E 7\% DE CIMENTO COMPACTADOS NA ENERGIA INTERMEDIARIA. 144

FIGURA A.6: CURVA DE COMPACTAÇÃO E VALORES DE RESISTENNCIA A COMPRESSÃO SIMPLES PARA CORPOS DE PROVA COMPOSTOS COM FOSFOGESSO A E $10 \%$ DE CIMENTO COMPACTADOS NA ENERGIA INTERMEDIARIA. 144

FIGURA A.7: CURVA DE COMPACTAÇÃO E VALORES DE RESISTENNCIA A COMPRESSÃO SIMPLES PARA CORPOS DE PROVA COMPOSTOS COM FOSFOGESSO A E $12 \%$ DE CIMENTO COMPACTADOS NA ENERGIA INTERMEDIÁRIA. 145

FIGURA A.8: CURVA DE COMPACTAÇÃO E VALORES DE RESISTENCIA A COMPRESSÃO SIMPLES PARA CORPOS DE PROVA COMPOSTOS COM FOSFOGESSO A E $15 \%$ DE CIMENTO COMPACTADOS NA ENERGIA INTERMEDIARIA. 145 
FIGURA A.9: CURVA DE COMPACTAÇÄO E VALORES DE RESISTÊNCIA A COMPRESSÃO SIMPLES PARA CORPOS DE PROVA COMPOSTOS COM FOSFOGESSO B E 0\% DE CIMENTO COMPACTADOS NA ENERGIA NORMAL. 146

FIGURA A.10: CURVA DE COMPACTAÇÃO E VALORES DE RESISTENCIA A COMPRESSÃO SIMPLES PARA CORPOS DE PROVA COMPOSTOS COM FOSFOGESSO B E 7\% DE CIMENTO COMPACTADOS NA ENERGIA NORMAL. 146

FIGURA A.11: CURVA DE COMPACTAÇÃO E VALORES DE RESISTENNCIA A COMPRESSÃO SIMPLES PARA CORPOS DE PROVA COMPOSTOS COM FOSFOGESSO B E $10 \%$ DE CIMENTO COMPACTADOS NA ENERGIA NORMAL. 147

FIGURA A.12: CURVA DE COMPACTAÇÃO E VALORES DE RESISTENNCIA A COMPRESSÃO SIMPLES PARA CORPOS DE PROVA COMPOSTOS COM FOSFOGESSO B E $12 \%$ DE CIMENTO COMPACTADOS NA ENERGIA NORMAL. 147

FIGURA A.13: CURVA DE COMPACTAÇÃO E VALORES DE RESISTENNCIA A COMPRESSÃO SIMPLES PARA CORPOS DE PROVA COMPOSTOS COM FOSFOGESSO B E 15\% DE CIMENTO COMPACTADOS NA ENERGIA NORMAL. 148

FIGURA A.14: CURVA DE COMPACTAÇÃO E VALORES DE RESISTÊNCIA A COMPRESSÃO SIMPLES PARA CORPOS DE PROVA COMPOSTOS COM FOSFOGESSO B E $0 \%$ DE CIMENTO COMPACTADOS NA ENERGIA INTERMEDIARIA. 148

FIGURA A.15: CURVA DE COMPACTAÇÃO E VALORES DE RESISTENNCIA A COMPRESSÃO SIMPLES PARA CORPOS DE PROVA COMPOSTOS COM FOSFOGESSO B E 7\% DE CIMENTO COMPACTADOS NA ENERGIA INTERMEDIÁRIA. 149

FIGURA A.16: CURVA DE COMPACTAÇÃO E VALORES DE RESISTENCIA A COMPRESSÃO SIMPLES PARA CORPOS DE PROVA COMPOSTOS COM FOSFOGESSO B E $10 \%$ DE CIMENTO COMPACTADOS NA ENERGIA INTERMEDIÁRIA. 149

FIGURA A.17: CURVA DE COMPACTAÇÃO E VALORES DE RESISTENNCIA A COMPRESSÃO SIMPLES PARA CORPOS DE PROVA COMPOSTOS COM FOSFOGESSO B E $12 \%$ DE CIMENTO COMPACTADOS NA ENERGIA INTERMEDIÁRIA. 150

FIGURA A.18 CURVA DE COMPACTAÇÃO E VALORES DE RESISTENNCIA A COMPRESSÃO SIMPLES PARA CORPOS DE PROVA COMPOSTOS COM FOSFOGESSO B E $15 \%$ DE CIMENTO COMPACTADOS NA ENERGIA INTERMEDIÁRIA. 150 
TABELA 2.1: ANÁLISE QUIMICA DE UM FOSFOgESSO PRODUZIDO EM SANTA CATARINA (FONTE: TRICHÊS \& MACCARINI, 1988)

TABELA 2.2: COMPOSIÇÃO QUIMICA TIPICA DO FOSFOGESSO PRODUZIDO PELOS ESTADOS DO TEXAS, LOUISIANA E FLORIDA (FONTE: TAHA \& SEALS, 1991).

TABELA 2.3: CONCENTRAÇÃO DOS TRAÇOS DE ELEMENTOS QUIMICOS TIPICOS NO FOSFOGESSO (FONTE TAHA \& SEALS, 1991).

TABELA 2.4: RESULTADOS DA ANÁLISE FISICA DOS FOSFOGESSOS PRODUZIDOS PELOS ESTADOS DO TEXAS, LOUISIANA E FLORIDA (FONTE: TAHA E SEALS, 1991).

TABELA 2.5: MASSA ESPECIFICA SECA MAXIMA E UMIDADE OTIMA PARA FOSFOGESSO DE 7 FONTES DISTINTAS COMPACTADOS NA ENERGIA NORMAL (FONTE: ADAPTADO DE CHANG E MANTELL, 1990). 24

TABELA 2.6: MASSA ESPECIFICA SECA MAXIMA E UMIDADE OTIMA PARA FOSFOGESSO DE 7 FONTES DISTINTAS COMPACTADOS NA ENERGIA MODIFICADA (FONTE: ADAPTADO DE CHANG E MANTELL, 1990). 24

TABELA 2.7: MASSA ESPECIFICA SECA MAXIMA E UMIDADE ÓTIMA PARA FOSFOGESSO DE 8 FONTES DISTINTAS COMPACTADOS NA ENERGIA MODIFICADA (FONTE: CHANG E MANTELL, 1990) 25

TABELA 2.8: COMPARAÇÄO DA RESISTÊNCIA A COMPRESSÃO SIMPLES DE MISTURAS DE FOSFOGESSO E $10 \%$ DE CIMENTO, PARA UM PERIODO DE CURA DE 28 DIAS, E SOB DIFERENTES PROCESSOS DE CURA E DUAS ENERGIAS DE COMPACTAÇÃO (FONTE: LIN APUD TAHA \& SEALS, 1991).

TABELA 2.9: VALORES DE MASSA ESPECIFICA SECA MAXIMA E UMIDADE ÓTIMA EM FUNÇÃO DA ENERGIA DE COMPACTAÇÃO, DO TEOR E DO TIPO DE CIMENTO (FONTE: ADAPTADO DE ONG ET AL.,1994). 40

TABELA 2.10: VALORES MÉDIOS DOS RESULTADOS DE RESISTENNCIA A COMPRESSÃO SIMPLES E MÓDULO DE RESILIENNCIA (FONTE: GERRITY, 1996). 45

TABELA 2.11: ESPESSURA DE BASES EXECUTADAS NAS RUAS DA CIDADE DE LA PORT, TEXAS (FONTE: ADAPTADO DE CHANG E MANTELL, 1990). 48

TABELA 2.12: DESENVOLVIMENTO DA RESISTENCIA A COMPRESSÃO EM FUNÇÃO DO TEMPO DAS MISTURAS ESTUDADAS PARA UTILIZAÇÃO COMO CONCRETO ROLADO COMPACTADO. (FONTE: ADAPTADO DE CHANG 1988). 51

TABELA 3.1: ENSAIOS DE CARACTERIZAÇÃO DO FOSFOGESSO (FONTE: PROGEO, 1994 APUD ORTIZ, 1997) 
Página xiii

TABELA 3.2: COMPOSIÇÃO QUÍMICA DO FOSFOGESSO ESTOCADO NA ÁREA DE DEPÓSITO DA FOSFERTIL (FONTE: FOSFERTIL) 70

TABELA 3.3: SEQÜENCIA DE TENSÖES APLICADAS NO ENSAIO TRIAXIAL DINÂMICO. 80

TABELA 4.1: VALORES DE UMIDADE ÓTIMA MASSA ESPECIFICA SECA MÁXIMA PARA MISTURAS DE FOSFOGESSO A E CIMENTO. 86

TABELA 4.2: VALORES DE RESISTENNCIA A COMPRESSÃO SIMPLES PARA MISTURAS DE FOSFOGESSO A E CIMENTO AOS 7 DIAS DE CURA. 88

TABELA 4.3: VALORES DE RESISTENCIA A COMPRESSÃO SIMPLES PARA MISTURAS CONTENDO FOSFOGESSO NEUTRALIZADO E FOSFOGESSO NÃO NEUTRALIZADO COM $10 \%$ DE CIMENTO, APÓS 7 DIAS DE CURA, E COMPACTAÇÃO NA ENERGIA NORMAL. 91

TABELA 4.4: VALORES DE UMIDADE ÓTIMA E MASSA ESPECIFICA SECA MAXIMA PARA MISTURAS DE FOSFOGESSO B E CIMENTO.

TABELA 4.5: VALORES DE RESISTENNCIA A COMPRESSÃO SIMPLES PARA MISTURAS DE FOSFOGESSO A E CIMENTO AOS 7 DIAS DE CURA. 97

TABELA 4.6: CRESCIMENTO PERCENTUAL DOS VALORES DE RESISTÊNCIA A COMPRESSÃO SIMPLES DO FOSFOGESSO B EM RELAÇÃO AO FOSFOGESSO A. 98

TABELA 4.7: VALORES DE UMIDADE E MASSA ESPECIFICA DOS CORPOS DE PROVA USADOS NO ENSAIO TRIAXIAL DINÂMICO. 120

TABELA 4.8:VALORES DE MR, RESISTÊNCIA A COMPRESSÃO SIMPLES (RCS) E MÓDULO TANGENTE INICIAL (EO) ENCONTRADOS PARA OS CORPOS DE PROVA 1,2 E 3.

TABELA 4.9:PARÂMETROS DE REGRESSÃO E COEFICIENTES DE DETERMINAÇÃO DOS MODELOS CONSIDERADOS PARA OS RESULTADOS DOS ENSAIOS REALIZADOS NOS CORPOS DE PROVA 1, 2 E 3.

TABELA 4.10: COMPARAÇÃO ENTRE OS RESULTADOS DE RESISTENCIA A COMPRESSÃO SIMPLES (RCS) E MÓDULO TANGENTE INICIAL (EO) PARA CORPOS DE PROVA COM DIMENSÕES DIFERENTES. 127

TABELA B.1: VALORES DE RESISTÊNCIA A COMPRESSÃO SIMPLES PARA CORPOS DE PROVA ENSAIADOS SEM IMERSÃO PRÉVIA E COMPACTADOS NA ENERGIA NORMAL. 152

TABELA B.2: VALORES DE RESISTÊNCIA A COMPRESSÃO SIMPLES PARA CORPOS DE PROVA ENSAIADOS COM IMERSÃO PRÉVIA E COMPACTADOS NA ENERGIA NORMAL. 153

TABELA B.3: VALORES DE RESISTÊNCIA A COMPRESSÃO SIMPLES PARA CORPOS DE PROVA ENSAIADOS SEM IMERSÃO PRÉVIA E COMPACTADOS NA ENERGIA INTERMEDIARIA. 154 
Página xiv

TABELA B.4: VALORES DE RESISTÊNCIA À COMPRESSÃO SIMPLES PARA CORPOS DE PROVA ENSAIADOS COM IMERSÃO PRÉVIA E COMPACTADOS NA ENERGIA INTERMEDIARIA. 155

TABELA C.1:VALORES DE MÓDULO TANGENTE INICIAL (EO) PARA CORPOS DE PROVA ENSAIADOS SEM IMERSÃO E COMPACTADOS NA ENERGIA NORMAL. 157

TABELA C.2: VALORES DE MÓDULO TANGENTE INICIAL (EO) PARA CORPOS DE PROVA ENSAIADOS SEM IMERSÃO E COMPACTADOS NA ENERGIA NORMAL. 158

TABELA C.3: VALORES DE MÓDULO TANGENTE INICIAL (EO) PARA CORPOS DE PROVA ENSAIADOS SEM IMERSÃO E COMPACTADOS NA ENERGIA INTERMEDIARIA. 159

TABELA C.4: VALORES DE MÓDULO TANGENTE INICIAL (EO) PARA CORPOS DE PROVA ENSAIADOS COM IMERSÃO E COMPACTADOS NA ENERGIA INTERMEDIÁRIA.160 


\begin{tabular}{ll} 
ABNT & - Associação Brasileira de Normas Técnicas; \\
AR & - Areia de Rio; \\
ASTM & - American Society for Testing and Materials; \\
CBR & - California Bearing Ratio (Índice de Suporte Califórnia); \\
CP & - Cimento Portland; \\
CR & - Cura Rápida; \\
CV & - Cinza Volante; \\
DER-SP & - Departamento de Estradas de Estradas de Rodagem de São \\
& Paulo; \\
DH & - Di-hidratado; \\
EESC & - Escola de Engenharia de São Carlos; \\
EPA & - Environmental Protection Agency; \\
EUA & - Estados Unidos da América; \\
FG & - Fosfogesso; \\
FIPR & - Florida Institute of Phosphate Research; \\
HDH & - Hemi-di-hidratado; \\
HH & - Hemi-hidratado; \\
HRB & - Highway Research Board; \\
IP & - Índice de Plasticidade; \\
LCPC & - Laboratoire Central des Ponts et Chaussées; \\
LL & - Limite de Liquidez; \\
LP & - Limite de Plasticidade; \\
LVDT & - Linear Variable Differential Transducers; \\
MCT & - Miniatura, Compactado, Tropical; \\
\hline &
\end{tabular}


MG

$M L$

MRE

MTS

NP

PI

PN

ppm

RCS

TIF

USCS

USP

c.p.

CSP

UCS
- Minas Gerais;

- Material siltoso de baixa plasticidade;

- Maximum Reasonable Exposure;

- Material Testing System;

- Não Plástico;

- Proctor intermediário;

- Proctor normal;

- parte por milhão;

- Resistência à Compressão Simples;

- The Fertilizer Institute;

- Unified Soil Classification System;

- Universidade de São Paulo;

- corpo de prova;

- Cement Stabilized Phosphogypsum;

- Unconfined Compressive Strength; 


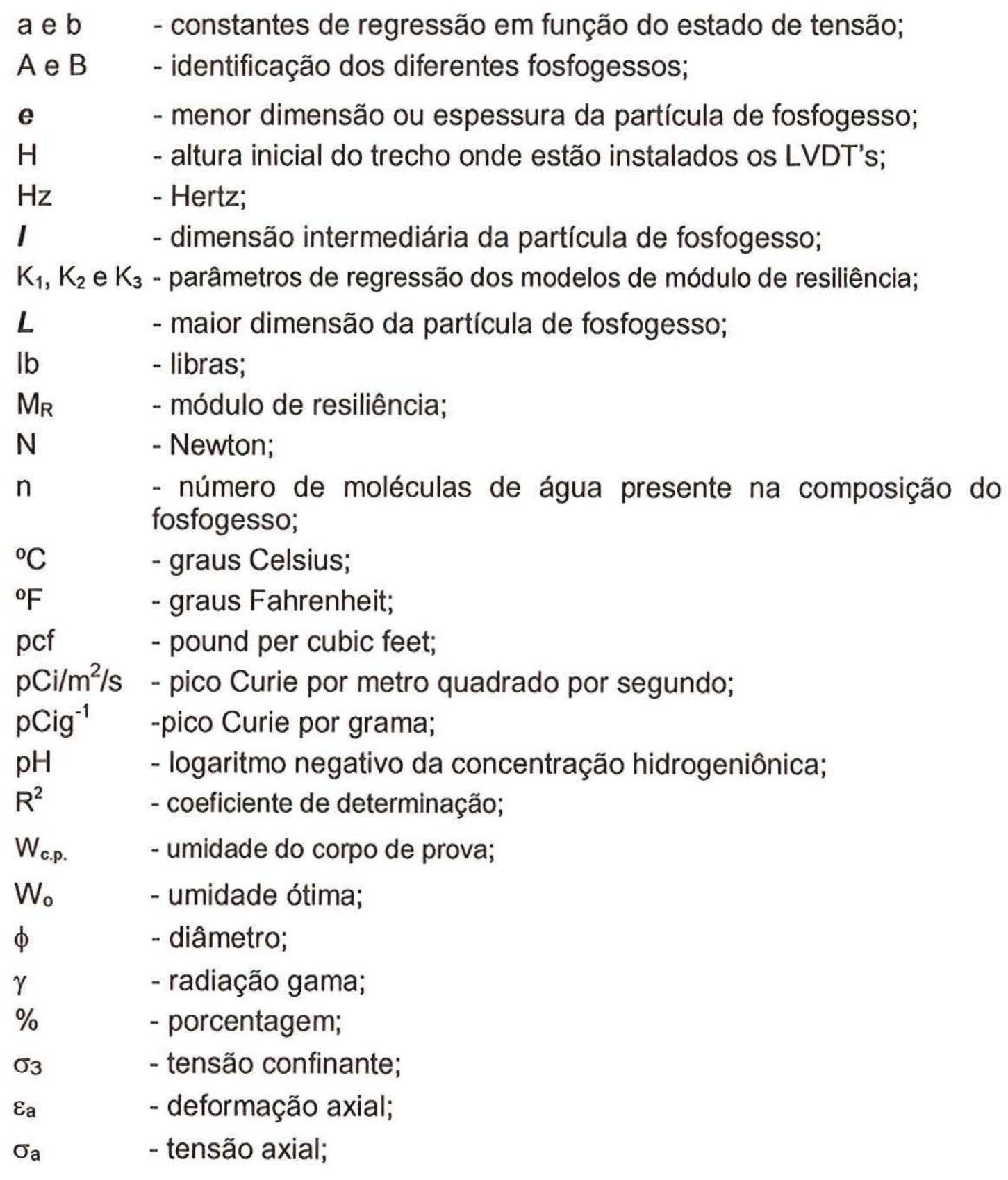


$\sigma_{d} \quad$ - tensão desvio;

$\rho_{\text {dc.p. }} \quad$ - massa específica seca do corpo de prova;

$\Delta \mathrm{h} \quad$ - deslocamentos recuperáveis medidos pelos LVDT's;

$\varepsilon_{R} \quad$ - deformação resiliente; 
RESUMO

O fosfogesso é um resíduo sólido da produção do ácido fosfórico, principal componente dos fertilizantes fosfatados, que por suas características químicas e radiológicas constitui-se num elemento agressivo ao meio-ambiente.

O crescimento dos estoques de fosfogesso e a preocupação cada vez maior com o meio ambiente têm levado ao aumento das restrições à continuidade do seu armazenamento a céu aberto, incentivando a busca de alternativas para o seu uso.

O objetivo principal deste trabalho é avaliar o efeito da adição de cimento ao fosfogesso com vistas a sua utilização na execução de bases e sub-bases rodoviárias. No estudo analisou-se a deformabilidade e a resistência à compressão simples de corpos de prova compactados compostos de misturas de fosfogesso e cimento. Estudaram-se misturas com 4 teores de cimento, $7 \%, 10 \%, 12 \%$ e $15 \%$. Os corpos de prova foram compactados na umidade ótima $\left(w_{0}\right)$ e na $w_{0} \pm 2 \%$, nas energias normal e intermediária, passando por 4 períodos de cura, $\mid 7,14,28$ e 84 dias, ensaiados em condições não imersas e imersas em água.

Os resultados obtidos evidenciam que o cimento é eficiente para estabilização do fosfogesso frente a ação da água. Observou-se que quantidades crescentes de cimento ao fosfogesso promovem o ganho de resistência, e a diminuição da deformabilidade. Ensaios realizados após imersão em água apresentaram valores de resistência à compressão simples (RCS) e módulo tangente inicial (Eo) menores do que os obtidos em ensaios sem imersão. $O$ aumento do tempo de cura e da energia de compactação influem de forma significativa no ganho de resistência e no crescimento do Eo. Não foi possível determinar-se uma tendência única que descrevesse o comportamento das misturas de fosfogesso e cimento em função da umidade de compactação. $O$ módulo de resiliência obtido para estas misturas é compatível com o observado para alguns materiais de uso corrente na construção de pavimentos.

Os resultados de laboratório indicam que misturas de fosfogesso e cimento têm potencial para aplicação como materiais de base e sub-base na construção rodoviária. 
Phosphogypsum is a solid by-product of phosphoric acid production, a major constituent of many fertilizers. Because of trace impurities, chemical and radiological properties, phosphogypsum may cause environmental problems.

As stockpiles continue growing and environmental constraints become more stringent, widespread uses of phosphogypsum must be developed.

The main objective of this research is to evaluate the addition of cement to the phosphogypsum for road base and subbase construction. The research program included the evaluation of unconfined compressive strength (UCS) and deformability testing results of compacted cement-stabilized phosphogypsum (CSP) specimens. Four different cement content were used, $7 \%, 10 \%, 12 \%$ and $15 \%$. The specimens were compacted at optimum moisture content $\left(w_{0}\right)$ and $w_{0} \pm 2 \%$, with two compaction energies: Standard and Intermediary Proctor; four ages for curing time, 7, 14, 28 and 84 days, tested under soaked and unsoaked conditions.

The results obtained from this research program showed that: the addition of cement stabilized the phosphogypsum, the results indicated that CSP mixtures are water resistant; with the increase in cement content there is a corresponding increase in the UCS and in the initial tangent modulus (Eo); tests under soaked conditions resulted in lower UCS and Eo than unsoaked condition; the increase of the compaction energy and curing time resulted in higher UCS and Eo. It was not possible to establish a unique trend which explains the compaction moisture influence; the CSP resilient modulus is compatible to those obtained from conventional unstabilized base materials used in road base construction.

The laboratory results indicate that cement-stabilized phosphogypsum mixtures have potential for application as road base and subbase materials. 


\subsection{NATUREZA DO PROBLEMA}

O crescimento populacional e a melhoria do seu padrão de consumo têm provocado um aumento na demanda por alimentos. Tal situação leva a um consumo crescente de fertilizantes, na medida em que a sua utilização tem efeito marcante na produtividade agrícola. TAHA \& SEALS (1991) afirmam que não existe no mundo um país com solo suficientemente rico que possa fornecer um suprimento de alimentos adequado para a crescente população sem o uso de fertilizantes.

Atualmente, os fertilizantes fosfatados, que usam o ácido fosfórico para sua produção, são os mais difundidos no meio agrícola. O processo de produção do ácido fosfórico utiliza a rocha fosfática e o ácido sulfúrico como matérias-primas. O resultado da reação entre esses dois elementos são o ácido fosfórico e um subproduto denominado de fosfogesso $\left(\mathrm{CaSO}_{4}\right)$. Em média, para a produção de 1 tonelada de ácido fosfórico são produzidas 4,5 toneladas de fosfogesso.

A elevada razão de produção do fosfogesso em relação ao ácido fosfórico e a não existência de aplicações consolidadas que o consumam, acarretam o crescimento desmesurado dos depósitos onde é armazenado a céu aberto, conforme mostra a Figura 1.1. Assim, dentre os problemas associados ao fosfogesso, destacam-se:

- a ocupação de grandes áreas para seu armazenamento, normalmente não disponíveis e de alto custo; 
- é um material que não possui uma aplicação prática consolidada, que possibilite dar vazão à toda produção, o que via de regra leva ao aumento dos estoques;

- o material contém um grande número de impurezas, entre elas se encontram elementos radioativos dos quais não se conhecem ainda os efeitos de exposição a longo prazo.

- na sua composição estão presentes traços de metais pesados e outros elementos químicos que podem contaminar o solo e mananciais de água;

- possui ainda característica ácida, podendo provocar alterações ambientais, principalmente no $\mathrm{pH}$ do lençol freático.

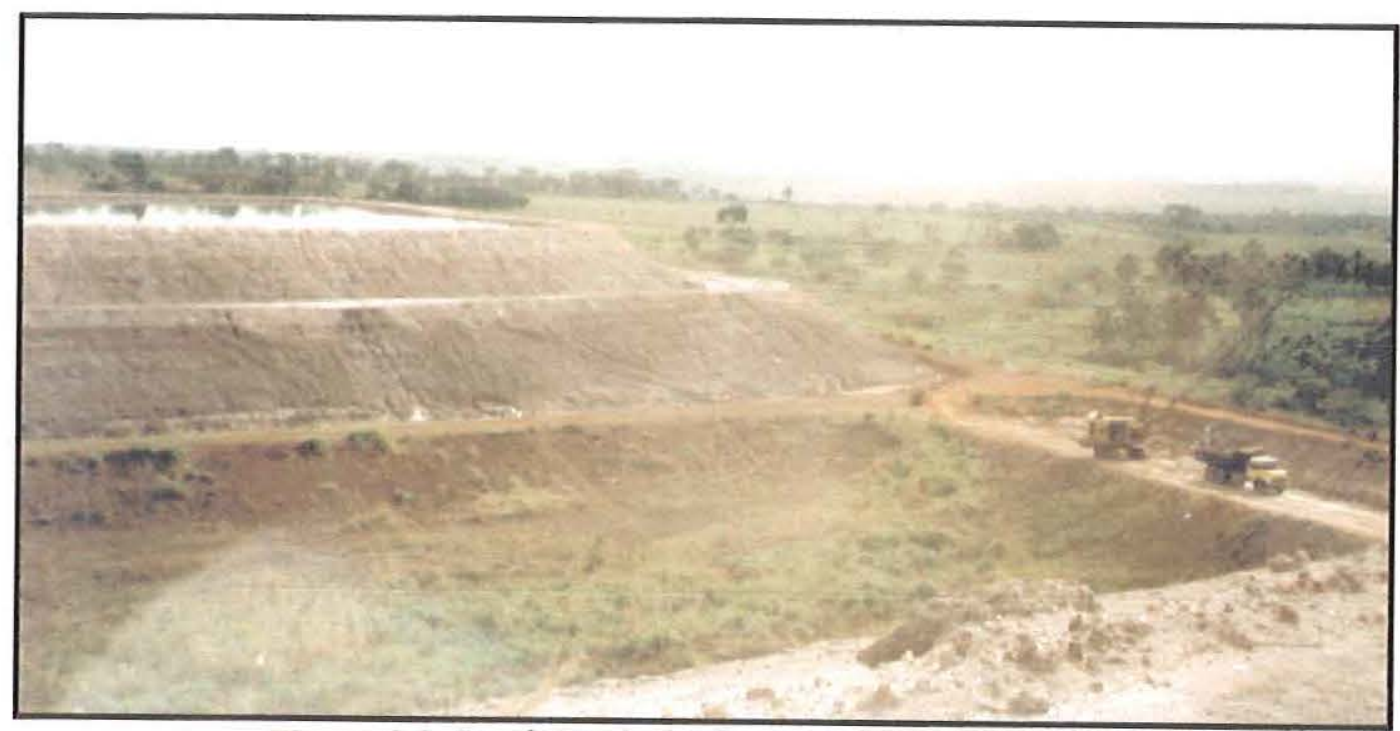

Figura 1.1: Depósito de fosfogesso (FOSFERTIL-Uberaba, MG)

A crescente preocupação com o meio ambiente deverá levar à criação de códigos de proteção cada vez mais rigorosos, acarretando restrições à manutenção dos depósitos de fosfogesso tais como hoje se encontram.

Para se ter uma dimensão do problema, segundo TAHA et al. (1995), nos Estados Unidos o fosfogesso é produzido a uma razão de 60 milhões de toneladas por ano. Previsões a longo prazo estimam que até o ano 2000 serão estocadas 1,54 bilhões de toneladas desse material nos estados da Florida, Louisiana e Texas. Na Austrália, são geradas anualmente 940.000 
toneladas de fosfogesso, existindo 8 milhões de toneladas em estoque (BERETKA, 1990). No ano de 1979, o Canadá produziu 4 milhões de toneladas de fosfogesso, possuindo até aquela data 50 milhões toneladas em estoque (COLLING, 1980). No Brasil, apenas a empresa FOSFERTIL, localizada no município de Uberaba - MG, produz 2 milhões de toneladas de fosfogesso anualmente, possuindo aproximadamente 25 milhões de toneladas em sua área de depósito. Num projeto de expansão, com conclusão prevista para agosto de 1998, esta empresa pretende ampliar a produção de ácido fosfórico em $23 \%$, aumentando ainda mais os problemas de armazenamento (PULITI, 1998).

Diante deste cenário, verifica-se a necessidade de se encontrar soluções para o problema, evitando-se assim o crescimento desmesurado dos depósitos. A solução ideal passa pelo desenvolvimento e exploração de aplicações comerciais para o fosfogesso, criando uma demanda por sua utilização. Segundo TAHA \& SEALS (1991), essa solução se apresenta como a mais viável economicamente para a redução dos custos de armazenagem a longo prazo.

\subsection{USOS ALTERNATIVOS DO FOSFOGESSO}

Diversas são as alternativas estudadas no sentido de desenvolver-se aplicações para o fosfogesso, sendo que, muitas ainda estão em fase de desenvolvimento. Algumas dessas alternativas são citadas a seguir.

Segundo LLOYD (1985), a utilização do fosfogesso pode ser reunida em três grandes grupos: utilização como matéria-prima química; aplicação na agricultura; e emprego como material de construção. 


\subsubsection{Matéria-prima química}

O fosfogesso mantém na sua composição resíduos do ácido sulfúrico utilizado na produção do ácido fosfórico. É possível, através de um processo termal, recuperar este material. No processo de recuperação do ácido sulfúrico podem ser obtidos, como subproduto, cimento Portland, cal, ou agregado sólido (AUSTIN, 1980; WHEELOCK, 1980; PRESSINOTTI, 1982; TAHA \& SEALS, 1992; FOXWORTHY et al., 1996). Além do processo termal, o processo microbiológico pode ser utilizado na recuperação do ácido sulfúrico, mas sua aplicação comercial não foi desenvolvida em função das baixas taxas de produção (LLOYD, 1985; TAYLOR, 1988). O sulfato de amônia é outro material que pode ser obtido do fosfogesso, através de um processo não termal, mas a concorrência com outras fontes de produção do material faz desse um processo sem atrativos econômicos (PRESSINOTTI, 1982; LLOYD, 1985). O fosfogesso pode, também, ser utilizado como retardante do tempo de pega do cimento em substituição ao gesso natural na indústria do cimento. Essa utilização é muito restrita em função das impurezas presentes no material.

\subsubsection{Aplicações na agricultura}

O fosfogesso tem um grande número de aplicações na agricultura, destacando-se a sua utilização na correção do $\mathrm{pH}$ de solos alcalinos e como redutor de salinidade. Tem ainda a função de fertilizante, já que apresenta na sua composição elementos nutrientes para as plantas, tais como o enxofre e o cálcio. Exerce também um papel importante no aumento da permeabilidade do solo (PRESSINOTTI, 1982; MISHRA, 1980; LLOYD, 1985; SUMMER et al., 1988; OSAKI, 1991).

LINDEKEN (1980), JOHNSON \& TRAUB (1996), além de apresentarem as aplicações já citadas, destacam que a utilização do fosfogesso na agricultura está condicionada ao seu nível de impurezas e 
radioatividade, tendo sido realizadas pesquisas onde são avaliadas as suas possíveis implicações na saúde humana e meio-ambiente.

\subsubsection{Materiais de construção}

O fosfogesso pode ser utilizado na construção civil e na construção rodoviária. Entre as possíveis aplicações na construção civil podem ser citadas: a produção de "plaster", ou argamassa de revestimento; "plasterboard", que são placas pré-fabricadas revestidas com papelão e usadas como paredes divisórias; e a produção de tijolos. Dentre essas alternativas, a produção de "plaster" e "plasterboard" são as alternativas que consomem o maior volume de gesso (PRESSINOTTI, 1982; CHANG \& MANTELL, 1990; BROWN \& BERETKA, 1990). Principalmente nas duas primeiras aplicações citadas, tem como concorrente o gesso natural, que na maioria dos casos apresenta-se como uma solução mais viável economicamente. Além desta concorrência, um dos maiores problemas para a sua utilização são as impurezas presentes no material.

O emprego do fosfogesso como material alternativo para construção rodoviária tem sido foco de estudos em todo o mundo. Sobre o assunto, destacam-se os estudos realizados pelo LCPC ("Laboratoire Central des Ponts et Chaussées"), na França, na pessoa dos pesquisadores MANGIN (1978b), COLOMBEL (1978), ANDRIEX et al. (1978), PUIATTI \& VIGEA (1978); e pelo FIPR ("Florida Institute of Phosphate Research"), nos Estados Unidos, com os pesquisadores LLOYD, (1985), CHANG (1988), CHANG \& MANTELL (1990). Ainda nos Estados Unidos, dedicaram-se ao estudo do fosfogesso como material de construção rodoviária os pesquisadores GREGORY et al. (1984), FIGUEROA et al. (1987), GADALLA et al. (1990), TAHA et al. (1992), ONG et al. (1994), TAHA et al. (1995). Diversas publicações tratam do comportamento do fosfogesso puro e em misturas com solo, cimento, cinza volante, cal, asfalto e alguns aditivos químicos. No Brasil, foram realizados estudos com fosfogesso puro e em mistura com 
cinzas volantes e rejeitos piritosos (TRICHÊS \& MACCARINI, 1988; MACCARINI, 1991a; MACCARINI, 1991b). No âmbito da Escola de Engenharia de São Carlos (EESC-USP), desenvolveu-se um trabalho onde estudaram-se misturas de solo e fosfogesso (ORTIZ, 1997).

\subsection{OBJETIVO}

O objetivo principal desse trabalho é avaliar o efeito da adição de cimento na estabilização do fosfogesso com vistas a sua utilização na execução de bases e sub-bases rodoviárias. O estudo foi feito em termos de se analisar a resistência à compressão simples e a deformabilidade de corpos prova compactados, compostos de misturas de fosfogesso e cimento, ensaiados em condições variadas.

Espera-se com este trabalho desenvolver-se uma alternativa para a utilização do fosfogesso, tentando, dessa forma, colaborar com a minimização dos possíveis prejuízos ambientais provocados por seu contínuo armazenamento.

\subsection{MÉTODO EXPERIMENTAL}

O fosfogesso puro não é adequado para aplicações na construção rodoviária, necessitando da melhoria de suas características (TAHA et al., 1992; ONG et al., 1994). Conhecendo tal situação, optou-se pela estabilização do fosfogesso com cimento Portland, esperando com isso um aumento de sua resistência, diminuição de sua deformabilidade e uma redução de sua susceptibilidade frente a ação da água. Utilizou-se no estudo misturas de fosfogesso com quatro teores de cimento, $7 \%, 10 \%, 12 \%$ e $15 \%$, compactadas nas energias normal e intermediária. Os corpos de prova provenientes da compactação passaram por 4 períodos de cura, 7, 14, 28 e 84 dias, sendo posteriormente ensaiados em condições imersas e não imersas 


\subsection{ORGANIZAÇÃO DO TRABALHO}

Este trabalho foi realizado como uma proposta de pesquisa, e desenvolvida na forma de dissertação de mestrado, estando dividida em 5 capítulos da seguinte maneira:

O Capítulo 2 apresenta a revisão bibliográfica realizada, destacandose os aspectos mais relevantes para o desenvolvimento do estudo. São abordados os processos de produção do fosfogesso, suas características físico-químicas; o comportamento, em laboratório, de misturas de fosfogesso com cimento, solo, cinza volante, cal e asfalto, e seu uso na construção de pavimentos.

O Capítulo 3 trata da caracterização dos materiais usados na pesquisa, fosfogesso e cimento, do método experimental utilizado e apresenta a escolha do fosfogesso a ser ensaiado.

O Capítulo 4 mostra os resultados obtidos a partir de ensaios de laboratório e discute aspectos relacionados à temperatura, relação umidade e massa específica seca, teor de cimento, umidade de compactação, condição de ensaio, $\mathrm{pH}$, e sua influência sobre a resistência à compressão simples e deformabilidade de corpos de prova compactados compostos de fosfogesso e cimento.

No Capítulo 5 são apresentadas as conclusões obtidas a partir da análise dos resultados laboratoriais. 


\subsection{INTRODUÇÃO}

O fosfogesso, também conhecido como gesso químico, é um resíduo da produção do ácido fosfórico, sendo este o principal componente dos fertilizantes fosfatados. Sua denominação, fosfogesso, indica sua origem industrial (fosfo) e seu componente principal (gesso). A formulação química do fosfogesso é a mesma do gesso natural, ou gipsita. Basicamente é um sulfato de cálcio $\left(\mathrm{CaSO}_{4}\right)$.

Existem dois processos principais para a produção do ácido fosfórico: o processo úmido e o processo da fornalha elétrica (TAHA \& SEALS, 1991). Entre esses processos, o mais utilizado é o processo úmido em suas diversas modificações: processo di-hidratado $(\mathrm{DH})$, processo hemi-hidratado $(\mathrm{HH})$, processo hemi-di-hidratado $(\mathrm{HDH})$ e o processo anidro.

A matéria-prima necessária para a produção do ácido fosfórico pelo processo úmido são a rocha fosfática e o ácido sulfúrico. LEGAL \& MYRICK apud TAHA \& SEALS (1991) descrevem o processo úmido como o ataque do ácido sulfúrico aos minerais da rocha fosfática.

Segundo SILVA (1980), emprega-se o termo rocha fosfática para uma rocha natural dotada de suficiente quantidade de minerais fosfatados, de forma a permitir sua utilização de modo imediato, ou logo após ter sofrido processos de beneficiamento, na manufatura de produtos fertilizantes. Ainda 
segundo SILVA (1980), de forma geral, os depósitos de rocha fosfática dividem-se em três grupos principais, a saber: jazidas apatíticas ou de origem magmática, jazidas de fosforitos ou de origem sedimentar, e jazidas resultantes de matéria orgânica.

Segundo MANGIN (1978a), BARBOSA (1980) e FERGUNSON (1988), o processo úmido pode ser descrito pela fórmula geral a seguir:

$\left[\mathrm{Ca}_{3}\left(\mathrm{PO}_{4}\right)_{2}\right]_{3} \mathrm{CaF}_{2}+10 \mathrm{H}_{2} \mathrm{SO}_{4}+10 n \mathrm{H}_{2} \mathrm{O} \rightarrow 6 \mathrm{H}_{3} \mathrm{PO}_{4}+10\left(\mathrm{CaSO}_{4}+n \mathrm{H}_{2} \mathrm{O}\right)+2 \mathrm{HF}(2.1)$

onde $n$ pode assumir três valores diferentes: $n=2$ quando 0 fosfogesso obtido é di-hidratado $\left(\mathrm{CaSO}_{4} \cdot 2 \mathrm{H}_{2} \mathrm{O}\right) ; n=1 / 2$ quando o fosfogesso obtido é hemi-hidratado $\left(\mathrm{CaSO}_{4} \cdot 1 / 2 \mathrm{H}_{2} \mathrm{O}\right)$; e $n=0$ quando o fosfogesso obtido é anidro $\left(\mathrm{CaSO}_{4}\right)$. Em resumo, o valor de $n$ indica o número de moléculas de água presente na composição do fosfogesso. Essas características dependem principalmente da temperatura de reação durante o processo de produção e da concentração de ácido fosfórico obtido. A quantidade de água usada para lavar e remover o ácido fosfórico do sulfato de cálcio durante a filtragem determina a concentração. Dessa forma, são esses dois fatores, temperatura e concentração do ácido fosfórico, que produzem as diferentes formas alotrópicas do fosfogesso, isto é, di-hidratado, hemi-hidratado, hemi-dihidratado ou anidro (TAHA \& SEALS, 1991).

\subsection{PROCESSOS DE PRODUÇÃO DO ÁCIDO FOSFÓRICO}

Em seguida são descritas algumas características principais dos processos utilizados na produção de ácido fosfórico. Os processos descritos referem-se ao processo úmido em suas diversas modificações: processos dihidratado, hemi-hidratado e hemi-di-hidratado e anidro. 


\subsubsection{Processo di-hidratado}

Segundo alguns pesquisadores (MANGIN, 1978; KOULOHERIS, 1980; CHANG \& MANTELL, 1990; TAHA \& SEALS, 1991) o processo dihidratado (DH) é o mais utilizado em todo o mundo, e um dos mais utilizados nos EUA, para a produção do ácido fosfórico. Esse processo se desenvolve a temperaturas variando de $71^{\circ} \mathrm{C}$ a $85^{\circ} \mathrm{C}\left(160^{\circ} \mathrm{F}\right.$ a $\left.185^{\circ} \mathrm{F}\right)$. O nível de temperatura empregado, considerado baixo em comparação às temperaturas usadas nos demais processos, minimiza os problemas de corrosão que ocorrem nos equipamentos de produção.

Pelo processo di-hidratado são obtidas concentrações de ácido fosfórico variando de $28 \%$ a $30 \%$. Esse processo leva a uma produção de 4,9 toneladas de fosfogesso di-hidratado $\left(\mathrm{CaSO}_{4} \cdot 2 \mathrm{H}_{2} \mathrm{O}\right)$ para cada tonelada de ácido fosfórico produzido. Além da maior relação de produção, o fosfogesso obtido pelo processo di-hidratado possui mais impurezas do que o produzido pelos demais processos, o que é considerado como uma desvantagem.

Entre as vantagens que fazem desse processo o mais utilizado em todo o mundo podem-se citar: requer baixo investimento de capital para implantação do sistema de produção, possui custo de produção relativamente baixo e uma grande flexibilidade para o uso de rochas de várias origens. Além disso, do resíduo obtido por esse processo é possível se efetuar a extração do urânio presente na sua composição.

\subsubsection{Processo hemi-hidratado}

O processo hemi-hidratado $(\mathrm{HH})$ é um dos mais utilizados na Europa, Japão e Africa. O processo se desenvolve a temperaturas variando de $93^{\circ} \mathrm{C}$ a $132^{\circ} \mathrm{C}\left(200^{\circ} \mathrm{F}\right.$ a $\left.270^{\circ} \mathrm{F}\right)$. As concentrações de ácido fosfórico obtido variam 
de $40 \%$ a $52 \%$ (KOULOHERIS, 1980; LEGAL \& MYRICK apud TAHA \& SEALS, 1991).

As vantagens do processo hemi-hidratado em relação ao processo dihidratado, além da maior concentração de ácido fosfórico, são a economia de energia, dissolução mais rápida da rocha fosfática e a maior rapidez no processo de filtragem. Entretanto, problemas na fase de filtragem podem dificultar e tornar a produção instável. Essa dificuldade ocorre pela presença de material di-hidratado, que em contato com o material hemi-hidratado promove sua hidratação.

Ainda em comparação com o processo $\mathrm{DH}$, o processo $\mathrm{HH}$ apresenta uma menor relação de produção entre o fosfogesso e o ácido fosfórico. São produzidas 4,3 toneladas de fosfogesso para cada tonelada de ácido fosfórico. O fosfogesso obtido por esse processo apresenta um teor mais alto de $\mathrm{CaSO}_{4}$ (sulfato de cálcio), provocado pelo menor teor de água na sua composição, e um menor nível de impurezas, mas ainda não satisfatório. Diferentemente do processo $\mathrm{DH}$, não existe atualmente um processo completamente desenvolvido para a extração do urânio existente na sua composição (KOULOHERIS, 1980).

Os custos de capital para implantação e produção são maiores no processo hemi-hidratado do que no processo di-hidratado. Esses custos, entretanto, são de certa forma balanceados pelo produto mais puro obtido (fosfogesso) e pela economia de energia no sistema (LEGAL \& MYRICK apud TAHA \& SEALS, 1991).

\subsubsection{Processo hemi-di-hidratado}

O processo hemi-di-hidratado é mais utilizado na Europa e Japão. O processo se desenvolve a temperaturas variando de $90^{\circ} \mathrm{C}$ a $100^{\circ} \mathrm{C}\left(194^{\circ} \mathrm{F}\right.$ a 
$212^{\circ} \mathrm{F}$ ). As concentrações obtidas variam de $40 \%$ a $52 \%$ de ácido fosfórico (KOULOHERIS, 1980; LEGAL \& MYRICK apud TAHA \& SEALS, 1991).

O processo hemi-di-hidratado $(\mathrm{HDH})$ combina as vantagens do processo di-hidratado com a possibilidade de se produzir um resíduo mais limpo, como o obtido pelo processo hemi-hidratado. O processo $\mathrm{HDH}$ envolve a precipitação do sulfato de cálcio na forma hemi-hidratada seguida pela recristalização para a forma di-hidratada (LEGAL \& MYRICK apud TAHA \& SEALS, 1991).

A relação de produção entre o fosfogesso e o ácido fosfórico é igual a do processo hemi-hidratado: para cada tonelada de ácido fosfórico são produzidas 4,3 toneladas de fosfogesso. A economia de energia se apresenta também nesse processo, entretanto, os custos de manutenção dos equipamentos são maiores do que no processo DH (KOULOHERIS, 1980).

\subsubsection{Processo anidro}

$\mathrm{O}$ processo anidro desenvolve-se a temperaturas variando de $120^{\circ} \mathrm{C}$ a $130^{\circ} \mathrm{C}\left(248^{\circ} \mathrm{F}\right.$ a $\left.266^{\circ} \mathrm{F}\right)$, consideradas altas quando comparadas aos processos $\mathrm{DH}$ e HH. Esse nível de temperatura provoca problemas de corrosão no equipamento de produção, aumentando os custos de manutenção, e problemas na fase de filtragem. A concentração de ácido fosfórico obtido pode variar de $40 \%$ a $50 \%$ (LEGAL \& MYRICK apud TAHA \& SEALS, 1991).

Apesar dos estudos direcionados para a solução dos problemas relacionados à temperatura e, devido ao maior nível de energia despendido no sistema para a produção do ácido fosfórico, o processo anidro não se mostra economicamente viável quando comparado aos demais processos. Isso faz com que seu emprego não seja muito difundido. 


\subsection{CARACTERISTICAS QUIIMICAS E FÍSICAS DO FOSFOGESSO}

Diversos são os estudos necessários para a caracterização físicoquímica do fosfogesso, entre eles estão: a análise química, a análise radiológica e a análise física.

As características químicas, físicas e radiológicas do fosfogesso podem variar em função de diversos fatores, dentre eles estão o tipo de rocha fosfática, o processo de produção e a eficiência da planta produtora. $\mathrm{A}$ combinação entre esses fatores deve conduzir à produção de fosfogessos com diferentes características. Por exemplo, a substituição de uma determinada rocha fosfática por uma outra de origem diferente numa mesma indústria, deve levar à produção de um fosfogesso com características diferentes. Ou ainda, o uso de uma mesma fonte de rocha fosfática por diferentes indústrias, com diferentes processos produtivos, deve produzir fosfogessos com diferentes características.

Em função dessa grande variabilidade de características do fosfogesso faz-se necessário o estudo individual do material para cada aplicação que se disponha a realizar.

\subsubsection{Análise química}

A Tabela 2.1 apresenta os resultados da análise química de um fosfogesso produzido no estado de Santa Catarina e objeto de estudo de TRICHÊS \& MACCARINI (1988).

A Tabela 2.2 mostra os resultados apresentados por TAHA \& SEALS (1991) como sendo a composição típica do fosfogesso produzido nos Estados Unidos, mais especificamente nos estados do Texas, Louisiana e Florida. 
Tabela 2.1: Análise química de um fosfogesso produzido em Santa Catarina (fonte: TRICHÊS \& MACCARINI, 1988)

\begin{tabular}{lc}
\hline \multicolumn{1}{c}{ Composto } & Teor (\%) \\
\hline $\mathrm{SiO}_{2}$ & 4,0 \\
$\mathrm{Fe}_{2} \mathrm{O}_{3}+\mathrm{Al}_{2} \mathrm{O}_{3}$ & 3,1 \\
$\mathrm{CaO}$ & 36,8 \\
$\mathrm{SO}_{4}$ & 50,5 \\
$\mathrm{MgO}$ & 0,22 \\
\hline
\end{tabular}

Tabela 2.2: Composição química típica do fosfogesso produzido pelos estados do Texas, Louisiana e Florida (fonte: TAHA \& SEALS, 1991).

\begin{tabular}{lccc}
\hline \multirow{2}{*}{ Composto } & \multicolumn{3}{c}{ Teor (\%) } \\
\cline { 2 - 4 } \multicolumn{1}{c}{$\mathrm{CaO}$} & Louisiana & Texas & Florida \\
\hline $\mathrm{SO}_{4}$ & $29-31$ & 32,5 & $25-31$ \\
$\mathrm{SiO}_{2}$ & $50-53$ & 53,1 & $55-58$ \\
$\mathrm{~F}$ & $5-10$ & 2,5 & $3-18$ \\
$\mathrm{P}_{2} \mathrm{O}_{5}$ & $0,3-1,0$ & 1,20 & $0,2-0,8$ \\
$\mathrm{Fe}_{2} \mathrm{O}_{3}$ & $0,7-1,3$ & 0,65 & $0,5-4,0$ \\
$\mathrm{Al}_{2} \mathrm{O}_{3}$ & $0,1-0,2$ & 0,10 & $0-0,1$ \\
$\mathrm{pH}$ & $0,1-0,3$ & 0,10 & $0,1-0,3$ \\
\hline
\end{tabular}

Além dos elementos citados na Tabela 2.2, os fosfogessos apresentam em sua composição traços de outros elementos químicos como o arsênio (As), bário $(\mathrm{Ba})$, cádmio $(\mathrm{Cd})$, cromo $(\mathrm{Cr})$, chumbo $(\mathrm{Pb})$, mercúrio $(\mathrm{Hg})$, selênio $(\mathrm{Se})$ e prata $(\mathrm{Ag})$, conforme mostra a Tabela 2.3 .

Tabela 2.3: Concentração dos traços de elementos químicos típicos no fosfogesso (fonte TAHA \& SEALS, 1991).

\begin{tabular}{ccc}
\hline Elemento & \multicolumn{2}{c}{ Concentração (ppm) } \\
\cline { 2 - 3 } & Louisiana & Florida \\
\hline $\mathrm{As}$ & $1-5$ & $2-8$ \\
$\mathrm{Ba}$ & 50 & $<10$ \\
$\mathrm{Cd}$ & $0,3-0,4$ & $3-4$ \\
$\mathrm{Cr}$ & $2-5$ & $15-30$ \\
$\mathrm{~Pb}$ & $2-10$ & $2-13$ \\
$\mathrm{Hg}$ & $0,02-0,05$ & $<0,5$ \\
$\mathrm{Se}$ & 1 & $<1$ \\
$\mathrm{Ag}$ & $0,1-0,2$ & $<3$ \\
$\mathrm{U}_{3} \mathrm{O}_{8}$ & $5-10$ & $\mathrm{NA}$ \\
\hline
\end{tabular}

NA: Não avaliável

Elementos radioativos também estão presentes na composição do fosfogesso produzidos nos estados do Texas, Louisiana e Florida, são eles: 
o urânio (U), o tório (Th), o rádio $(\mathrm{Ra})$ e o radom, ou radônio $(\mathrm{Rn}) . \mathrm{O}$ pH do fosfogesso produzido nestes três estados americanos varia dentro de uma faixa de 2,5 a 6,0 .

Observando-se os valores apresentados nas Tabelas 2.1, 2.2 e 2.3, pode-se verificar a variabilidade da composição do fosfogesso produzido por diferentes industrias.

Num estudo realizado por MANGIN (1978), em fosfogessos produzidos com rochas fosfáticas provenientes de vários países, observouse uma variação na composição do fosfogesso em função da origem da rocha. $\mathrm{O} \mathrm{pH}$ desses materiais situa-se entre 2 e 3, justificado pela presença de sais solúveis e traços residuais de ácidos (ácido sulfúrico, ácido fluorídrico e ácido fosfórico).

Um dos fatores que mereceu grande atenção nas pesquisas realizadas com o fosfogesso foi $\circ \mathrm{pH}$, devido, principalmente, a sua influência sobre misturas estabilizadas quimicamente, como por exemplo com cimento. Esse tema é abordado no item 2.4.

\subsubsection{Análise morfológica}

A morfologia do fosfogesso está relacionada à forma dos cristais formadores do material. Alguns estudos foram realizados com o intento de caracterizar o fosfogesso quanto à forma de suas partículas, entre eles pode-se citar os estudos realizados por MANGIN (1978), TAHA (1991), TAHA et al. (1992) e TAHA et al. (1995).

Os estudos realizados por TAHA (1991), TAHA et al. (1992) e TAHA et al. (1995), com auxilio de microscópios ótico e eletrônico, utilizando fosfogesso de duas fontes distintas, mostraram que o material se apresenta como um aglomerado lamelar de partículas. O material mais antigo, ou mais 
exposto aos efeitos de intempéries, mostrou partículas mais arredondadas $e$ mais densas. Acredita-se que essa diferença possa afetar o comportamento de misturas estabilizadas e não estabilizadas de fosfogesso.

No estudo realizado por MANGIN (1978) sobre a morfologia dos cristais de fosfogesso, foi possível distinguir quatro formas características de cristais, dependentes do mineral usado na produção do ácido fosfórico e do processo de produção. Os cristais de fosfogesso podem ser classificados em:

- cristais aciculares (forma de agulhas), que apresentam suas dimensões variando de - L: $80 \mu \mathrm{m}$ a $500 \mu \mathrm{m}$; I: $20 \mu \mathrm{m}$ a $100 \mu \mathrm{m}$; e: 20 $\mu \mathrm{m}$ a $100 \mu \mathrm{m}$; onde $\boldsymbol{L}$ corresponde à maior dimensão da partícula, $\boldsymbol{I}$ corresponde à dimensão intermediária da partícula e, e corresponde à menor dimensão ou espessura da partícula;

- cristais tabulares (forma tabular), que apresentam dimensões variando de - L: $40 \mu \mathrm{m}$ a $200 \mu \mathrm{m}$; I: $30 \mu \mathrm{m}$ a $150 \mu \mathrm{m}$; e: $5 \mu \mathrm{m}$ a $10 \mu \mathrm{m}$;

- os cristais compactos, que são os cristais tabulares nos quais a espessura atinge dezenas de microns;

- agregados policristalinos, que são um conjunto de cristais em forma de "ouriço", e que podem ser circunscritos por uma esfera de $50 \mu \mathrm{m}$ a $100 \mu \mathrm{m}$ de diâmetro.

As Figuras 2.1, 2.2 e 2.3 ilustram, respectivamente, os cristais aciculares, os cristais tabulares e os agregados policristalinos, conforme apresentado por MANGIN (1978). 


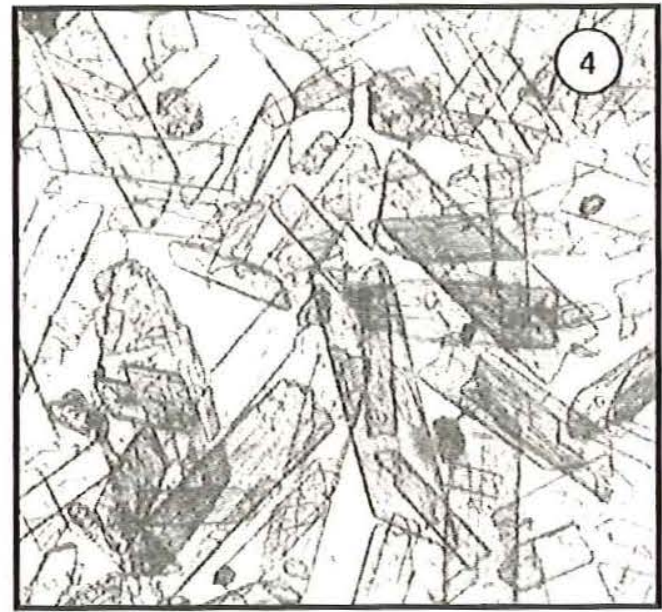

Figura 2.1: Cristais aciculares (fonte: MANGIN, 1978).

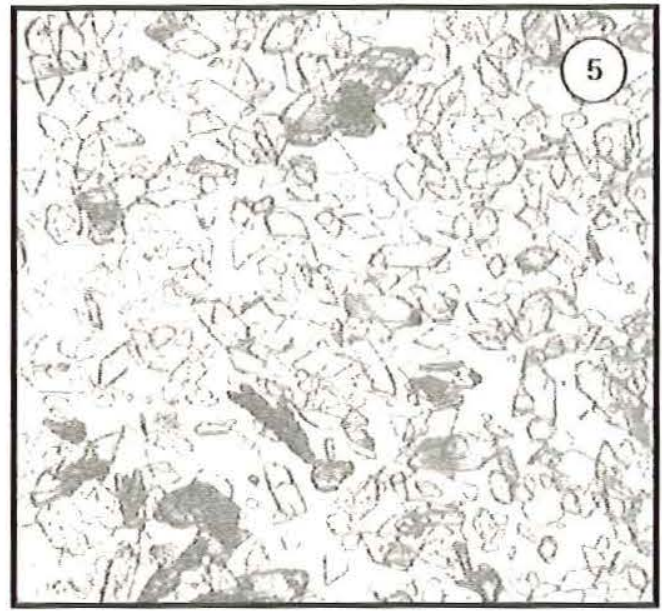

Figura 2.2: Cristais tabulares (fonte: MANGIN, 1978)

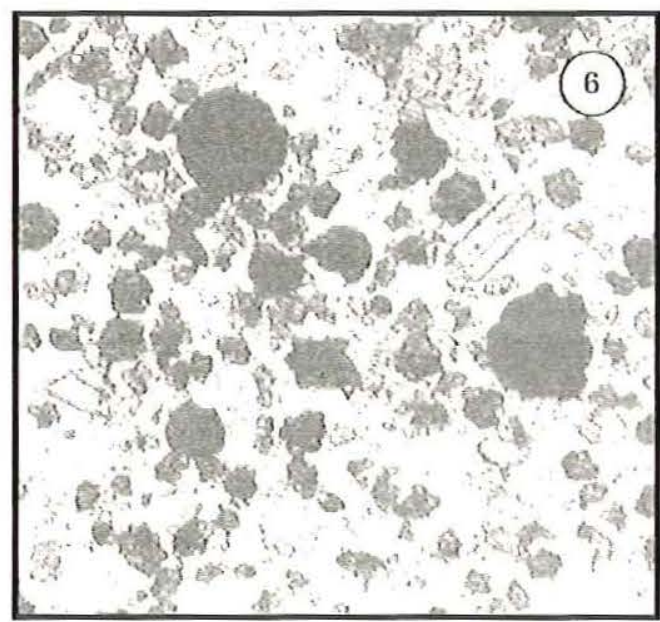

Figura 2.3: Agregados policristalinos (fonte: MANGIN, 1978) 


\subsubsection{Análise Radiológica}

Diversos estudos realizados, principalmente pelo FIPR (Florida Institute of Phosphate Research), dão conta da importância de se avaliar os efeitos da exposição humana e do meio-ambiente à radiação produzida pelo fosfogesso. Entre esses estudos pode-se citar TREFLER et al. (1988), CHIN (1988), BERISH (1990), ROESSLER (1990), WALSH (1990), JOHNSON \& TRAUB (1996), JAMES (1996).

O fosfogesso possui na sua composição traços de nuclídeos, tais como o urânio $(U)$, o tório $(T h)$, o polônio $(\mathrm{Po})$, o rádio $(\mathrm{Ra})$ e o radônio $(\mathrm{Rd})$. Segundo RUSSEL (1982), na ausência de influências externas muitos nuclídeos são permanentemente estáveis. Entretanto, alguns não o são e sofrem decaimento radioativo, também conhecido como desintegração nuclear. Se um núcleo é instável ele se desintegra, e se o núcleo filho é instável ele também se desintegra. O processo continua até que se forme um núcleo estável.

Entre os elementos mais preocupantes presentes no fosfogesso estão o ${ }^{238} \mathrm{U}$, o ${ }^{234} \mathrm{U}$ e os produtos do decaimento do urânio. Os elementos contaminadores emanados das pilhas de fosfogesso promovem prejuízos ao meio ambiente e à saúde humana. As fontes de contaminação incluem: a lixiviação de água para os aqüíferos subterrâneos e para os sistemas de água superficial; a difusão gasosa de radônio $\left({ }^{222} \mathrm{Rn}\right)$ pelo ar; partículas de radionuclídeos em suspensão no ar; e irradiação direta de radiação gama $(\gamma)$. Os riscos de contaminação do meio ambiente e os riscos à saúde humana decrescem em função da distância das pilhas. Todas essas informações foram obtidas a partir do estudo realizado por BERISH (1990).

A preocupação com as emanações radioativas do fosfogesso teve seu ápice em 1992 quando a entidade americana EPA (Environmental Protection Agency), agência de proteção ambiental dos Estados Unidos, 
regulamentou a deposição do fosfogesso, permitida apenas em pilhas ou minas monitoradas, proibindo o seu uso na construção rodoviária e restringindo a sua aplicação na agricultura a materiais contendo até 10 pCig${ }^{1}$ de ${ }^{226} \mathrm{Ra}$. Limitou também, a quantidade de fosfogesso que poderia ser usada em qualquer pesquisa e projeto em desenvolvimento a $317,50 \mathrm{~kg}$ (700 Ib).

O Instituto do Fertilizante (TIF - The Fertilizer Institute), baseado na constatação de um provável erro de cálculo que levou à superavaliação dos riscos à exposição ao fosfogesso, obteve a reconsideração dessa limitação, que foi revista ainda em 1992, permitindo o uso de 1587,6 kg (3500 lb) em pesquisas e projetos em desenvolvimento. Permitiu-se também o uso do fosfogesso para aplicações na agricultura e construção, desde que observada a redução apropriada da concentração de ${ }^{226} \mathrm{Ra}$ a limites aceitáveis (JAMES 1996).

Para se verificar se um fosfogesso, com uma concentração típica de $26 \mathrm{pCi} \mathrm{g}{ }^{-1}$ de ${ }^{226} \mathrm{Ra}$, poderia ou não ser usado na agricultura ou construção sem regulamentação própria, a EPA adotou um critério para se estimar o risco máximo adicional a um indivíduo que estivesse exposto à radiação do fosfogesso, que não poderia exceder $3 \times 10^{-4}$. Para avaliação desse risco, a EPA considerou vários cenários hipotéticos para definir a exposição razoável máxima (MRE - Maximum Reasonable exposure) à radiação produzida pelo fosfogesso em aplicações na agricultura e construção. Na construção rodoviária, o cenário mais crítico indicou um risco máximo de $9,3 \times 10^{-3}$ para um indivíduo que morasse durante 70 anos em uma casa construída sobre uma rodovia abandonada executada utilizando-se fosfogesso, e onde o leito da rodovia estivesse intacto (JAMES, 1996; JOHNSON \& TRAUB, 1996).

Esses resultados são contestados num estudo realizado por JOHNSON \& TRAUB (1996), que recalcularam os riscos individuais para a totalidade dos cenários contemplados pela EPA. Os riscos variaram de $6,2 \mathrm{x}$ 
$10^{-5}$ a $8,1 \times 10^{-5}$, estando, portanto, dentro do limite de risco individual máximo admitido pela EPA.

JAMES (1996) ainda contesta os critérios da EPA para estabelecer um risco individual adicional aceitável de $3 \times 10^{-4}$, comparando o risco de vida diário de uma pessoa que escolhesse viver durante toda a sua existência em uma casa construída sobre uma velha rodovia que tenha incorporado fosfogesso na sua construção, com a de outras situações de risco:

- O risco de se morrer em um acidente aéreo é quase o mesmo;

- O risco de se morrer prematuramente de câncer causado pelo radionuclídeo natural potássio $40\left({ }^{40} \mathrm{~K}\right)$, presente no nosso corpo, é duas vezes maior;

- O risco de se morrer em um incêndio em casa é três vezes maior;

- O risco de morte por afogamento é sete vezes maior;

- O risco de morte em um acidente de carro é vinte e cinco vezes maior;

- O risco de ser vitima de um assassinato é vinte sete vezes maior.

Deve-se considerar que esses exemplos de morte violenta implicam em uma redução substancial do tempo de vida. Em contraste, qualquer câncer causado por exposição a longo prazo à radiação produzida pelo fosfogesso ocorrerá em idades avançadas, dessa forma, tem pequeno efeito sobre o tempo de vida do indivíduo (JAMES, 1996).

\subsubsection{Análise física}

A Tabela 2.4 apresenta os resultados da análise física dos fosfogessos produzidos nos estados do Texas, Louisiana e Florida. Esses resultados foram apresentados por TAHA \& SEALS (1991), como característicos dos fosfogessos produzidos nos Estados Unidos. 


\begin{tabular}{|c|c|c|c|}
\hline \multirow{2}{*}{ Propriedades } & \multicolumn{3}{|c|}{ Valores } \\
\hline & Louisiana & Texas & Florida \\
\hline Umidade (\%) & $8-12$ & 20 & $3-18$ \\
\hline Massa específica dos sólidos $\left(\mathrm{g} / \mathrm{cm}^{3}\right)$ & $2,32-2,35$ & 2,30 & $2,31-2,53$ \\
\hline Partículas $(\%<\# 200)$ & $74-75$ & 75 & $30-82$ \\
\hline
\end{tabular}

$\mathrm{Na}$ Tabela 2.4 são apresentados os valores de umidade, massa específica dósólidos e porcentagem de fosfogesso que passa na peneira \#200 (0,074 mm). Os teores de umidade variaram de $3 \%$ a $20 \%$ nos três estados, mostrando uma grande variação de resultados. Com relação a massa específica dos sólidos, a totalidade dos resultados permaneceu entre $2,30 \mathrm{~g} / \mathrm{cm}^{3}$ e $2,53 \mathrm{~g} / \mathrm{cm}^{3}$. Observou-se, para o fosfogesso produzido na Florida, uma grande variação na porcentagem passada na peneira \# 200 , os resultados variaram de $30 \%$ a $82 \%$. Já o fosfogesso produzido nos estados do Texas e Louisiana tiveram uma porcentagem passada na peneira \#200 variando de $74 \%$ a $75 \%$. Os resultados de umidade e massa específica seca mostraram uma grande dispersão para o fosfogesso produzido no estado da Florida, da mesma forma que o observado para a porcentagem passada na peneira \#200.

Essa dispersão nos resultados pode ser explicada pelas diferentes origens do fosfogesso. Essa mesma explicação foi dada por SCHAEFFNER (1978) para justificar as variações dos resultados de massa específica dos sólidos em fosfogessos produzidos na França. Os resultados variaram de $2,3 \mathrm{~g} / \mathrm{cm}^{3}$ a $2,6 \mathrm{~g} / \mathrm{cm}^{3}$.

Num estudo realizado por GREGORY et al. (1984), com um fosfogesso di-hidratado fornecido pela "Mobil Chemical Company", a massa específica dos sólidos encontrado foi $2,3 \mathrm{~g} / \mathrm{cm}^{3}$.

TRICHÊS \& MACCARINI (1988), encontraram, para um fosfogesso produzido em Santa Catarina, um valor de massa específica dos sólidos igual a $2,4 \mathrm{~g} / \mathrm{cm}^{3}$. 
SCHAEFFNER (1978) também realizou ensaios para determinação dos limites de Atterberg (limites de liquidez e limites de plasticidade), para os fosfogessos produzidos na França. Os valores do limite de liquidez foram em média $27 \%$. Já os limites de plasticidade foram impossíveis de se determinar. Segundo o autor, essa condição é justificada pela ausência total de propriedades coloidais, confirmada pelos valores quase nulos de absorção de azul de metileno.

Os fosfogessos das diversas fontes produtoras do Texas, Louisiana e Florida apresentaram pouca ou nenhuma plasticidade. De acordo com a classificação pela USCS (Sistema Unificado de Classificação de Solos) o fosfogesso é classificado como um material siltoso (ML), e pelo sistema de classificação de solos da HRB, seria definido como um solo siltoso (A-4) (TAHA \& SEALS, 1991). As curvas granulométricas características dos fosfogessos produzidos nos Estados Unidos foram apresentadas por TAHA \& SEALS (1991), e estão ilustradas na Figura 2.4.

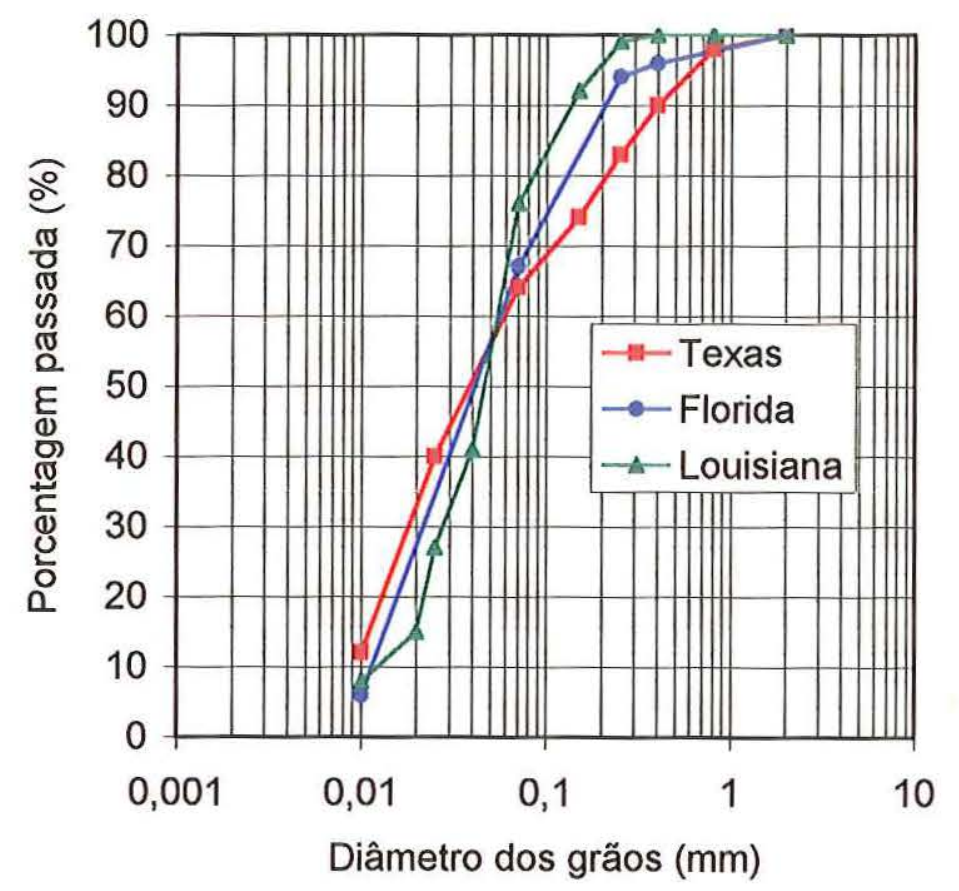

Figura 2.4: Curvas granulométricas dos fosfogessos produzidos nos Estados Americanos do Texas, Florida e Louisiana (fonte: adaptado de TAHA \& SEALS, 1991) 
Segundo TAHA \& SEALS (1991), observando-se a Figura 2.4 verificase a existência de uma diferença na distribuição do diâmetro das partículas, para todas as fontes de fosfogesso, especialmente para partículas com diâmetro inferior a $0,250 \mathrm{~mm}$ (peneira \#60). Os autores salientam ainda que as curvas granulométricas apresentadas não podem ser tratadas como a curva granulométrica de cada um dos fosfogessos produzidos no Texas, Louisiana ou Florida, sendo apenas valores típicos e, portanto, podem não ser representativos de todos os fosfogessos produzidos em cada estado.

\subsection{CARACTERÍSTICAS E PROPRIEDADES DO FOSFOGESSO COMPACTADO}

Algumas das propriedades do fosfogesso puro são determinadas através de ensaios de compactação e compressão simples, entre elas podese citar a relação entre a massa específica seca e a umidade ótima, e a resistência à compressão simples, e além desses, a deformabilidade, compressão triaxial, módulo de resiliência, ensaios de permeabilidade e fadiga. A seguir são apresentados os resultados de alguns estudos realizados para se determinar o comportamento do fosfogesso em função desses parâmetros. De maneira geral, são esses os estudos realizados para verificar-se a adequabilidade do uso do fosfogesso na construção rodoviária.

\subsubsection{Relação entre massa específica seca e umidade}

HO \& ZIMPFER apud CHANG \& MANTELL (1990), e HO \& ZIMPFER apud TAHA \& SEALS (1991), estudaram as relações entre massa específica seca e umidade para fosfogessos de 7 fontes distintas da Florida. Foram consideradas nesse estudo duas energias de compactação, equivalentes ao Proctor normal e ao Proctor modificado. As Tabela 2.5 e 2.6 apresentam, respectivamente, os valores de massa específica seca máxima e umidade ótima para fosfogessos compactados na energia normal e intermediária. 
Tabela 2.5: Massa específica seca máxima e umidade ótima para fosfogesso de 7 fontes distintas compactados na energia normal (fonte: adaptado de CHANG e MANTELL, 1990).

\begin{tabular}{lcc}
\hline \multirow{1}{*}{ Fonte } & \multicolumn{2}{c}{ Energia normal } \\
\cline { 2 - 3 } & $\begin{array}{c}\text { Massa específica seca máxima } \\
\left(\mathrm{g} / \mathrm{cm}^{3}-\mathrm{pcf}\right)\end{array}$ & $\begin{array}{c}\text { Teor de umidade ótima } \\
(\%)\end{array}$ \\
\hline W. R. Grace & $1,47-91,7$ & 12,8 \\
AMAX & $1,33-83,0$ & 19,2 \\
Occidental 1 & $1,47-91,7$ & 18,9 \\
Gardinier & $1,52-95,0$ & 16,8 \\
Occidental & $1,36-84,6$ & 21,6 \\
Conserv & $1,45-90,4$ & 19,1 \\
I.M.C & $1,47-91,9$ & 18,4 \\
\hline
\end{tabular}

Tabela 2.6: Massa específica seca máxima e umidade ótima para fosfogesso de 7 fontes distintas compactados na energia modificada (fonte: adaptado de CHANG \&: MANTELL, 1990).

\begin{tabular}{lcc}
\hline \multirow{2}{*}{ Fonte } & \multicolumn{2}{c}{ Energia modificada } \\
\cline { 2 - 3 } & $\begin{array}{c}\text { Massa específica seca máxima } \\
\left(\mathrm{g} / \mathrm{cm}^{3}-\mathrm{pcf}\right)\end{array}$ & $\begin{array}{c}\text { Teor de umidade ótima } \\
(\%)\end{array}$ \\
\hline W. R. Grace & $1,56-97,1$ & 15,0 \\
AMAX & $1,45-90,3$ & 18,4 \\
Occidental 1 & $1,48-92,2$ & 17,3 \\
Gardinier & $1,62-101,0$ & 14,1 \\
Occidental 2 & $1,47-91,6$ & 17,7 \\
Conserv & $1,52-94,9$ & 15,0 \\
I.M.C & $1,55-96,9$ & 16,4 \\
\hline
\end{tabular}

Os autores, observando os resultados apresentados nas Tabelas 2.5 e 2.6, mostraram que, para uma mesma energia de compactação, o uso de fosfogesso de fontes diversas conduzem a resultados diferentes quando comparados entre si. Para a compactação realizada na energia normal, os resultados de massa específica seca máxima variaram de $1,33 \mathrm{~g} / \mathrm{cm}^{3}(83$ pcf) a $1,52 \mathrm{~g} / \mathrm{cm}^{3}$ (95 pcf), e os resultados de umidade ótima variaram de $12,8 \%$ a $21,6 \%$. Para a compactação na energia intermediária, os resultados de massa específica seca máxima variaram de $1,45 \mathrm{~g} / \mathrm{cm}^{3}$ (90,3 pcf) a 1,62 $\mathrm{g} / \mathrm{cm}^{3}$ (101 pcf), e os resultados de umidade ótima variaram de $15,0 \%$ a $18,4 \%$.

Pôde-se constatar nesse mesmo estudo a influência da energia de compactação sobre os valores de massa específica seca máxima e umidade ótima. De forma geral, o aumento na energia de compactação conduziu a 
maiores valores de massa específica seca máxima, e a menores valores umidade ótima. Segundo HO \& ZIMPFER apud CHANG \& MANTELL (1990), e HO \& ZIMPFER apud TAHA \& SEALS (1991), os valores de massa específica seca máxima para os fosfogessos compactados na energia normal são até $0,112 \mathrm{~g} / \mathrm{cm}^{3}$ (7pcf) menores que os do fosfogesso compactado na energia intermediária.

CHANG, CHIN \& HO (1989), LIN et al. apud CHANG \& MANTELL (1990) e LIN apud CHANG \& MANTELL (1990) também estudaram fosfogessos produzidos na Florida. Os autores estudaram materiais provenientes de 8 fontes distintas, sendo que alguns deles foram os mesmos estudados por HO \& ZIMPFER apud CHANG \& MANTELL (1990), e HO \& ZIMPFER apud TAHA \& SEALS (1991). A energia de compactação usada nesse estudo foi a modificada. Os resultados estão resumidos na Tabela 2.7.

Tabela 2.7: Massa específica seca máxima e umidade ótima para fosfogesso de 8 fontes distintas compactados na energia modificada (fonte: CHANG e MANTELL, 1990)

\begin{tabular}{lcc}
\hline \multirow{1}{*}{ Fonte } & \multicolumn{2}{c}{ Energia modificada } \\
\cline { 2 - 3 } & $\begin{array}{cc}\text { Massa específica seca máxima } \\
\left(\mathrm{g} / \mathrm{cm}^{3}-\mathrm{pcf}\right)\end{array}$ & $\begin{array}{c}\text { Teor de umidade ótima } \\
\text { (\%) }\end{array}$ \\
\hline Gardinier & $1,54-96,0$ & 17,5 \\
Agrico & $1,56-97,3$ & 17,2 \\
USS & $1,66-103,9$ & 15,0 \\
Oxy & $1,47-92,0$ & 19,5 \\
I.M.C & $1,60-99,7$ & 17,3 \\
W. R. Grace & $1,59-99,1$ & 15,1 \\
Royster & $1,50-93,6$ & 16,2 \\
Farmland & $1,56-97,4$ & 16,0 \\
\hline
\end{tabular}

A comparação entre os resultados apresentados nas Tabelas $2.6 \mathrm{e}$ 2.7 mostram, para as fontes comuns nos dois estudos citados anteriormente (Gardinier, Oxy, IMC e Grace), uma certa discrepância entre os resultados, tanto de umidade ótima quanto de massa específica seca máxima. Nos resultados apresentados por CHANG, CHIN \& HO (1989), LIN et al. apud CHANG \& MANTELL (1990) e LIN apud CHANG \& MANTELL (1990), os 
valores de massa específica seca máxima variaram de $1,47 \mathrm{~g} / \mathrm{cm}^{3}$ (92,0 pcf) a $1,66 \mathrm{~g} / \mathrm{cm}^{3}$ (103,9 pcf), e os valores de umidade ótima variaram de $15 \%$ a $19,5 \%$, para compactação na energia modificada. Entre as observações feitas no estudo está a de que o uso de fosfogessos de fontes distintas conduzem a resultados diferentes entre si, observação semelhante à apresentada por HO \& ZIMPFER apud CHANG \& MANTELL (1990), e HO \& ZIMPFER apud TAHA \& SEALS (1991).

MACCARINI (1991) encontrou, para um fosfogesso produzido em Santa Catarina, valores de massa específica seca máxima de aproximadamente $1,40 \mathrm{~g} / \mathrm{cm}^{3}$ e um teor de umidade ótima próximo de $28 \%$, para compactação na energia normal.

\subsubsection{Resistência à compressão simples}

Com o intuito de analisar o desenvolvimento da resistência à compressão do fosfogesso di-hidratado puro CHANG, CHIN \& HO (1989), LIN et al. apud CHANG \& MANTELL (1990) e LIN apud CHANG \& MANTELL (1990) realizaram estudos com fosfogesso de 8 fontes distintas da Florida, apresentadas na Tabela 2.7. Nesse estudo foram usados cilindros de $5,08 \mathrm{~cm}$ (2") de diâmetro por 10,16cm (4") de altura, e compactação nas energias normal e modificada. Cada valor de resistência é resultado da média de três valores. Foram empregados três condições de ensaio:

1. seco ao ar: os corpos de prova foram armazenados em uma sala com $60 \%$ de umidade e temperatura de aproximadamente $24^{\circ} \mathrm{C}$ por um período de 7 dias antes do ensaio de compressão simples;

2. selado: os corpos de prova são testados na exata umidade resultante da cura selada, envolvido por filme plástico;

3. imerso: os corpos de prova são submetidos à imersão dois dias antes do ensaio de compressão. 
A Figura 2.5 mostra um resumo comparativo entre os resultados de resistência à compressão simples em função da umidade para os fosfogessos de 8 fontes distintas e compactadas no Proctor Modificado.

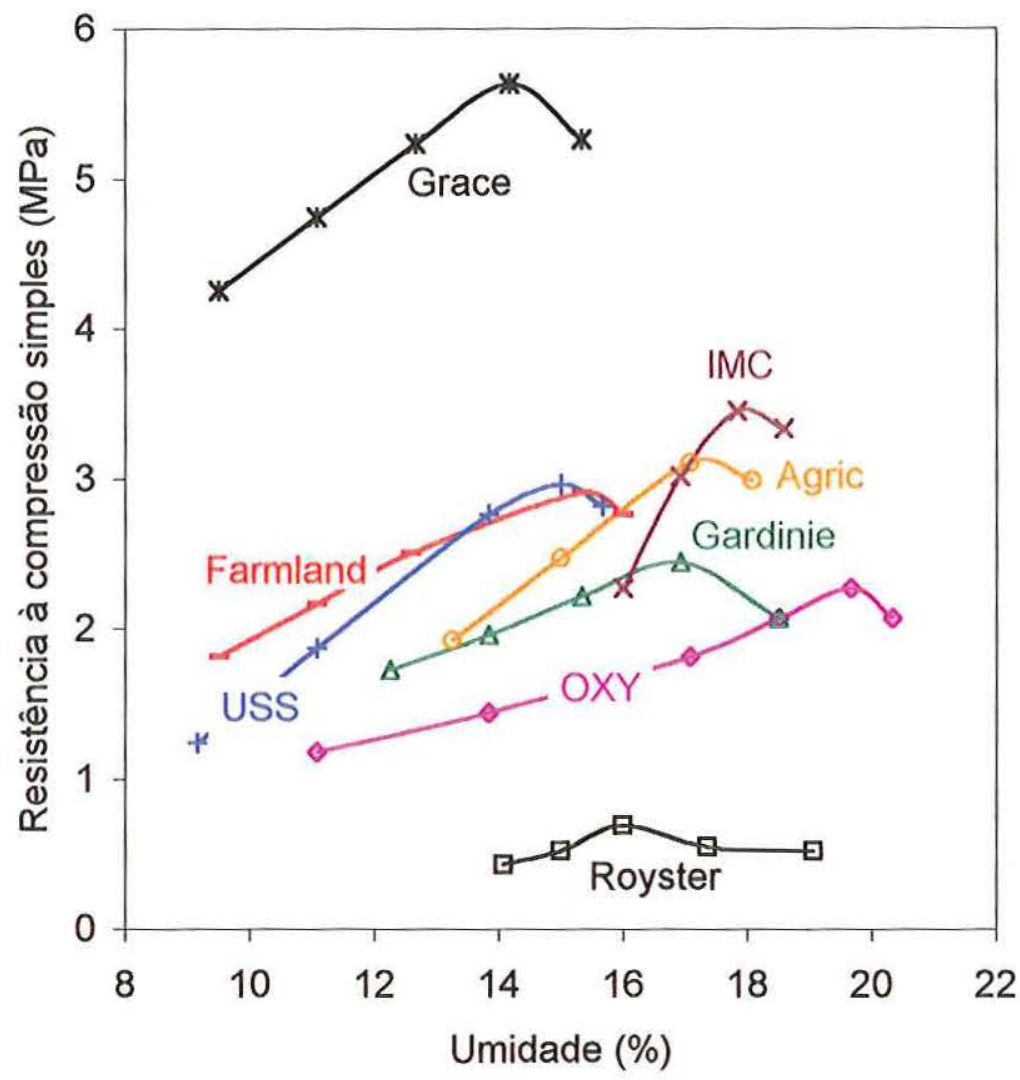

Figura 2.5: Comparação entre a resistência à compressão simples de 8 fontes distintas de fosfogesso produzidos nos Estados Unidos, compactados no Proctor Modificado, ensaiado na condição seco ao ar (fonte: adaptado de CHANG \& MANTELL, 1990).

Como pode ser observado na Figura 2.5, a resistência à compressão simples máxima, sob condições seca ao ar, varia de 0,69 MPa (100 psi) a $5,52 \mathrm{MPa}$ (800 psi), entretanto a maioria das resistências varia entre 2,07 MPa (300 psi) e 3,45 MPa (500 psi). Acreditam os autores que a fonte do fosfogesso tem uma influência importante sobre a resistência à compressão simples.

Uma observação importante desse estudo é que os corpos de prova quando submetidos à imersão se desintegraram, não apresentando, portanto, estabilidade frente a ação da água. 
As Figuras 2.6 e 2.7 exemplificam a relação entre resistência à compressão simples, massa específica seca e umidade de compactação para fosfogesso di-hidratado de duas das indústrias envolvidas no estudo realizado por CHANG, CHIN \& HO (1989). Neste estudo o fosfogesso foi compactado na energia modificada e ensaiada na condição seca ao ar.

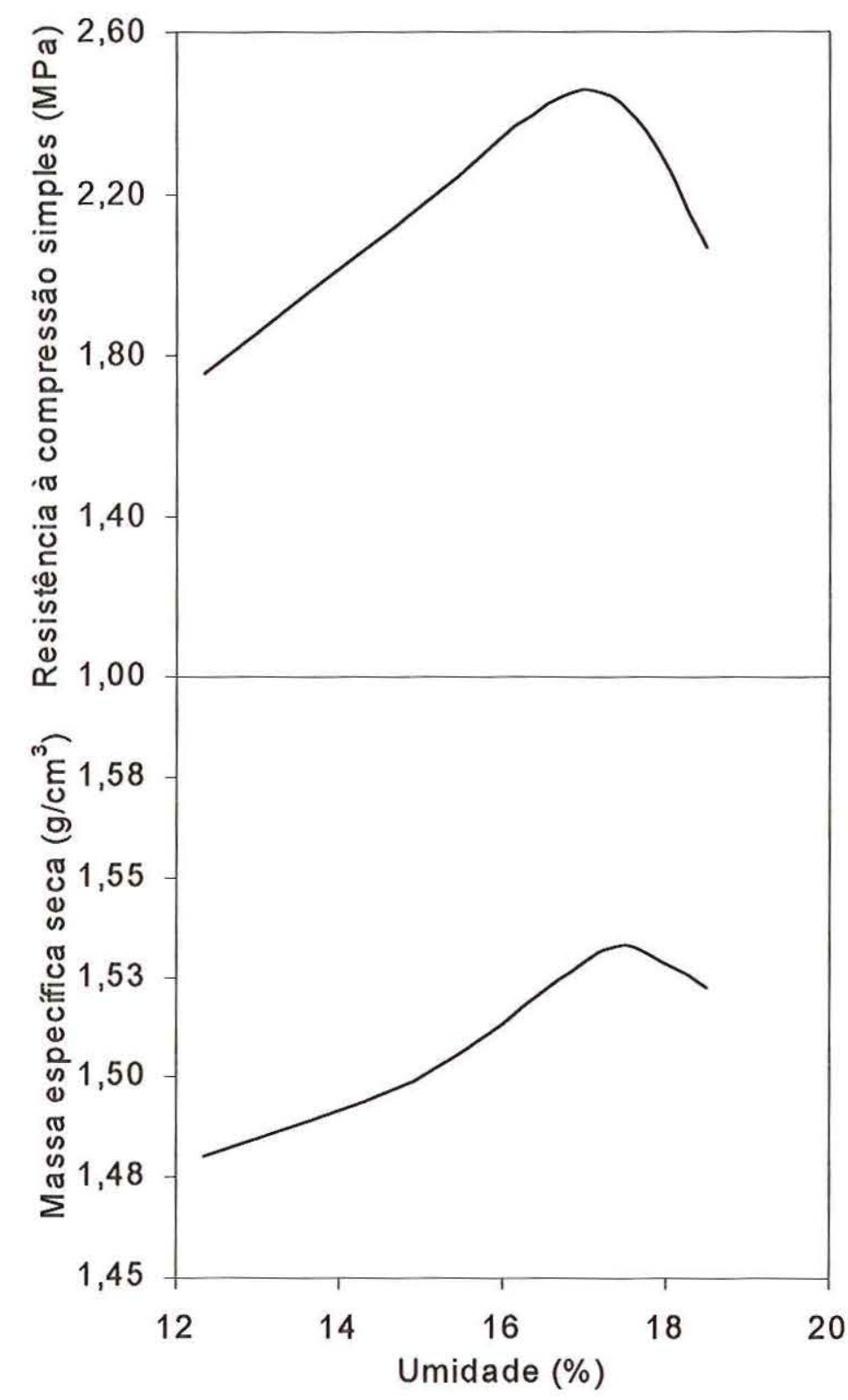

Figura 2.6: Relação entre umidade, massa especifica seca e resistência à compressão simples para o fosfogesso di-hidratado produzido pela indústria Gardinier, compactado na energia modificada e ensaiado em condições seca ao ar (fonte: adaptado de CHANG, CHIN \& HO, 1989 e CHANG \& MANTELL, 1990). 


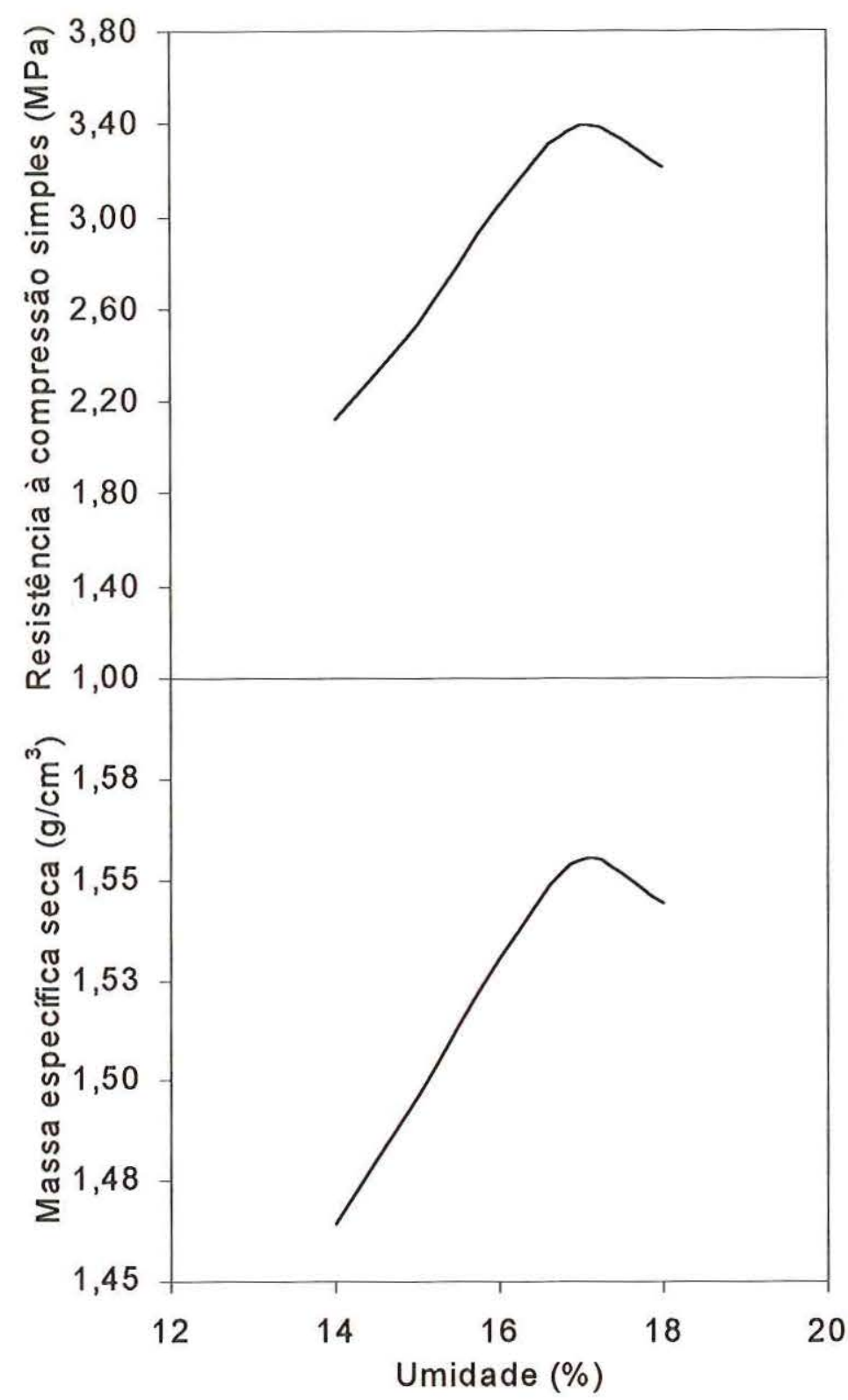

Figura 2.7: Relação entre umidade, massa específica seca e resistência à compressão simples para o fosfogesso di-hidratado produzido pela indústria Agrico, compactado na energia modíficada e ensaiado em condições seca ao ar (fonte: adaptado de CHANG, CHIN \& HO, 1989 e CHANG \& MANTELL, 1990).

Pode-se observar nas Figuras 2.6 e2.7 que a resistência à compressão máxima do fosfogesso ocorre, geralmente, com a compactação na umidade ótima, isto é, o teor de umidade onde a massa específica seca máxima é obtida. Dessa forma, é importante que se realize a compactação do fosfogesso no teor de umidade ótimo a fim de se alcançar os valores máximos de massa específica e resistência (CHANG, CHIN \& HO, 1989). 


\subsection{CARACTERÍSTICAS E PROPRIEDADES DE MISTURAS COMPACTADAS CONTENDO FOSFOGESSO}

Observa-se na bibliografia pesquisada que a avaliação da adequação do uso do fosfogesso na construção de pavimentos, em geral, ocorre com o estudo de misturas compactadas contendo fosfogesso, e com o estudo da influência da adição desse material nos valores de resistência à compressão simples das misturas com fosfogesso.

$\mathrm{Na}$ seqüência são apresentados diferentes trabalhos de pesquisa relacionados a misturas contendo fosfogesso, com maior destaque para os estudos relacionados a misturas de fosfogesso e cimento.

\subsubsection{Fosfogesso e cimento}

Esse tipo de mistura tem sido objeto de estudo de diversos pesquisadores, entre eles pode-se citar os trabalhos realizados por GREGORY et al. (1984), SAYLAK (1988), CHANG \& MANTTEL (1990), GADALLA et al.(1990), TAHA \& SEALS (1991), TAHA et al. (1992), ONG et al. (1994) e TAHA et al. (1995).

Conforme descrito anteriormente, o fosfogesso compactado não é estável frente a ação da água, necessitando de uma melhoria em suas características para ser usado na construção rodoviária.

De forma geral, existe um consenso entre os pesquisadores de que o fosfogesso estabilizado com cimento pode ser utilizado como material na execução de bases e sub-bases rodoviárias. Também é consenso a existência de influência do teor e tipo de cimento, energia de compactação, idade, entendida como período de cura, e $\mathrm{pH}$, sobre a resistência à compressão simples. 
No estudo realizado por GREGORY et al. (1984) utilizou-se um fosfogesso di-hidratado fornecido pela "Mobil Chemical Company" originário de três depósitos diferentes, denominados pilhas 1, 2 e 3 . O sistema de numeração reflete a idade relativa das pilhas, sendo a de número 1 , a mais velha. $\mathrm{Na}$ época da pesquisa, as pilhas 2 e 3 eram consideradas ativas, ou ainda em uso, enquanto a 1 era considerada inativa. Pesquisas iniciais, utilizando material da pilha 3 , produziram misturas com baixa resistência à compressão. Já os estudos realizados com fosfogesso da pilha 2 produziram misturas com características de resistência à compressão mais aceitáveis. Credita-se tal fato ao $\mathrm{pH}$ do fosfogesso, enquanto $\mathrm{opH}$ do material proveniente da pilha 3 era 2,5 , o encontrado no material da pilha 2 era de 5,2 .

Segundo SAYLAK et al. (1988), as atividades de pesquisa dirigidas pela "Texas A\&M University" com o fosfogesso da "Mobil Chemical Company" mostraram que a resistência alcançada com a estabilização por cimento Portland foi consideravelmente maior em depósitos inativos, com 7 anos de idade, do que em depósitos ativos. Um fator que parecia exercer influência primordial na resistência era a acidez do material, refletido no $\mathrm{pH}$. Os depósitos ativos, $\mathrm{pH}$ aproximadamente 2,5, desenvolveram pouca ou nenhuma resistência à compressão, enquanto que os depósitos envelhecidos, ou inativos ( $\mathrm{pH} 5,2)$, mostraram um alto grau de estabilização, conforme ilustrado na Figura 2.8. Outra constatação foi a existência de granulometria e forma das partículas mais variada no material envelhecido. Essas características permitem, por si só, a obtenção de maiores densidades e estabilidade, através de uma melhor compactação.

Segundo TAHA et al. (1992), o pH influi no desenvolvimento da resistência à compressão na medida em que uma parcela do cimento, adicionado para melhorar as características de resistência, será consumido na neutralização do fosfogesso mais ácido. 


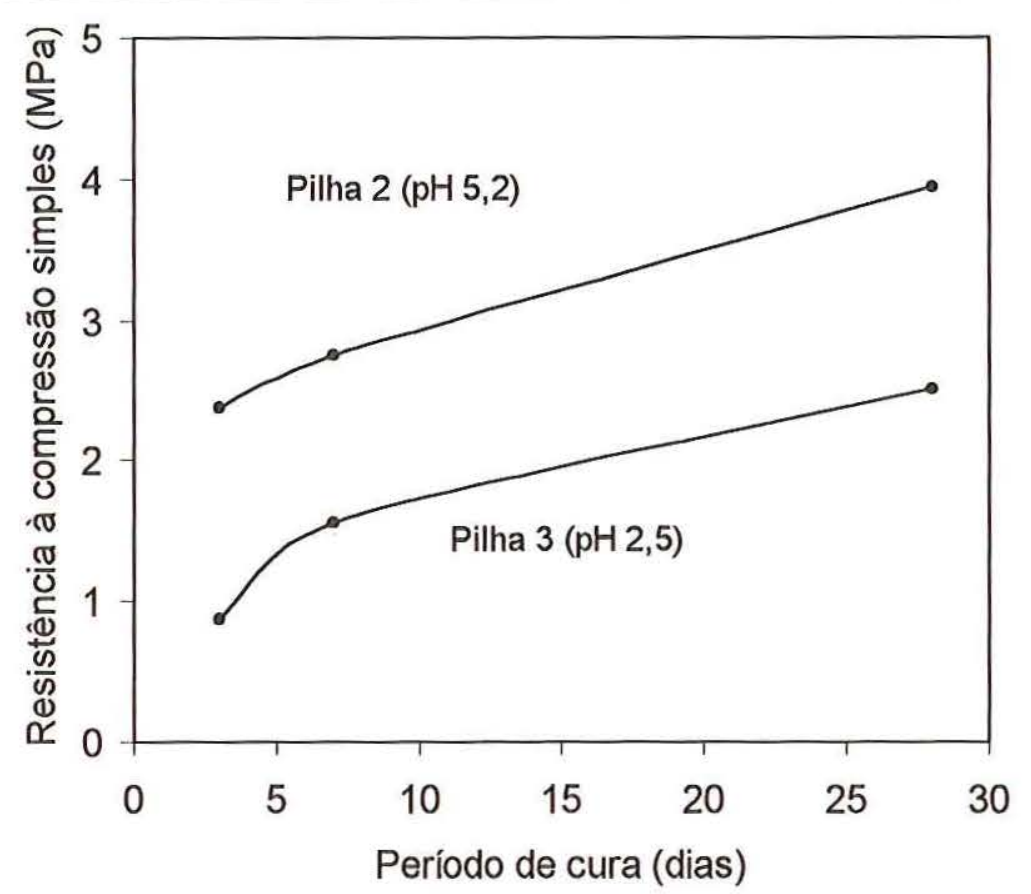

Figura 2.8: Comparação entre a resistência à compressão de fosfogesso estabilizado com $6 \%$ de cimento em função do tempo de cura e pH (fonte: adaptado de SAYLAK et al., 1988).

Numa segunda fase do estudo realizado por GREGORY et al. (1984) utilizou-se misturas de fosfogesso da pilha 2 com teores de cimento de $3 \%$, $6 \%$ e $10 \%$, compactados na energia equivalente ao Proctor modificado. De modo geral, verificou-se pelos resultados da pesquisa que a resistência à compressão simples aumenta à medida em que aumentam o teor de cimento e o tempo de cura. A inexistência de normas específicas sobre resistência mínima para misturas de fosfogesso e cimento levou a adoção como valor de comparação o valor mínimo de resistência aos 7 dias de argamassas convencionais de cimento e areia. Para esse material as resistências devem estar dentro do intervalo de 1,38 MPa (200 psi) a 2,07 $\mathrm{MPa}$ (300 psi). Os resultados mostraram que todas as misturas apresentaram resistência aos 7 dias acima de 1,38 $\mathrm{MPa}$, e que para teores de cimento de $6 \%$ e $10 \%$ os valores de resistência foram superiores a 2,07 $\mathrm{MPa}$. 
A Figura 2.9 ilustra os resultados de resistência à compressão simples em função do tempo de cura no estudo realizado por GREGORY et al. (1984). O pH do material usado era 5, e a energia de compactação equivalente ao Proctor modificado.

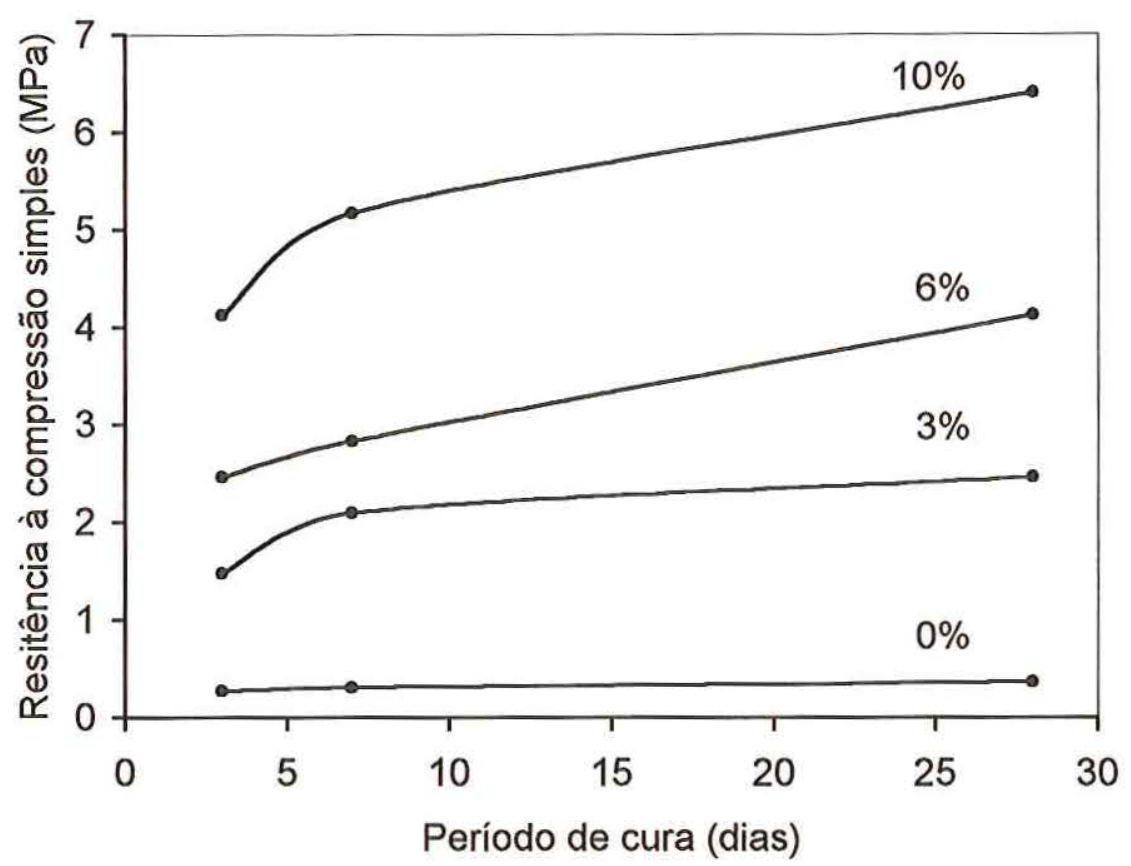

Figura 2.9: Desenvolvimento da resistência à compressão do fosfogesso proveniente da pilha 2, estabilizado com cimento Portland, em função do período de cura (fonte: adaptado de GREGORY et al., 1984).

NANNI (1985) apud CHANG \& MANTTEL (1990) estudou o efeito do tempo de cura e do teor de cimento na resistência à compressão simples. No estudo sobre a influência do tempo de cura foi utilizada uma mistura contendo um teor de cimento de $10 \%$, sendo que, os procedimentos de cura adotados foram: seco ao ar e imerso. Os resultados mostraram um padrão similar ao padrão desenvolvido pelo concreto convencional: aos 28 dias, ou menos, obtém-se aproximadamente a resistência à compressão máxima; para períodos de cura além de 13 dias, o gradiente de crescimento da resistência diminui, tendo pequena influência no aumento da resistência à compressão máxima. Aproximadamente $90 \%$ da resistência à compressão máxima é alcançada após 6 dias de cura, e aproximadamente $75 \%$ deste valor é alcançado após 2 dias de cura. A influência do teor de cimento foi 
estudada variando-se de $10 \%$ para $30 \%$ o seu valor. Esta variação no teor de cimento praticamente dobrou a resistência à compressão dos corpos de prova.

LIN (1984) apud TAHA \& SEALS (1991) estudou a influência dos processos de cura sobre a resistência à compressão simples para misturas contendo fosfogesso di-hidratado e $10 \%$ de cimento. Os ensaios foram realizados para duas energias de compactação, normal e modificada, um período de cura igual a 28 dias e sob três condições de ensaio: seca ao ar, selada ou envolvida em filme plástico, e imersa em água por 48 horas antes da realização do ensaio. A Tabela 2.8 apresenta os resultados dos ensaios.

Tabela 2.8: Comparação da resistência à compressão simples de misturas de fosfogesso e $10 \%$ de cimento, para um período de cura de 28 dias, e sob diferentes processos de cura e duas energias de compactação (fonte: LIN apud TAHA \& SEALS, 1991).

\begin{tabular}{lccc}
\hline Energia de & \multicolumn{3}{c}{ Resistência à compressão simples (psi/MPa) } \\
\cline { 2 - 4 } compactação & Selado & Imerso & Seco ao ar \\
\hline Normal & $621 / 4,28$ & $520 / 3,59$ & $1307 / 9,01$ \\
Modificado & $841 / 5,80$ & $641 / 4,42$ & $1660 / 11,45$ \\
\hline
\end{tabular}

Observa-se na Tabela 2.8 que as maiores resistências foram obtidas para a situação de cura seca ao ar, entretanto esse processo não simula as condições encontradas no campo. Verifica-se também que o aumento na energia de compactação resultou num aumento dos valores de resistência à compressão para todas as situações.

TAHA et al. (1992) estudou a influência do tempo de cura, do teor de cimento e da energia de compactação sobre a resistência à compressão simples de misturas de fosfogesso di-hidratado e cimento. Nesse estudo os corpos de prova foram submetidos a cura selada, envolvidos em filme plástico, por períodos variáveis. A compactação foi realizada com as energias normal e intermediária. A Figura 2.10 ilustra o efeito do tempo de cura e teor de cimento nos valores de resistência de misturas de fosfogesso e cimento. A Figura 2.11 ilustra os resultados de resistência para corpos de 
prova curados por 7 dias e 28 dias, compactados nas energias normal e intermediária, e imersos em água por 4 horas antes do ensaio.

Pelos resultados obtidos, exemplificados nas Figura 2.10 e 2.11, os pesquisadores puderam observar que com um aumento no tempo de cura e no teor de cimento existe um aumento correspondente na resistência à compressão simples. Observaram também que a compactação com o Proctor modificado apresentou maiores valores de massa específica seca, e resultaram em valores de resistência à compressão simples para 7 dias e 28 dias aproximadamente $130 \%$ e $90 \%$, respectivamente, maiores do que os obtidos com a energia normal, ou seja, o aumento na energia de compactação promove um aumento nos valores de resistência à compressão simples.

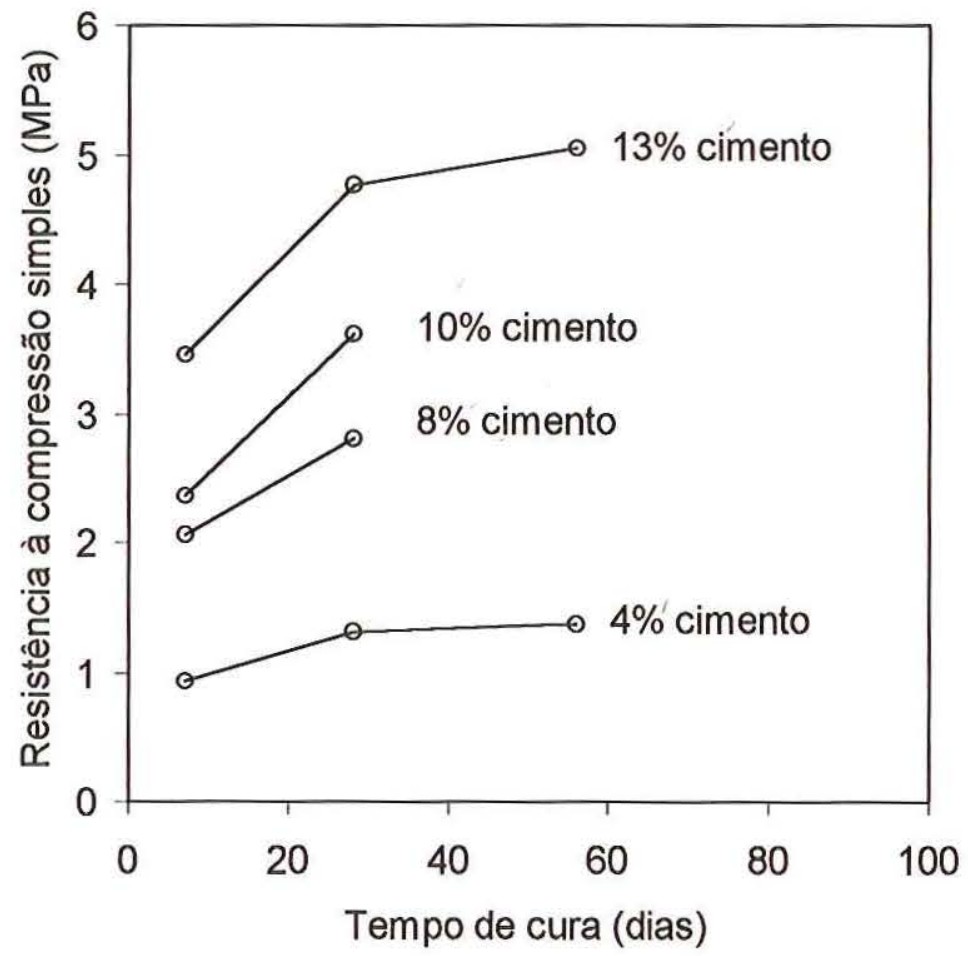

Figura 2.10: Resistência à compressão simples em função do tempo de cura e teor de cimento (fonte: adaptado de TAHA et al. 1992) 


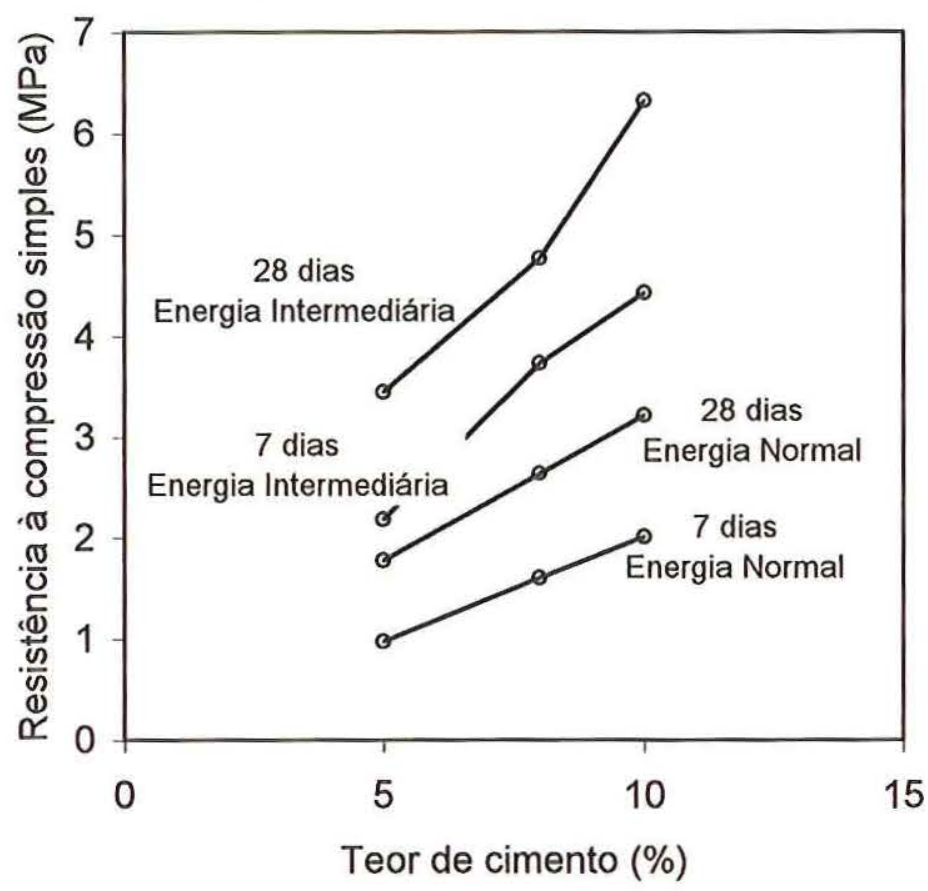

Figura 2.11: Resistência à compressão simples de misturas compactadas nas energias normal e intermediaria, estabilizadas com cimento e curadas por 7 dias e 28 dias (fonte: adaptado de TAHA et al. 1992).

Segundo SAYLAK et al. (1988), em investigações sobre a influência da energia de compactação na resistência à compressão simples verificouse a existência de uma relação direta e aproximadamente linear entre estas variáveis. Isso poderia significar que uma mistura compactada no Proctor normal necessitaria de uma quantidade maior de estabilizante para alcançar a mesma resistência de uma mistura compactada na energia modificada.

GADALLA et al. (1990), frente ao problema da diminuição da resistência das misturas diante da acidez do fosfogesso, desenvolveram estudos de neutralização do material com posterior estabilização por cimento Portland. Os agentes neutralizantes estudados foram o hidróxido de cálcio $\left(\mathrm{Ca}(\mathrm{OH})_{2}\right)$ e o hidróxido de sódio $(\mathrm{NaOH})$. Os neutralizantes foram usados para induzir três níveis de pH: não neutralizado, ou seja, sem a adição de hidróxidos; parcialmente neutralizado; e com excesso de neutralizante. Os corpos de prova foram compactados em energia equivalente ao Proctor normal, e submetidos a períodos de cura de 3,7, 28 e 42 dias. A cura foi realizada com os corpos de prova envoltos em filme plástico. Os resultados 
desse estudo mostraram que a variação do tipo de neutralizante empregado, hidróxido de sódio ou de cálcio, não afeta significativamente o valor da resistência, sendo entretanto, afetada pelo teor de cimento e pelo valor do $\mathrm{pH}$ : para um mesmo valor de $\mathrm{pH}$ maiores resistências podem ser alcançadas com a adição de mais cimento e, para um mesmo teor de cimento, quanto maior o pH maiores são as resistências. Entretanto, segundo SAYLAK et al. (1988), apenas a neutralização não é suficiente para emprestar ao fosfogesso o mesmo nível de resistência alcançado pelo fosfogesso envelhecido, pois uma grande parcela dessa resistência, aproximadamente $50 \%$, é função da dimensão e forma das partículas.

TAHA et al. (1992) e ONG et al.(1994) estudaram a influência do tipo de cimento sobre a resistência à compressão simples e expansibilidade de misturas com fosfogesso di-hidratado. Os problemas relacionados com o tipo de cimento são devidos principalmente à presença do aluminato tricálcico $\left(C_{3} A\right)$. Esse elemento quando em presença de sulfatos, elemento abundante no fosfogesso, reage levando a formação de cristais expansivos denominados de etringita (trissulfoaluminato), conferindo características expansivas à mistura.

No estudo realizado por TAHA et al. (1992) foram usadas as energias normal e modificada, um teor de cimento (10\%) e 6 fontes distintas cimento, sendo divididos em 3 tipos, são eles:

- Tipo I: cimento Citadel Demopolis ( $11 \%$ de $\left.\mathrm{C}_{3} \mathrm{~A}\right)$;

- Tipo II: cimento Ideal fine grind $\left(7 \%\right.$ de $\left.\mathrm{C}_{3} \mathrm{~A}\right)$;

- Tipo II: cimento Dundee $\left(5,6 \%\right.$ de $\left.\mathrm{C}_{3} \mathrm{~A}\right)$;

- Tipo II: cimento Gifford-Hill (5\% de $\left.\mathrm{C}_{3} \mathrm{~A}\right)$;

- Tipo V: cimento Gifford-Hill ( $5 \%$ de $\left.\mathrm{C}_{3} \mathrm{~A}\right)$;

- Tipo V: cimento Citadel Leharve $\left(5 \%\right.$ de $\left.\mathrm{C}_{3} \mathrm{~A}\right)$;

- Tipo V: cimento United(3\% de $\left.\mathrm{C}_{3} \mathrm{~A}\right)$;

- Tipo II: cimento Lone Star $\left(0 \%\right.$ de $\left.\mathrm{C}_{3} \mathrm{~A}\right)$; 
Para se verificar a adequação do cimento Portland na estabilização do fosfogesso, TAHA et al. (1992) desenvolveram um estudo de longo prazo para determinar-se a influência do teor de $\mathrm{C}_{3} \mathrm{~A}$ sobre a expansibilidade das misturas. Os corpos de prova usados nesse estudo foram curados por aproximadamente três anos em câmara úmida. A Figura 2.12 ilustra os resultados de ensaios de expansão realizados com cimentos apresentando 4 teores diferentes de $\mathrm{C}_{3} \mathrm{~A}$. Esses ensaios foram realizados segundo o Método de ensaio ASTM C511 e C490, com corpos de prova de 10,16 cm (4") de diâmetro e $28,58 \mathrm{~cm}\left(11,25^{\prime \prime}\right)$ de altura. No ensaio de expansão determina-se a variação de dimensão no sentido de eixo longitudinal do corpo de prova.

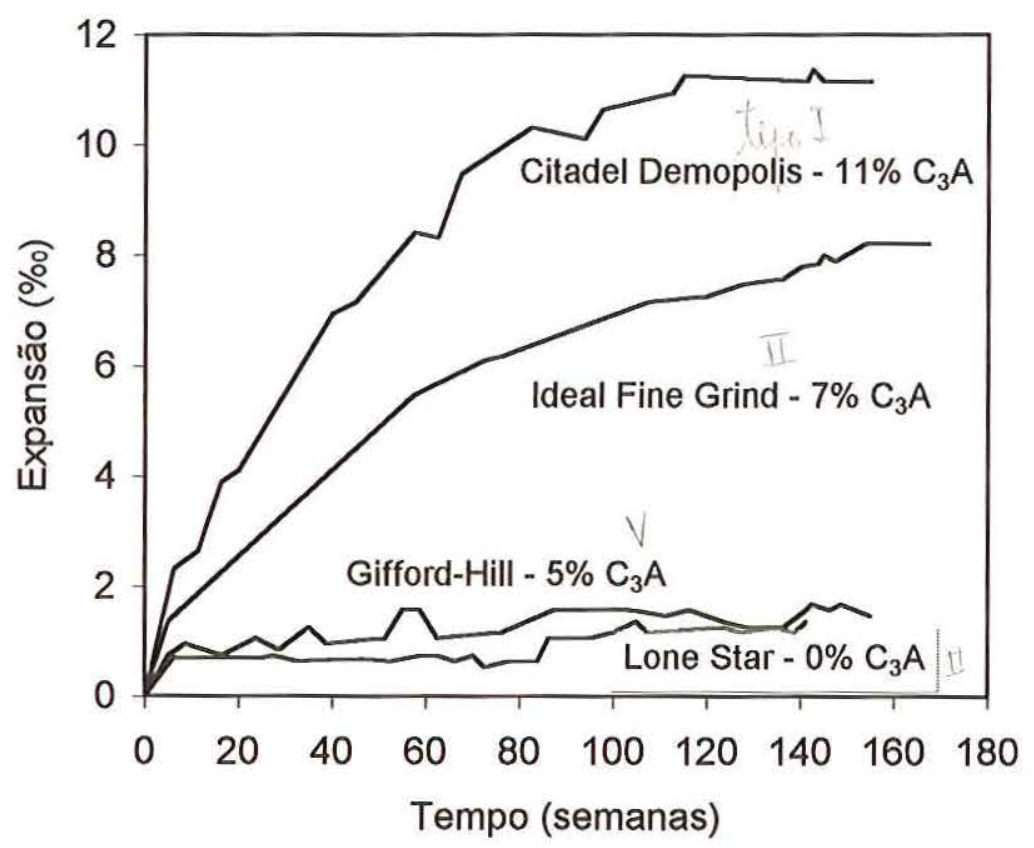

Figura 2.12: Resultados de ensaios de expansão para misturas de fosfogesso e $10 \%$ de cimento (fonte: adaptado de TAHA et al., 1992).

Baseado nesses resultados, os autores observaram que existe um aumento nos valores de expansão das misturas com o aumento no teor $\mathrm{C}_{3} \mathrm{~A}$ do cimento. Os maiores valores de expansão foram observados nas misturas com o cimento do Tipo I (Citadel Demopolis), que apresenta 11\% de $\mathrm{C}_{3} \mathrm{~A}$, e os menores em misturas com cimento do Tipo II (Lone Star), que apresenta $0 \%$ de $\mathrm{C}_{3} \mathrm{~A}$. Observações através de microscópio eletrônico 
indicaram a formação de cristais de etringita nas misturas de fosfogesso e cimento do Tipo I (Citadel Demopolis).

A influência do tipo de cimento sobre a massa específica seca máxima, umidade ótima e resistência à compressão das misturas de fosfogesso e cimento foi estudada por ONG et al.(1994). Nesse estudo foram usadas as energias normal e modificada, e 4 tipos diferentes cimento, são eles:

- Tipo I: cimento comum;

- Tipo II: moderada resistência a sulfatos;

- Tipo IIA: cimento com baixo teor de $\mathrm{C}_{3} \mathrm{~A}$;

- Tipo V: cimento com alta resistência a sulfatos.

Os resultados mostraram um comportamento típico, com a resistência à compressão simples aumentando com o teor de cimento, mas variando em função do tipo de cimento.

A Tabela 2.9 apresenta um resumo dos resultados do estudo realizado por ONG et al.(1994). Consta desta tabela a massa específica seca máxima e o teor de umidade ótimo para as misturas de fosfogesso e cimento, variando em função do tipo e teor de cimento, e da energia de compactação.

As Figuras 2.13 e 2.14 mostram, respectivamente, os resultados de resistência à compressão simples para misturas compactadas nas energias normal e modificada, variando-se os teores e tipos de cimento.

Os autores, analisando os resultados ilustrados nas Figuras $2.13 \mathrm{e}$ 2.14, observaram que as resistências alcançadas pela compactação na energia normal e com um teor de $8 \%$ cimento, considerado economicamente viável, não são adequados para os requisitos do Departamento de Transportes e Desenvolvimento da Louisiana, que determinam uma 
resistência aos 7 dias de 1,7 MPa. Acrescentam que esse nível de resistência pode ser obtido elevando-se o teor de cimento para mais de $14 \%$, ou pelo aumento da energia de compactação: usando-se a energia modificada, para teores de cimento variando de $4 \%$ a $6 \%$, é possível alcançar-se a resistência estipulada.

Verificou-se ainda nesse estudo que uma pequena alteração na massa específica seca máxima tem um efeito significativo nos valores de resistência à compressão simples: aumentando-se a massa específica seca máxima promove-se um aumento correspondente nos valores de resistência à compressão simples.

Uma outra observação obtida nesse estudo mostrou, em ensaios de expansão, que o aumento no teor de $\mathrm{C}_{3} \mathrm{~A}$ implica em aumento dos valores de expansão, correspondendo a uma diminuição nos valores de resistência à compressão simples.

Tabela 2.9: Valores de massa específica seca máxima e umidade ótima em função da energia de compactação, do teor e do tipo de cimento (fonte: adaptado de ONG et al.,1994).

\begin{tabular}{|c|c|c|c|c|c|}
\hline \multirow{2}{*}{\multicolumn{2}{|c|}{ Cimento }} & \multicolumn{4}{|c|}{ Procedimento de compactação } \\
\hline & & \multicolumn{2}{|c|}{ Proctor Normal } & \multicolumn{2}{|c|}{ Proctor Modificado } \\
\hline Teor (\%) & Tipo & $\begin{array}{c}\text { Massa } \\
\text { específica seca } \\
\text { máxima }\left(t / \mathrm{m}^{3}\right)\end{array}$ & $\begin{array}{c}\text { Teor de } \\
\text { umidade } \\
\text { ótima (\%) }\end{array}$ & $\begin{array}{c}\text { Massa específica } \\
\text { seca máxima } \\
\left(t / \mathrm{m}^{3}\right)\end{array}$ & $\begin{array}{c}\text { Teor de } \\
\text { umidade } \\
\text { ótima (\%) }\end{array}$ \\
\hline \multicolumn{2}{|c|}{ Sem cimento } & 1,38 & 22,0 & & \\
\hline \multirow{4}{*}{4} & II & 1,36 & 21,4 & 1,57 & 14,6 \\
\hline & V & 1,37 & 22,7 & 1,55 & 13,8 \\
\hline & i & 1.38 & 19,3 & 1.54 & 16.7 \\
\hline & $\| A$ & 1,40 & 21,5 & 1,55 & 14,2 \\
\hline \multirow{4}{*}{8} & II & 1,41 & 20,8 & 1,57 & 14,4 \\
\hline & V & 1,43 & 19,2 & 1,56 & 15,3 \\
\hline & 1 & 1,40 & 20,7 & 1,56 & 14,2 \\
\hline & $\| A$ & 1,40 & 19,3 & 1,58 & 13,5 \\
\hline \multirow{3}{*}{10} & II & 1,35 & 23,4 & & \\
\hline & $\mathrm{V}$ & 1,38 & 21,6 & & \\
\hline & $\| A$ & 1,36 & 23,5 & & \\
\hline \multirow{3}{*}{14} & II & 1,38 & 23,5 & & \\
\hline & V & 1,37 & 23,8 & & \\
\hline & $\| A$ & 1,38 & 23,5 & & \\
\hline
\end{tabular}




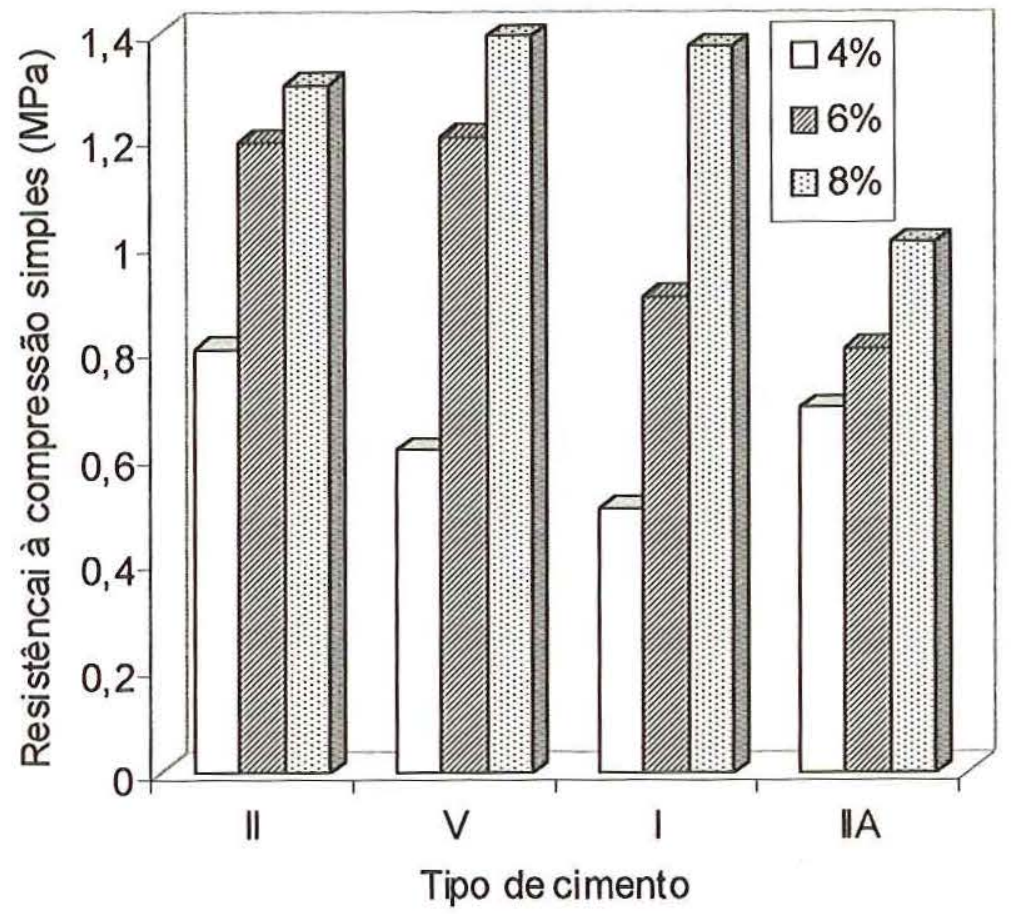

Figura 2.13: Efeito do tipo e teor de cimento sobre a resistência à compressão simples em misturas de fosfogesso e cimento submetidas a um período de cura de 7 dias e compactadas na energia normal (fonte: adaptado de ONG et al., 1994).

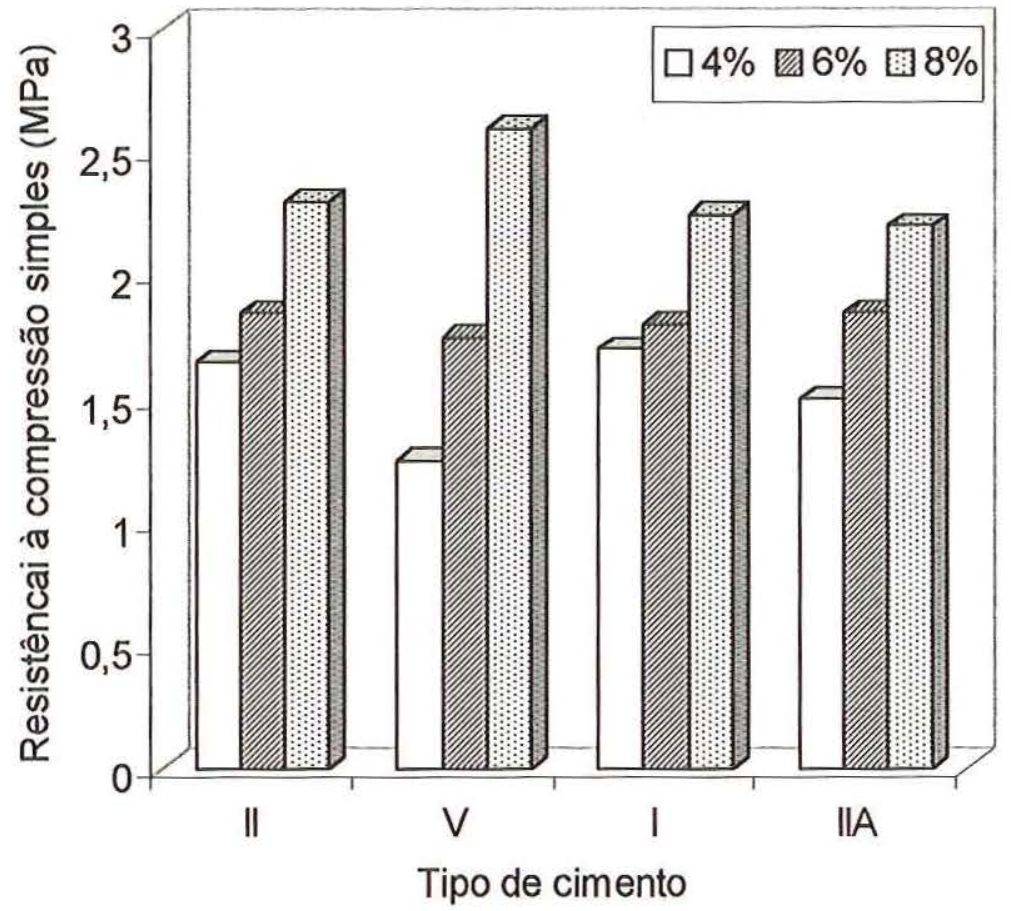

Figura 2.14: Efeito do tipo e teor de cimento sobre a resistência à compressão simples em misturas de fosfogesso e cimento submetidas a um período de cura de 7 dias e compactadas na energia intermediária (fonte: adaptado de ONG et al., 1994). 
Como os critérios de resistência são considerados aos 7 dias, e sabendo-se que o sulfato de cálcio retarda a pega do cimento, ONG et al. (1994), num estudo complementar, consideraram o uso de um cimento de ARI - alta resistência inicial (Tipo III). A expectativa era a de que os níveis de resistência alcançados aos 7 dias fossem maiores do que com o uso de um cimento Portland comum. Entretanto, apesar das resistência aos 3 dias serem maiores, os efeitos sobre a resistência aos 7 dias foram pequenos para ter valor prático.

Um outro parâmetro estudado, importante para a compreensão do comportamento das misturas de fosfogesso e cimento, é o módulo de resiliência. Estudos sobre o assunto foram apresentados por LITTLE et al. apud TAHA \& SEALS (1991) e GERRITY et al. (1994).

LITTLE et al. apud TAHA \& SEALS (1991) apresentam os resultados de ensaios realizados com amostras de fosfogesso da Mobil Chemical Company, onde os valores do módulo de resiliência são comparados com os de vários materiais convencionais usados na construção de bases rodoviárias. A Figura 2.15 ilustra essa comparação.

Os resultados apresentados nesse estudo indicaram que misturas de fosfogesso e cimento podem ter um desempenho melhor do que materiais não estabilizados, entretanto, os demais materiais estabilizados com cimento apresentaram valores consideravelmente maiores de módulo de resiliência. Nesse estudo, uma mistura de fosfogesso estabilizado com $6 \%$ de cimento apresentou um módulo de resiliência de $2131 \mathrm{MPa}$.

Num outro estudo, GERRITY et al. (1994) avaliaram em laboratório o comportamento do fosfogesso estabilizado com cimento em termos resistência à compressão simples e módulo de resiliência. O comportamento do fosfogesso estabilizado com cimento foi comparado com 0 comportamento de uma areia de rio estabilizada com cimento, material esse 
de uso comum no estado da Louisiana para a construção de rodovias secundárias.

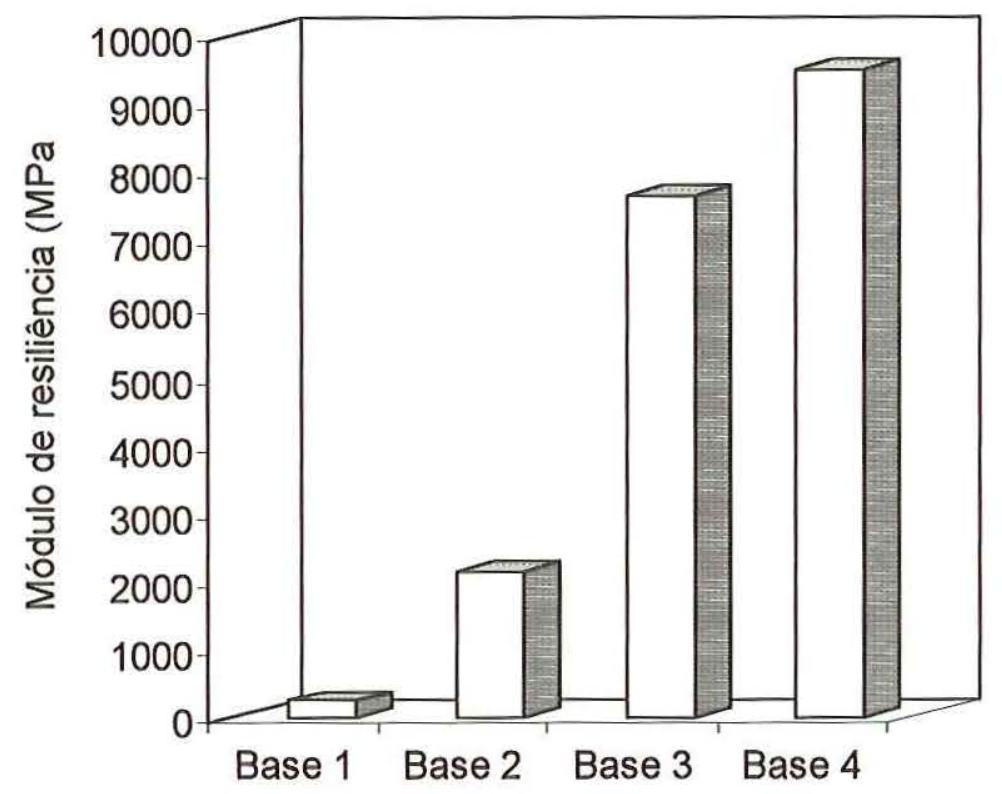

Base 1: pedra britada não estabilizada;

Base 2: Fosfogesso estabilizado com $6 \%$ de cimento;

Base 3: Granito e gesso estabilizado com $6 \%$ de cimento;

Base 4: pedra britada estabilizada com $5 \%$ de cimento.

Figura 2.15: Comparação entre os valores do módulo de resiliência do fosfogesso estabilizado com cimento e materiais convencionais para execução de bases rodoviárias (fonte: TAHA e SEALS, 1991).

A Figura 2.16 ilustra a curva Tensão x Deformação para uma mistura de fosfogesso com $8 \%$ de cimento, compactado na energia modificada e submetido a 7 dias de cura, ensaiado até a ruptura em condições não imersas. Essa curva é descrita pelos autores como típica para misturas de fosfogesso e cimento.

A Figura 2.17 mostra uma curva de Tensão x Deformação para misturas de fosfogesso com $8 \%$ de cimento, compactadas na energia modificada e curadas por 7 dias. Os corpos de prova foram submetidos a ensaio com carregamento repetido para uma tensão de confinamento de $0,27 \mathrm{MPa}$, em condições não imersas. 


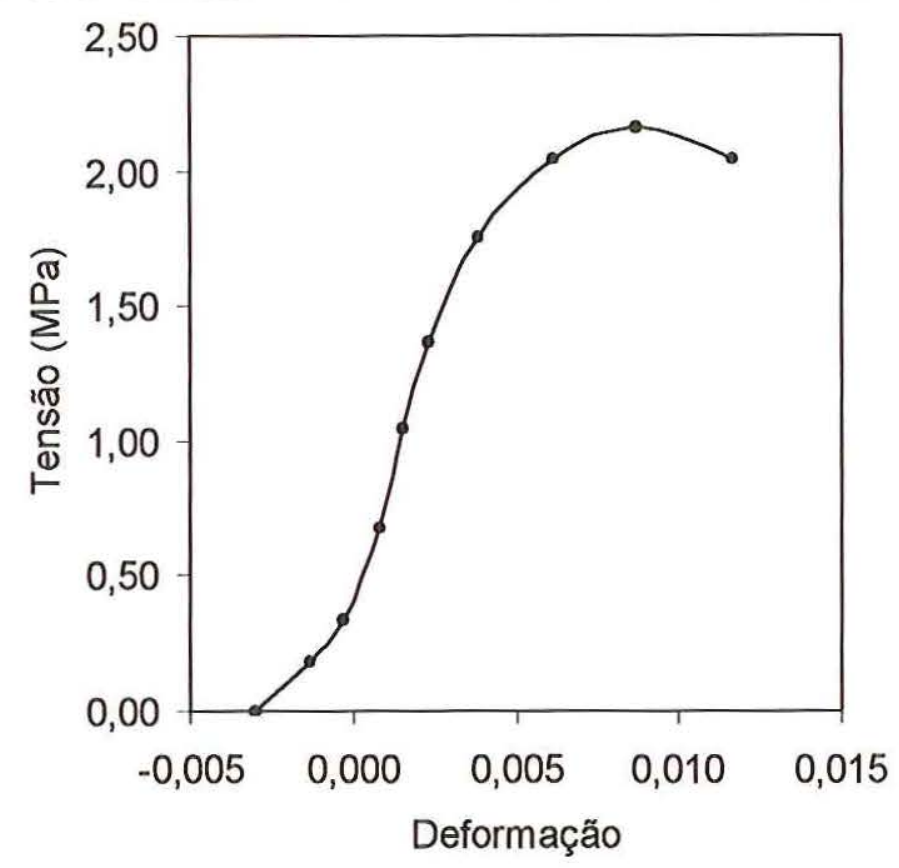

Figura 2.16: Curva Tensão $x$ Deformação típica para misturas de fosfogesso $e$ cimento (fonte: adaptado de GERRITY, 1996).

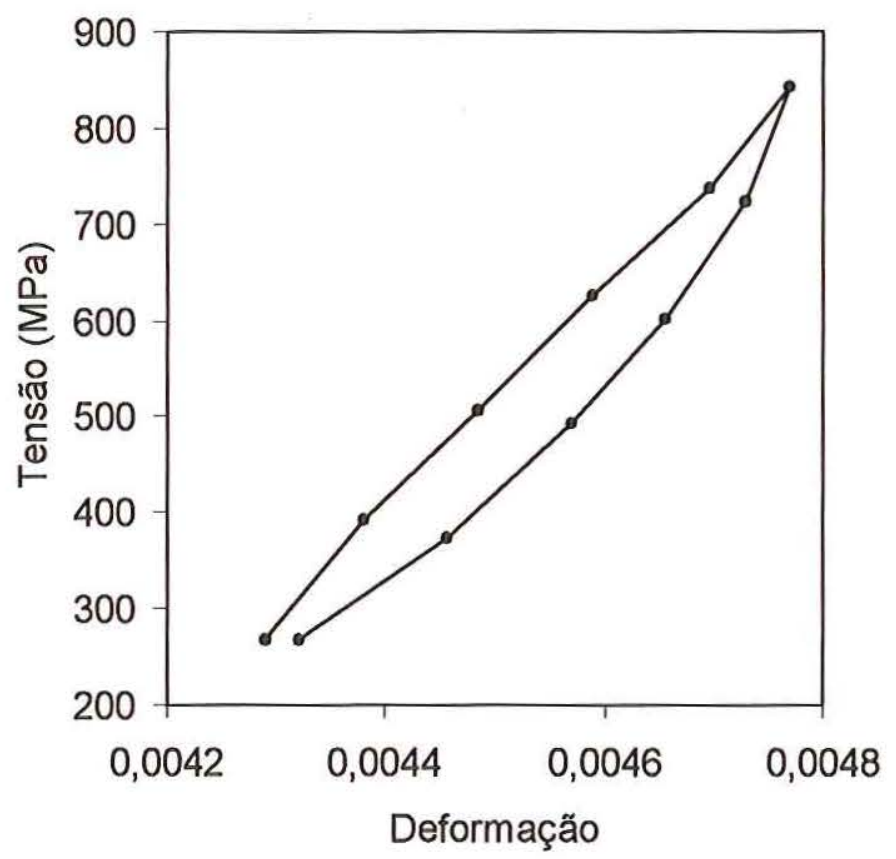

Figura 2.17: Curva Tensão $x$ Deformação para misturas de fosfogesso e cimento submetido a carregamento cíclico (fonte: adaptado de GERRITY, 1996).

A Tabela 2.10 apresenta os resultados médios de resistência à compressão simples e módulo de resiliência para amostras de fosfogesso e areia de rio estabilizadas com cimento Portland do Tipo I. Os ensaios de 
módulo de resiliência foram realizados com uma carga repetida equivalente a $30 \%$ da resistência à compressão simples. Os corpos de prova foram compactados na energia normal e na modificada, sendo submetidas a períodos de cura de 7 dias e 28 dias e ensaiadas em condições não imersas.

Tabela 2.10: Valores médios dos resultados de resistência à compressão simples e módulo de resiliência (fonte: GERRITY, 1996).

\begin{tabular}{lcc}
\hline Material & $\begin{array}{c}\text { Média da } \\
\text { RCS }(\mathrm{MPa})\end{array}$ & $\begin{array}{c}\text { Média do módulo de } \\
\text { resiliência }(\mathrm{MPa})\end{array}$ \\
\hline $12 \%$ CP, FG, normal, 7 dias & 0,452 & 283 \\
$10 \%$ CP, AR, normal, 7 dias & 0,917 & 276 \\
$12 \%$ CP, FG, 95\% modificada, 7 dias & 2,331 & 1014 \\
$12 \%$ CP, FG, 95\% modificada, 28 dias & 3,082 & 1655 \\
$10 \%$ CP, AR, 95\% modificada, 7 dias & 1,469 & 435 \\
$10 \%$ CP, AR, modificada, 7 dias & 1,489 & 441 \\
\hline
\end{tabular}

OBS.: cada valor é o resultado da média de três amostras

$\mathrm{CP}=$ cimento Portland

$A R=$ areia de rio

$F G=$ fosfogesso

Conforme observa-se na Tabela 2.10, o valor do módulo de resiliência para misturas de fosfogesso estabilizadas com $12 \%$ de cimento, compactadas na energia normal e curadas por 7 dias é equivalente ao módulo de resiliência para misturas de areia de rio estabilizadas com $10 \%$ de cimento e compactadas e curadas nas mesmas condições. Já o uso da energia modificada para compactação de misturas de fosfogesso estabilizadas com $12 \%$ de cimento, apresentou resultados bastante superiores, tanto para a resistência à compressão simples quanto para o módulo de resiliência, quando comparados aos resultados obtidos com misturas de areia de rio estabilizadas com $10 \%$ compactadas na energia intermediária.

Entre as conclusões obtidas nesse estudo, os autores citam: que a resistência e o módulo de resiliência aumentam com o aumento do teor de cimento; fosfogesso estabilizado com teores de $10 \%$ e $12 \%$ de cimento do Tipo I apresentaram módulo de resiliência variando entre 275 MPa e 1655 MPa para compactação nas energias normal e intermediária; as relações 
Capítulo 2 - Revisão Bibliográfica

Página 46

entre a resistência à compressão simples e o módulo de resiliência devem ser determinados para cada uma das misturas estudadas, e não admitir uma única relação para todas as misturas; o fosfogesso estabilizado com cimento pode ser usado de forma efetiva para construção de bases em rodovias de baixo volume, desde que seja usado um teor de cimento apropriado, uma compactação adequada, e que uma condição de drenagem seja assegurada, entretanto, faz-se necessária a construção de uma pista experimental para se determinar se as misturas estabilizadas com fosfogesso podem suportar as condições ambientais encontradas no campo.

A integração do fosfogesso ao meio-ambiente, como parte constante de uma rodovia, foi estuda por TITTLEBAUM et al. (1995) e TAHA et al. (1995). Nesses estudos foram avaliadas as características de lixiviação do fosfogesso puro compactado e misturas compactadas de fosfogesso e cimento. Foram considerados, para ambas as pesquisas, quatro tipos e dois teores de cimento, e duas energias de compactação.

Segundo TITTLEBAUM et al. (1995), a maior preocupação com relação ao fosfogesso é que os metais pesados presentes em sua composição sejam liberados ou lixiviados dos estoques, prejudicando o meio-ambiente e a saúde humana. O perigo potencial do fosfogesso inclui a contaminação do lençol freático pela lixiviação vertical ou lateral dentro do aqüífero, bem como a contaminação da água superficial.

Os resultados apresentados por TITTLEBAUM et al. (1995) mostraram que o fosfogesso estabilizado forma uma laje monolítica, contendo componentes insolúveis, que ajudam a aprisionar os metais pesados dentro do bloco. Assim, o impacto do fosfogesso estabilizado com cimento sobre o meio-ambiente foi considerado como menor do que o impacto provocado pelo fosfogesso natural. Segundo o autor, o tipo de cimento afeta as características de lixiviação das misturas de fosfogesso e 
cimento, nesse caso o uso de um cimento Portland do Tipo I produziu uma maior concentração de metais lixiviados.

Segundo os estudos realizados por TAHA et al. (1995), em geral, a lixiviação do fosfogesso estabilizado com cimento não foi afetada significativamente pela energia de compactação, mas o tipo e teor de cimento produziram alterações significativas. Os autores destacam ainda que $o$ assunto mais importante, na atualidade, na pesquisa sobre as características ambientais do fosfogesso é a incerteza sobre os possíveis efeitos, na saúde humana, relacionados com a emanação de radônio desse material.

O fosfogesso contem rádio $226\left({ }^{226} \mathrm{Ra}\right)$ e urânio $238\left({ }^{238} \mathrm{U}\right)$, elementos de ocorrência natural em rochas fosfáticas. Na produção do ácido fosfórico $86 \%$ do ${ }^{238} \mathrm{U}$ fica retido neste material, enquanto $80 \%$ do ${ }^{226} \mathrm{Ra}$ segue com o fosfogesso. A EPA regulamentou o uso do fosfogesso principalmente pela existência do radônio $222\left({ }^{226} \mathrm{Rd}\right)$, um produto da decomposição espontânea do ${ }^{226} \mathrm{Ra}$ (TITTLEBAUM et al., 1995).

TAHA et al. (1995), informaram que estudos sobre a emanação de radônio estão em desenvolvimento no Instituto para Materiais Recicláveis da Universidade da Louisiana. Esses estudos encerram previsões teóricas e medidas experimentais da emanação de radônio para o fosfogesso puro e para o fosfogesso estabilizado com cimento. Os resultados desse estudo indicam, para amostras com 20,32 cm (8") de espessura, taxas de emanação de $10 \mathrm{pCi} / \mathrm{m}^{2} / \mathrm{s}$ ou menores, para várias combinações de teor e tipo de cimento, umidade e energia de compactação e período de cura. Os padrões da EPA indicam para os estoques de fosfogesso, um fluxo limite para a emanação de radônio igual a $20 \mathrm{pCi} / \mathrm{m}^{2} / \mathrm{s}$.

ANDERSON (1986) e CHANG \& MANTELL (1990) apresentam o primeiro projeto de pesquisa de campo, iniciado em Junho de 1983, com 
misturas de fosfogesso e cimento. Nesse projeto construiu-se uma pista experimental em via urbana, na cidade de La Port, Texas, dividida em 7 seções de estudo, sendo 3 de fosfogesso estabilizado com cimento, 2 de fosfogesso e cinza volante, e 2 seções de controle executadas com pedra britada. A estrutura dos pavimentos construídos consistiam de uma sub-base de 15,24 cm (6") estabilizada com cal, seguida de uma base de 20,32 cm (8"), e um revestimento superficial duplo. A espessura das camadas era constante para todas as seções, variando-se apenas o tipo de material da base. As três seções executadas com base de fosfogesso foram estabilizados com teores de cimento iguais a $5 \%, 7,5 \%$ e $10 \%$. As seções construídas eram avaliadas periodicamente com o uso do equipamento Dynaflect como parte de um estudo de 4 anos realizado pelo Instituto de Transportes da Texas A\&M University. A Tabela 2.11 apresenta os resultados das medidas para 2 e 3 anos das seções de controle e das estabilizadas com cimento. Os autores salientam que a espessura de base instalada em todos os casos foi de $20,32 \mathrm{~cm}\left(8^{\prime \prime}\right)$.

Tabela 2.11: Espessura de bases executadas nas ruas da Cidade de La Port, Texas (fonte: adaptado de CHANG \& MANTELL, 1990).

\begin{tabular}{ccc}
\hline & \multicolumn{2}{c}{ Espessura efetiva (cm) } \\
\cline { 2 - 3 } Material de base & Agosto, 1985 & Julho, 1986 \\
2 anos e 2 meses & 3 anos e 1 mês \\
\hline Pedra britada (controle) & 13,21 & 14,22 \\
FG + 10\% CP & 18,03 & 19,81 \\
FG + 5\% CP & 23,62 & 24,64 \\
Pedra britada (controle) & 16,00 & 16,76 \\
FG + 7,5\% CP & 21,34 & 21,59 \\
\hline
\end{tabular}

Observa-se pelos resultados apresentados Tabela 2.11 que a espessura efetiva para todas as bases executadas com fosfogesso estabilizado com cimento excederam significativamente as duas seções de controle. Num relatório apresentado pela "Texas A\&M University" colocou-se que as seções executadas com fosfogesso mantiveram sua capacidade de carga, sendo bons materiais para base. Nenhum sinal de degradação foi notado (ANDERSON, 1986 e CHANG \& MANTELL, 1990). 
CROCKFORD et al. apud TAHA \& SEALS (1991), após os 4 anos de avaliação da pista experimental, apresentaram as seguintes conclusões:

- A seção estabilizada com $5 \%$ de cimento foi superior a todas as outras seções, baseado nos resultados de deflexão máxima, expansibilidade e espessura efetiva. $\mathrm{O}$ uso de teores de cimento do Tipo I (cimento comum) acima de 5\% teve um efeito danoso. Problemas construtivos ou o teor de $C_{3} A$, ou ainda uma combinação entre esses dois fatores, provavelmente foram a causa do efeito danoso. Em projetos futuros, o uso de um cimento do Tipo II (moderada resistência a sulfatos) pode melhorar o desempenho das misturas;

- Práticas construtivas e condições meteorológicas durante a construção podem fazer uma diferença significativa no desempenho futuro do pavimento. Considerações quanto a umidade e compactação parecem ser particularmente importantes para tornar o material efetivo para a construção;

- Se efeitos ambientais são a causa de variações sazonais, as seções estabilizadas com cinza volante parecem ser mais sensíveis às mudanças do que as seções estabilizadas com cimento.

TAHA \& SEALS (1991) apresentam dois exemplos do uso misturas de fosfogesso e cimento para a execução de bases. O primeiro diz respeito a uma área de estacionamento construída em Houston, nos Estados Unidos. A sub-base foi executada com solo argiloso estabilizado com cimento. Após um ano em uso o pátio de estacionamento apresentou afundamento em toda sua área. Amostras retiradas do material de base apresentaram teores altos de umidade e baixa massa específica. O cimento usado foi do Tipo II, com $6 \%$ de $\mathrm{C}_{3} \mathrm{~A}$. Não se sabe se o afundamento foi causado pelo solo usado na sub-base ou se foi causado pelo fosfogesso estabilizado com cimento. $O$ segundo exemplo é da rodovia estadual 146 construída em La Porte, Texas. Após 122 dias da execução, a base e o revestimento apresentaram trincas. 
A causa desses defeitos é indeterminada, pode ser conseqüência de uma série de fatores, incluindo: projeto impróprio, base ou sub-base fraca, juntas de dilatação, trincas por reflexão, e alteração no volume da base, revestimento ou sub-base. O teor de cimento usado nesse projeto foi $9 \%$, considerado alto, o que pode ter contribuído, junto com o excesso de umidade, para a ocorrência das trincas.

\subsubsection{Concreto rolado compactado usando fosfogesso}

Uma outra mistura estudada, e que também teve aplicação prática, foi a de fosfogesso e concreto rolado compactado. CHANG (1988), NANNI \& CHANG (1989), CHANG \& MANTTEL (1990), CHANG (1990), TAHA \& SEALS (1991) relatam o uso desse tipo de mistura. As primeiras referências à utilização dessa mistura em construção rodoviária dizem respeito a execução de duas áreas de estacionamento, a primeira em 1985, na área da Universidade de Miami, e a segunda em 1988, no FIPR ("Florida Institute of Phosphate Research").

O concreto rolado é definido como uma mistura de cimento Portland com "slump" 0 , tendo como componentes a água, o cimento e agregados grossos e finos, permitindo que o material seja espalhado no local da obra e compactado logo a seguir. Para a compactação são usados compactadores vibratórios de aço e pneu. Nesse tipo de mistura o fosfogesso pode substituir parcialmente ou completamente a fração fina (TAHA \& SEALS, 1991).

CHANG (1988) avaliou o comportamento de uma mistura de concreto rolado com $73 \%$ de agregados finos e grossos, $13 \%$ de cimento e $14 \%$ de fosfogesso (C13-14), comparando-a com uma mistura com $13 \%$ de cimento mas sem fosfogesso (C13-0). A energia de compactação usada foi equivalente ao Proctor modificado. Os resultados desse estudo estão apresentados na Tabela 2.12. 
Tabela 2.12: Desenvolvimento da resistência à compressão em função do tempo das misturas estudadas para utilização como concreto rolado compactado. (fonte: adaptado de CHANG 1988).

\begin{tabular}{ccc}
\hline Tempo & \multicolumn{2}{c}{ Resistência à compressão $(\mathrm{MPa} / \mathrm{psi})$} \\
\cline { 2 - 3 } (horas) & $\mathrm{C} 13-14$ & $\mathrm{C} 13-0$ \\
\hline 4 & $0,2-29$ & $0,50-72$ \\
8 & $0,26-38$ & $2,41-349$ \\
18 & $0,63-92$ & $8,10-1175$ \\
74 & $19,37-2809$ & $22,11-3207$ \\
168 & $23,05-3343$ & $26,00-3772$ \\
\hline
\end{tabular}

Pela análise dos resultados descritos acima, os autores concluíram que o fosfogesso retarda o tempo de pega da mistura. Conforme observa-se na Tabela 2.12, após 18 horas da mistura as amostras C13-14 apresentaram valores de resistência à compressão muito baixos quando comparados com as amostras de referência, C13-0; as resistências após 18 horas das amostras C13-14 alcançaram o mesmo nível de resistência das amostras de referência após 4 horas; no entanto, após 74 horas da mistura a diferença de resistência entre as amostras C13-14 e C13-0 foram da ordem de 15\% (CHANG, 1988).

A mistura estudada por CHANG (1988), C13-14, foi a mesma usada na construção do estacionamento na área do FIPR. Três semanas após a construção, amostras retiradas do pavimento mostraram a não ocorrência de segregação durante o transporte e disposição da mistura. Após três meses, inspeções visuais não indicaram o aparecimento de trincas. Análises anteriores mostraram que os valores de resistência à compressão, aos 28 dias, de amostras retiradas no campo foram superiores aos valores obtidos em laboratório. Os valores encontrados foram, respectivamente para amostras de campo e laboratório, 21,88 MPa (3174 psi) e 19,08 MPa (2767 psi).

Segundo CHANG (1988), esse estudo indica a viabilidade do uso do fosfogesso no concreto rolado para a construção de áreas de estacionamento, apresentando vantagens no seu uso. São elas: 
1. O fosfogesso fornece uma quantidade adicional de finos, levando a uma melhor compactação, trabalhabilidade e acabamento superficial sem reduzir a durabilidade a longo prazo;

2. Compensa os problemas relacionados a retração ao limitar o trincamento;

3. Retarda o tempo de pega, assegurando a continuidade das juntas frias.

CHANG (1988) destaca ainda a importância do teor de umidade durante a operação de pavimentação. Altos teores de umidade na mistura resultam em exsudação da água, prejudicando a compactação.

\subsubsection{Fosfogesso e solo}

Entre os diversos tipos de misturas estudadas podem-se destacar os estudos realizados com misturas contendo fosfogesso e solo. KENLEY \& CHANG (1988), HO et al. (1988), CHANG, CHIN \& HO (1989), HO (1990), ZHOU apud CHANG \& MANTTEL (1990), ZHOU et al. apud CHANG \& MANTTEL (1990), TAHA \& SEALS (1991), NIFONG \& HARRIS (1993) relatam o emprego deste tipo de mistura na construção rodoviária. Alguns desses estudos resultaram na construção de 2 pistas experimentais no estado da Florida, nos municípios de Polk e Columbia, e os demais tratam da investigação do impacto ambiental do uso do fosfogesso: são analisadas amostras de ar, solo e água retiradas antes e após a construção das pistas experimentais e apresentados os resultados de seu constante monitoramento. Na Escola de Engenharia de São Carlos (EESC-USP), desenvolveu-se um trabalho onde foram estudadas misturas desse tipo (ORTIZ, 1997).

Segundo CHANG \& MANTELL (1990), os primeiros estudos com esse tipo de mistura foram realizados por ZHOU e ZHOU et al., em 1986. Estes pesquisadores pretendiam avaliar o uso de misturas de fosfogesso e solo 
para a construção rodoviária. Com a conclusão desses estudos definiram-se parâmetros para a construção de duas pistas experimentais no estado da Florida, mais especificamente no municípios de Polk e Columbia. Foram usados dois tipos de fosfogesso, di-hidratado e hemi-hidratado, e o solo foi obtido na localidade da construção. Os dois solos, apesar de origens distintas, foram classificados, segundo a HRB, como do tipo A-3.

CHANG \& MANTEL (1990) apresentam os resultados do estudo com as misturas de fosfogesso di-hidratado e solo usadas na construção da pista experimental em Polk. São avaliadas as relações entre massa específica seca e umidade, e a influência do tempo de cura e energia de compactação sobre a resistência à compressão das misturas. A energia de compactação usada foi a modificada, e as misturas estudadas apresentavam as proporções 1:1, 1:2 e 1:3 de fosfogesso e solo. A Figura 2.18. mostra a relação entre umidade e massa específica seca para cada uma das misturas.

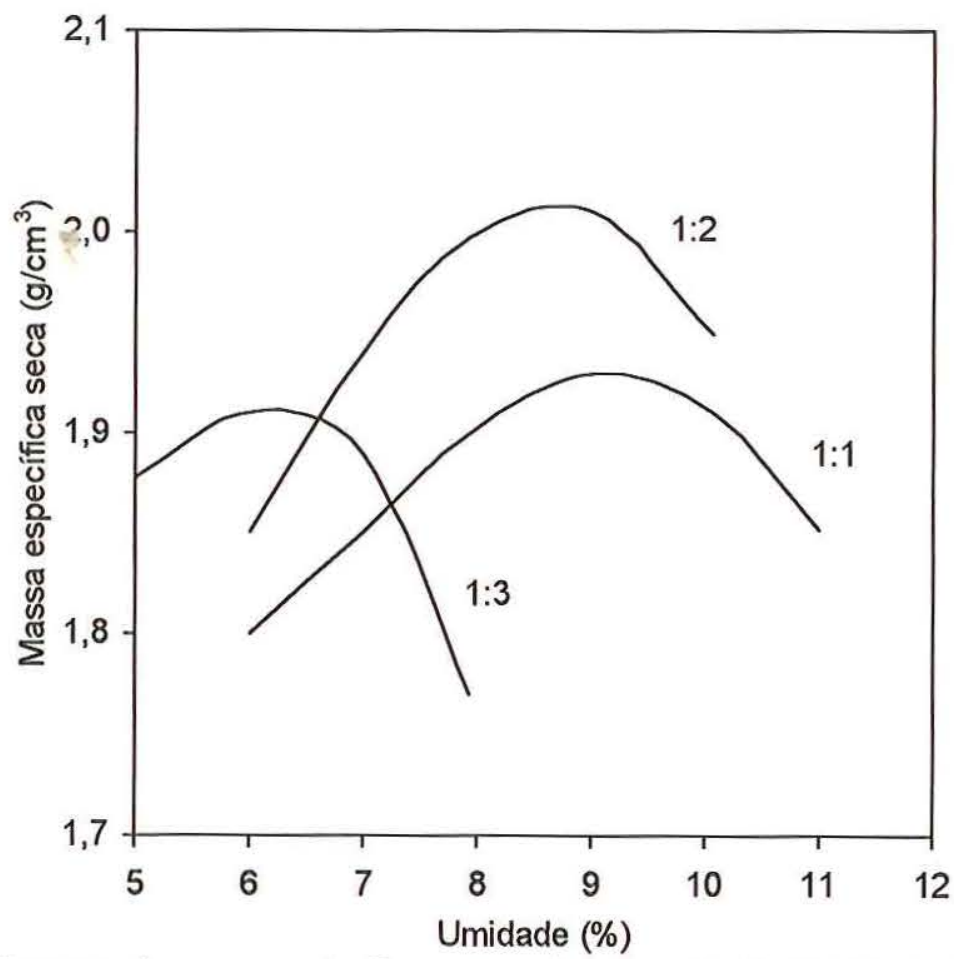

Figura 2.18: Curvas de compactação para misturas de fosfogesso e solo (fonte: CHANG \& MANTEL 1990). 
Observa-se que o maior valor de massa específica seca foi obtida na mistura de proporção 1:2 de fosfogesso e solo, alcançando um valor igual a $2,01 \mathrm{~g} / \mathrm{cm}^{3}$, e correspondendo a um teor de umidade ótimo de aproximadamente $8,8 \%$. A redução na quantidade de solo da mistura, até uma proporção de 1:1 de fosfogesso e solo, levou a uma redução nos valores de massa específica seca. Essa diminuição pode ser atribuída ao fato do fosfogesso ter uma massa específica dos sólidos menor do que o solo. Para o fosfogesso hemi-hidratado, usado na construção da pista experimental no município de Columbia, os maiores valores de resistência ocorreram em misturas com proporção de 2:1 de fosfogesso hemi-hidratado e solo. O teor de umidade ótimo foi $9,5 \%$ para uma massa específica seca máxima igual a $2,07 \mathrm{~g} / \mathrm{cm}^{3}$

As misturas foram submetidas a ensaios de compressão simples, em condições não imersas, com intuito de se identificar a influência do tempo de cura e da energia de compactação sobre os valores de resistência. Os maiores valores de resistência à compressão foram obtidos para misturas com a proporção de 1:2 de fosfogesso di-hidratado e solo, e proporção de 2:1 de fosfogesso hemi-hidratado e solo, em função disso essas misturas foram escolhidas para a continuidade dos ensaios.

O maior valor de resistência à compressão simples obtido, para misturas com fosfogesso di-hidratado, foi 0,28 MPa (40 psi) para ensaio imediatamente após a compactação, e correspondendo a uma umidade de $7,8 \%$. Os pesquisadores também puderam verificar que a resistência à compressão aumenta com o aumento do tempo de cura. A Figura 2.19 ilustra os resultados do estudo da influência do tempo de cura sobre a resistência à compressão simples, para misturas compactadas na proporção de 1:2 de fosfogesso e solo, e com teores de umidade de compactação iguais a $6 \%, 7 \%, 8 \%, 9 \%$ e $10 \%$. 


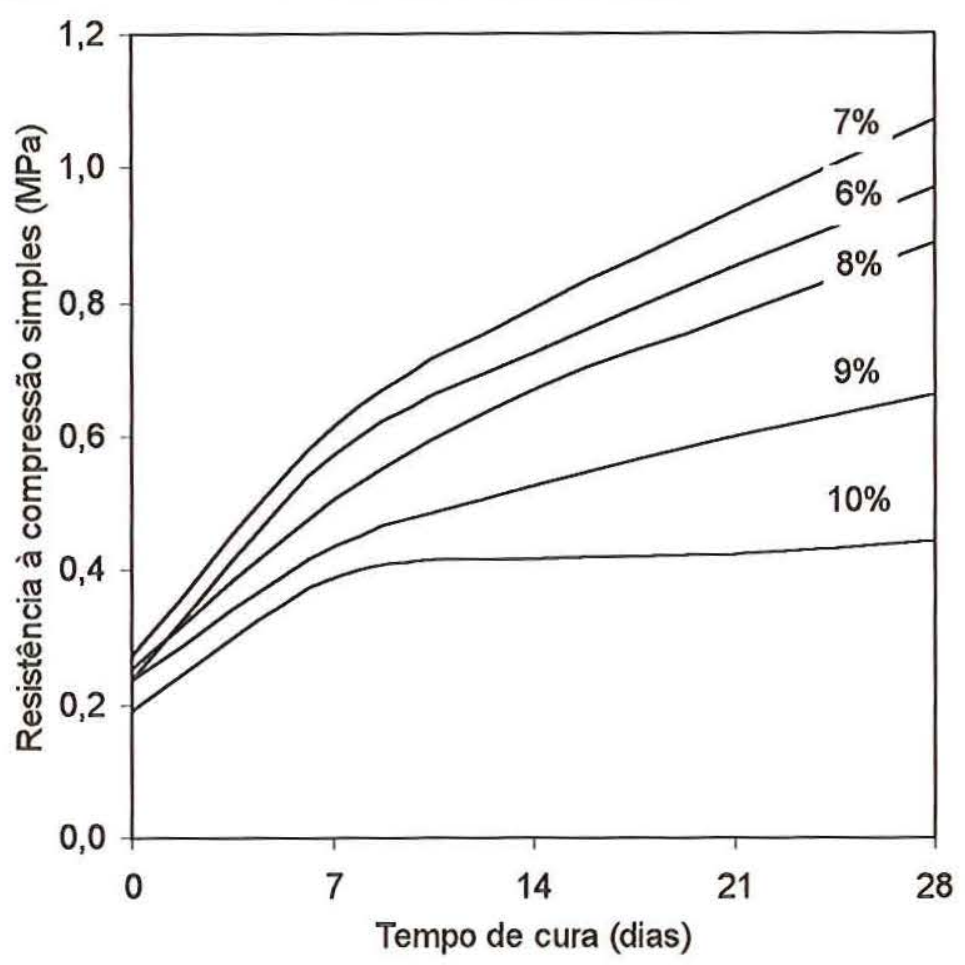

Figura 2.19: Resistência à compressão simples em função do tempo de cura para misturas de fosfogesso e solo na proporção de 1:2, compactadas com teores de umidade variáveis (fonte: adaptado de CHANG \& MANTELL, 1990).

Conforme observado na Figura 2.19, o teor de umidade para o qual se apresentam os maiores níveis de resistência corresponde a $7 \%$, valor esse diferente do valor de umidade ótima para as misturas de fosfogesso e solo com proporção de 1:2, e determinado anteriormente como 8,8\% (Figura 2.19). Segundo ORTIZ (1997), para misturas de solo e fosfogesso, aparentemente os maiores valores de resistência à compressão simples são obtidos para umidades um pouco menores que a umidade ótima, qualquer que seja a energia aplicada durante a moldagem dos corpos de prova.

A resistência à compressão simples de misturas de fosfogesso e solo submetidas a imersão também foram estudadas. Os resultados dos ensaios indicaram que misturas de fosfogesso di-hidratado e solo não resistem a água, isto é, entram em colapso quando imersos em água. Já as misturas com fosfogesso hemi-hidratado e solo apresentaram boa resistência frente a ação da água (CHANG, CHIN \& HO, 1989). 
A avaliação do efeito da energia de compactação sobre a resistência das misturas foi feita com o uso da proporção 1:2 de fosfogesso di-hidratado e solo. Os corpos de prova foram compactados nas energias normal e modificada, e submetidos a condição de cura seca ao ar. Os resultados mostraram que a energia de compactação tem efeito significativo sobre os valores de resistência. A maior energia de compactação do Proctor modificado conduziu a maiores valores de resistência (CHANG, CHIN \& HO, 1989).

Segundo CHANG \& MANTELL (1991), algumas conclusões podem ser tiradas da construção das pistas experimentais, são elas:

1. As misturas com fosfogesso são mais fáceis de se trabalhar do que as misturas com solo argiloso;

2. Os custos de operação, incluindo as horas de equipamento, são menores em estradas construídas com fosfogesso do que em estradas construídas com solo argiloso;

3. Tempestades durante a construção não causaram atraso excessivo, pois o fosfogesso compactado não absorveu água em grandes quantidades;

4. Trincas de retração, de ocorrência comum em estradas executadas com solos argilosos, não apareceram nas executadas com fosfogesso;

5. A estabilidade das misturas compactadas de fosfogesso e solo é superior à de solos com características argilosas.

$\mathrm{Na}$ tentativa de se resolver o problema de estabilidade das misturas de fosfogesso di-hidratado e solo frente a ação da água, FIGUEROA et al. (1987) e LIN \& ZHOU et al. apud CHANG \& MANTTEL (1990) realizaram estudos com a adição de materiais betuminosos à mistura.

Foram estudadas misturas com diversos materiais betuminosos, tais como emulsões e asfaltos diluídos (cut-back). Entretanto, à exceção do 
asfalto diluído de cura rápida, CR-70, os resultados obtidos não foram satisfatórios.

FIGUEROA et al. (1987) realizaram estudos com cinco misturas diferentes, variando em função do teor de fosfogesso di-hidratado, solo e CR-70. As misturas foram compactadas no Proctor modificado, são elas:

\begin{tabular}{ccc}
\hline Fosfogesso di-hidratado & Solo & CR-70 \\
\hline $33,3 \%$ & $66,6 \%$ & \\
$25,0 \%$ & $75,0 \%$ & \\
$33,3 \%$ & $66,6 \%$ & $1 \%$ \\
$50,0 \%$ & $50,0 \%$ & \\
33,3 & $66,6 \%$ & $2 \%$ \\
\hline
\end{tabular}

Essas misturas foram submetidas a ensaios com ciclos de imersão e secagem. Após o primeiro ciclo de imersão, as misturas sem CR-70 entraram em colapso, restando apenas as misturas com material betuminoso. Os resultados indicaram que, apesar de apresentarem um nível mais de baixo de resistência à compressão após a imersão, a presença do CR-70 foi eficiente para a estabilização da mistura frente a ação da água.

FIGUEROA et al. (1987), estudaram também a influência do tempo de cura sobre a resistência à compressão simples das misturas de solo, fosfogesso e CR-70. A Figura 2.20 ilustra os resultados desse estudo. As misturas foram compactadas na energia modificada variando-se as porcentagens dos componentes, fosfogesso, solo e CR-70. Nota-se que todas as misturas apresentaram ganhos de resistência com o decorrer do tempo. A mistura com $2 \%$ de CR-70 apresentou resistências mais baixas quando comparada com a mistura contendo $1 \%$ de CR-70.

LIN \& ZHOU et al. apud CHANG \& MANTELL (1990), também estudaram a adição de materiais betuminosos a misturas de fosfogesso e solo para diminuir a sua susceptibilidade frente a ação da água. Nesse estudo utilizaram-se misturas com $33 \%$ de fosfogesso, $66 \%$ de solo e dois tipos de materiais betuminosos: asfalto diluído de cura rápida CR-70 e o 
alcatrão. As misturas com alcatrão foram compactadas na energia normal, $\mathrm{e}$ as misturas com CR-70 foram compactadas na energia modificada. Em ambos os casos os corpos de prova foram ensaiados em condições imersas e seca ao ar. A Figura 2.21 ilustra os resultados encontrados para misturas com CR-70.

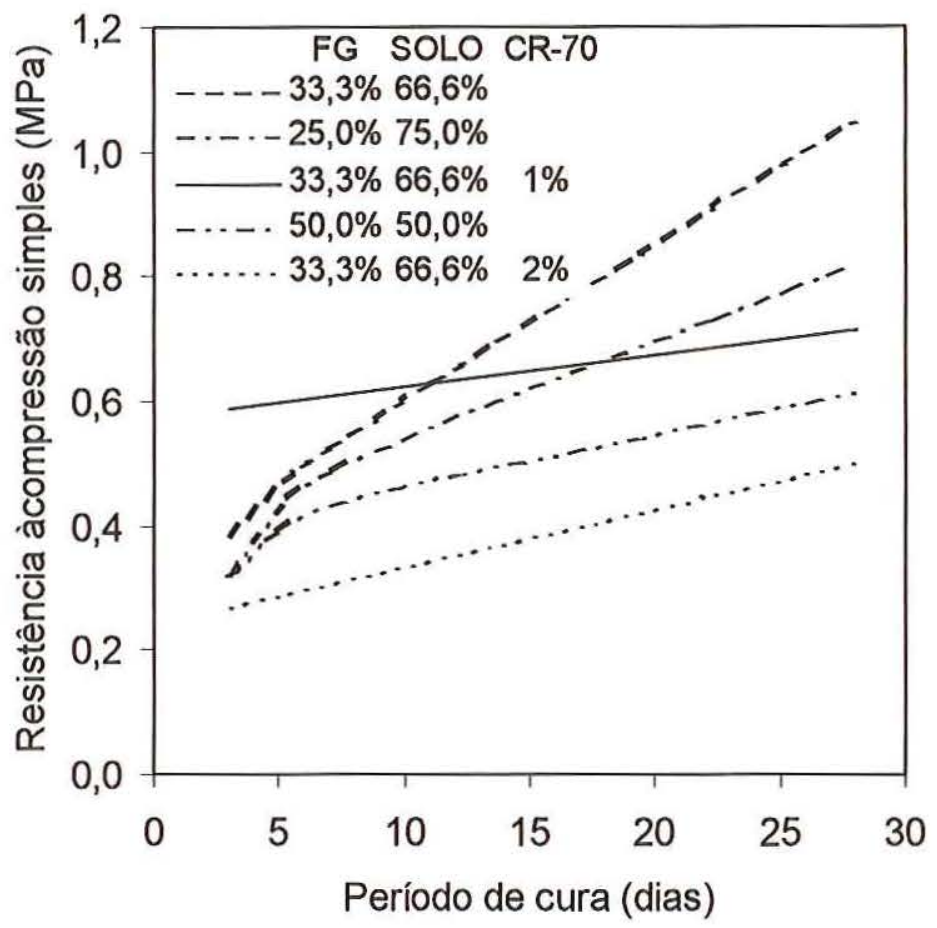

Figura 2.20: Resistência à compressão simples em função do tempo de cura para misturas de fosfogesso di-hidratado, solo e CR-70 (fonte: adaptado de FIGUEROA, 1987).

Nota-se pela Figura 2.21 que, para condição seca ao ar, as resistências diminuem até teores de CR-70 próximos de $3 \%$, para as misturas com alcatrão a queda de resistência foi observada até teores próximos de $5 \%$. Entretanto, para a condição imersa, a adição de teores até $4 \%$ de alcatrão ou CR-70 tendem a aumentar os valores de resistência, estabilizando-se para teores acima desse.

Uma outra maneira estudada para promover a estabilização das misturas de fosfogesso di-hidratado e solo frente a ação da água foi o uso de fosfogesso anidro em substituição ao di-hidratado nas misturas. Estudaram o 
assunto TRICHÊS \& MACCARINI (1988), MACCARINI (1991) e ORTIZ (1997).

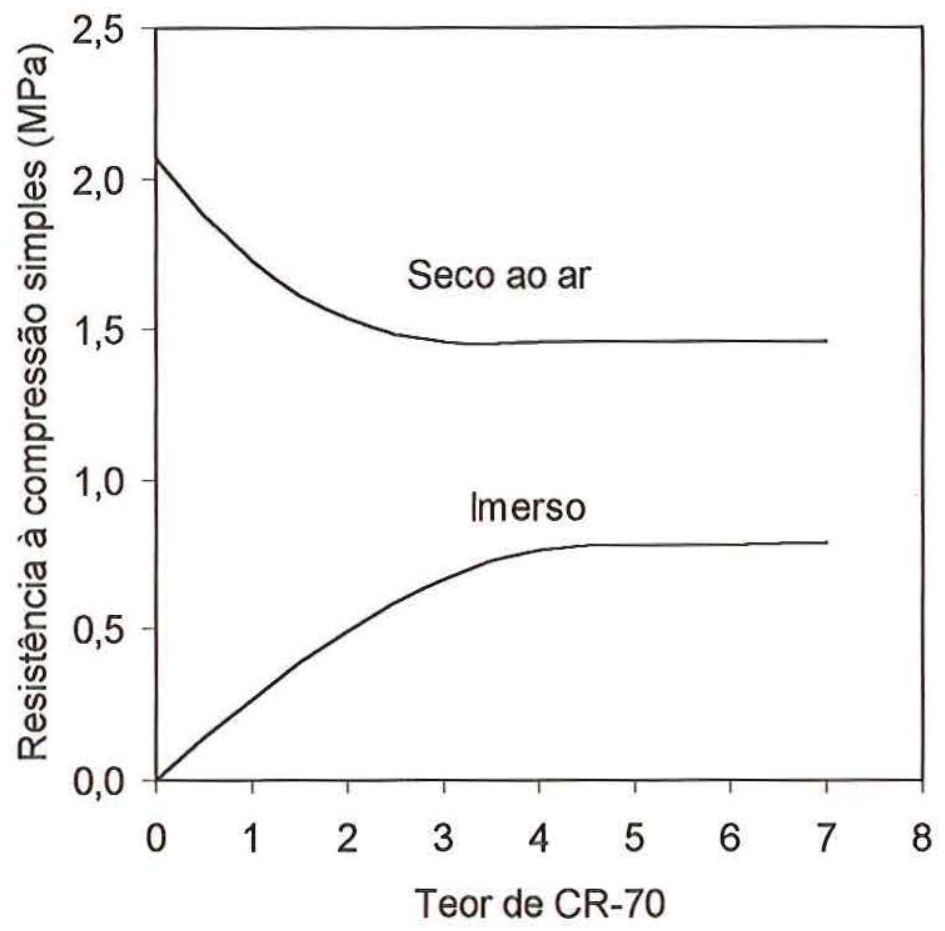

Figura 2.21: Efeito do teor de CR-70 na resistência à compressão simples de misturas de fosfogesso di-hidratado e solo sob condições imersas e seca ao ar (fonte: adaptado de CHANG \& MANTELL, 1990).

Para a obtenção do fosfogesso anidro, MACCARINI (1991) e ORTIZ (1997) submeteram o fosfogesso di-hidratado a uma temperatura de $130^{\circ} \mathrm{C}$ em estufa por 24 horas. Ensaios preliminares indicaram que as misturas de fosfogesso anidro e solo apresentavam estabilidade frente a ação da água.

No estudo realizado por ORTIZ (1997), os corpos de prova foram compactados na energia normal, na umidade ótima $\left(W_{0}\right)$ e em outras 4 umidades, 2 no ramo seco e no ramo úmido da curva de compactação. Os corpos de prova foram então submetidos a diferentes períodos de cura, 3,7 , 28 e 84 dias, e ensaiados a compressão simples em condições imersas e não imersas. Estudaram-se misturas com teores de fosfogesso anidro de $0 \%, 20 \%, 40 \%, 60 \%, 80 \%$ e $100 \%$. 
Segundo ORTIZ (1997), para condições imersas e não imersas, a adição de quantidades crescentes de fosfogesso anidro ao solo conduz a um ganho crescente de resistência. Entretanto os corpos de prova ensaiados com imersão apresentaram resistências menores do que os ensaiados sem imersão. Analisou-se também o efeito do tempo de cura sobre a resistência à compressão simples das misturas, verificou-se que nos primeiros 28 dias o aumento de resistência é pronunciado principalmente para os teores de fosfogesso mais elevados, e após esse período, a resistência tende a se estabilizar ou mesmo a diminuir ligeiramente.

\subsubsection{Fosfogesso e cinza volante}

Misturas contendo fosfogesso e cinzas volantes, e misturas com fosfogesso, cinzas volantes e cal, foram também, objeto de estudos. Assim como o fosfogesso, as cinzas volantes são um problema ambiental, principalmente pelas grandes áreas ocupadas para seu armazenamento. $A$ sua utilização na construção rodoviária vem sendo estudada por vários pesquisadores. Entre os trabalhos com esse tipo de mistura destacam-se os estudos realizados por ANDRIEX et al. (1978), GREGORY et al. (1984), GREGORY et al. apud CHANG \& MANTTEL (1990), TAHA \& SEALS (1991).

Segundo VAIDERGORIN (1988), a cinza volante é uma pozolana artificial, resultante da combustão de carvão mineral em usinas termelétricas, finamente dividida que, em contato com hidróxido de cálcio, na presença de umidade, formam compostos aglomerantes análogos aos do cimento Portland.

No estudo realizado por GREGORY et al. (1984), além das misturas com fosfogesso e cimento, já tratadas no item 2.4.1, foram estudadas misturas com fosfogesso e cinza volante. Segundo GREGORY et al. apud CHANG \& MANTELL (1990), numa investigação preliminar do estudo definiram-se alguns fatores que afetam a resistência das misturas de 
fosfogesso e cinza volante, são elas: energia de compactação, tempo de hidratação da cinza volante na presença de sulfato de cálcio, quantidade de água disponível para hidratação, o valor de $\mathrm{pH}$ e a disponibilidade de cal livre na cinza volante para iniciar a reação pozolânica.

Os corpos de prova usados no estudo realizado por GREGORY et al. (1984) foram compactados na energia modificada, com 5 teores de cinza volante, e submetidos a tempos de cura de 3, 7 e 28 dias. A Figura 2.22 ilustra os resultados de resistência à compressão simples para misturas com fosfogesso e teores de cinza volantes iguais a $0 \%, 10 \%, 15 \%, 20 \%$ e $30 \%$. Nota-se que o aumento no teor de cinza volante e no tempo de cura significam um aumento nos valores de resistência à compressão simples das misturas.

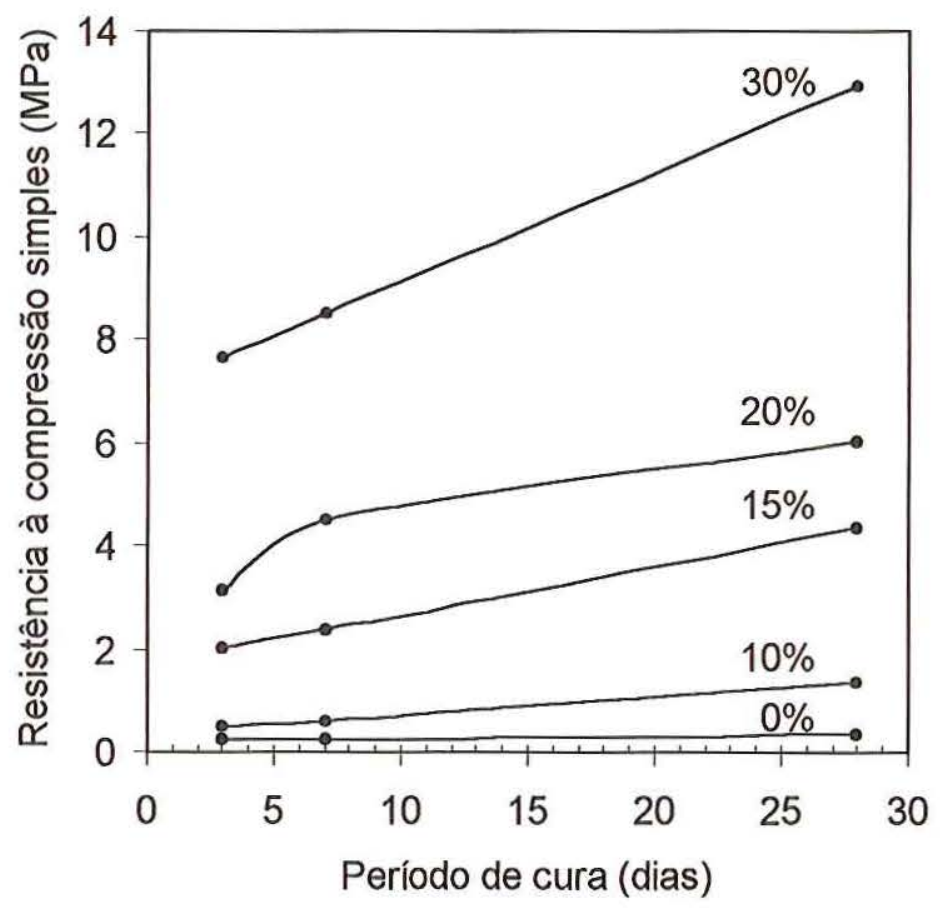

Figura 2.22: Desenvolvimento da resistência à compressão simples para misturas de fosfogesso e cinza volante em função do tempo de cura (fonte: adaptado de GREGORY et al. 1984).

Segundo TAHA \& SEALS (1991), no uso da cinza volante para estabilização do fosfogesso, as condições de formação de cristais de etringita são similares às existentes nas misturas de fosfogesso e cimento. $\mathrm{O}$ 
óxido de cálcio $(\mathrm{CaO})$ e óxido de alumínio $\left(\mathrm{Al}_{2} \mathrm{O}_{3}\right)$ presentes na cinza volante, também podem levar à formação de cristais de etringita.

Conforme citado no item 2.4.1, misturas de fosfogesso e cinza volante fizeram parte da construção de seções de pistas experimentais no município de La Porte, estado do Texas. Foram usados teores de $15 \%$ e $25 \%$ de cinza volante para a estabilização do fosfogesso.

LIN apud CHANG \& MANTELL (1990), estudaram o efeito da adição de cal a misturas de fosfogesso com cinza volante que apresentam baixos teores de cal livre em sua composição. O autor estudou separadamente misturas de fosfogesso e $1 \%, 3 \%$ e $5 \%$ de cal, e misturas de fosfogesso e $5 \%, 10 \%, 20 \%$ e $33 \%$ de cinza volante. Para ambos os casos, os valores de resistência após 84 dias de cura foram considerados como não aceitáveis. Entretanto, misturas contendo os três elementos, fosfogesso di-hidratado, cinza volante e cal, desenvolveram valores significativos de resistência à compressão simples. As proporções de mistura estudadas foram $5 \%$ de cal, $20 \%$ a $50 \%$ de cinza volante, e $75 \%$ a $45 \%$ de fosfogesso di-hidratado. Os corpos de prova foram compactados no Proctor normal, e submetidos a condição de cura selada. A Figura 2.23 ilustra os resultados do estudo em função do tempo de cura.

Observa-se na Figura 2.23 que o aumento no tempo de cura representou um aumento nos valores de resistência para todas as misturas. As resistências apresentaram um gradiente de crescimento mais acentuado até períodos de cura próximos a 4 semanas, ou 28 dias, atenuando-se a partir daí. Aos 84 dias, ou 12 semanas, as resistências alcançaram valores superiores a 5,52 MPa (800 psi). 


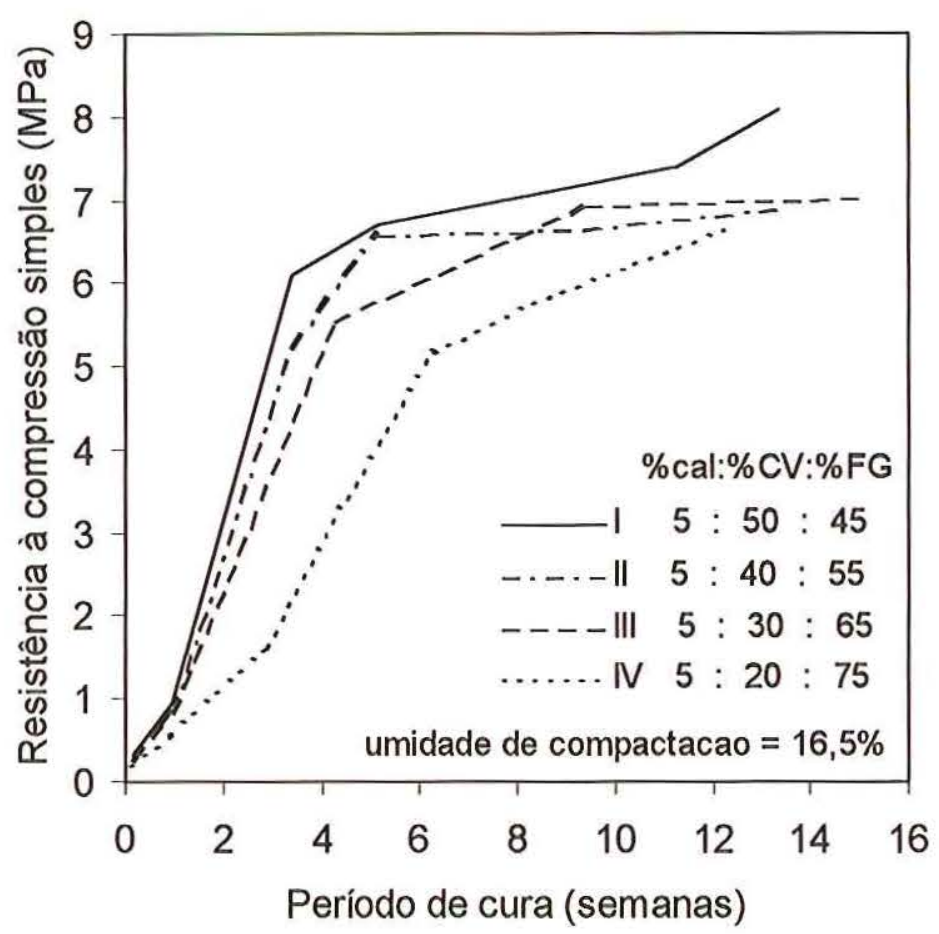

Figura 2.23: Comparação entre a resistência à compressão simples de várias misturas de fosfogesso, cinza volante e cal (fonte: adaptado de CHANG \& MANTELL 1990). 


\subsection{INTRODUÇÃO}

O efeito da adição de cimento ao fosfogesso di-hidratado é o ponto principal a ser investigado nesta pesquisa. Essa avaliação é feita em termos de se analisar os efeitos dessa adição sobre a resistência à compressão simples e deformabilidade de misturas de fosfogesso e cimento.

Os experimentos foram planejados de forma a permitir a avaliação da influência de certos parâmetros sobre a resistência à compressão simples e deformabilidade das misturas de fosfogesso e cimento. Os parâmetros investigados são: a energia de compactação, o teor de cimento, o tempo de cura, a condição de ensaio (com imersão prévia e sem imersão) e a umidade de compactação.

Para se alcançar os objetivos propostos, definiu-se o uso das energias normal e intermediária, com compactação dos corpos de prova na umidade ótima $\left(w_{0}\right)$ e na $w_{0} \pm 2 \%$, variando-se o teor de cimento de $7 \%, 10 \%$, $12 \%$ e $15 \%$, períodos de cura de $7,14,28$ e 84 dias, e ensaios realizados com imersão prévia em água por 4 horas, e sem imersão.

A parte experimental da pesquisa foi conduzida segundo duas etapas: Estudo Preliminar e Estudo Definitivo. No Estudo Preliminar, analisaram-se as conseqüências da variação do $\mathrm{pH}$ do fosfogesso na resistência das misturas e foram definidas as curvas de compactação de misturas 
compostas com dois fosfogesso de diferentes idades. O Estudo Definitivo foi realizado a partir da opção pelo fosfogesso mais antigo. Foram moldados corpos de prova tomando-se os resultados obtidos dos ensaios de compactação no estudo anterior, de maneira que se permitisse a análise da resistência e deformabilidade das misturas de fosfogesso e cimento.

Apresentam-se neste capítulo, os resultados da caracterização dos materiais usados na pesquisa, os procedimentos observados para a realização dos ensaios, a composição e as condições em que as misturas foram ensaiadas e o método empregado para a análise dos resultados.

\subsection{CARATERÍSTICAS DOS MATERIAIS}

\subsubsection{Fosfogesso}

O fosfogesso usado neste estudo foi fornecido pela indústria FOSFERTIL, sendo do tipo di-hidratado. O material encontra-se estocado no Laboratório de Estradas do Departamento de Transportes, na EESC-USP. Para a realização da pesquisa foram selecionados dois materiais, um com idade estimada em 4 anos e o segundo, com idade estimada em 10 anos. Para efeito de diferenciação, denominou-se de fosfogesso A o fosfogesso com 4 anos e, de fosfogesso B o fosfogesso com 10 anos.

Os dois materiais, depois de coletados, foram submetidos a ensaios de caracterização na sua forma natural (di-hidratado) para determinação da granulometria, massa específica dos sólidos e limites de Atterberg (limites de plasticidade e liquidez).

\subsubsection{Granulometria}

A análise granulométrica dos materiais foi realizada através do ensaio de granulometria conjunta (peneiramento + sedimentação) segundo norma 
específica (M 6-61 DER-SP). A Figura 3.1 ilustra as curvas granulométricas obtidas para o fosfogesso A e para o fosfogesso B. Os resultados mostram que o fosfogesso comporta-se granulometricamente como um silte, com uma porcentagem acima de $80 \%$ dentro dessa faixa, aproximando-se do resultado obtido pela PROGEO, empresa de consultoria, que ensaiou o fosfogesso de Uberaba, sob encomenda da FOSFERTIL ( vide Tabela 3.1).

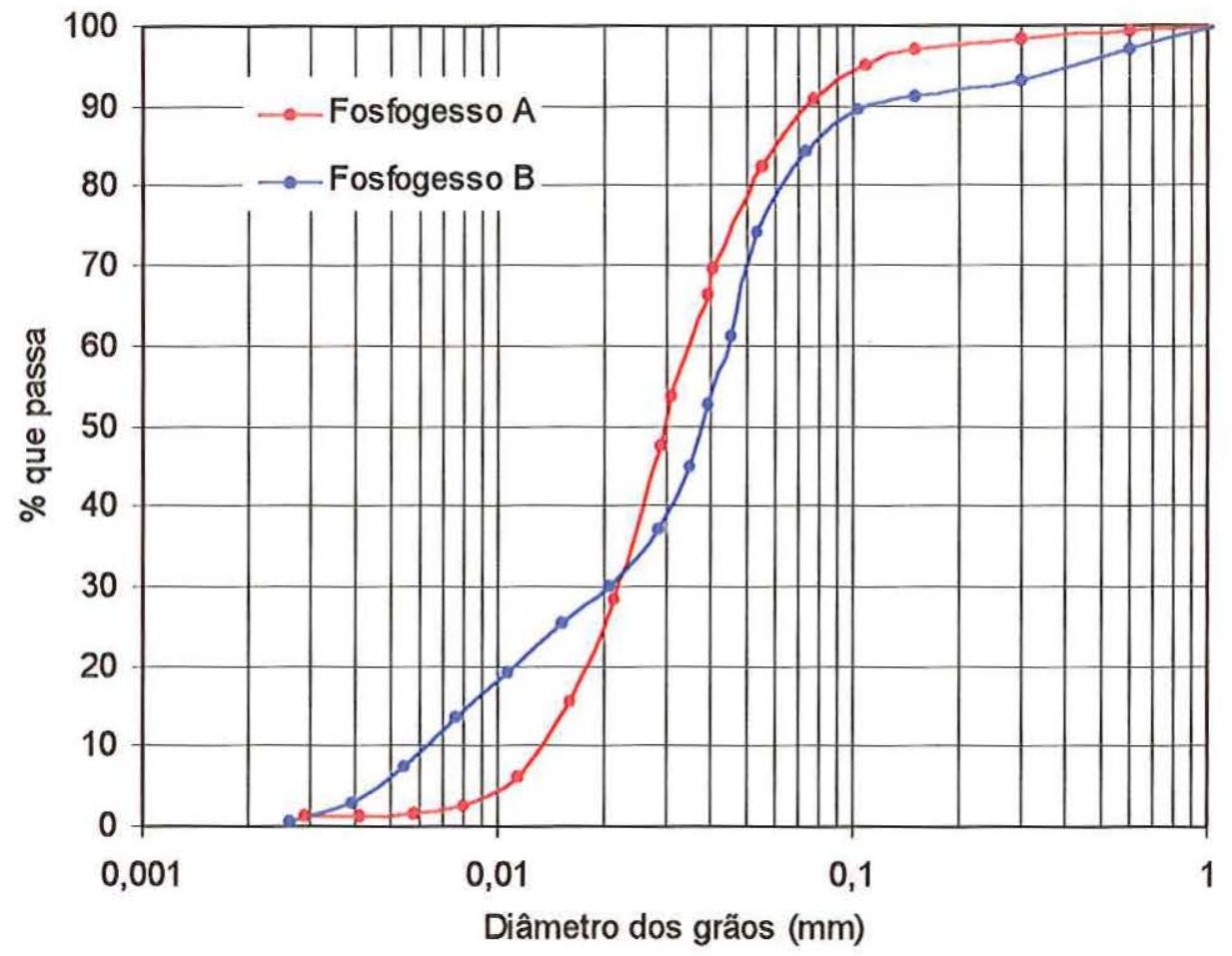

Figura 3.1: Curvas granulométricas dos fosfogessos A e B.

\subsubsection{Massa específica dos sólidos}

A determinação da massa específica dos sólidos, realizada segundo a norma M 3-61 DER-SP, mostrou como resultado um valor de 2,320 g/ $\mathrm{cm}^{3}$ para o fosfogesso $A$, e um valor de $2,308 \mathrm{~g} / \mathrm{cm}^{3}$ para o fosfogesso $B$, valores esses, coerentes com os valores encontrados na bibliografia pesquisada. Como exemplo, podem-se citar os valores obtidos por CHANG \& MANTELL (1990), que encontraram resultados variando de $2,31 \mathrm{~g} / \mathrm{cm}^{3}$ a $2,53 \mathrm{~g} / \mathrm{cm}^{3}$ para fosfogessos de 7 diferentes fontes do estado da Florida; e TAHA et al. (1995), que encontraram um valor de $2,35 \mathrm{~g} / \mathrm{cm}^{3}$ para um fosfogesso do 
estado da Louisiana. O valor obtido pela PROGEO foi de $2,36 \mathrm{~g} / \mathrm{cm}^{3}$ (vide Tabela 3.1).

\subsubsection{Limites de Atterberg}

As tentativas de se determinar os limites de Atterberg dos dois materiais foram infrutíferas. A moldagem dos bastonetes no ensaio de plasticidade, segundo norma específica (M 5-61 DER-SP) não foi possível, levando o material a ser classificado como não plástico (NP). Segundo SCHAEFFNER (1978), para alguns fosfogessos não é possível a determinação do limite de plasticidade, condição essa, justificada pela ausência total de propriedades coloidais do material. Segundo TAHA et al. (1995), o ensaio com um fosfogesso do estado da Louisiana classificou-o como um material não plástico. Entretanto, nos ensaios realizados pela PROGEO foi possível a determinação desses limites, os resultados obtidos foram $37 \%$ e $25 \%$ para os limites de liquidez e plasticidade, respectivamente.

A Tabela 3.1 apresenta o resumo dos resultados dos ensaios de caracterização do fosfogesso analisado pela PROGEO. Esses resultados são interessantes por se tratar de um material originário da mesma indústria, servindo como comparação para os resultados dos ensaios de caracterização realizados no Laboratório de Estradas da EESC-USP.

\subsubsection{Análise química}

A Tabela 3.2 fornece a composição química de um fosfogesso originário da área de depósito da FOSFERTIL. A análise foi realizada pela PROGEO.

A característica ácida do fosfogesso é devida principalmente a presença de sulfatos livres $\left(\mathrm{SO}_{4}\right)$ na sua constituição. Conforme mostra a Tabela 3.2, esse elemento representa aproximadamente $53 \%$ da 
composição total do fosfogesso. Verifica-se também a presença de óxido de cálcio, $\mathrm{CaO}(30,90 \%)$, e íons de cálcio, $\mathrm{Ca}^{++}(22,08 \%)$. Sendo esses os elementos predominantes, juntamente com os sulfatos livres, na composição do fosfogesso.

Tabela 3.1: Ensaios de caracterização do fosfogesso (fonte: PROGEO, 1994 apud ORTIZ, 1997)

\begin{tabular}{ll}
\hline \multicolumn{1}{c}{ GRANULOMETRIA (\%) } \\
\hline Pedregulho $(\phi>4,6 \mathrm{~mm})$ & 0,00 \\
Areia grossa $(2 \mathrm{~mm}<\phi<4,6 \mathrm{~mm})$ & 0,00 \\
Areia média $(0,42 \mathrm{~mm}<\phi<2 \mathrm{~mm})$ & 0,00 \\
Areia fina $(0,074 \mathrm{~mm}<\phi<0,42 \mathrm{~mm})$ & 0,29 \\
Silte $(0,002 \mathrm{~mm}<\phi<0,074 \mathrm{~mm})$ & 96,12 \\
Argila $(\phi<0,002 \mathrm{~mm})$ & 3,59 \\
\hline \multicolumn{2}{c}{ MASSA ESPECÍFICA DOS SÓLIDOS } \\
\hline \multicolumn{1}{c}{ LIMITES DE CONSISTÊNCIA } \\
\hline Limite de liquidez (LL) & $37,36 \mathrm{~g} / \mathrm{cm}^{3}$ \\
Limite de plasticidade (LP) & 25 \\
Índice de plasticidade (IP) & 12 \\
\hline
\end{tabular}

Tabela 3.2: Composição química do fosfogesso estocado na área de depósito da FOSFERTIL (fonte: FOSFERTIL)

\begin{tabular}{lc}
\hline COMPOSTO & PORCENTAGEM \\
\hline Água combinada & $19,53 \%$ \\
$\mathrm{TiO}_{2}$ & $0,92 \%$ \\
$\mathrm{~F}^{-}$ & $0,25 \%$ \\
$\mathrm{CaO}$ & $30,90 \%$ \\
$\mathrm{SO}_{4}$ & $52,80 \%$ \\
$\mathrm{P}_{2} \mathrm{O}_{5}$ solúvel em água & $0,15 \%$ \\
$\mathrm{P}_{2} \mathrm{O}_{5}$ SCAN + água & $0,57 \%$ \\
$\mathrm{P}_{2} \mathrm{O}_{5}$ TOTAL & $0,76 \%$ \\
$\mathrm{Al}_{2} \mathrm{O}_{3}$ & $0,06 \%$ \\
$\mathrm{Fe}_{2} \mathrm{O}_{3}$ & $0,20 \%$ \\
$\mathrm{MgO}^{\mathrm{BaO}}$ & $0,01 \%$ \\
$\mathrm{SiO}$ & $0,03 \%$ \\
$\mathrm{Ca}$ & $1,81 \%$ \\
$\mathrm{~S}$ & $22,08 \%$ \\
$\mathrm{BS}$. SCAN = Solúvel em citrato de amônia neutro
\end{tabular}

Quanto à acidez, de acordo com determinações realizadas no Laboratório de Estradas da EESC-USP, o fosfogesso $\mathrm{A}$ apresentou um $\mathrm{pH}$ de 2,4, enquanto o fosfogesso $\mathrm{B}$ apresentou um $\mathrm{pH}$ de 5,0 , sendo, portanto, este último material menos ácido que o primeiro. Acredita-se que a 
exposição às intempéries promova uma redução da acidez do fosfogesso, conseqüência da lixiviação dos elementos que fornecem essa característica ao material.

\subsubsection{Cimento}

Optou-se pela utilização de um cimento do tipo CP II - F 32, por ser um cimento comercial e de fácil aquisição no mercado. Conforme mostrado na revisão bibliográfica, um dos fatores mais importantes relacionados ao cimento é o teor de aluminato tricálcico $\left(\mathrm{C}_{3} \mathrm{~A}\right)$ presente na sua composição. Segundo VAIDERGORIN (1988), cimentos semelhantes ao usado nesta pesquisa apresentam, em média, $10 \%$ de $\mathrm{C}_{3} \mathrm{~A}$, teor considerado elevado se comparado com os teores deste componente presentes nos cimentos utilizados em estudos congêneres.

\subsection{ESTUDO PRELIMINAR}

Nesta etapa do estudo foram obtidas as curvas de compactação de todas as misturas dos fosfogessos, A e B, e cimento, fazendo-se assim possível a determinação do par ordenado massa específica seca máxima e umidade ótima. Além disso, realizou-se uma avaliação inicial do nível de resistência alcançado pelas misturas. Isso foi feito com os corpos de prova provenientes do próprio ensaio de compactação.

As Figuras de $A .1$ a $A .8$, apresentadas no ANEXO $A$, ilustram os resultados dos ensaios de compactação e compressão simples para cada uma das misturas de fosfogesso A e cimento, e as Figuras de A.9 a A.18 ilustram os resultados dos ensaios de compactação e compressão simples para as misturas de fosfogesso B e cimento.

Em seguida, descreve-se o procedimento experimental utilizado no Estudo Preliminar. 


\subsubsection{Preparação dos materiais}

O fosfogesso di-hidratado foi colocado para secar ao ar até atingir a umidade higroscópica. Após a secagem, o material passou por um processo de peneiramento (peneira número 4), e homogeneização. Logo após, foi embalado em sacos plásticos e armazenado para uso posterior.

O cimento não passou por nenhum processo de preparação específico, sendo usado na forma como é comercializado. Tomou-se o cuidado de manter a embalagem sempre fechada e utiliza-lo dentro do seu prazo de validade.

\subsubsection{Dosagem e mistura}

Foram compostas misturas de fosfogesso com 4 teores diferentes de cimento, $7 \%, 10 \%, 12 \%$ e $15 \%$. O teor de cimento foi calculado em relação à massa seca do fosfogesso, levando-se em conta a umidade higroscópica dos 2 materiais.

A preparação da mistura inicia-se com a associação e homogeneização do fosfogesso e cimento. Em seguida, adiciona-se a quantidade de água necessária para se alcançar a umidade desejada, repetindo-se o processo de homogeneização. A mistura deve então ser passada na peneira número 4 (abertura de malha $4,76 \mathrm{~mm}$ ) e novamente homogeneizada. Nesse momento, retira-se uma amostra para a determinação da umidade da mistura.

\subsubsection{Compactação dos corpos de prova}

A compactação foi realizada em equipamento de dimensões reduzidas (Figura 3.2), conforme a norma 191/88 DER-SP, resultando em corpos de prova com dimensões de $5 \mathrm{~cm}$ de altura e $5 \mathrm{~cm}$ de diâmetro. As 
Página 71

misturas de fosfogesso e cimento foram compactadas na umidade ótima nas energias equivalentes ao do Proctor normal e intermediário. Após a compactação, os corpos de prova devem ser embalados evitando-se dessa forma possíveis perdas de umidade durante o período de cura. O corpo de prova é envolvido com filme de PVC e etiquetado para a sua identificação.

É importante observar que durante todo o processo de compactação a mistura de fosfogesso e cimento deve permanecer coberta, ou ser colocada em saco plástico, evitando-se assim, perdas de umidade. Vale também ressaltar que a compactação foi realizada sem o reaproveitamento de material, repetindo-se o processo de mistura para cada umidade de compactação.

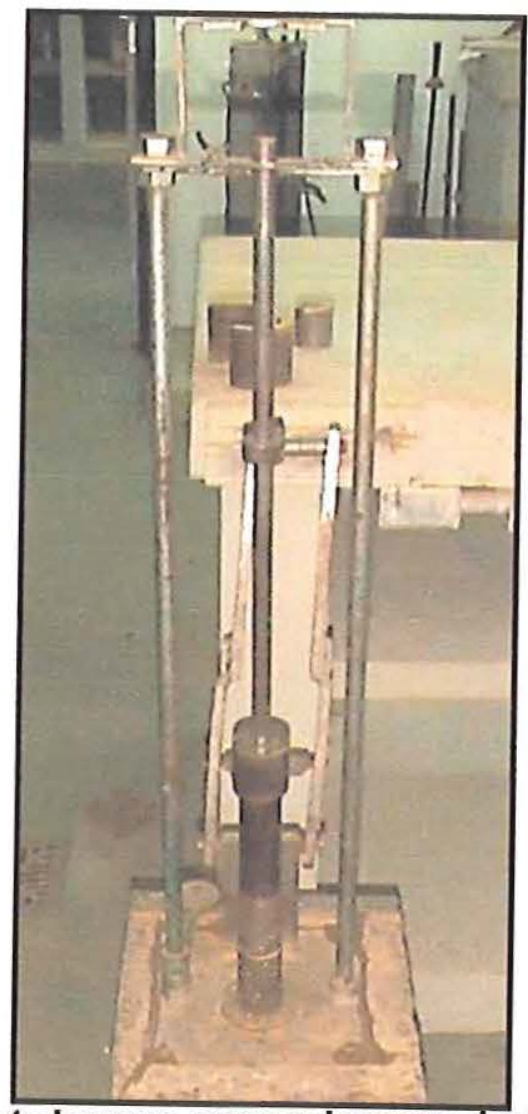

Figura 3.2: Compactador para corpos de prova de dimensões reduzidas. 


\subsubsection{Procedimento de cura}

Os corpos de prova depois de embalados foram colocados em processo de cura, que foi realizada dentro de uma caixa de isopor, com a intenção de se manter as condições de umidade e temperatura pouco variáveis.

\subsubsection{Ensaio de compressão simples}

Após decorrido o período de cura, os corpos de prova foram submetidos ao ensaio de compressão simples em duas condições: corpos de prova sem imersão prévia e corpos de prova previamente imersos em água por 4 horas antes do ensaio, simulando uma situação crítica para o pavimento. Nessa fase de estudo, Estudo Preliminar, utilizou-se a prensa para ensaio de Mini-CBR (Figura 3.3) existente no Laboratório de Estradas da EESC-USP para a realização dos ensaios de compressão simples.

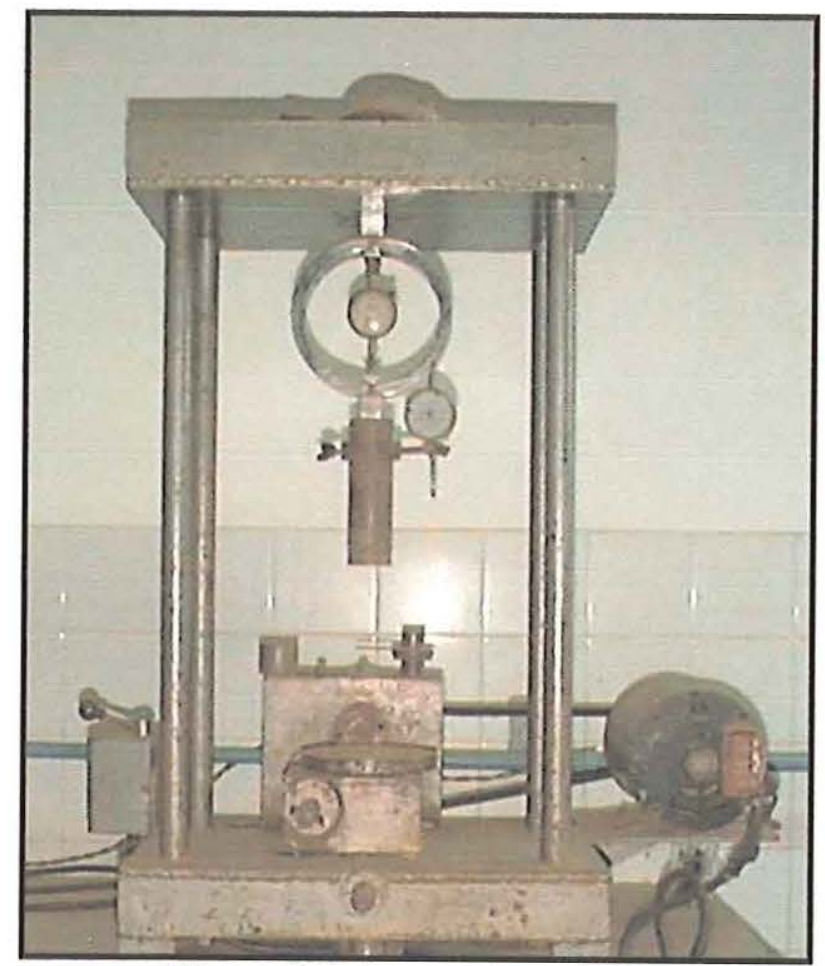

Figura 3.3: prensa de Mini-CBR. 


\subsection{ESCOLHA DO FOSFOGESSO}

A escolha do fosfogesso a ser usado no Estudo Definitivo baseou-se nos resultados do Estudo Preliminar. Os resultados desse estudo forneceram subsídios para a escolha do material.

Como já descrito, os dois fosfogessos usados nesta pesquisa, fosfogesso A e B, passaram por ensaios de compactação para obtenção do par ordenado massa específica seca máxima e umidade ótima. E posteriormente, os corpos de prova obtidos foram submetidos a ensaios de compressão simples para uma avaliação inicial do nível de resistência alcançado. Os resultados dos ensaios de compactação e resistência das misturas com fosfogesso A e B são apresentados no Capítulo 4, respectivamente nos itens 4.2 .2 e 4.2.4.

Apenas um dos materiais foi usado para o desenvolvimento da pesquisa na sua fase definitiva, no caso o fosfogesso B. A opção pelo fosfogesso $B$ foi conseqüência do maior nível de resistência alcançado pelas misturas desse material com cimento, quando comparado ao nível de resistência obtido por misturas com fosfogesso $\mathrm{A}$ e cimento.

Entretanto, deve-se salientar que o estudo dos dois materiais não foi realizado de forma concomitante. Inicialmente, dispunha-se do fosfogesso $A$, usado anteriormente numa pesquisa com misturas de fosfogesso e solo (ORTIZ, 1997). As resistências para misturas compactadas contendo esse fosfogesso e cimento não foram compatíveis com os níveis de resistência observados na bibliografia para misturas do mesmo gênero. A revisão da bibliografia mostrou então que a acidez do material, medida pelo seu $\mathrm{pH}$, poderia exercer influência significativa sobre a resistência destas misturas, conforme descrito no Capítulo 2. A bibliografia cita alguns estudos em que a neutralização do fosfogesso através de aditivos químicos possibilitava a obtenção de resistências mais elevadas. Resolveu-se então aplicar este 
procedimento ao fosfogesso $\mathrm{A}$. Os resultados dos ensaios de neutralização do fosfogesso A são apresentados no Capítulo 4, item 4.2.3. Entretanto, a neutralização, da forma como foi realizada, não se mostrou efetiva para emprestar ao fosfogesso o mesmo nível de resistência esperado. Por esse motivo resolveu-se optar por um outro fosfogesso que apresentasse, naturalmente, um $\mathrm{pH}$ mais alto, ou seja, um material menos ácido que o fosfogesso $A$, no caso o fosfogesso $B$.

\subsection{ESTUDO DEFINITIVO}

Definidos no Estudo Preliminar o fosfogesso a ser utilizado e os valores de umidade ótima e massa específica seca máxima para cada uma das composições das misturas do fosfogesso B e cimento, deu-se prosseguimento à pesquisa.

A análise de cada uma das situações cobertas pelo Estudo Definitivo foi realizada a partir do ensaio de trincas de corpos de prova. Exceção feita a condições em que algum dos corpos de prova, dos três ensaiados, tenha sido descartado após uma verificação da sua repetibilidade, os resultados de resistência e deformabilidade apresentados neste trabalho, correspondem à média de três valores. $O$ procedimento usado no estudo da repetibilidade está descrito no ANEXO D.

O procedimento experimental adotado na preparação dos materiais, dosagem e mistura, compactação dos corpos de prova e cura repete aquele adotado no Estudo Preliminar. A única diferença está nos períodos de cura empregados, que para esta fase estendem-se para 7, 14, 28 e 84 dias. Em seguida são descritos o ensaio de compressão simples, onde o equipamento difere daquele utilizado inicialmente, e o ensaio de compressão triaxial dinâmico, que não foi utilizado no Estudo Preliminar. 


\subsubsection{Resumo das situações analisadas}

O Estudo Definitivo foi subdividido em 5 etapas de maneira que possibilitasse a análise do comportamento da resistência e deformabilidade das misturas de fosfogesso e cimento segundo diversas situações.

ESTUDO 1:

Neste estudo os corpos de prova foram compactados na umidade ótima $\left(w_{0}\right)$ com o uso da energia normal, utilizando-se teores de cimento iguais a $7 \%, 10 \%, 12 \%$ e $15 \%$.

Os corpos de prova foram submetidos aos períodos de cura de 7,14 , 28 e 84 dias, sendo então ensaiados após imersão em água por 4 horas e sem imersão prévia.

O intuito deste estudo foi verificar a influência da adição de cimento, do período de cura e da condição de ensaio sobre a resistência à compressão simples e deformabilidade das misturas de fosfogesso e cimento compactadas na energia normal.

No total, no estudo 1 foram ensaiados 96 corpos de prova.

\section{ESTUDO 2:}

No estudo 2 avaliou-se a influência da variação da umidade sobre os valores de resistência à compressão simples e deformabilidade de misturas de fosfogesso e cimento compactadas na energia normal. Para este estudo usaram-se misturas de fosfogesso com $10 \%$ e $15 \%$ de cimento.

Essas misturas foram compactadas na $w_{0}+2 \%$ e na $w_{0}-2 \%$, sendo submetidas a três períodos de cura, 7,28 e 84 dias, e ensaiadas sem 
Página 76

imersão e com imersão prévia. Neste estudo foram ensaiados 72 corpos de prova.

Os resultados deste estudo, complementados pelos resultados obtidos para a umidade ótima no estudo 1, permitiram avaliar a influência da variação da umidade de compactação sobre resistência à compressão simples e deformabilidade das misturas ensaiadas.

\section{ESTUDO 3:}

O procedimento usado neste estudo é semelhante ao usado no estudo 1, a diferença reside na energia de compactação usada. Os corpos de prova foram compactados na energia intermediária e na $w_{0}$. Os teores de cimento usados foram de $7 \%, 10 \%, 12 \%$ e $15 \%$.

Os corpos de prova compactados foram submetidos a períodos de cura de 7, 14, 28 e 84 dias, e ensaiados sem imersão prévia e após prévia imersão.

Avaliou-se através deste estudo a influência da adição de cimento, do período de cura e da condição de ensaio sobre a resistência à compressão simples e deformabilidade das misturas de fosfogesso e cimento compactadas na energia intermediária.

Os resultados deste estudo em conjunto com os resultados do estudo 1 permitiram a avaliação da influência do aumento da energia de compactação sobre os valores de resistência à compressão simples e deformabilidade das misturas de fosfogesso e cimento. No total, foram ensaiados 96 corpos de prova.

\section{ESTUDO 4:}


De forma semelhante ao descrito no estudo 2 , no estudo 4 avaliou-se o efeito da variação da umidade de compactação sobre os valores de resistência à compressão simples e deformabilidade das misturas de fosfogesso e cimento compactadas com a energia intermediária. Para esse estudo usaram-se misturas com $7 \%$ e 10\% de cimento e ensaiaram-se 72 corpos de prova.

\section{ESTUDO 5}

Esta etapa diz respeito à avaliação do módulo de resiliência de misturas de fosfogesso e cimento. Ensaiaram-se três corpos de prova, sendo dois compactados na energia equivalente ao do Proctor normal e um na energia equivalente ao do Proctor intermediário. Os teores de cimento usados foram $7 \%$ e $15 \%$ para os corpos de prova compactados na energia normal e $7 \%$ para o corpo de prova compactado na energia intermediária. Os ensaios triaxiais dinâmicos foram executados com corpos de prova sem imersão prévia em água.

Esses ensaios permitiram que se avaliasse a influência da variação da energia de compactação e do teor de cimento nos valores do módulo de resiliência das misturas.

\subsubsection{Ensaio de compressão simples}

Após decorrido o período de cura, os corpos de prova foram submetidos ao ensaio de compressão simples em duas condições: corpos de prova não imersos e corpos de prova previamente imersos em água por 4 horas antes do ensaio, simulando uma situação crítica para o pavimento.

Os ensaios de compressão simples foram realizados no laboratório do Departamento de Geotecnia da EESC-USP, numa prensa da marca WYKEHAM FARRANCE ENGLAND, modelo TRISTAR $5000 \mathrm{~kg}$ STEPLESS 
(Figura 3.4). Esta prensa possui velocidade de aplicação de carga controlável, sendo que neste estudo utilizou-se uma velocidade de 1,27 $\mathrm{mm} / \mathrm{mim}$.

A força aplicada foi determinada através de anéis dinamométricos com capacidade de $14,71 \mathrm{kN}$ (1500 kgf). A deformação do anel e o deslocamento dos corpos de prova foram medidos com o uso de LVDT's (Linear Variable Differential Transducers) acoplados a um sistema de aquisição automática de dados que permite a armazenagem e posterior manuseio dos resultados obtidos.

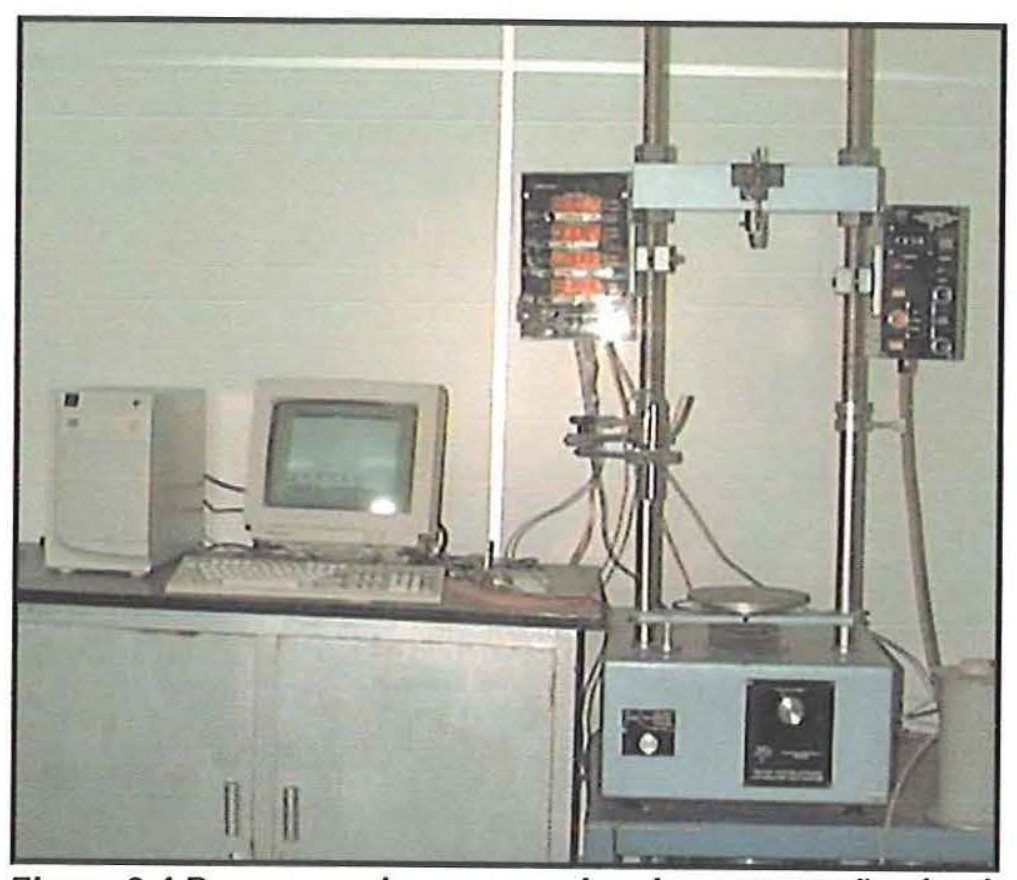

Figura 3.4:Prensa usada para ensaios de compressão simples

A realização dos ensaios de compressão simples em prensa dotada com sistema de aquisição automática de dados fornece o monitoramento contínuo do ensaio, permitindo o traçado das respectivas curvas tensão $\mathrm{x}$ deformação possibilitando assim o cálculo do módulo tangente inicial (Eo). É importante observar que o estudo da deformabilidade das misturas será realizada a partir da análise da variação de Eo. 
Para o cálculo do módulo tangente inicial, adotou-se, neste trabalho, 0 procedimento apresentado por DUNCAN \& CHANG (1970), que supõe a curva tensão $\mathrm{x}$ deformação como uma hipérbole, conforme a equação 3.1 :

$$
\frac{\varepsilon_{\mathrm{a}}}{\sigma_{\mathrm{a}}}=\mathrm{a}+\mathrm{b} \cdot \varepsilon_{\mathrm{a}}
$$

onde:

$\varepsilon_{\mathrm{a}}$ - deformação axial;

$\sigma_{\mathrm{a}}$ - tensão axial;

a e $b$ - coeficientes de regressão considerando a reta que melhor se ajusta aos resultados experimentais.

Desta forma, o módulo tangente inicial (Eo) será:

$$
\text { Eo }=\frac{1}{a}
$$

\subsubsection{Ensaio de compressão triaxial dinâmico}

Para a realização dos ensaios triaxiais dinâmicos foi usada uma prensa da marca MTS (Material Testing System), modelo 815 (Figura 3.5), pertencente ao Laboratório de Geotecnia da EESC-USP. Esta prensa permite, através de um gerador de funções, que se selecione previamente a forma, duração e freqüência de aplicação das cargas.

A célula de carga usada é da marca WYKEHAM FARRANCE, com capacidade máxima de carga de $10 \mathrm{kN}$, calibrada para o valor máximo de 5 $\mathrm{kN}$ e posicionada internamente à câmara triaxial. $\mathrm{O}$ fluido de confinamento usado foi o ar.

A medida dos deslocamentos foi feita com o auxílio de dois LVDT's, da marca Solotest, instalados nos terços médios dos corpos de prova. Os 
LVDT's possuem curso de $8 \mathrm{~mm}$, com linearidade entre -2 e $4 \mathrm{~mm}$, e sensibilidade mínima de $1 \mathrm{mVN}$.

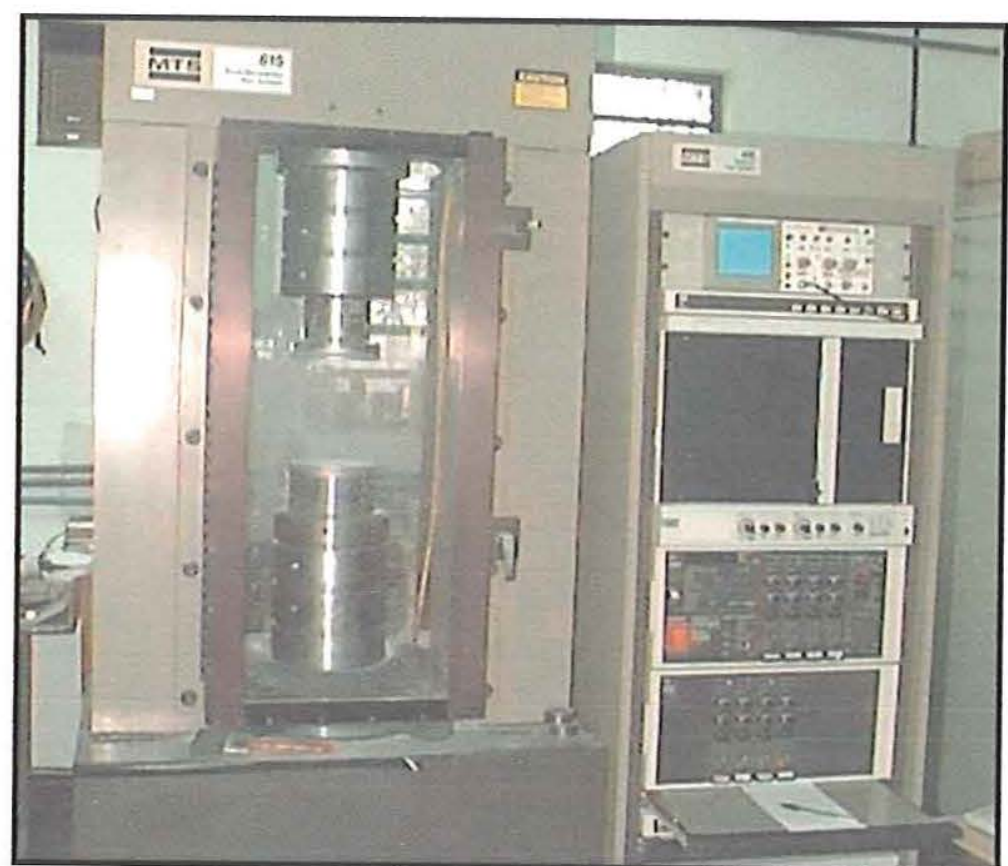

Figura 3.5: Prensa usada para os ensaios triaxiais dinâmicos.

Para o ensaio triaxial dinâmico, os corpos de prova usados possuíam dimensão de $5 \mathrm{~cm}$ de diâmetro e $10 \mathrm{~cm}$ de altura, sendo compactados de forma diferente do especificado no item 3.3.3. A compactação, neste caso, foi realizada com cilindro bipartido, em 6 camadas.

Como não existe norma específica para ensaio de materiais do gênero usado nesta pesquisa, utilizou-se o procedimento descrito por GERRITY et al. (1994) para a realização dos ensaios de compressão triaxial dinâmico.

O padrão de carregamento e condicionamento usado foi o triangular, com períodos de carga de $0,1 \mathrm{~s}$, e $0,9 \mathrm{~s}$ de repouso, ou seja com freqüência de $60 \mathrm{~Hz}$. A Tabela 3.5 apresenta a seqüência de tensões usadas nos ensaios triaxiais dinâmicos. 
Tabela 3.3: Seqüência de tensões aplicadas no ensaio triaxial dinâmico.

\begin{tabular}{cccc}
\hline Etapa & $\begin{array}{c}\sigma_{3} \\
(\mathrm{kPa})\end{array}$ & $\begin{array}{c}\sigma_{\mathrm{d}(\text { ciclica })} \\
(\mathrm{kPa})\end{array}$ & $\begin{array}{c}\mathrm{N}^{\circ} \text { de } \\
\text { aplicações } \\
\text { de carga }\end{array}$ \\
\hline $0^{*}$ & 103,4 & 93,1 & 500 \\
1 & 34,5 & 31,0 & 100 \\
2 & 34,5 & 62,0 & 100 \\
3 & 34,5 & 93,1 & 100 \\
4 & 68,9 & 62,0 & 100 \\
5 & 68,9 & 124,1 & 100 \\
6 & 68,9 & 186,1 & 100 \\
7 & 103,4 & 62,0 & 100 \\
8 & 103,4 & 93,1 & 100 \\
9 & 103,4 & 186,1 & 100 \\
\hline
\end{tabular}

*Etapa de condicionamento.

Para cada nível de tensão aplicado no ensaio triaxial dinâmico foram armazenados os valores dos últimos cinco ciclos de carregamento. $\mathrm{O}$ valor do deslocamento resiliente $(\Delta \mathrm{h})$ é dado pela média dos valores registrados nos dois LVDT's. A média dos deslocamento resilientes dos últimos cinco ciclos define o valor adotado para o calculo da deformação resiliente $\left(\varepsilon_{R}\right)$. Conforme definido na equação 3.3, o valor da deformação resiliente é dado por:

$$
\varepsilon_{\mathrm{R}}=\frac{\Delta \mathrm{h}}{\mathrm{H}}
$$

onde:

$\varepsilon_{\mathrm{R}}$ - deformação resiliente;

$\Delta \mathrm{h}$ - média dos deslocamentos resilientes dos últimos 5 ciclos;

$\mathrm{H}$ - altura inicial do trecho onde estão instalados os LVDT's.

O módulo de resiliência $\left(M_{R}\right)$ é então calculado para cada estado de tensão através da equação 3.4.

$$
\mathrm{M}_{\mathrm{R}}=\frac{\sigma_{\mathrm{d}}}{\varepsilon_{\mathrm{R}}}
$$


onde:

$M_{R}$ - módulo de resiliência;

$\sigma_{d}-$ tensão desvio aplicada;

$\varepsilon_{R}-$ deformação resiliente.

Após o final da seqüência de carregamento, os corpos de prova foram ensaiados à compressão simples no mesmo equipamento, com velocidade de carregamento de $1,27 \mathrm{~mm} / \mathrm{min}$. 


\section{CAPÍTULO 4 - APRESENTAÇÃO E DISCUSSÃO DOS RESULTADOS}

\subsection{INTRODUÇÃO}

Os resultados descritos neste capítulo dizem respeito aos ensaios realizados para a avaliação do uso de misturas de fosfogesso e cimento na construção rodoviária.

O programa de ensaios desenvolvido neste trabalho de pesquisa foi dividido em duas etapas: Estudo Preliminar e Estudo Definitivo. São apresentados e descritos, nesta ordem, as atividades executadas e resultados obtidos em cada etapa da pesquisa.

\subsection{ESTUDO PRELIMINAR}

Conforme descrito no Capítulo 3, o fosfogesso inicialmente usado na pesquisa foi substituído por outro fosfogesso proveniente da mesma indústria, mas com características, principalmente de $\mathrm{pH}$, diferentes. Antes porém que se fizesse a substituição, o primeiro material, aqui denominado de fosfogesso A, foi foco de uma série de estudos, entre eles: análise sobre a temperatura adequada de secagem para determinação da umidade, ensaios de compactação para a obtenção do par ordenado massa específica seca máxima e umidade ótima para cada uma das diferentes composições de misturas estudas, e ensaios de neutralização. Apresentam-se na seqüência, os estudos realizados com o fosfogesso $A$ e posteriormente, os 
estudos realizados com o segundo material utilizado, aqui denominado de fosfogesso B.

Para fins de uma melhor compreensão, vale lembrar que o fosfogesso A é aquele que apresentou um $\mathrm{pH}$ de 2,4 , e o fosfogesso $\mathrm{B}$, é aquele que apresentou um $\mathrm{pH}$ de 5,0. A descrição dos dois materiais é feita no Capítulo 3.

\subsubsection{Temperatura de secagem do fosfogesso}

Como já citado anteriormente, o fosfogesso é basicamente um sulfato de cálcio hidratado, podendo ser di-hidratado, hemi-hidratado ou anidro. Nesta pesquisa, deseja-se investigar o efeito da adição de cimento ao fosfogesso di-hidratado, para tanto alguns cuidados devem ser tomados com relação à temperatura a que se submete o fosfogesso. Sabe-se pela bibliografia pesquisada que temperaturas superiores a $60{ }^{\circ} \mathrm{C}$ iniciam um processo de desidratação, levando o fosfogesso di-hidratado a converter-se em hemi-hidratado (TAHA et al., 1992; ONG et al., 1994; TAHA et al., 1995). Conhecendo esta situação, a preocupação inicial foi determinar a temperatura ideal de secagem do fosfogesso para a obtenção de sua umidade, visto que as temperaturas usuais em laboratório levam à evaporação de sua água molecular. Seguindo a recomendação de SAYLAK et al. (1988), adotou-se a temperatura de $40{ }^{\circ} \mathrm{C}$ como padrão para a determinação da umidade. Estudos posteriores mostraram, que em estufa com ventilação forçada, a temperatura de $40{ }^{\circ} \mathrm{C}$ mantida por 24 horas, é suf́lciente para a secagem do material e não interfere com a água molecular. Essa situação foi confirmada por ensaios realizados na Universidade Federal de São Carlos, usando-se um fosfogesso seco, determinou-se que, para o fosfogesso em questão, apenas temperaturas a partir de $90^{\circ} \mathrm{C}$ iniciam o processo de desidratação do fosfogesso, convertendo-o de di-hidratado para anidro. O resultado desta análise é apresentada no ANEXO E. 


\subsubsection{Ensaios de compactação e compressão simples para 0 fosfogesso $\mathrm{A}$}

Foram realizados os ensaios de compactação para 4 misturas de fosfogesso $\mathrm{A}$ e cimento nas energias equivalentes ao Proctor normal e ao Proctor intermediário. As Figuras 4.1 e 4.2 apresentam as curvas de compactação para cada uma destas misturas.

Essas mesmas curvas, separadas segundo o teor de cimento na mistura, estão apresentadas nas Figuras de A.1 a A.8 do Anexo A.

A Tabela 4.1 apresenta resumidamente os valores de umidade ótima e massa específica seca máxima obtidos para todas as misturas de fosfogesso A e cimento, nas energias de compactação usadas.

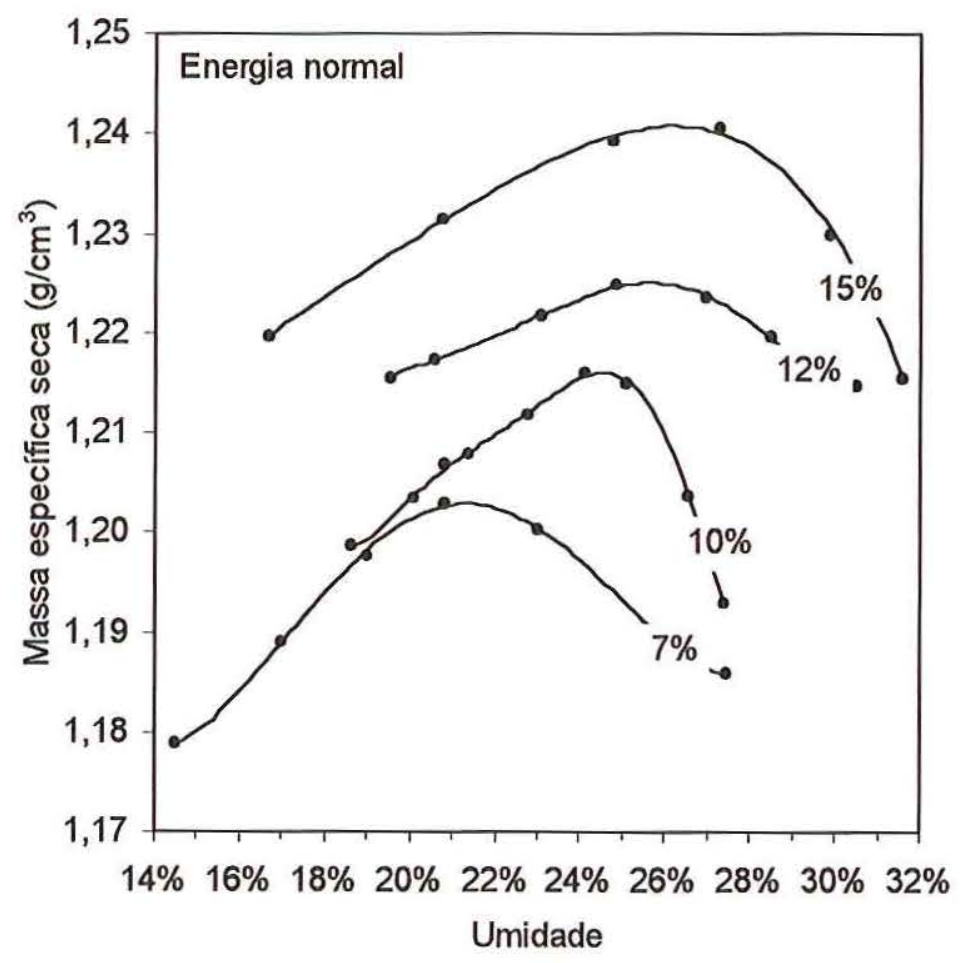

Figura 4.1: Curvas de compactação para misturas de fosfogesso $\mathrm{A}$ e cimento compactadas na energia normal. 


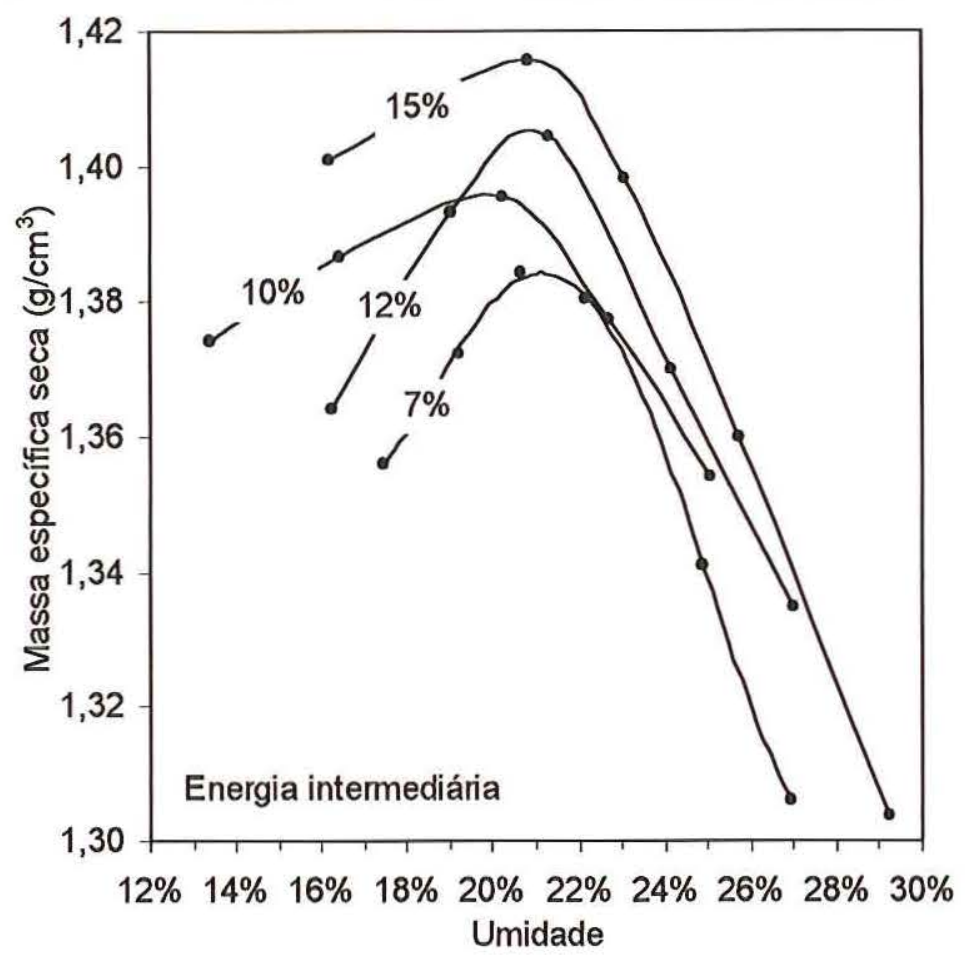

Figura 4.2: Curvas de compactação para misturas de fosfogesso $A$ e cimento compactadas na energia intermediária

Tabela 4.1: Valores de umidade ótima massa específica seca máxima para misturas de fosfogesso A e cimento.

\begin{tabular}{ccc|cc}
\hline Teor de & \multicolumn{4}{c}{ Energia de compactação } \\
\cline { 2 - 5 } $\begin{array}{c}\text { cimento } \\
(\%)\end{array}$ & \multicolumn{2}{c}{ Normal } & \multicolumn{2}{c}{ Intermediária } \\
\cline { 2 - 5 } & Umidade & Massa específica & Umidade & Massa específica \\
seca máxima $\left(\mathrm{g} / \mathrm{cm}^{3}\right)$ & ótima (\%) & seca máxima $\left(\mathrm{g} / \mathrm{cm}^{3}\right)$ \\
\hline 7 & 21,10 & 1,203 & 21,16 & 1,384 \\
10 & 24,53 & 1,216 & 19,57 & 1,396 \\
12 & 25,63 & 1,225 & 20,84 & 1,406 \\
15 & 26,16 & 1,241 & 20,34 & 1,415 \\
\hline
\end{tabular}

Pode-se observar pelos resultados apresentados na Tabela 4.1 a influência da energia de compactação e teor de cimento na mistura sobre os valores de umidade ótima e massa específica seca máxima. Quanto à umidade, para a energia do Proctor normal, porcentagens crescentes de cimento conduzem a valores crescentes de umidade ótima, que variaram de $21,10 \%$ a $26,16 \%$. No caso da energia intermediária, a umidade ótima foi pouco afetada pelo teor de cimento, situando-se em torno do valor de $20,5 \%$. Quanto à massa específica seca, porcentagens crescentes de cimento conduzem a valores crescentes de massa específica seca máxima, e o 
aumento da energia de compactação também concorre para o aumento desta variável.

Posteriormente, os corpos de prova obtidos na compactação foram submetidos a ensaios de compressão simples para uma avaliação inicial dos valores de resistência apresentados pelas misturas. Esses ensaios foram realizados após um período de cura de 7 dias sem imersão e após imersão. As Figuras 4.3 e 4.4 ilustram os resultados destes ensaios. A observação dessas Figuras fornece indicações de que a resistência à compressão simples não apresenta um padrão de variação bem definido no tocante à influência da umidade de compactação.

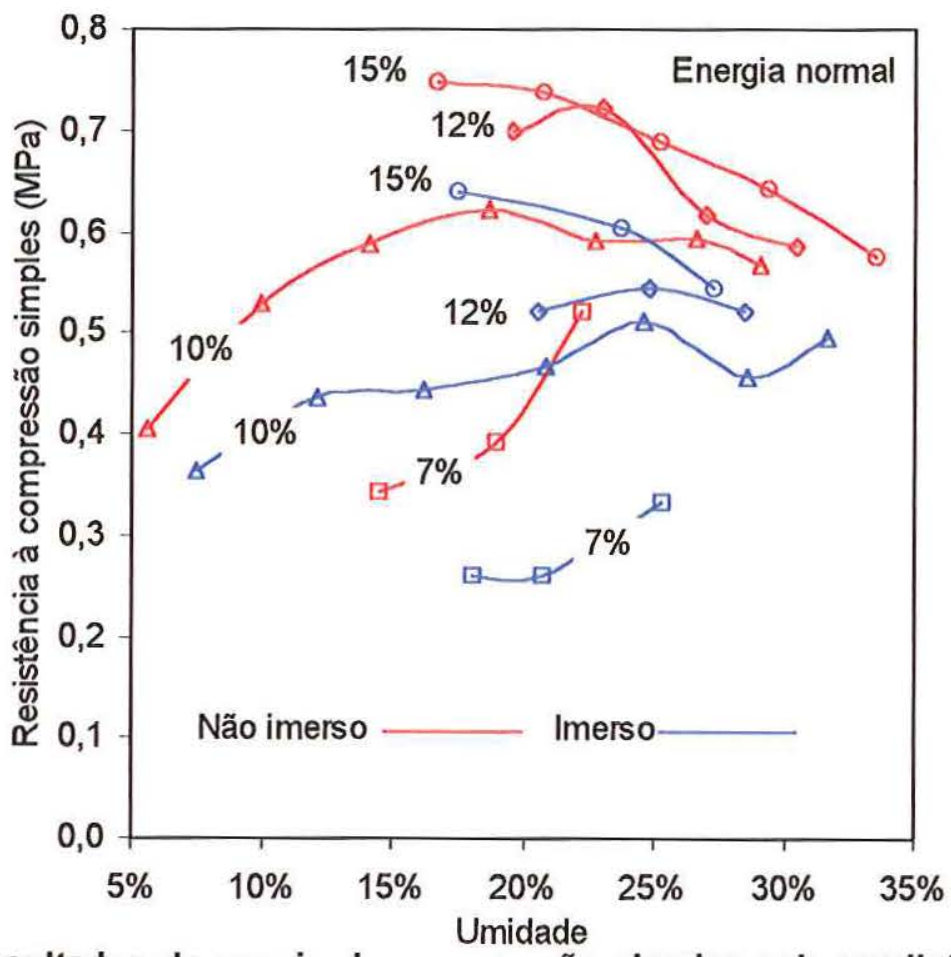

Figura 4.3: Resultados do ensaio de compressão simples sob condiçöes imersas e não imersas, após 7 dias de cura, para corpos de prova compactados na energia normal. 


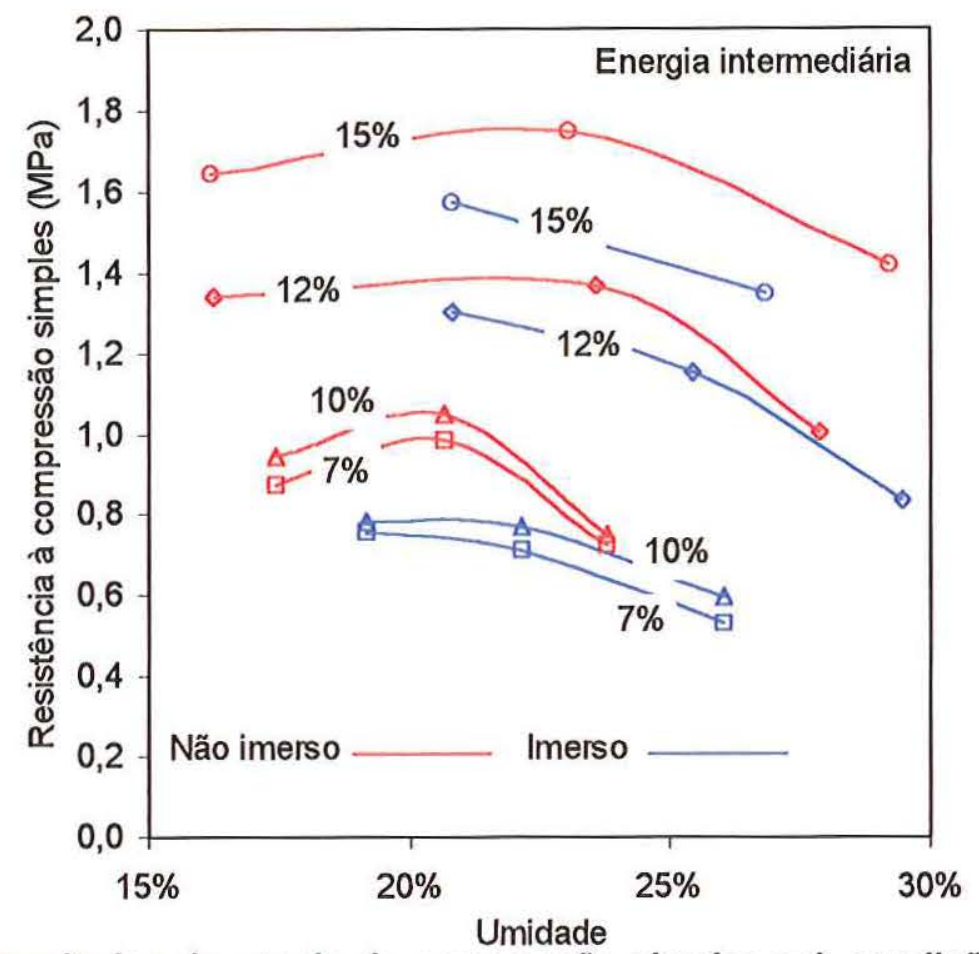

Figura 4.4: Resultados do ensaio de compressão simples sob condiçöes imersas e não imersas, após 7 dias de cura, para corpos de prova compactados na energia intermediária.

A Tabela 4.2 mostra o maior valor de resistência à compressão simples obtido para cada uma das misturas de fosfogesso A e cimento aos 7 dias de cura, para corpos de prova compactados nas energias normal e intermediária, e ensaiados sem imersão e após imersão.

Tabela 4.2: Valores de resistência à compressão simples para misturas de fosfogesso A e cimento aos 7 dias de cura.

\begin{tabular}{ccc|cc}
\hline Teor de & \multicolumn{3}{c}{ Resistência à compressão simples (MPa) } \\
\cline { 2 - 5 } cimento & \multicolumn{2}{c}{ Energia normal } & \multicolumn{2}{c}{ Energia intermediária } \\
\cline { 2 - 5 }$(\%)$ & Não imerso & Imerso & Não imerso & Imerso \\
\hline 7 & 0,52 & 0,33 & 0,98 & 0,76 \\
10 & 0,62 & 0,51 & 1,05 & 0,78 \\
12 & 0,72 & 0,55 & 1,36 & 1,30 \\
15 & 0,75 & 0,66 & 1,75 & 1,58 \\
\hline
\end{tabular}

Analisando-se o efeito da adição de cimento sobre a resistência, verifica-se que o seu valor aumenta à medida em que se aumenta o teor de cimento das misturas. Quanto ao efeito da imersão em água sobre a resistência, verifica-se que corpos de prova ensaiados após imersão 
apresentaram menor resistência que os corpos de prova ensaiados sem imersão prévia.

Quando comparado aos estudos realizados por outros pesquisadores (GREGORY et al. 1984, CHANG \& MANTELL 1990, ONG et al. 1994), o nível de resistência obtido, tanto para a compactação na energia normal, quanto para a compactação na energia intermediária, não se mostrou compatível com os obtidos em pesquisas realizadas com misturas do mesmo gênero. Essa constatação levou à busca, na bibliografia existente, de possíveis justificativas para o baixo nível de resistência alcançado.

\subsubsection{Estudo do efeito da neutralização do fosfogesso A}

Ao que parece, a acidez do fosfogesso, refletida no $\mathrm{pH}$, exerce papel importante no desenvolvimento da resistência do material. Segundo SAYLAK et al. (1988), em estudos realizados com o fosfogesso da "Mobil Chemical Company's Pasadena", verificou-se que a resistência alcançada com estabilização por cimento Portland foi consideravelmente maior com material proveniente de depósitos inativos, com 7 anos de idade, do que com o fosfogesso proveniente de depósitos ativos, ainda em uso para armazenagem. Os depósitos ativos, com pH de aproximadamente 2,5, proporcionaram o desenvolvimento de pouca ou nenhuma resistência, enquanto que os depósitos mais antigos, com pH de aproximadamente 5,5, levaram a amostras com uma maior estabilidade e resistência. Uma outra constatação desse estudo foi que a distribuição granulométrica e a forma das partículas do material proveniente dos depósitos inativos é mais variada do que a encontrada nos depósitos ativos. Essas características proporcionam, por si só, a obtenção de maiores densidades na compactação e maior estabilidade frente à ação da água.

Ainda com relação à influência do $\mathrm{pH}$, estudos realizados por GADALLA et al. (1990), também mostram que a resistência à compressão 
simples do fosfogesso diminui sensivelmente com o aumento de sua acidez. Dessa forma, quanto menor o seu $\mathrm{pH}$, tanto menor será a sua resistência. $\mathrm{Na}$ presente pesquisa, o fosfogesso $\mathrm{A}$ possui um $\mathrm{pH}$ igual a 2,4 , exibindo portanto, uma acidez elevada. Assim, como próxima etapa deste estudo, resolveu-se variar o pH do fosfogesso através da adição de um agente neutralizante, no caso o hidróxido de sódio $(\mathrm{NaOH})$, conhecido comercialmente como soda cáustica, e analisar a sua influência na resistência alcançada.

Para a realização deste estudo elegeu-se uma mistura de fosfogesso e $10 \%$ de cimento, variando-se a quantidade do agente neutralizante. As quantidades de neutralizante empregadas foram medidas em termos de porcentagem de massa seca de fosfogesso, sendo adotados os seguintes teores de $\mathrm{NaOH}: 0,5 \%, 1 \%, 5 \%$ e $10 \%$.

Foram escolhidas duas situações para a análise em questão: neutralização do fosfogesso com imediata mistura com cimento e compactação dos corpos de prova; e neutralização, cura por um período de 24 horas e posterior mistura com cimento e compactação dos corpos de prova. O estudo sob esta última condição fez-se necessária pela desconfiança existente sobre a necessidade de um período de tempo para a ocorrência da reação de neutralização. Vale salientar que a neutralização é apenas do fosfogesso e não da mistura de fosfogesso e cimento.

Os resultados dos ensaios de compressão simples realizados após a tentativa de neutralização do fosfogesso estão resumidos na Tabela 4.3. Nesta tabela são apresentados os valores de resistência à compressão simples de misturas contendo fosfogesso não neutralizado e fosfogesso neutralizado com $10 \%$ de cimento, ensaiadas em condições não imersas, e imersas em água por 4 horas antes do ensaio, após um período de cura de 7 dias, para as duas situações já citadas. A energia de compactação adotada neste estudo foi o Proctor normal. 


\begin{tabular}{|c|c|c|c|c|c|c|}
\hline \multirow{4}{*}{$\begin{array}{c}\text { abela 4.3: Valores de } \\
\text { fosfogesso } \\
\text { cimento, apó } \\
\begin{array}{c}\text { Teor de } \\
\text { neutralizante }\end{array}\end{array}$} & \multicolumn{6}{|c|}{$\begin{array}{l}\text { resistência à compressão simples para misturas } \\
\text { neutralizado e fosfogesso não neutralizado com } \\
\text { s } 7 \text { dias de cura, e compactação na energia normal. }\end{array}$} \\
\hline & \multicolumn{6}{|c|}{ compactação imediata - RCS (MPa) } \\
\hline & \multicolumn{3}{|c|}{ não imerso } & \multicolumn{3}{|c|}{ imerso } \\
\hline & c.p. 1 & c.p. 2 & c.p. 3 & c.p. 4 & c.p. 5 & c.p. 6 \\
\hline $0 \% \mathrm{NaOH}$ & \multicolumn{3}{|c|}{0,62 (Tabela 4.2) } & \multicolumn{3}{|c|}{ 0,51 (Tabela 4.2) } \\
\hline $0,5 \% \mathrm{NaOH}$ & 0,76 & 0,79 & 0,77 & 0,71 & 0,72 & 0,71 \\
\hline $1 \% \mathrm{NaOH}$ & 0,77 & 0,77 & 0,79 & 0,6 & 0,6 & 0,76 \\
\hline $5 \% \mathrm{NaOH}$ & 0,73 & 0,72 & 0,77 & 0,65 & 0,5 & 0,57 \\
\hline $10 \% \mathrm{NaOH}$ & 0,64 & 0,69 & 0,66 & 0,49 & 0,49 & 0,48 \\
\hline \multirow{3}{*}{$\begin{array}{c}\text { Teor de } \\
\text { neutralizante }\end{array}$} & \multicolumn{6}{|c|}{ compactação após $24 \mathrm{~h}$ - RCS (MPa) } \\
\hline & \multicolumn{3}{|c|}{ não imerso } & \multicolumn{3}{|c|}{ imerso } \\
\hline & c.p. 1 & c.p. 2 & c.p.3 & c.p. 4 & c.p. 5 & c.p. 6 \\
\hline $0,5 \% \mathrm{NaOH}$ & 0,75 & 0,78 & 0,78 & 0,71 & 0,71 & 0,73 \\
\hline $1 \% \mathrm{NaOH}$ & 0,77 & 0,75 & 0,80 & 0,65 & 0,65 & 0,70 \\
\hline $5 \% \mathrm{NaOH}$ & 0,72 & 0,69 & 0,74 & 0,59 & 0,66 & 0,65 \\
\hline $10 \% \mathrm{NaOH}$ & 0,71 & 0,69 & 0,69 & 0,47 & 0,45 & 0,48 \\
\hline
\end{tabular}

Analisando-se os resultados apresentados na Tabela 4.3 observa-se que o excesso de agente neutralizante deve provocar uma redução no valor de resistência à compressão simples: as resistências para misturas com fosfogesso neutralizado a teores de $5 \%$ e $10 \%$ de $\mathrm{NaOH}$ são inferiores aos valores de resistência para misturas com fosfogesso neutralizado com $0,5 \%$ e $1 \%$ de $\mathrm{NaOH}$. Observa-se ainda que o período de $24 \mathrm{~h}$ antes da compactação parece não ser necessário, ou então seria insuficiente, para influenciar significativamente no desenvolvimento da resistência à compressão simples. Finalmente, conclui-se que a neutralização, da forma como foi realizada, não foi eficiente para alterar de forma significativa os valores de resistência à compressão simples, visto que o aumento de resistência obtido foi pequeno: de $0,62 \mathrm{MPa}$, sem neutralização, para 0,79 com neutralização de $0,5 \%$ a $1 \%$ de $\mathrm{NaOH}$.

Segundo SAYLAK et al. (1988), apenas a neutralização não é suficiente para emprestar ao fosfogesso o mesmo nível de resistência alcançado pelo fosfogesso envelhecido, visto que uma grande parcela dessa resistência, aproximadamente $50 \%$, seria função da dimensão e forma das partículas. 
Como os resultados do estudo sobre a neutralização do fosfogesso não se mostraram satisfatórios no tocante à obtenção de resistências mais elevadas, optou-se pela substituição do fosfogesso $A$ pelo fosfogesso $B$, mais velho, conforme descrito no Capítulo 3.

\subsubsection{Ensaios de compactação e compressão simples com o fosfogesso B}

Como primeira etapa do estudo com o fosfogesso $\mathrm{B}$, procedeu-se à obtenção do par ordenado massa específica seca máxima e umidade ótima, através do levantamento das curvas de compactação de cada uma das misturas deste material e cimento, para as energias de compactação normal e intermediária. Os resultados dos ensaios de compactação podem ser observados nas Figuras 4.5 e 4.6, onde são apresentadas as curvas para as misturas de fosfogesso B e cimento, respectivamente para as energias normal e intermediária.

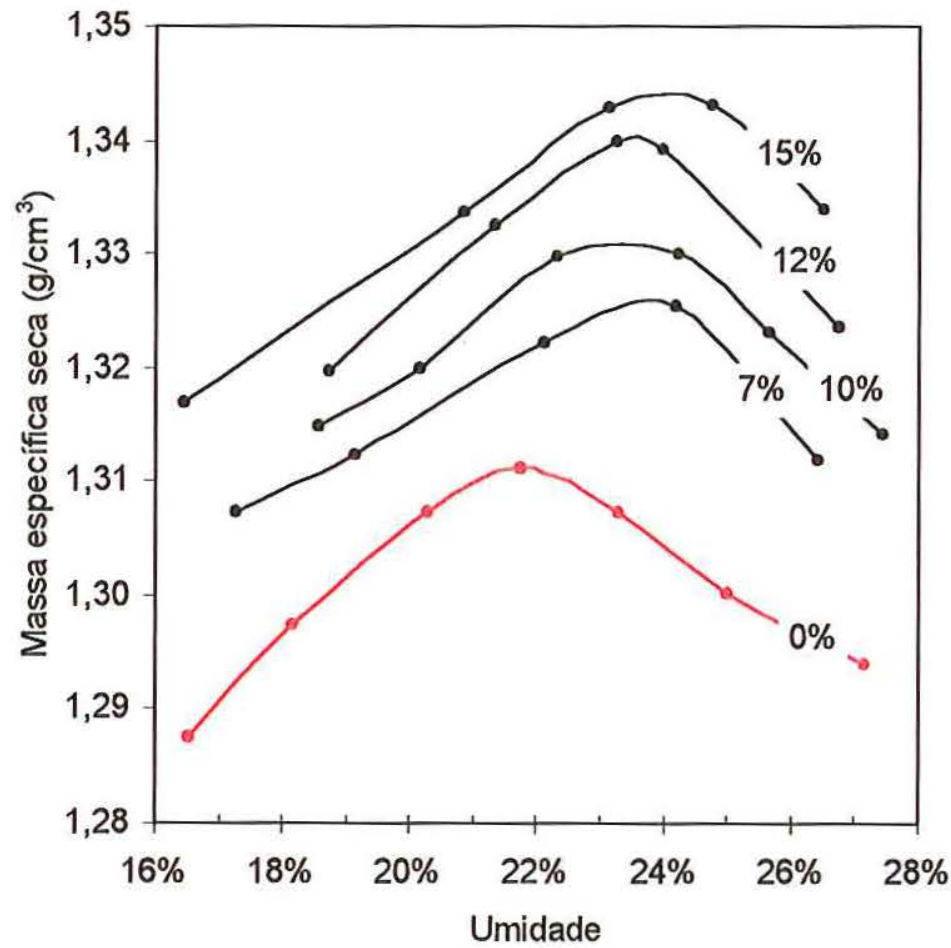

Figura 4.5: curvas de compactação para misturas de fosfogesso B e cimento compactadas na energia normal. 


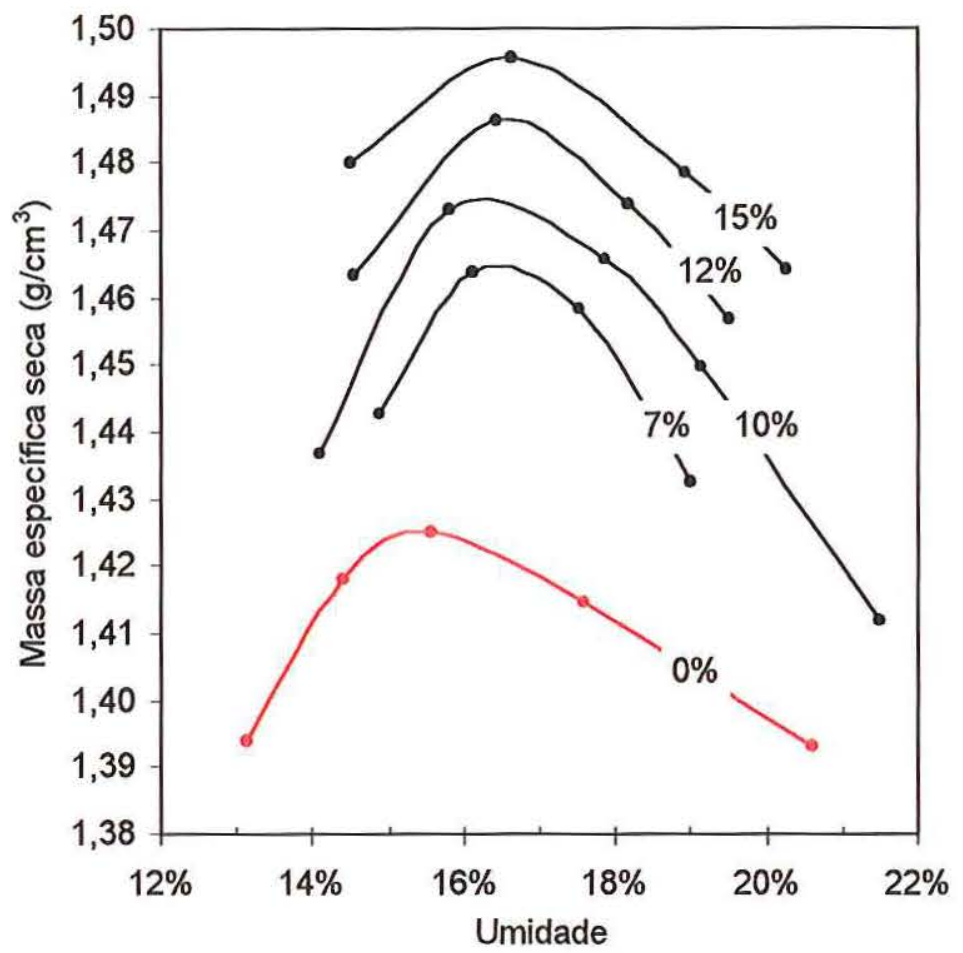

Figura 4.6: curvas de compactação para misturas de fosfogesso B e cimento compactadas na energia intermediária.

Essas mesmas curvas, separadas segundo o teor de cimento na mistura, estão apresentadas nas Figuras de A.9 a A.18, do Anexo A.

A Tabela 4.4 apresenta resumidamente os valores de umidade ótima e massa específica seca máxima obtidos para as misturas de fosfogesso B e cimento, nas duas energias de compactação usadas.

Tabela 4.4: Valores de umidade ótima e massa específica seca máxima para misturas de fosfogesso B e cimento.

\begin{tabular}{ccc|cc}
\hline \multirow{2}{*}{$\begin{array}{c}\text { Teor de } \\
\text { cimento }\end{array}$} & \multicolumn{3}{c}{ Energia de compactação } \\
\cline { 2 - 5 }$(\%)$ & Umidade & Massa específica & \multicolumn{2}{c}{ Intermediária } \\
& ótima $(\%)$ & seca máxima $\left(\mathrm{g} / \mathrm{cm}^{3}\right)$ & ótima $(\%)$ & Massa específica \\
seca máxima $\left(\mathrm{g} / \mathrm{cm}^{3}\right)$ \\
\hline 7 & 21,67 & 1,311 & 15,72 & 1,425 \\
10 & 23,91 & 1,326 & 16,49 & 1,465 \\
12 & 23,29 & 1,332 & 16,37 & 1,475 \\
15 & 23,36 & 1,340 & 16,42 & 1,487 \\
\hline
\end{tabular}

Pelos resultados apresentados na Tabela 4.4, observa-se um acréscimo nos valores de massa específica seca máxima para misturas 
contendo o fosfogesso B e cimento, quando comparados aos valores observados para misturas contendo o fosfogesso A e cimento (Tabela 4.1). Para o fosfogesso $A$, na compactação com energia normal, os valores de massa específica seca máxima variam de $1,203 \mathrm{~g} / \mathrm{cm}^{3}$ a $1,241 \mathrm{~g} / \mathrm{cm}^{3}$ enquanto para o fosfogesso $B$, esses valores variam de $1,326 \mathrm{~g} / \mathrm{cm}^{3}$ a 1,344 $\mathrm{g} / \mathrm{cm}^{3}$. Para compactação na energia intermediária, os valores de massa específica seca máxima do fosfogesso $A$ variam de $1,384 \mathrm{~g} / \mathrm{cm}^{3}$ a 1,415 $\mathrm{g} / \mathrm{cm}^{3}$, e do fosfogesso $B$, variam de $1,465 \mathrm{~g} / \mathrm{cm}^{3}$ a $1,496 \mathrm{~g} / \mathrm{cm}^{3}$. Tanto para o fosfogesso $A$ quanto para o fosfogesso $B$, os valores de massa específica seca máxima aumentam à medida em que se aumenta o teor de cimento das misturas. Esses resultados são coerentes com os resultados obtidos em outras pesquisas, por exemplo: ONG et al. (1994) encontraram valores de massa específica seca máxima variando de $1,54 \mathrm{~g} / \mathrm{cm}^{3}$ a $1,58 \mathrm{~g} / \mathrm{cm}^{3}$ para misturas com teores variáveis de cimento compactadas na energia modificada, e valores de massa específica seca máxima variando de 1,35 $\mathrm{g} / \mathrm{cm}^{3}$ a $1,40 \mathrm{~g} / \mathrm{cm}^{3}$ para misturas com teores variáveis de cimento compactadas na energia normal (Tabela 2.9).

Para as misturas contendo fosfogesso B, em ambas as energias, normal e intermediária, os valores de umidade ótima encontrados para os diversos teores de cimento são bastante próximos, permitindo a adoção nos estudos que se seguem, de um valor único de umidade para todas as misturas. O valor adotado para o material compactado na energia normal é $23,5 \%$, e para o material compactado na energia intermediária é $16,5 \%$. A Figura 4.7 mostra a variação da umidade ótima em função do teor de cimento para as duas energias de compactação.

A Figura 4.8 mostra a variação da massa específica seca máxima em função do teor de cimento para as energias normal e intermediária. Apesar de pequena, essa variação mostra uma tendência contrária ao observado para outras misturas estabilizadas quimicamente, o solo-cimento por exemplo: porcentagens crescentes de cimento conduzem a menores valores 
de massa específica seca máxima. No caso do fosfogesso, porcentagens crescentes de cimento conduzem a maiores valores de massa específica seca máxima.

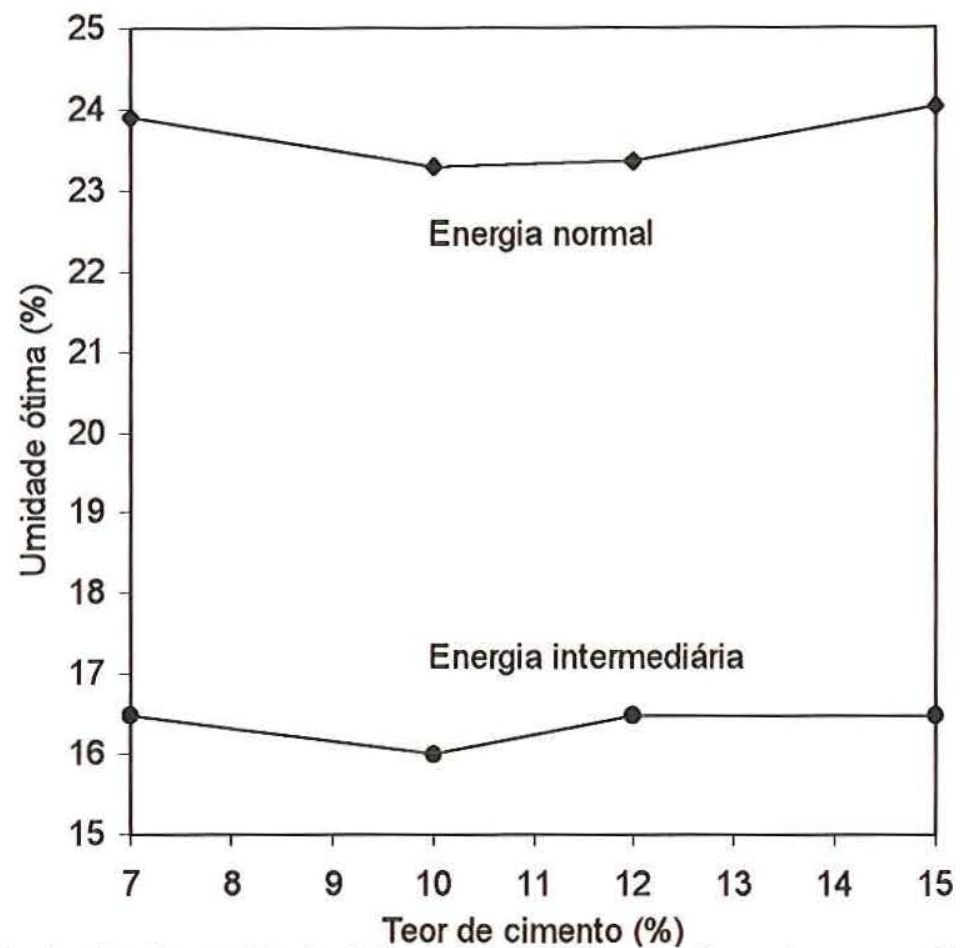

Figura 4.7: Variação da umidade ótima com o teor de cimento para o fosfogesso B.

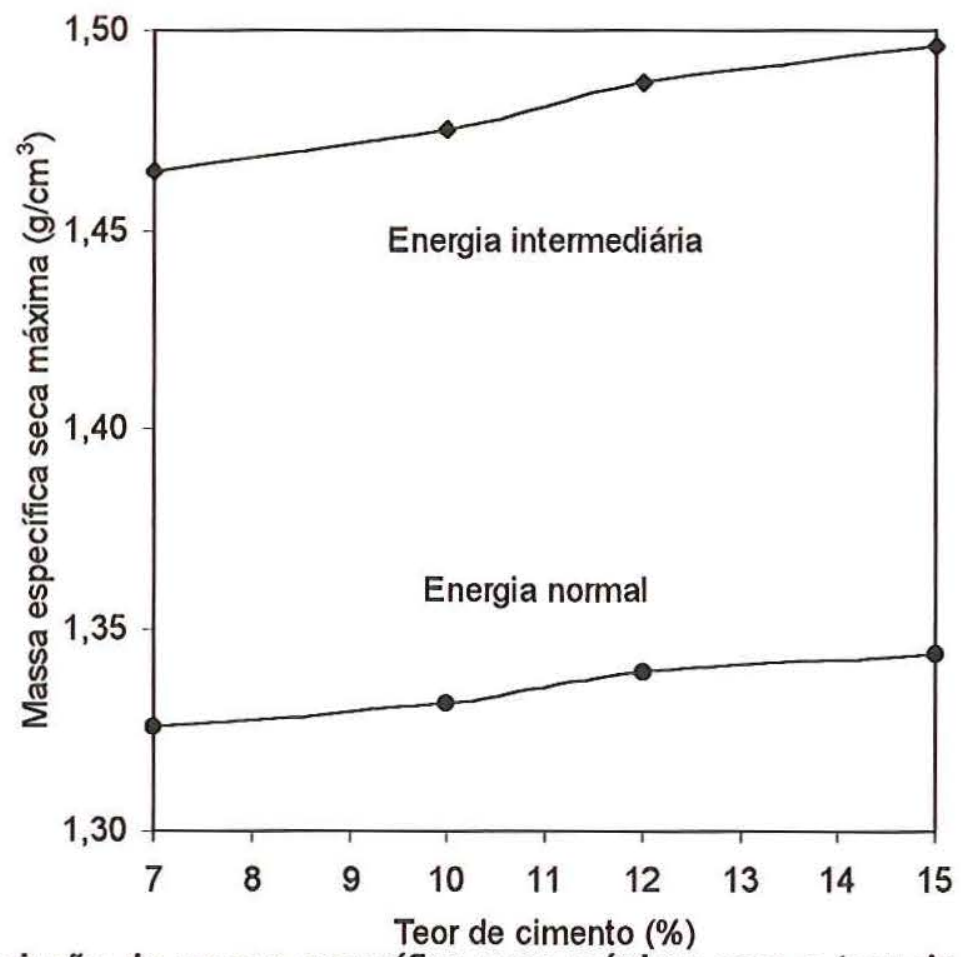

Figura 4.8: Variação da massa específica seca máxima com o teor de cimento para compactação nas energias normal e intermediária. 
Os corpos de prova provenientes do ensaio de compactação das misturas com fosfogesso B e cimento foram submetidos a ensaios de compressão simples. Os resultados desses ensaios podem ser observados nas Figuras 4.9 e 4.10. De forma similar ao verificado para misturas contendo fosfogesso $A$, os valores de resistência a compressão simples de misturas contendo fosfogesso $\mathrm{B}$ aumentam à medida em que se aumenta o teor de cimento, e não existe um padrão bem definido para a sua variação com a variação da umidade de compactação.

A Tabela 4.5 apresenta os maiores valores de resistência à compressão simples obtidos para as misturas de fosfogesso B e cimento ensaiadas aos 7 dias em condições imersas e não imersas, para corpos de prova compactados nas energias normal e intermediária.

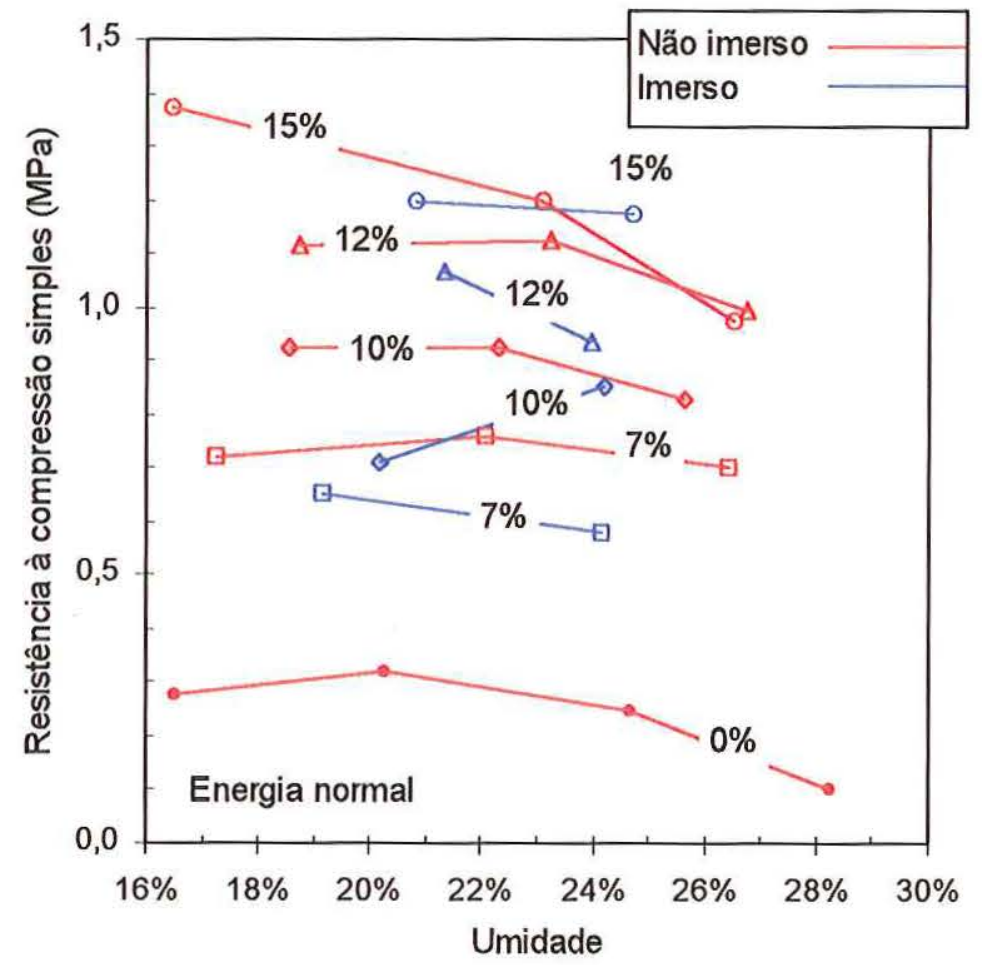

Figura 4.9: Valores de resistência à compressão simples para misturas contendo fosfogesso B, compactadas na energia normal e ensaiadas após 7 dias de cura sob duas condições, imerso e não imerso. 


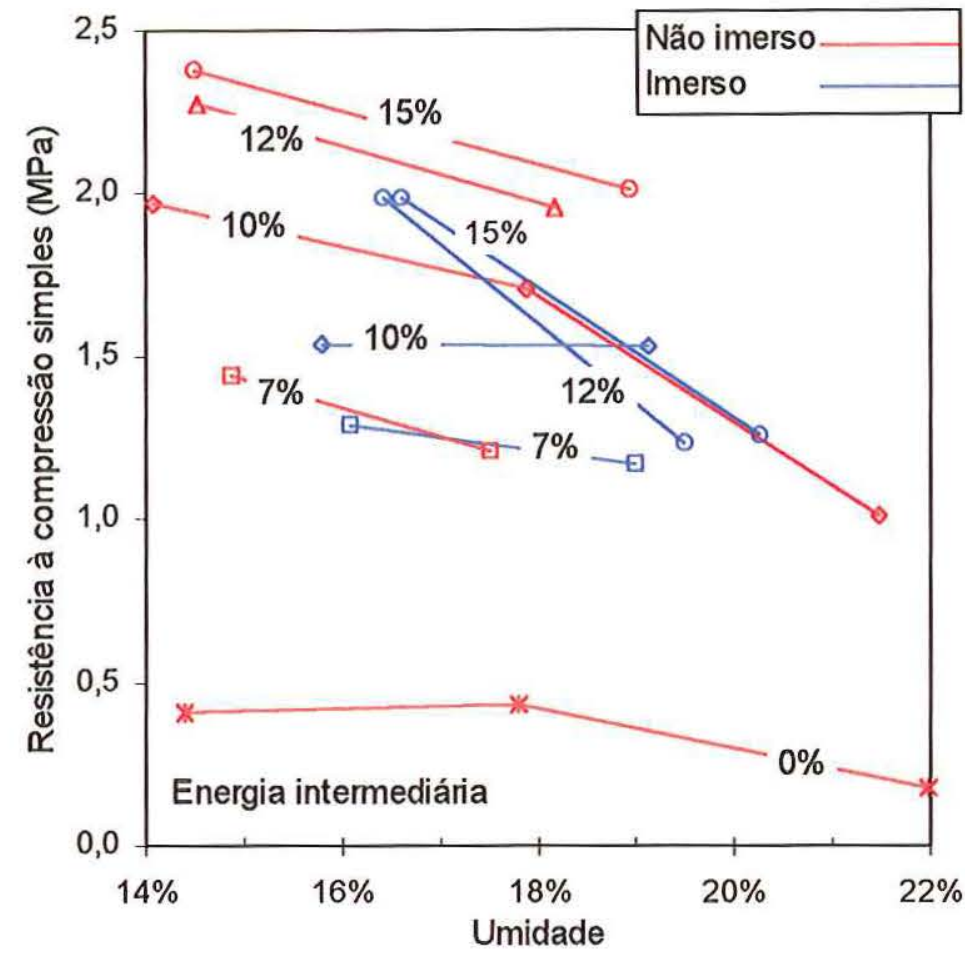

Figura 4.10: Valores de resistência à compressão simples para misturas contendo fosfogesso B, compactadas na energia intermediária e ensaiadas após 7 dias de cura sob duas condições, imerso e não imerso.

Tabela 4.5: Valores de resistência à compressão simples para misturas de fosfogesso B e cimento aos 7 dias de cura.

\begin{tabular}{|c|c|c|c|c|}
\hline \multirow{3}{*}{$\begin{array}{c}\text { Teor de } \\
\text { cimento } \\
\text { (\%) }\end{array}$} & \multicolumn{4}{|c|}{ Resistência à compressão simples (MPa) } \\
\hline & \multicolumn{2}{|c|}{ Energia normal } & \multicolumn{2}{|c|}{ Energia intermediária } \\
\hline & Não imerso & Imerso & Não imerso & Imerso \\
\hline 0 & 0,32 & * & 0,43 & * \\
\hline 7 & 0,76 & 0,65 & 1, & 1,29 \\
\hline 10 & 0,92 & 0,85 & 1,97 & 1,54 \\
\hline 12 & 1,13 & 1,07 & 2, & 1,99 \\
\hline 15 & 1,37 & 1,20 & 2,38 & 1,99 \\
\hline
\end{tabular}

* esses corpos de prova ao serem submetidos a imersão não apresentaram estabilidade frente a ação da água, entrando em colapso, não permitindo portanto a realização do ensaio de compressão simples.

A Tabela 4.6 apresenta o crescimento, em termos percentuais, dos valores de resistência à compressão simples do fosfogesso $\mathrm{B}$ em relação ao fosfogesso $A$. Esses valores são baseados nos resultados apresentados nas Tabelas 4.2 e 4.5 
Tabela 4.6: Crescimento percentual dos valores de resistência à compressão simples do fosfogesso $B$ em relação ao fosfogesso $A$.

\begin{tabular}{ccc|cc}
\hline & \multicolumn{3}{c}{ Fosfogesso A x Fosfogesso B } \\
\hline \multirow{2}{*}{$\begin{array}{c}\text { Teor de } \\
\text { cimento }\end{array}$} & \multicolumn{3}{c}{ Crescimento percentual } \\
\cline { 2 - 5 }$(\%)$ & \multicolumn{2}{c}{ Energia normal } & Energia intermediária \\
\cline { 2 - 5 } & Não imerso & Imerso & Não imerso & Imerso \\
\hline 7 & $46,15 \%$ & $96,97 \%$ & $47,96 \%$ & $69,74 \%$ \\
10 & $48,39 \%$ & $66,67 \%$ & $87,62 \%$ & $97,44 \%$ \\
12 & $56,94 \%$ & $94,55 \%$ & $67,65 \%$ & $53,08 \%$ \\
15 & $82,67 \%$ & $81,82 \%$ & $36,00 \%$ & $25,95 \%$ \\
\hline
\end{tabular}

Portanto, frente aos resultados apresentados na Tabela 4.6, resolveuse adotar o fosfogesso B para a continuidade dos estudos, visto que o aumento nos valores de resistência é significativo, variando de 25,95\% a $97,44 \%$.

\subsection{ESTUDO DEFINITIVO}

O Estudo Definitivo foi desenvolvido a partir do ensaio de corpos de prova compactados nas energias normal e intermediária, nas umidades ótima e ótima $\pm 2 \%$ definidas no Estudo Preliminar para as misturas de fosfogesso B e cimento. Foram realizados ensaios de compressão simples e compressão triaxial dinâmica que permitiram que se analisassem aspectos relacionados à resistência e deformabilidade destas misturas. Maiores detalhes dos procedimentos adotados nesta fase da pesquisa estão descritos no Capítulo 3. Tabelas com o detalhamento dos resultados dos ensaios são apresentados nos Anexos B e C.

\subsubsection{Resistência determinada através de ensaios de compressão simples para o fosfogesso B}

Os resultados de resistência à compressão simples de cada um dos corpos de prova ensaiados são apresentados no Anexo B, Tabelas de B.1 a B.4. Todos os gráficos baseados na resistência à compressão simples foram construídos usando-se os valores apresentados nessas Tabelas. 
A resistência à compressão simples é um critério comum para a avaliação da adequabilidade do uso de solos estabilizados para a execução de camadas de pavimento. Como não se dispõe de norma específica para misturas de fosfogesso e cimento, adotou-se as normas de solo-cimento como um parâmetro de comparação (ABNT, 1992). Essa norma estabelece um padrão mínimo de resistência de 2,1 MPa aos 7 dias. No entanto, estudos mostram que no Brasil existem pavimentos executados com solocimento que apresentaram resistência à compressão, aos 7 dias, de até 1,0 MPa (Pitta, 1997). Como o objetivo principal do uso do fosfogesso é o descarte de grandes volumes de material, admite-se que, para misturas de fosfogesso e cimento, valores próximos ao menor valor de resistência para misturas de solo-cimento sejam aceitáveis. Dessa forma, considera-se que valores de resistência à compressão inferiores aos especificados pela norma de solo-cimento sejam admissíveis para misturas de fosfogesso e cimento.

Os resultados dos ensaios de compressão simples forneceram subsídios para a avaliação da influência da energia de compactação, do teor de cimento, do tempo de cura e da umidade de compactação sobre os valores de resistência máxima das misturas de fosfogesso e cimento.

As Figuras 4.11 e 4.12 ilustram, respectivamente, os valores de resistência à compressão simples das misturas de fosfogesso e cimento em função do tempo de cura, para condições não imersas e imersas. Cada valor apresentado nestas Figuras é resultado da média de 3 valores correspondentes ao ensaio de 3 corpos de prova. Os resultados em questão dizem respeito a corpos de prova compactados na umidade ótima $\left(W_{0}\right)$. 


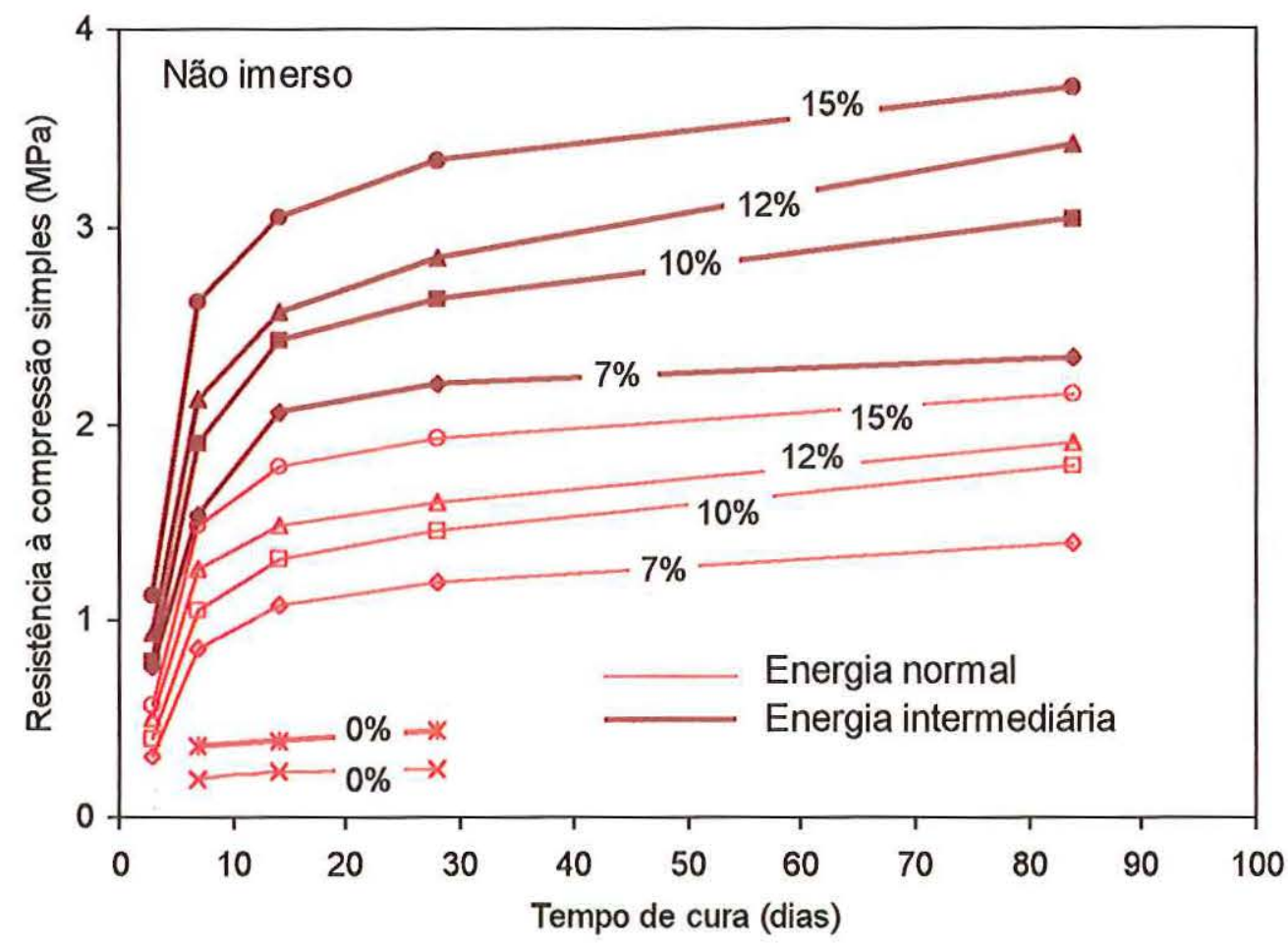

Figura 4.11:Resistência à compressão simples em função da energia de compactação, do tempo de cura e do teor de cimento para ensaio sem imersão prévia.

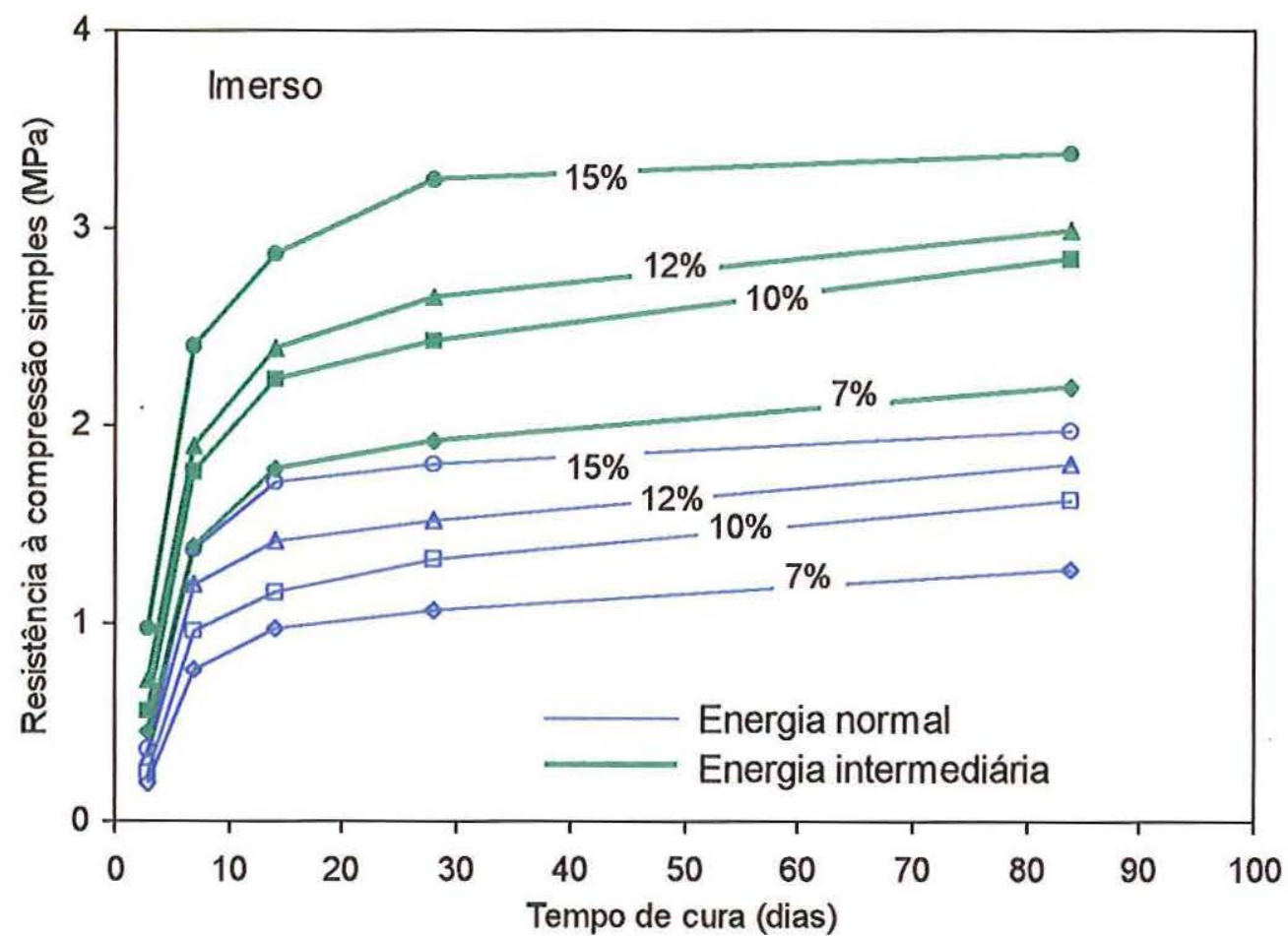

Figura 4.12: Resistência à compressão simples em função da energia de compactação, do tempo de cura e do teor de cimento para ensaio com imersão prévia. 


\subsubsection{Influência do teor de cimento}

A resistência à compressão simples para misturas com $100 \%$ de fosfogesso e $0 \%$ de cimento apresentaram, para ensaios sem imersão, valores bastante inferiores quando comparados às demais misturas. Já para os ensaios com imersão, ficou confirmada a instabilidade do fosfogesso dihidratado frente a ação da água. Os corpos de prova quando não se desmanchavam durante a imersão, não apresentaram resistência à compressão quando submetidos a carregamento.

Como mostram as Figuras 4.11 e 4.12 o aumento do teor de cimento nas misturas promove um aumento nos valores de resistência, concordando com o verificado em estudos já realizados com esse tipo de mistura (GREGORY et al. 1984, CHANG \& MANTELL 1990, TAHA et al. 1992, ONG et al. 1994). De forma geral, a resistência para as diferentes misturas, aumenta segundo um mesmo padrão com o crescimento do tempo de cura. As resistências para misturas com $10 \%$ de cimento são, em média, $25 \%$ maiores do que as resistências para misturas com $7 \%$ de cimento, independente do período de cura. As misturas com $12 \%$ e $15 \%$ de cimento são, em média, $39 \%$ e $64 \%$, respectivamente, maiores do que as resistências observadas para misturas com $7 \%$ de cimento. Essa constatação se repete para as duas energias de compactação e para as duas condições de ensaio.

As Figuras 4.13 e 4.14 mostram estes mesmos resultados de resistência à compressão simples em função do teor de cimento para os diversos períodos de cura rearranjados, respectivamente, para misturas compactadas com as energias normal e intermediária.

Nota-se nas Figuras 4.13 e 4.14, que a relação entre a resistência à compressão e o teor de cimento apresenta uma tendência de variação aproximadamente linear. Dessa forma poder-se ia, através de interpolação e 
extrapolação, estimar os teores de cimento necessários para se alcançar os valores de resistência citados anteriormente, 1,0 $\mathrm{MPa}$ e 2,1 $\mathrm{MPa}$, para as condições imersas e não imersas, e para 7 dias de cura. Para a energia normal, teores de cimento em torno de $9,0 \%$ e $23,0 \%$, para condição não imersa, conduzem, respectivamente, a valores de resistência iguais a 1,0 MPa e 2,1 MPa. Esses níveis de resistência são alcançados para teores de $10,0 \%$ e $24,0 \%$ de cimento na condição imersa. Para compactação na energia intermediária, os valores de resistência de 1,0 $\mathrm{MPa}$ e 2,1 $\mathrm{MPa}$ podem ser obtidos, respectivamente, para teores de cimento em torno $3,0 \%$ e $11,5 \%$, para condição não imersa, e 4,0\% e 13,0\%, para condição imersa.

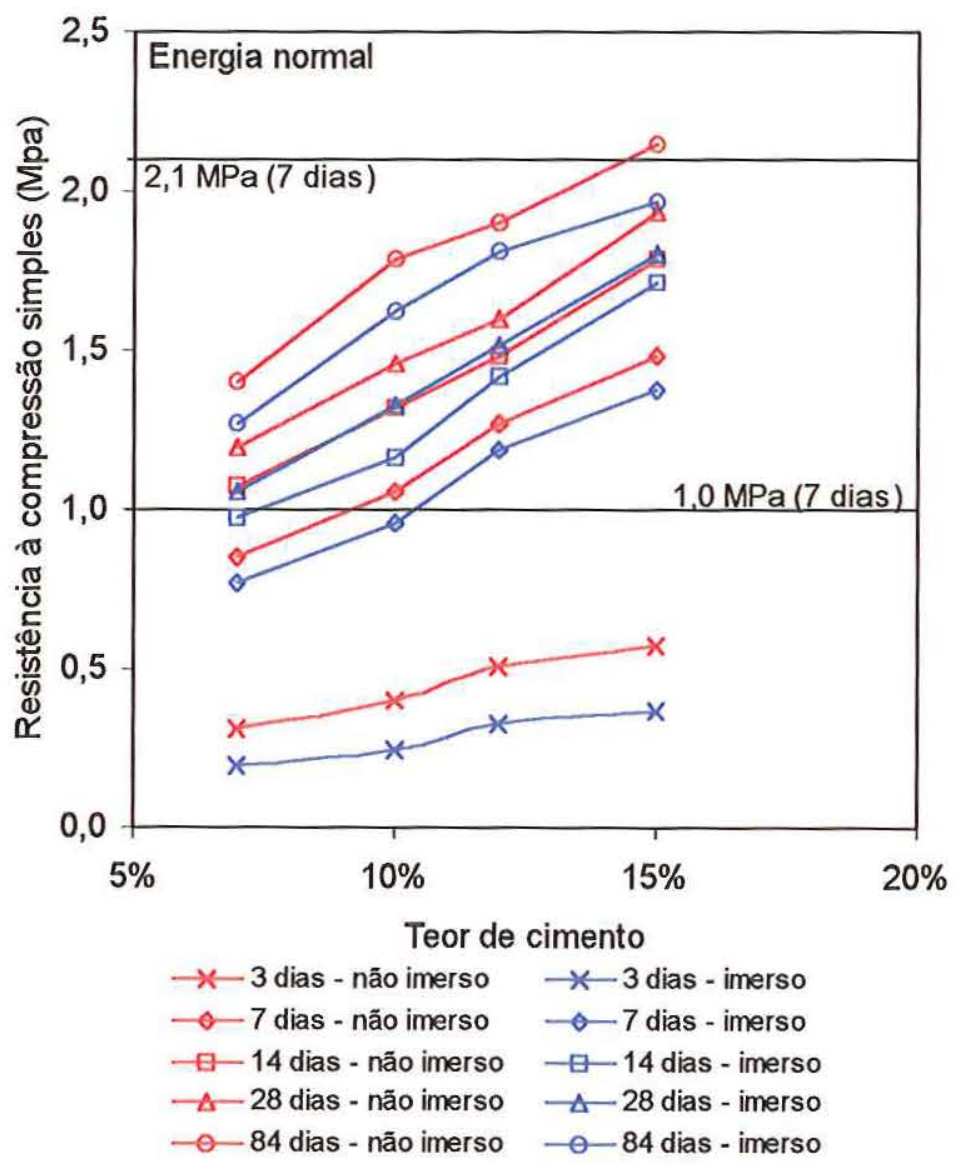

Figura 4.13: Resistência à compressão simples em função do teor de cimento para misturas compactadas na energia normal e ensaiadas em condições imersas e não imersas. 


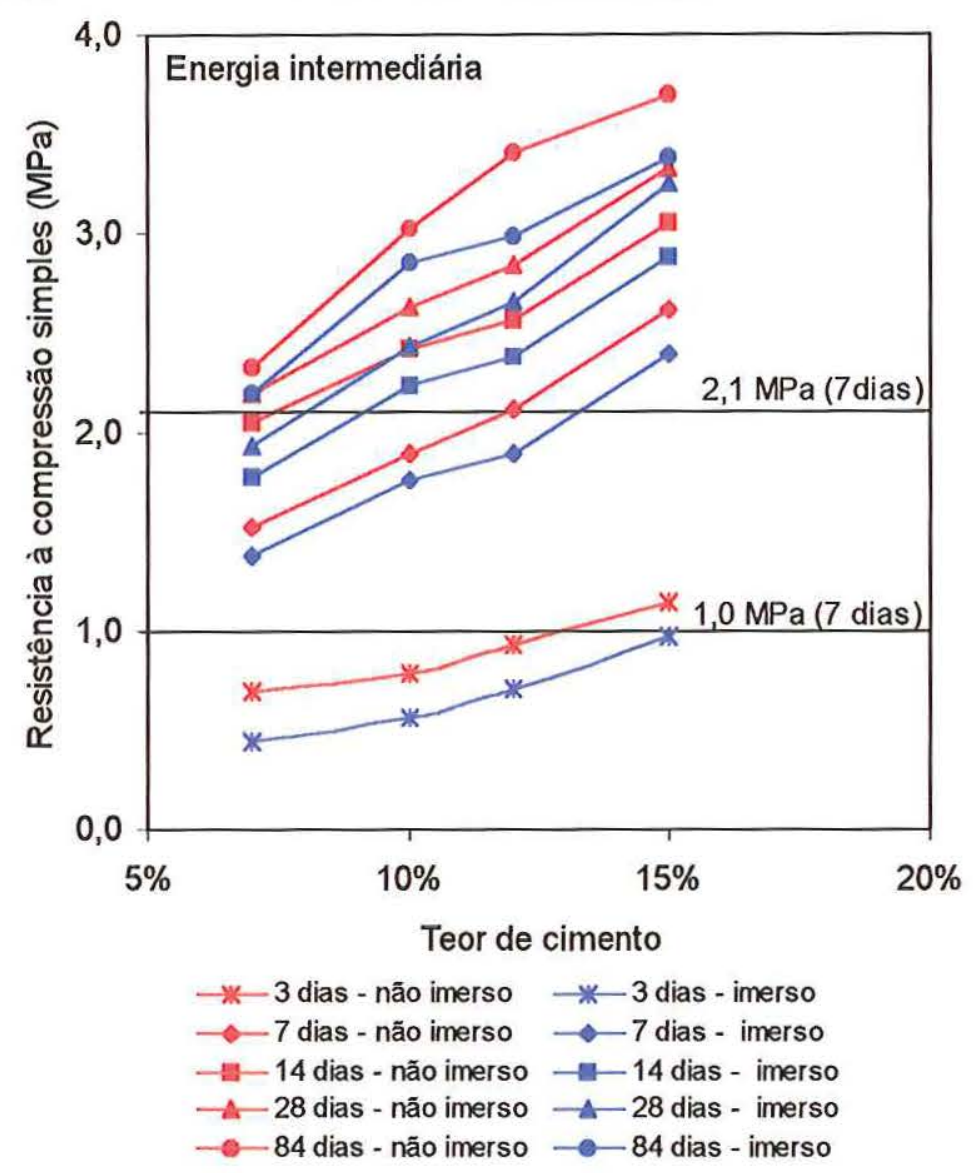

Figura 4.14: Resistência à compressão simples em função do teor de cimento para misturas compactadas na energia intermediária e ensaiadas em condições imersas e não imersas.

Conforme esperado, a adição do cimento ao fosfogesso foi eficiente para a estabilização do material, tornando as misturas assim constituídas, estáveis frente a ação da água e conferindo-Ihes resistências mais elevadas que aquelas oferecidas pelo fosfogesso puro.

\subsubsection{Influência do tempo de cura}

As Figuras 4.11 e 4.12 permitem ainda a análise do efeito do tempo de cura sobre a resistência à compressão das misturas. Como pode-se observar, os valores de resistência à compressão simples aumentam com o aumento no período de cura para todos os teores de cimento, para as duas energias de compactação e para as duas condições de ensaio. Observa-se um maior gradiente de crescimento da resistência no período até 14 dias. 
Nesse intervalo, as misturas, em média, alcançaram $79 \%$ da resistência obtida aos 84 dias. Aos 3 dias, as misturas alcançaram, em média, $27 \%$ da resistência aos 84 dias e aos 7 dias, alcançaram, em média, $65 \%$ da resistência aos 84 dias. Esse padrão está de acordo com observado por CHANG \& MANTELL (1990), que encontraram, para misturas de fosfogesso e cimento, um comportamento semelhante ao do concreto convencional.

\subsubsection{Inf́luência da energia de compactação}

A influência da energia de compactação sobre os valores de resistência à compressão simples pode ser analisada a partir das Figuras $4.11,4.12,4.13$ e 4.14. Para as duas condições de ensaio, imerso e não imerso, o aumento na energia de compactação promoveu um aumento na resistência à compressão para todas as misturas de fosfogesso e cimento, e para todos os períodos de cura, de conformidade com o já verificado em estudos anteriores (GREGORY et al. 1984, TAHA et al. 1992, ONG et al. 1994). No caso da presente pesquisa, esse aumento variou de $66 \%$ a $91 \%$. Observou-se que o aumento na energia de compactação foi mais efetivo no ganho de resistência para menores teores de cimento, $7 \%$ e $10 \%$, quando elevou em $80 \%$ os valores de resistência. Para teores de $12 \%$ e $15 \%$ de cimento esse crescimento foi da ordem de $70 \%$.

As Figuras 4.15 e 4.16 apresentam os resultados de resistência à compressão simples das misturas de fosfogesso e cimento separados em função da energia de compactação. Conforme observa-se na Figura 4.16, apenas as misturas contendo acima de $12 \%$ de cimento compactadas na energia intermediária satisfazem o limite estabelecido pela norma de solocimento, 2,1 $\mathrm{MPa}$ aos 7 dias. Em contrapartida, misturas contendo acima de $10 \%$ de cimento compactadas na energia normal, conforme mostra a Figura 4.15, e todas as misturas compactadas na energia intermediária satisfazem a condição de 1,0 MPa, menor valor de resistência encontrado em pavimentos brasileiros executados com solo-cimento. 


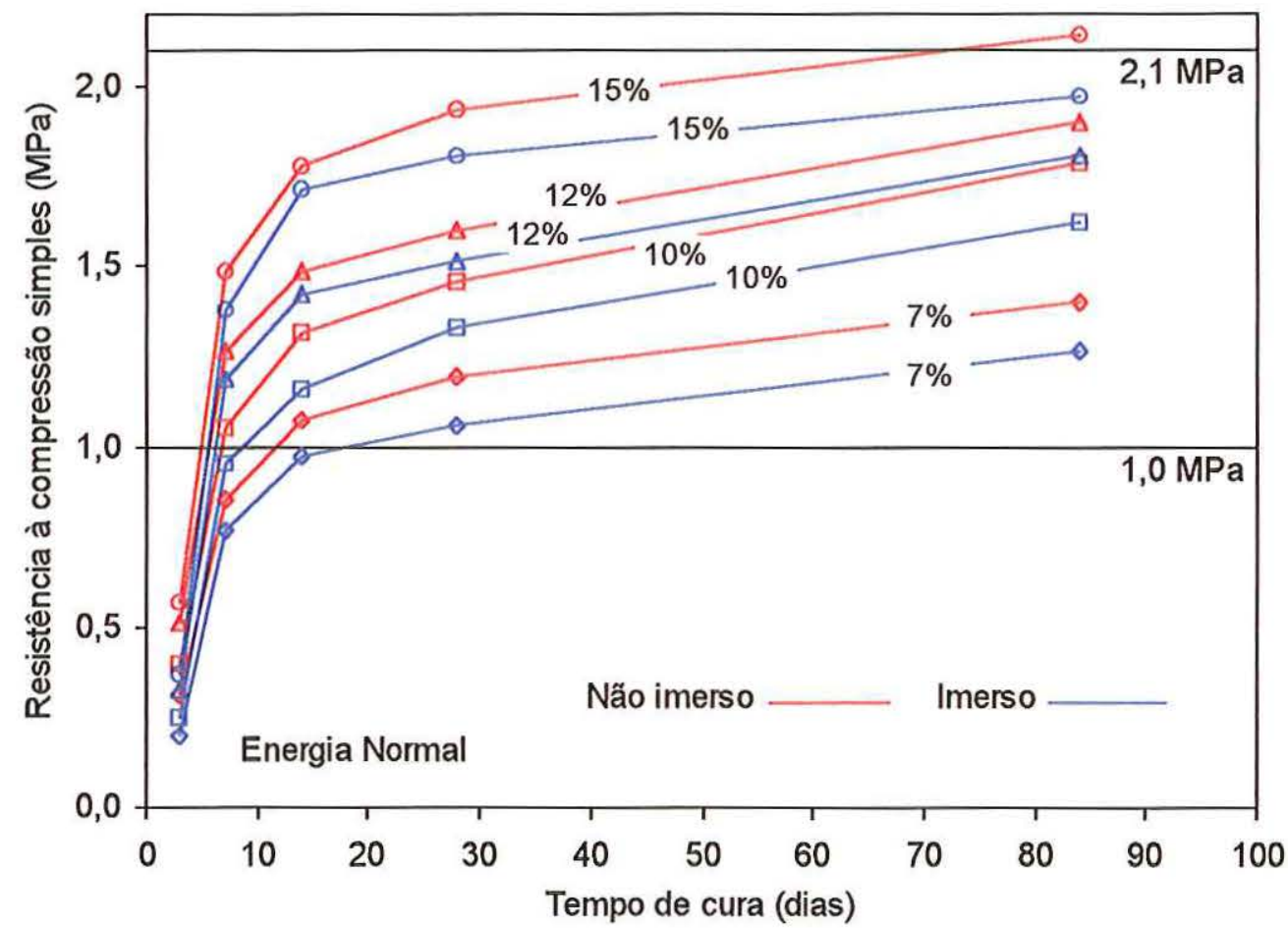

Figura 4.15:Resistência à compressão simples em função do tempo de cura, do teor de cimento e da condição de ensaio para misturas compactadas na energia normal.

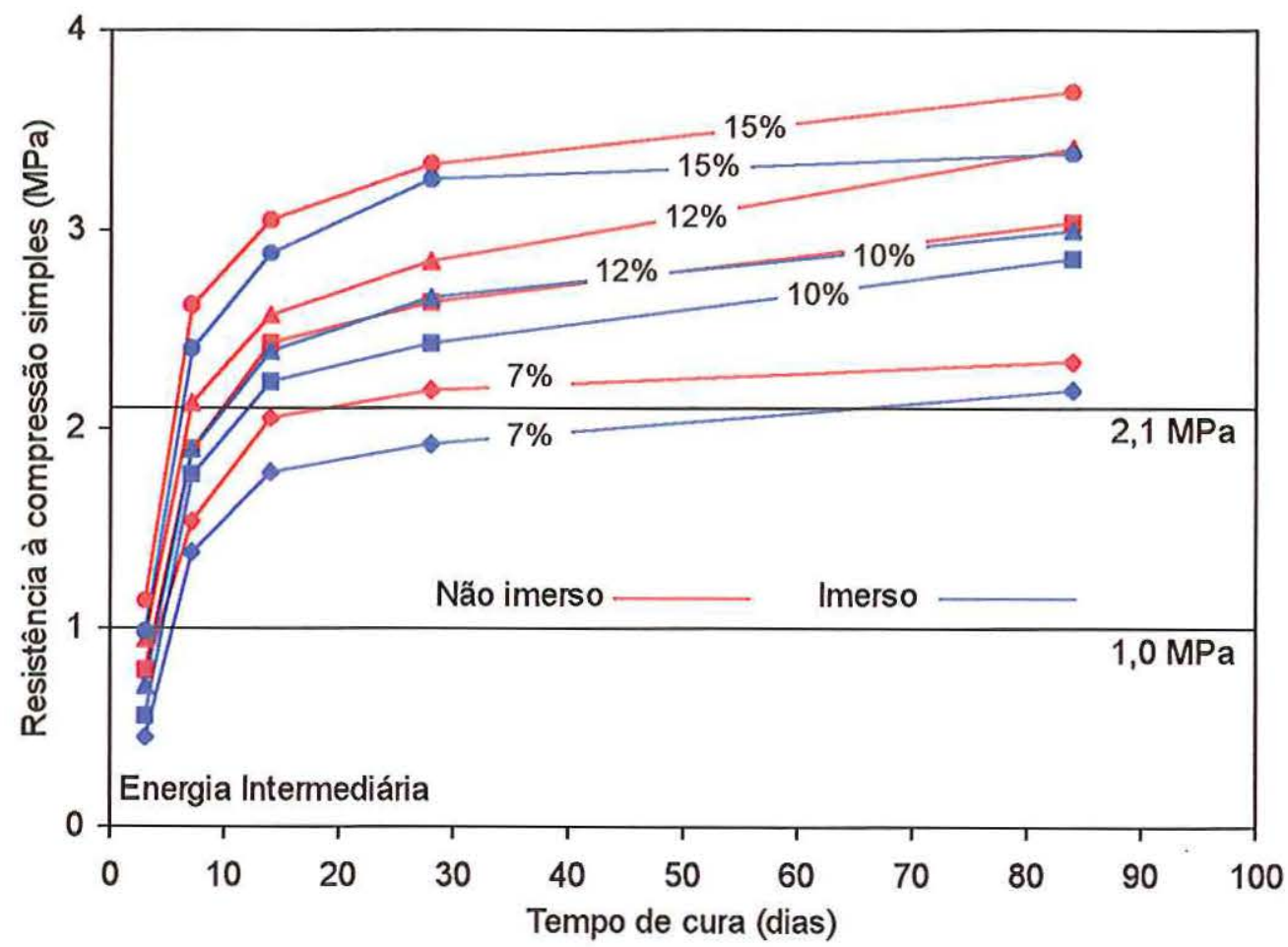

Figura 4.16: Resistência à compressão simples em função do tempo de cura, do teor de cimento e da condição de ensaio para misturas compactadas na energia intermediária. 


\subsubsection{Inf́luência da condição de ensaio: sem imersão e após imersão}

Ao se analisar os efeitos da imersão em água sobre a resistência à compressão simples verifica-se que os corpos de prova ensaiados após a imersão apresentam menor resistência que os corpos de prova ensaiados sem imersão prévia. Em média, as resistências imersas são $8 \%$ menores do que as resistências não imersas, independente do teor de cimento e do tempo de cura. As Figuras 4.15 e 4.16 ilustram essa situação.

\subsubsection{Influência da umidade de compactação}

Para o estudo da influência da variação da umidade de compactação sobre a resistência à compressão foram selecionados 2 teores de cimento para cada energia de compactação. $\mathrm{Na}$ compactação com energia normal utilizaram-se misturas contendo $10 \%$ e $15 \%$ de cimento e, para misturas compactadas na energia intermediária utilizaram-se misturas com $7 \%$ e $10 \%$ de cimento. Além da umidade ótima, foram ensaiados corpos de prova compactados nos ramos seco e úmido $\left(\mathrm{w}_{0} \pm 2 \%\right)$.

As Figuras 4.17, 4.18, 4.19 e 4.20 mostram a variação da resistência à compressão simples em função da umidade. Apresentam-se nessas Figuras os valores de resistência à compressão para misturas compostas com $7 \%, 10 \%$ e $15 \%$ de cimento, compactadas na umidade ótima $\left(w_{0}\right)$ e nas umidades $w_{0} \pm 2 \%$ com as energias normal e intermediária, submetidas a períodos de cura de 7, 28 e 84 dias e ensaiadas sob condições imersas e não imersas.

Verificou-se que a resistência à compressão simples não sofre uma influência significativa da umidade de compactação, variando pouco para teores em torno da umidade ótima, concordando com o observado por ONG et al. (1994). 


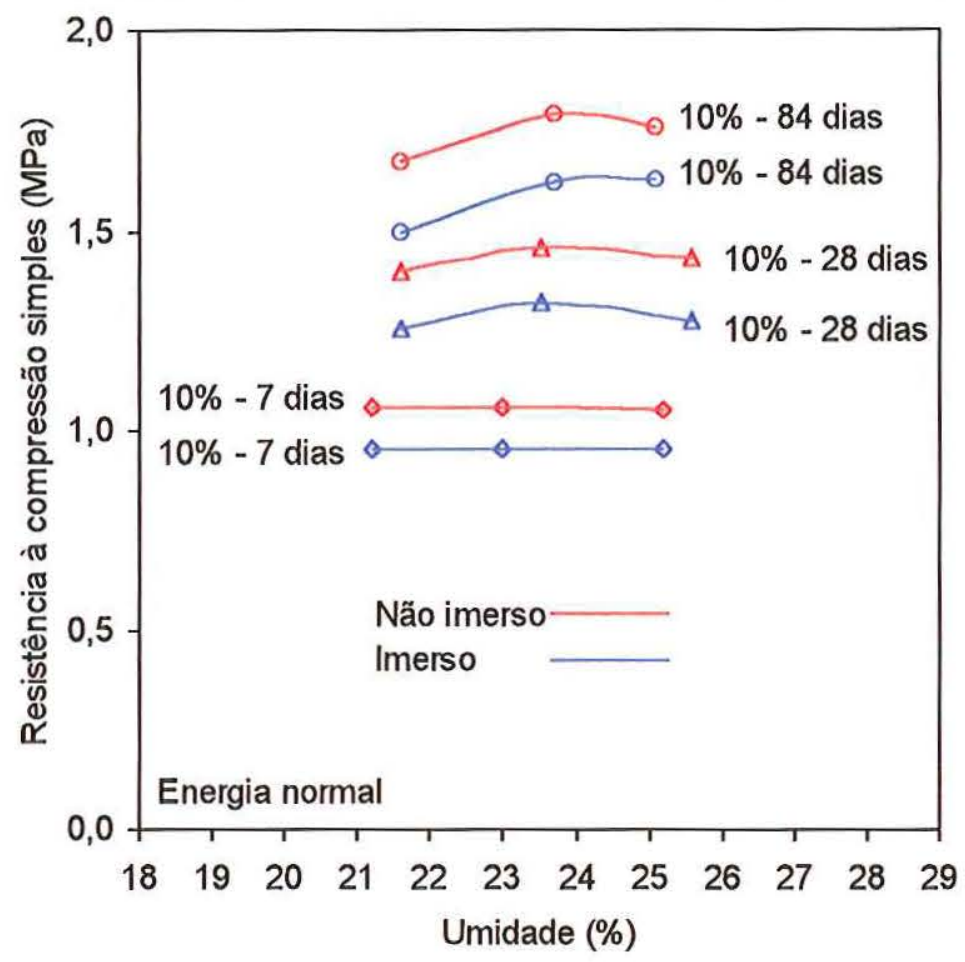

Figura 4.17: Resistência à compressão simples em função da umidade de compactação para misturas com $10 \%$ de cimento, submetidas a períodos de cura de 7, 28 e 84 dias, ensaiadas em condições imersas e não imersas e compactadas na energia normal.

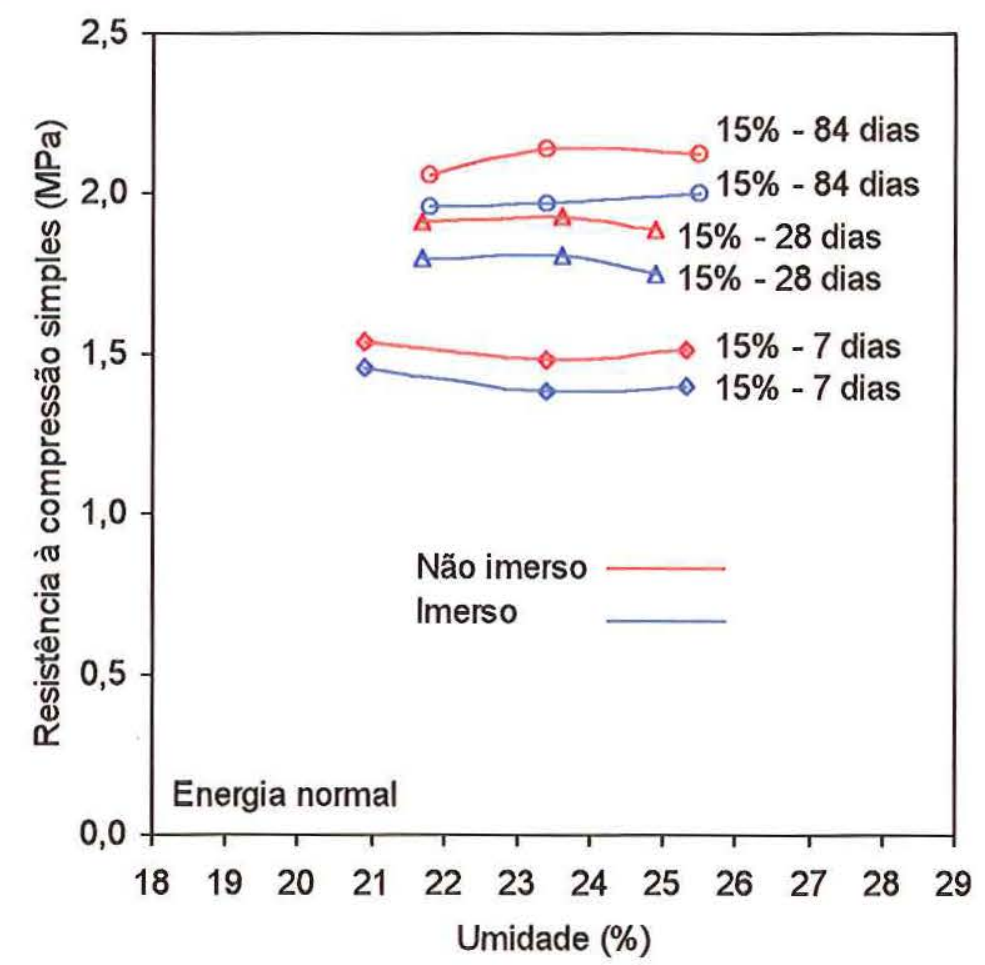

Figura 4.18: Resistência à compressão simples em função da umidade de compactação para misturas com $15 \%$ de cimento, submetidas a períodos de cura de 7, 28 e 84 dias, ensaiadas em condições imersas e não imersas e compactadas na energia normal. 


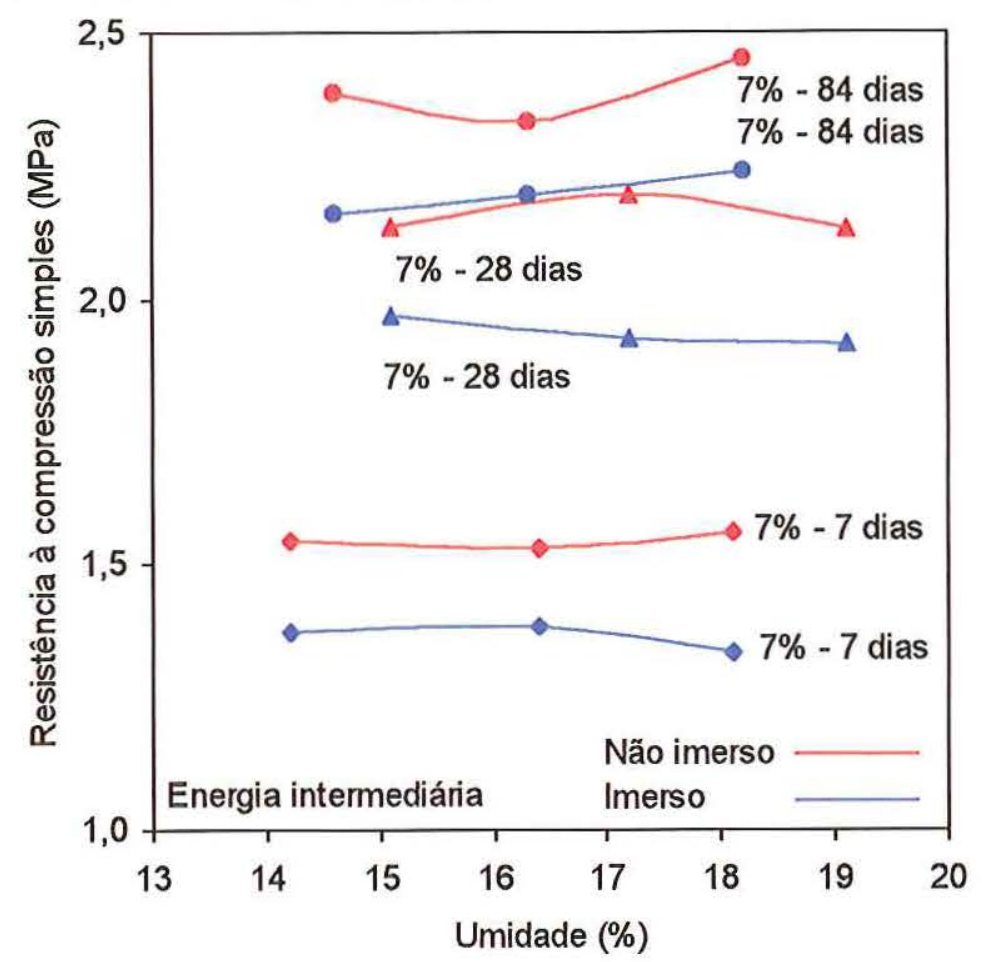

Figura 4.19: Resistência à compressão simples em função da umidade de compactação para misturas com $7 \%$ de cimento, submetidas a períodos de cura de 7, 28 e 84 dias, ensaiadas em condições imersas e não imersas e compactadas na energia intermediária.

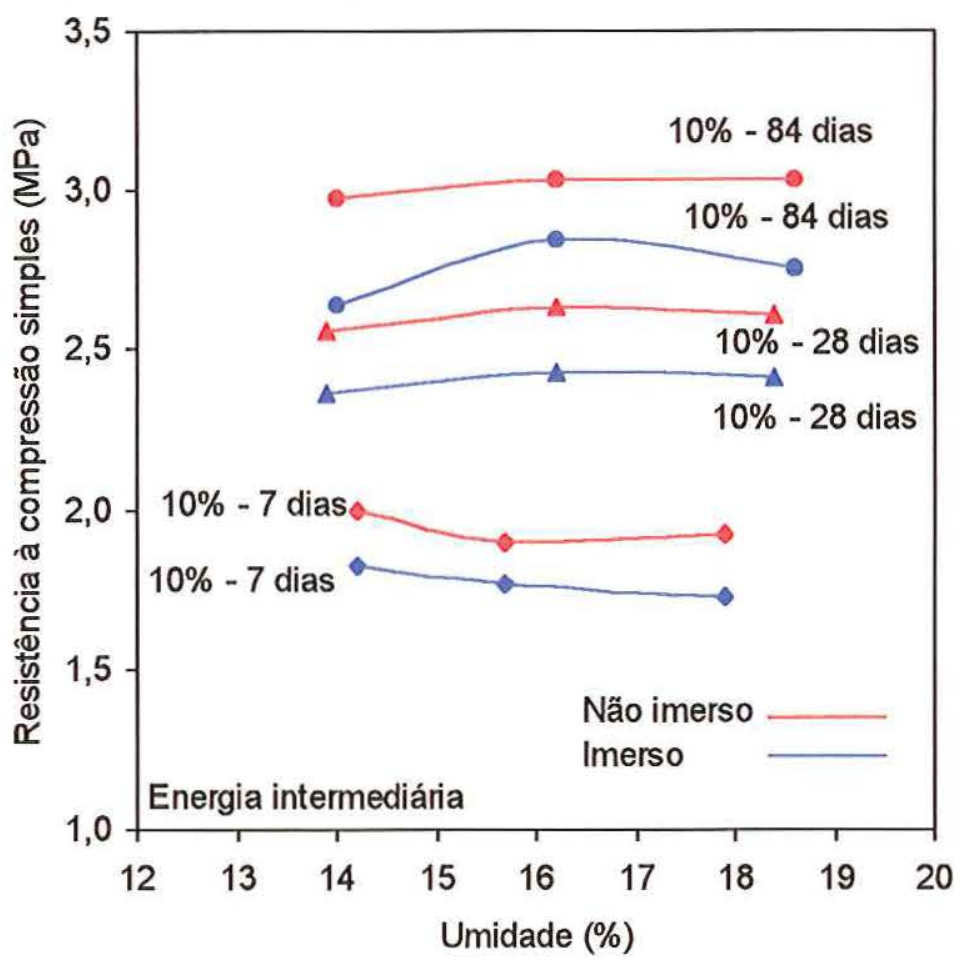

Figura 4.20: Resistência à compressão simples em função da umidade de compactação para misturas com $10 \%$ de cimento, submetidas a períodos de cura de 7, 28 e 84 dias, ensaiadas em condições imersas e não imersas e compactadas na energia intermediária. 
Não foi possível estabelecer um padrão único que traduzisse 0 comportamento da resistência em função da variação da umidade de compactação: desvios de umidade com relação à umidade ótima, positivos ou negativos, ora conduziam a resistências maiores e ora, a resistências menores que às observadas para a umidade ótima.

\subsubsection{Deformabilidade determinada através de ensaios de compressão simples para o fosfogesso B}

A realização dos ensaios de compressão simples em prensa com aquisição automática de dados permitiu a construção das curvas tensão $\mathrm{x}$ deformação, exemplificadas pela Figura 4.21, para todos os corpos de prova ensaiados, possibilitando o estudo das características de deformabilidade das misturas. Esse estudo é feito através da análise da variação do módulo tangente inicial (Eo) obtido a partir das referidas curvas, que, conforme mostram alguns estudos (RUIZ, 1963 e DRUMM et al., 1990), guarda uma estreita relação com o módulo dinâmico.

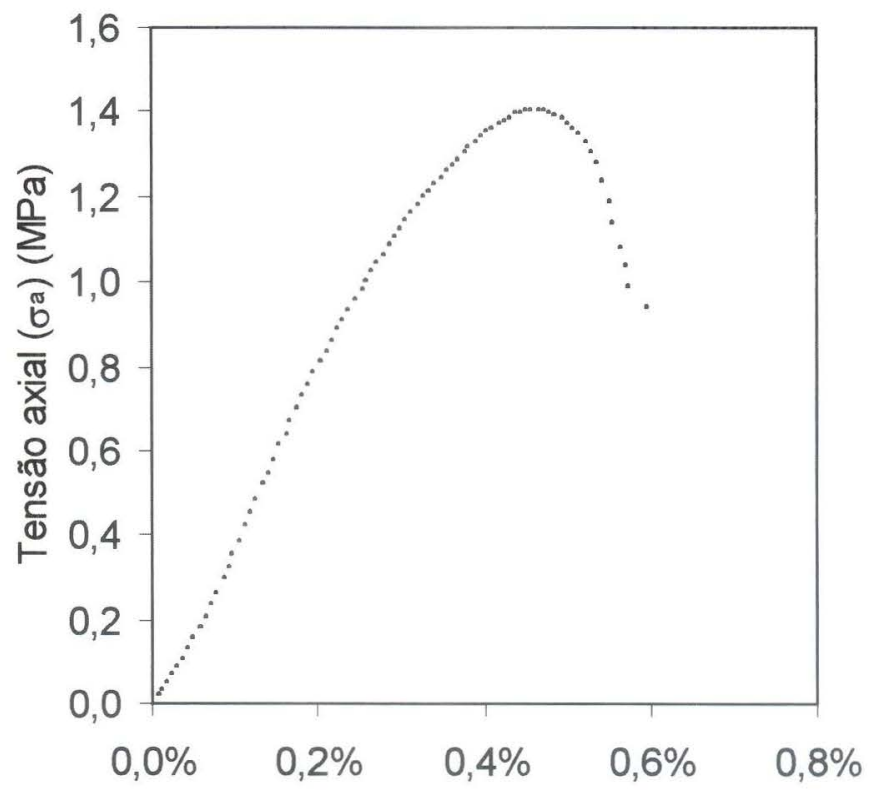

Deformação específica $\left(\varepsilon_{\mathrm{a}}\right)$

Figura 4.21: Exemplo de uma curva $x$ tensão deformação, correspondendo ao corpo de prova 5 , com $7 \%$ de cimento, compactado na $w_{0}$ com energia equivalente ao Proctor intermediário, submetido a 7 dias de cura e ensaiado após imersão prévia em água. 
Conforme exposto no Capítulo 3, item 3.5.1, foi usado o procedimento proposto por DUNCAN \& CHANG (1970) para cálculo do módulo tangente inicial, que supõe a curva tensão $x$ deformação como uma hipérbole, conforme descrita pela equação 3.1 , e apresentada a seguir.

$$
\frac{\varepsilon_{\mathrm{a}}}{\sigma_{\mathrm{a}}}=\mathrm{a}+\mathrm{b} \cdot \varepsilon_{\mathrm{a}}
$$

onde:

$\varepsilon_{\mathrm{a}}$ - deformação axial;

$\sigma_{\mathrm{a}}$ - tensão axial;

a e b-coeficientes de regressão considerando a reta que melhor se ajusta aos resultados experimentais.

Desta forma, o módulo tangente inicial $(E o)$ será: Eo $=\frac{1}{a}$

A determinação do coeficiente a é feita através da reta que melhor se ajusta aos resultados experimentais, para tal, lança-se em gráfico os valores de deformação axial $\left(\varepsilon_{a}\right)$ nas abcissas, e os valores da relação entre deformação axial e tensão axial $\left(\frac{\varepsilon_{\mathrm{a}}}{\sigma_{\mathrm{a}}}\right)$ nas ordenadas, conforme exemplifica a Figura 4.22 .

A Figura 4.22 mostra a reta de ajuste dos resultados experimentais do ensaio de compressão simples apresentado na Figura 4.21, juntamente com o respectivo valor do parâmetro a e o módulo tangente inicial correspondente ao corpo de prova ensaiado.

Vale ressaltar que devem ser descartados os pontos iniciais da curva tensão $x$ deformação, devido à imprecisão existente na sua determinação, e também os pontos anteriores à ruptura do corpo de prova. Os pontos a serem descartados foram identificados visualmente, através de gráficos 
como o exemplificado pela Figura 4.22. Do trecho selecionado, via de regra o mais retilíneo, determina-se o intercepto, através de regressão linear, que corresponde ao coeficiente a. No caso em questão, o valor determinado de a foi 0,002076 , portanto o valor de Eo calculado é 481,70 MPa.

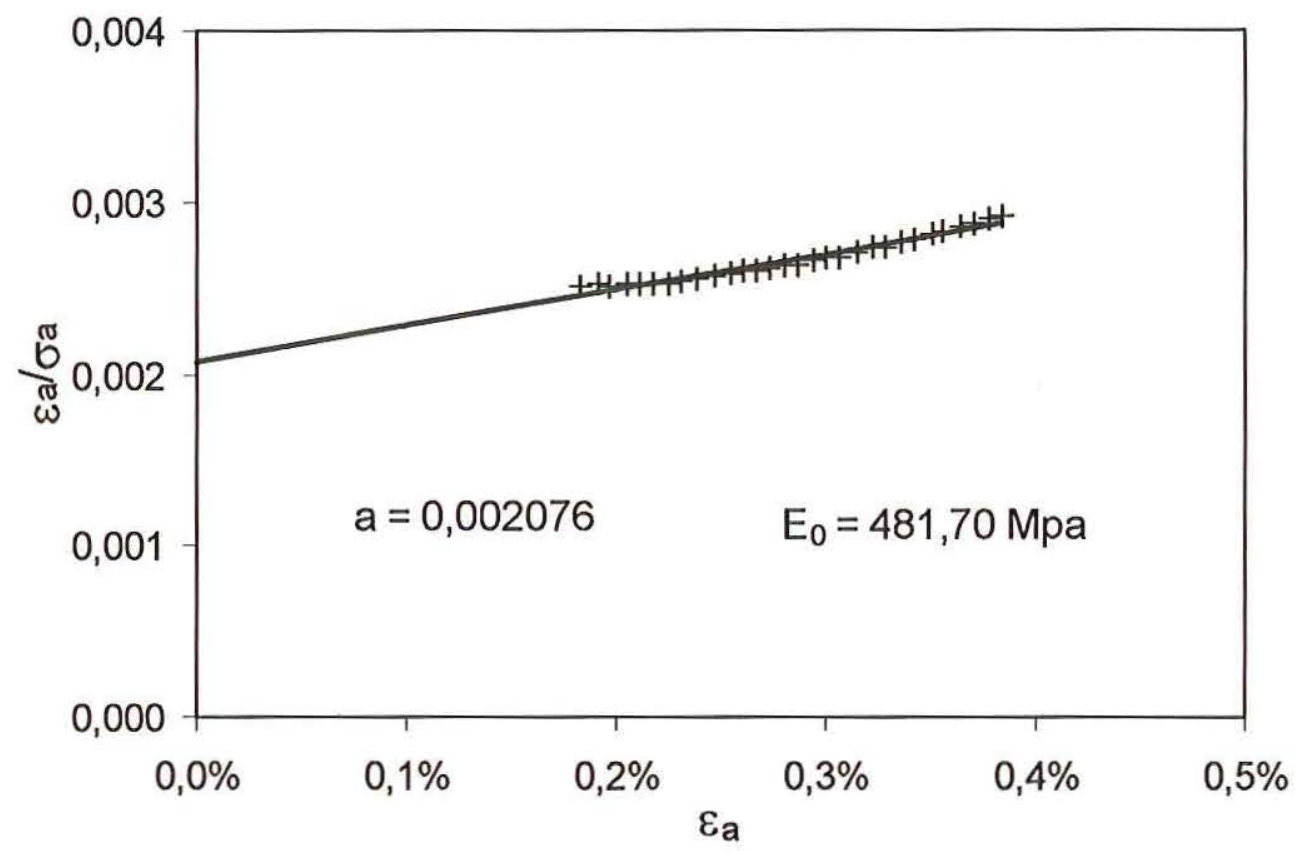

Figura 4.22: Exemplo de determinação do coeficiente a para cálculo do $E_{0}$. Determinada a partir dos resultados apresentados na Figura 4.21

Foram analisadas a influência do teor de cimento, do tempo de cura, da energia de compactação, da condição de ensaio e da umidade de compactação sobre os valores do módulo tangente inicial (Eo). É importante ressaltar que o período de cura de 3 dias não foi incluído nesta análise, visto que os ensaios correspondentes foram realizados numa prensa que não dispõe de aquisição automática de dados. Essa prensa foi a mesma usada na etapa preliminar de estudos (Figura 3.3).

No Anexo C, Tabelas de C.1 a C.4, são apresentados os valores de Eo encontrados. Todos os gráficos baseados no módulo tangente inicial foram construídos com os valores apresentados na Tabela C.1. 


\subsubsection{Influência do teor de cimento}

De forma semelhante ao observado para a resistência à compressão simples, a variação do módulo tangente inicial com o crescimento do teor de cimento é positiva e aproximadamente linear.

As Figuras 4.23 e 4.24 mostram, respectivamente, os valores de módulo tangente inicial em função do teor de cimento para as energias normal e intermediária de compactação. Cada um dos valores apresentados é resultado da média de três valores, obtidos através de três diferentes corpos de prova compactados na umidade ótima $\left(w_{0}\right)$.

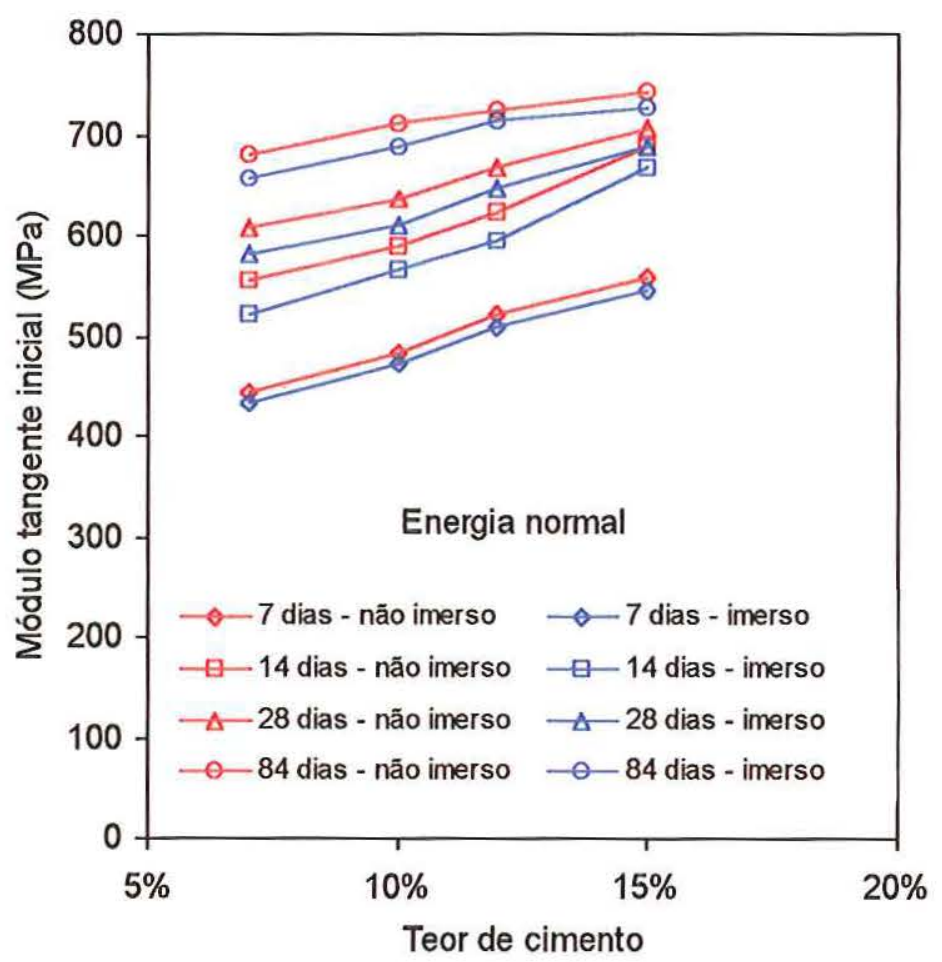

Figura 4.23: Módulo tangente inicial em função do teor de cimento para misturas compactadas na energia normal e ensaiadas em condições imersas e não imersas. 


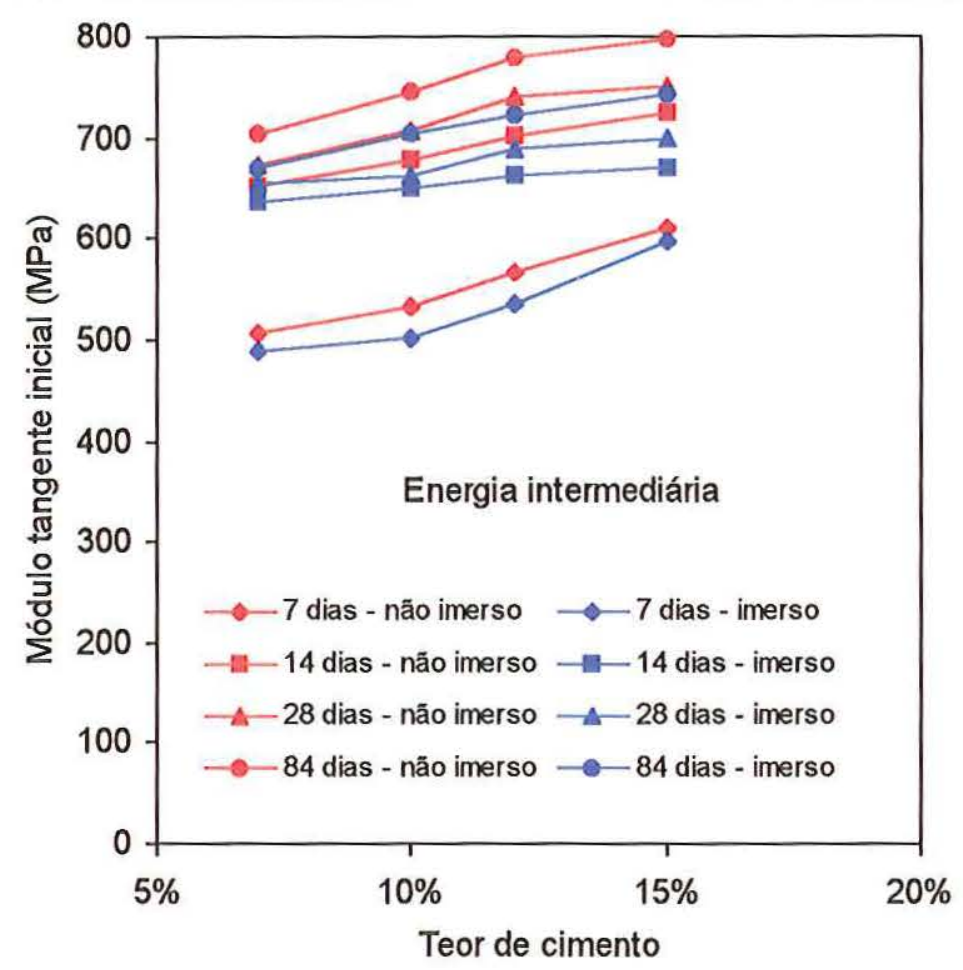

Figura 4.24: Módulo tangente inicial em função do teor de cimento para misturas compactadas na energia intermediária e ensaiadas em condições imersas e não imersas.

\subsubsection{Inf́luência do tempo de cura}

As Figuras 4.25, 4.26, 4.27 e 4.28 permitem a análise do efeito do tempo de cura sobre o módulo tangente inicial. Como pode-se observar, os valores de Eo aumentam com o aumento do período de cura. Essa situação verifica-se para todos os teores de cimento, para as duas energias de compactação e para as duas condições de ensaio.

Da mesma forma que o observado para a resistência à compressão simples, constata-se também um maior gradiente de crescimento do Eo no período até 14 dias.

$\mathrm{Na}$ compactação com a energia normal, aos 7 dias as misturas alcançaram em média $70 \%$ do Eo aos 84 dias, e aos 14 dias as misturas, em média, alcançaram $85 \%$ do Eo obtido aos 84 dias. Para compactação na 
energia intermediária, aos 7 dias as misturas alcançaram em média $74 \%$ do Eo obtido aos 84dias, e aos 14 dias alcançaram $92 \%$ do Eo aos 84 dias.

Analisando-se também as Figuras 4.25 e 4.26 , fica evidente que 0 gradiente de ganho de resistência com o tempo de cura após 14 dias é maior para a energia normal do que para a energia intermediária, principalmente para corpos de prova ensaiados após imersão. Assim, nesta condição de ensaio e após 84 dias de cura, estas duas energias conduzem a valores de Eo muito próximos.

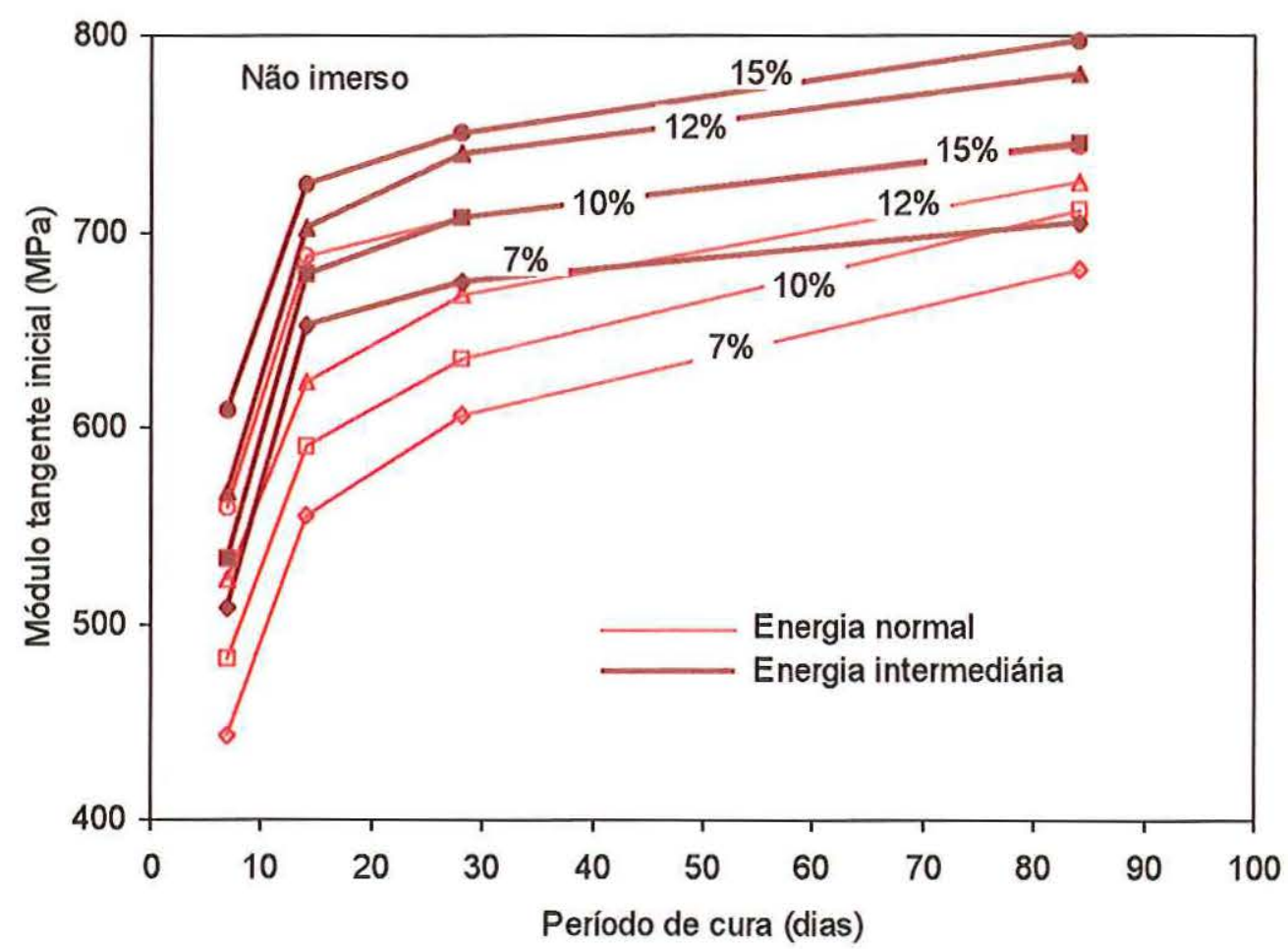

Figura 4.25: Módulo tangente inicial em função da energia de compactação, do tempo de cura e do teor de cimento para ensaio sem imersão prévia. 


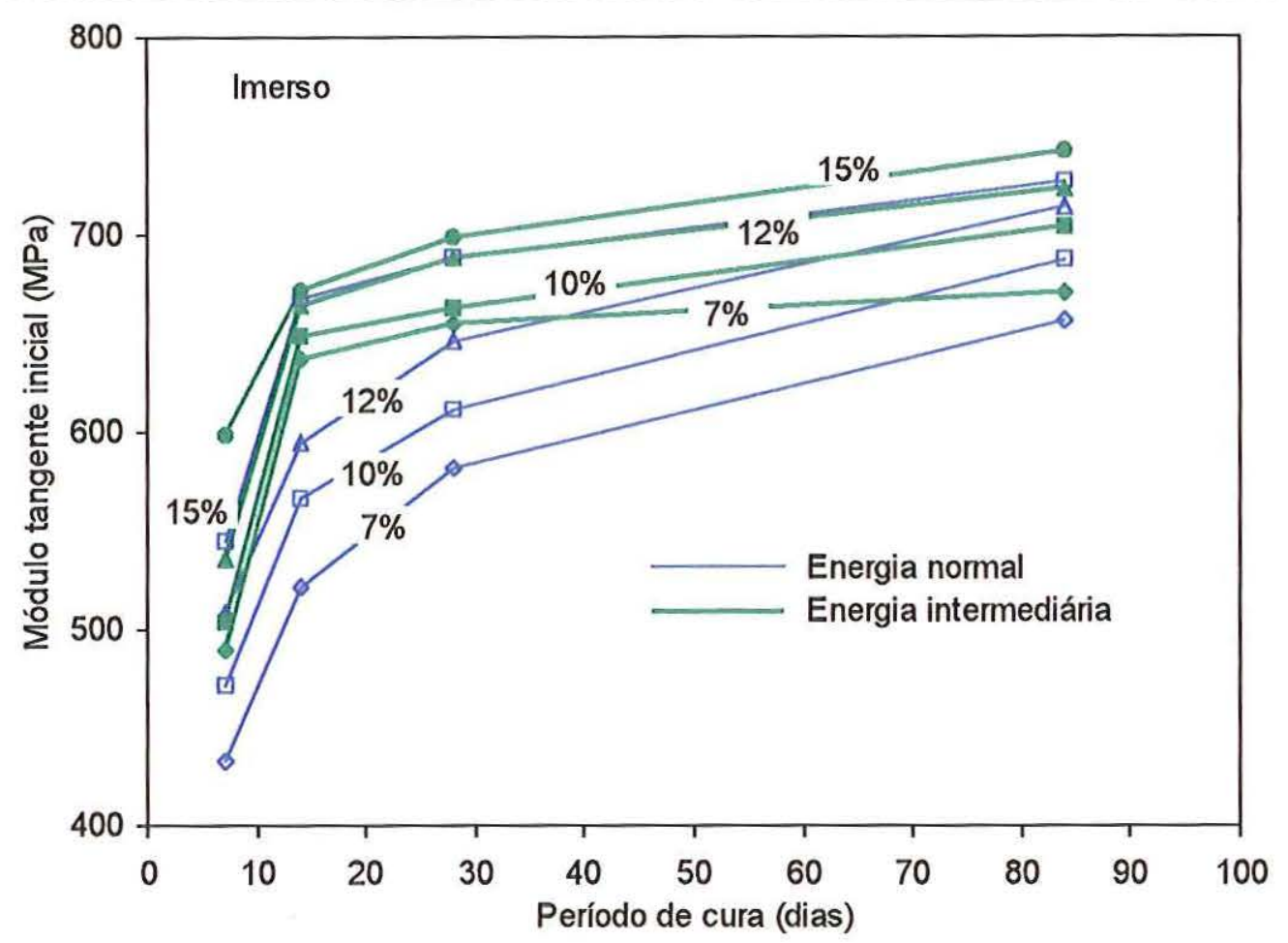

Figura 4.26: Módulo tangente inicial em função da energia de compactação, do tempo de cura e do teor de cimento para ensaio com imersão prévia.

\subsubsection{Influência da energia de compactação}

A influência da energia de compactação sobre módulo tangente inicial pode ser observada pelas Figuras 4.25 e 4.26. Para as duas condições de ensaio, imerso e não imerso, o aumento na energia de compactação promoveu um aumento no Eo para todas as misturas de fosfogesso e cimento e para todos os períodos de cura. Entretanto, esse aumento não foi tão significativo quanto o observado para a resistência à compressão simples, variando de $4 \%$ a $17 \%$, enquanto a resistência varia de $66 \%$ a $91 \%$.

\subsubsection{Influência da condição de ensaio}

Os valores de módulo tangente inicial obtidos para corpos de prova ensaiados após imersão foram menores que os obtidos para corpos de prova ensaiados sem imersão prévia. A redução nos valores de Eo variou em função da energia de compactação: para energia normal os valores de 
Eo foram, em média, 3,2\% menores do que os valores de Eo em condições não imersas; já para a energia intermediária, os valores são, em média, $5,2 \%$ menores. Comparando-se com a queda de resistência frente a imersão, o efeito da água é menos sensível no caso da deformabilidade, visto que a resistência diminui, em média $8,0 \%$ para as duas energias de compactação. As Figuras 4.27 e 4.28 ilustram essa situação para os corpos de prova compactados na umidade ótima $\left(\mathrm{W}_{0}\right)$.

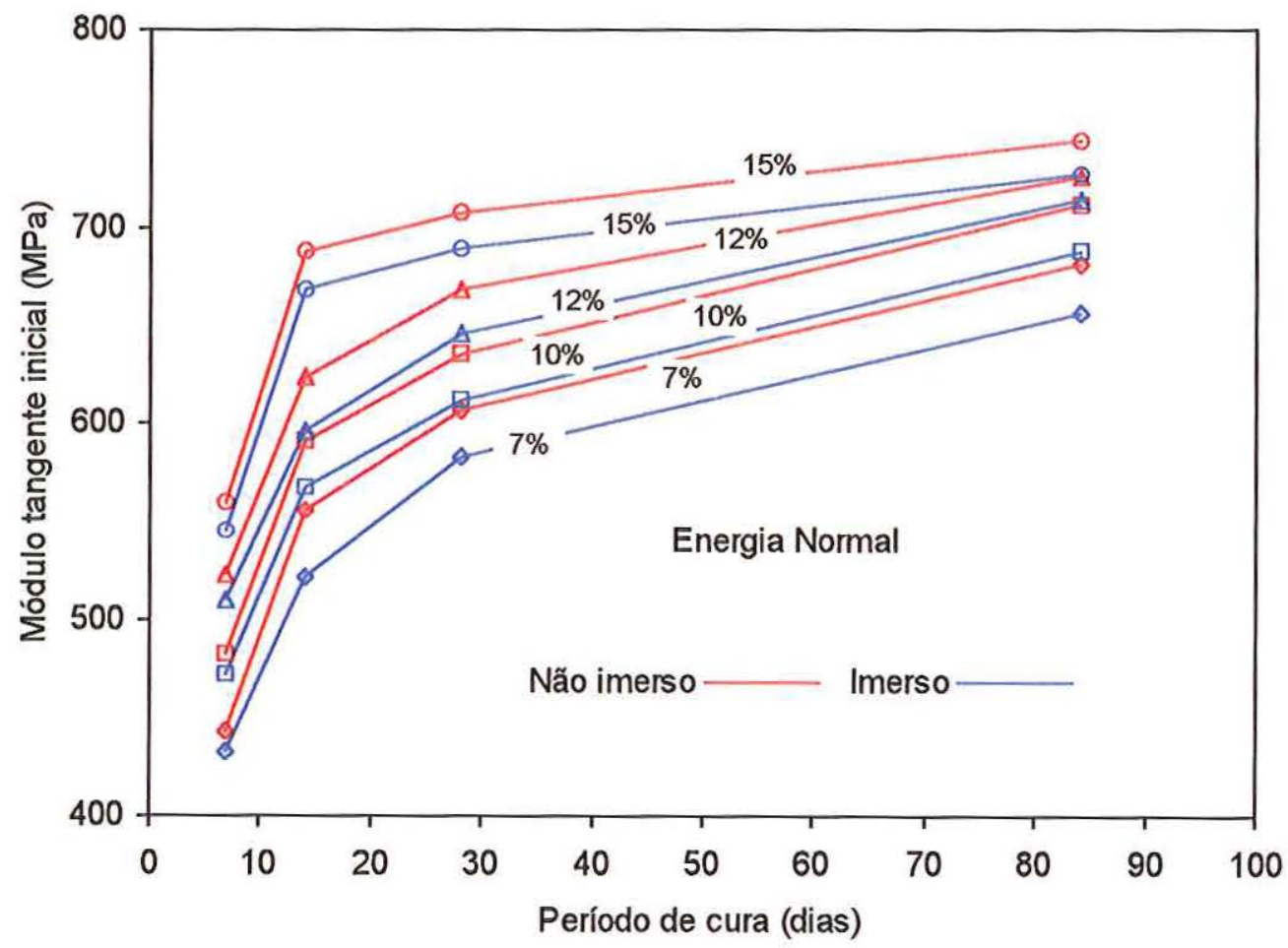

Figura 4.27: Módulo tangente inicial em função do tempo de cura, do teor de cimento e da condição de ensaio para misturas compactadas na energia normal. 


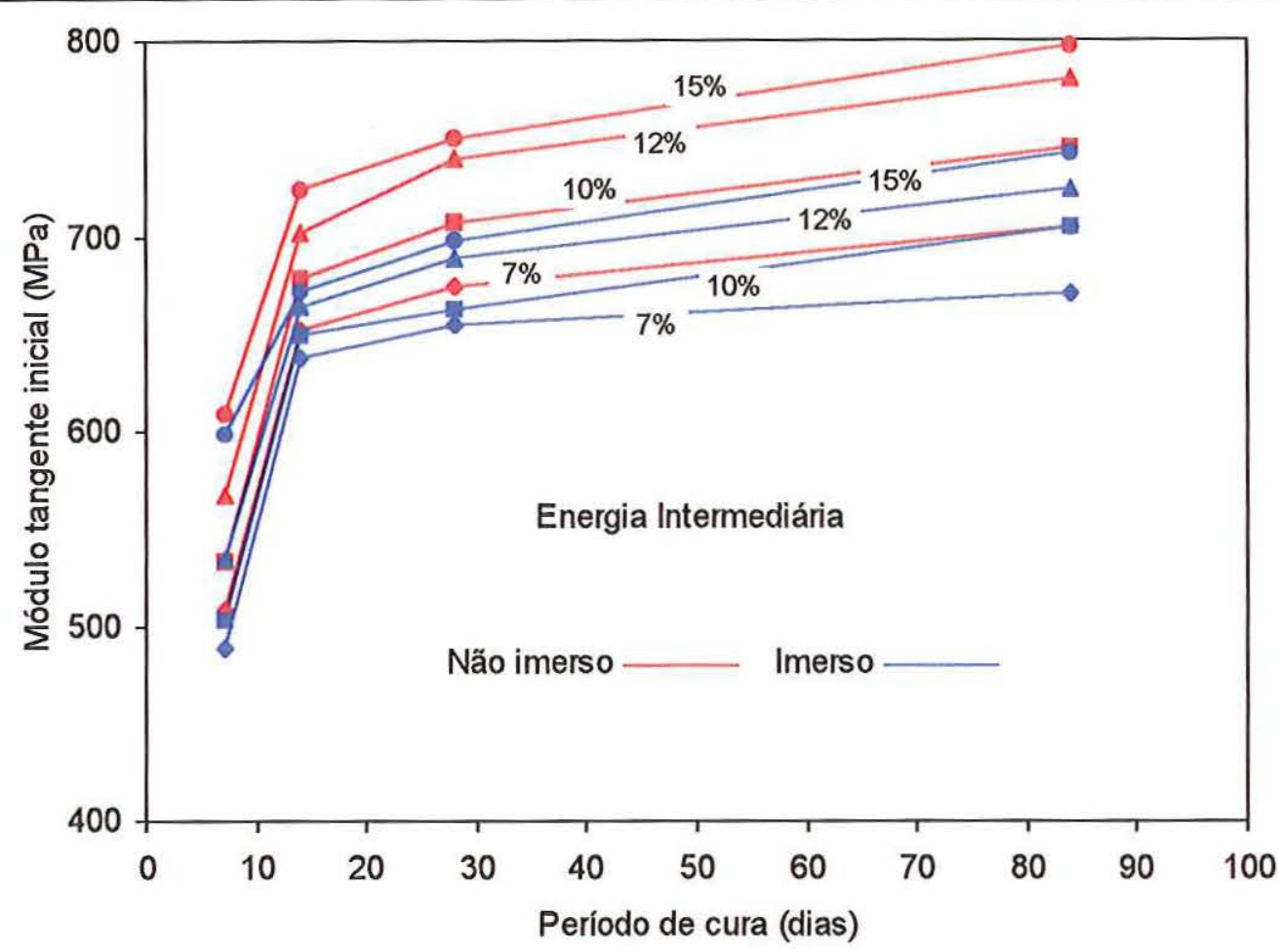

Figura 4.28: Módulo tangente inicial em função do tempo de cura, do teor de cimento e da condição de ensaio para misturas compactadas na energia intermediária.

\subsubsection{Inf́luência da umidade de compactação}

Foram considerados nesse estudo as mesmas condições do estudo realizado para resistência à compressão simples, ou seja, foram selecionados 2 teores de cimento para cada energia de compactação. Para compactação na energia normal, utilizaram-se misturas contendo $10 \%$ e $15 \%$ de cimento e, para misturas compactadas na energia intermediária, utilizaram-se misturas com $7 \%$ e $10 \%$ de cimento.

As Figuras 4.29, 4.30, 4.31 e 4.32 ilustram a variação do módulo tangente inicial em função da umidade de compactação. Apresentam-se nessas Figuras os valores de Eo para misturas compostas com 7\%, $10 \%$ e $15 \%$ de cimento, compactadas nas energias normal e intermediária para teores de umidade iguais a $w_{0}$ e $w_{0} \pm 2$, submetidas a períodos de cura de 7 , 28 e 84 dias, e ensaiadas sob condições imersas e não imersas. 


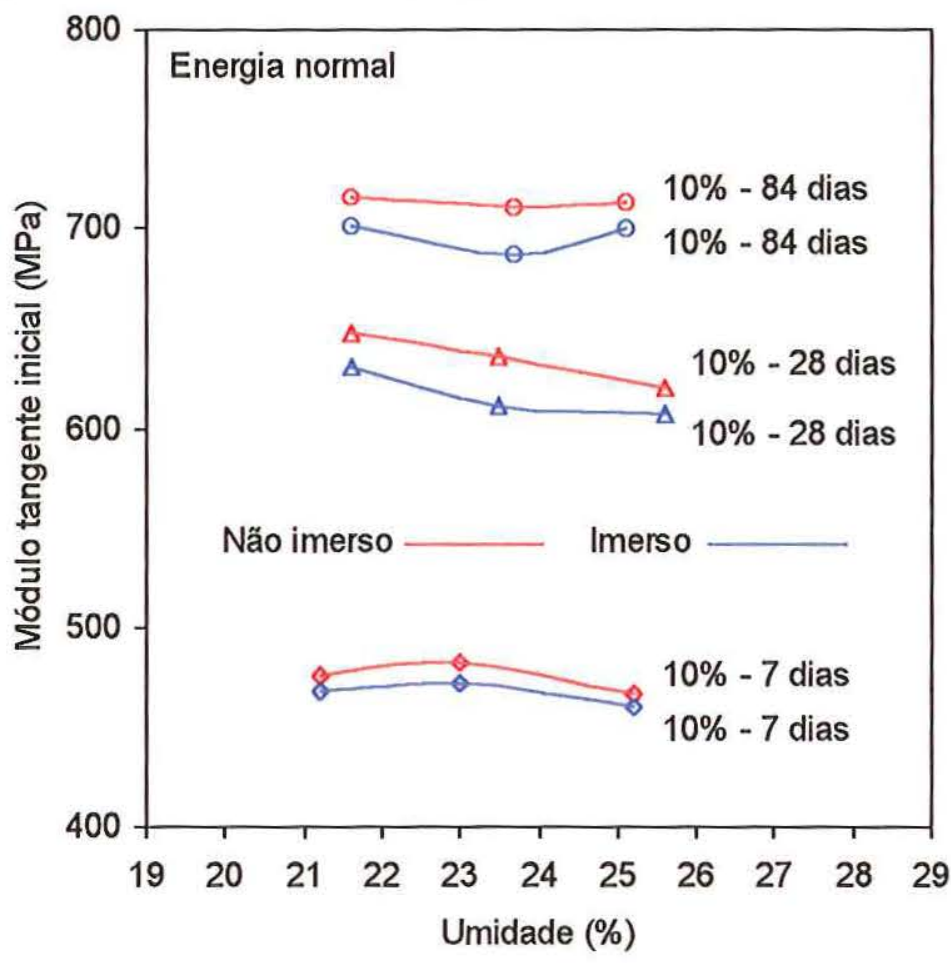

Figura 4.29: Módulo tangente inicial em função da umidade de compactação para misturas com $10 \%$ de cimento, submetidas a períodos de cura de 7,28 e 84 dias, ensaiadas em condições imersas e não imersas, e compactadas na energia normal.

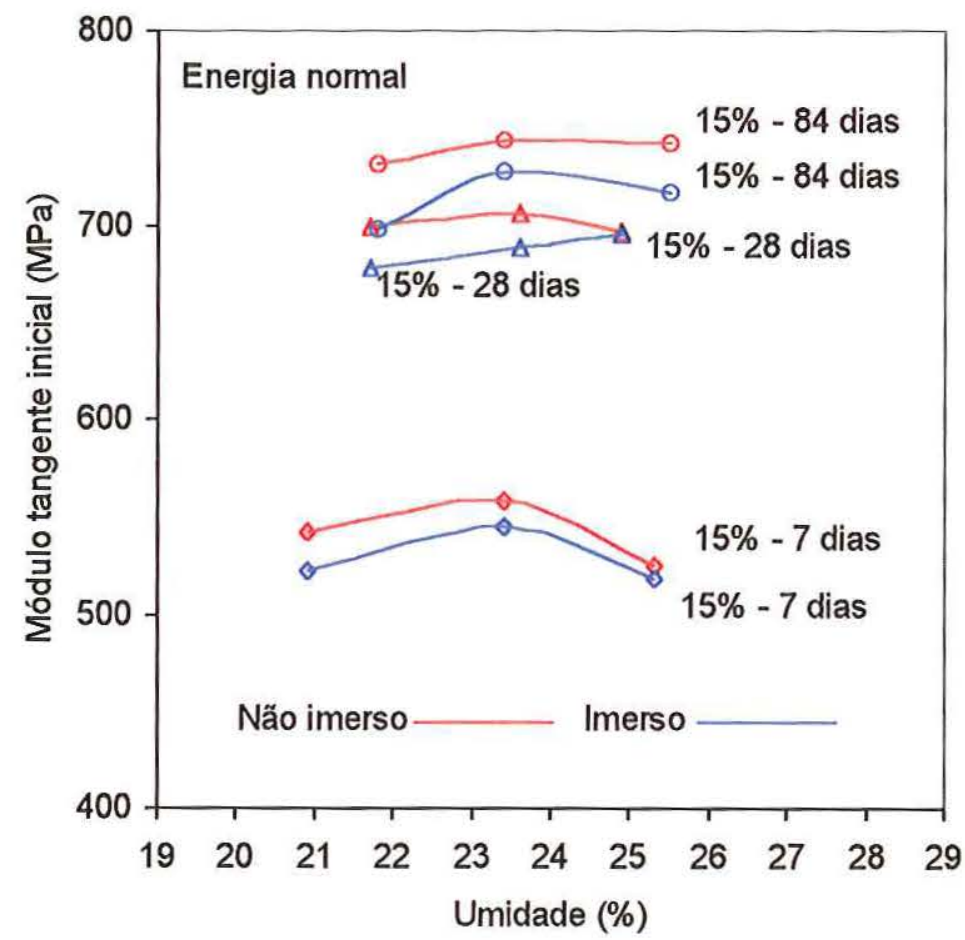

Figura 4.30: Módulo tangente inicial em função da umidade de compactação para misturas com $15 \%$ de cimento, submetidas a períodos de cura de 7,28 e 84 dias, ensaiadas em condições imersas e não imersas, e compactadas na energia normal. 


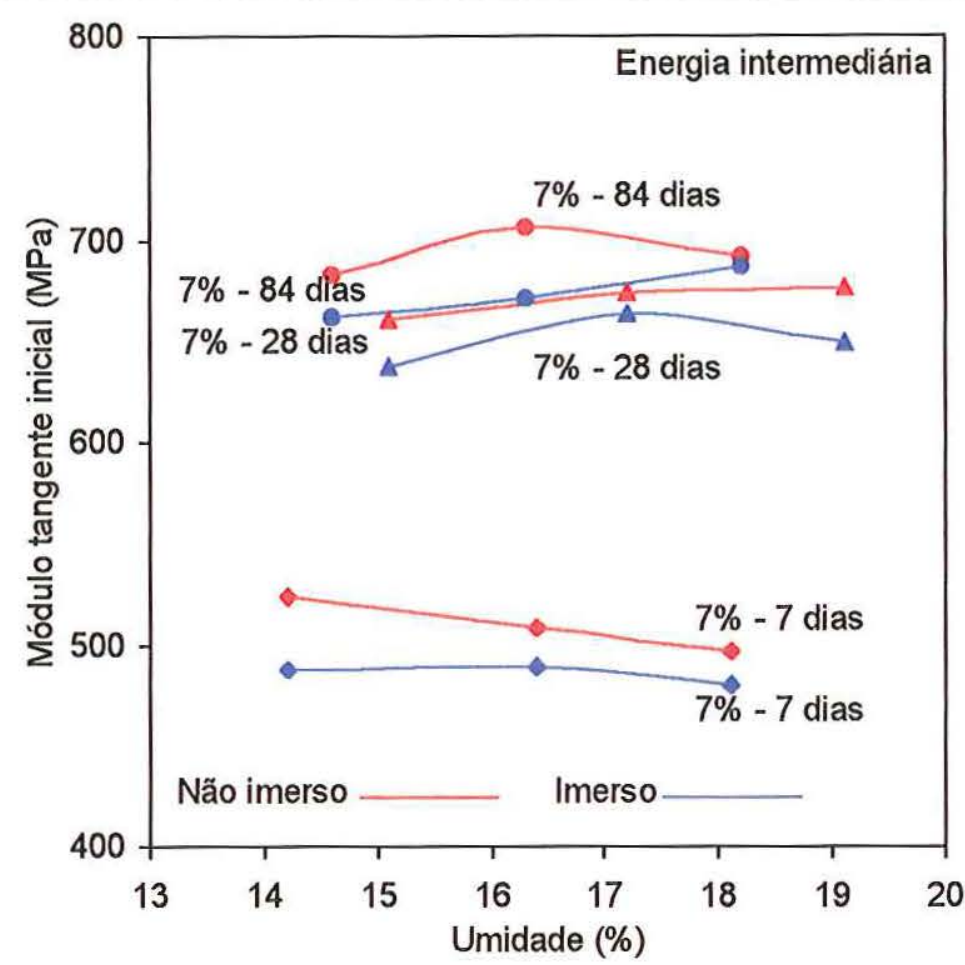

Figura 4.31: Módulo tangente inicial em função da umidade de compactação para misturas $\operatorname{com} 7 \%$ de cimento, submetidas a períodos de cura de 7,28 e 84 dias, ensaiadas em condições imersas e não imersas, e compactadas na energia intermediária.

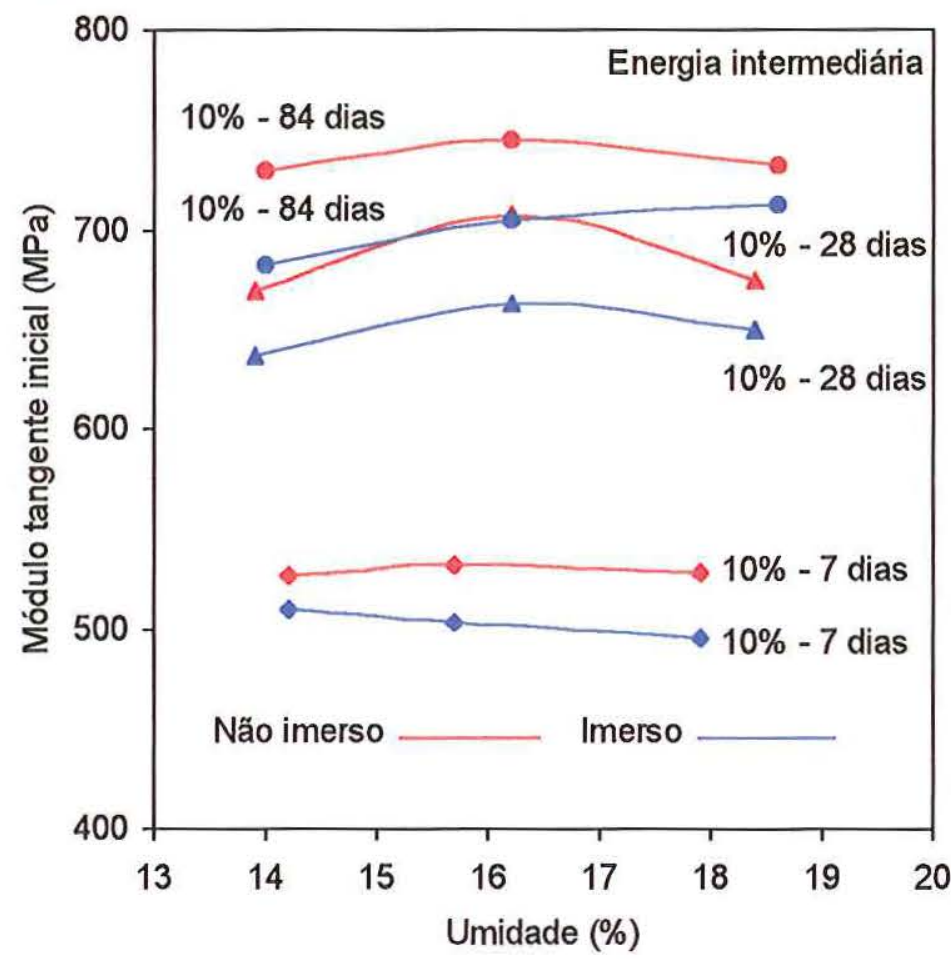

Figura 4.32: Módulo tangente inicial em função da umidade de compactação para misturas com $10 \%$ de cimento, submetidas a períodos de cura de 7, 28 e 84 dias, ensaiadas em condições imersas e não imersas, e compactadas na energia intermediária. 
Aqui também pode-se verificar que o Eo não sofre uma influência significativa da umidade de compactação, variando pouco para teores diferentes da umidade ótima e não sendo possível identificar um padrão para esta variação.

\subsubsection{Deformabilidade determinada através de ensaios triaxiais dinâmicos.}

Definiu-se para a realização desse ensaio o uso de três corpos de prova, sendo dois compactados na energia normal com teores de $7 \%$ e $15 \%$ de cimento, e um na energia intermediária, com $7 \%$ de cimento, ensaiados sem imersão. Foi dessa forma avaliado o efeito da variação da energia de compactação e do teor de cimento, para períodos de cura de 7 dias, sobre os valores do módulo de resiliência. Os procedimentos usados na execução do ensaio estão descritos no Capítulo 3, item 3.5.2.

A Tabela 4.7 mostra os valores de umidade, massa específica seca e grau de compactação dos corpos de prova usados nesse ensaio.

Tabela 4.7: Valores de umidade e massa específica dos corpos de prova usados no ensaio triaxial dinâmico.

\begin{tabular}{cccccc}
\hline c.p. & $\begin{array}{c}\text { Cimento } \\
(\%)\end{array}$ & $\begin{array}{c}\mathrm{w}_{\text {c.p. }} \\
(\%)\end{array}$ & $\begin{array}{c}\mathrm{w}_{\mathrm{o}}-\mathrm{w}_{\text {c.p }} \\
(\%)\end{array}$ & $\begin{array}{c}\rho_{\text {dcp }} \\
\left(\mathrm{g} / \mathrm{cm}^{3}\right)\end{array}$ & $\begin{array}{c}\text { Grau de } \\
\text { Compactação }\end{array}$ \\
\hline 1 & 7 & 23,98 & $+0,48$ & 1,283 & $96,78 \%$ da normal \\
2 & 15 & 23,30 & $-0,20$ & 1,325 & $98,57 \%$ da normal \\
3 & 7 & 16,68 & $-0,18$ & 1,447 & $98,78 \%$ da intermediária \\
\hline
\end{tabular}

Finalizado o ensaio triaxial dinâmico, os corpos de prova foram submetidos à compressão simples até a ruptura, permitindo a determinação do valor de resistência à compressão simples e do módulo tangente inicial para cada um dos corpos de prova ensaiados. A Tabela 4.8 apresenta os valores de módulo de resiliência encontrados para cada um dos níveis de carregamento e os valores de resistência à compressão simples e módulo tangente inicial (Eo) obtidos. 
Tabela 4.8:Valores de $M_{R}$, resistência à compressão simples (RCS) e módulo tangente inicial (Eo) encontrados para os corpos de prova 1,2 e 3.

\begin{tabular}{cccccc}
\hline & $\sigma_{3}$ & $\sigma_{\mathrm{d}}$ & \multicolumn{3}{c}{$\mathrm{M}_{\mathrm{R}}(\mathrm{MPa})$} \\
\cline { 4 - 6 } & $(\mathrm{kPa})$ & $(\mathrm{kPa})$ & $\begin{array}{c}\text { c.p. 1 } \\
7 \%-\mathrm{PN}\end{array}$ & $\begin{array}{c}\text { c.p. 2 } \\
15 \%-\mathrm{PN}\end{array}$ & $\begin{array}{c}\text { c.p. 3 } \\
7 \%-\mathrm{PI}\end{array}$ \\
\hline 1 & 34,5 & 31,0 & 568,639 & 698,569 & 736,483 \\
2 & 34,5 & 62,2 & 620,145 & 1160,336 & 857,392 \\
3 & 34,5 & 93,1 & 671,255 & 1918,106 & 1155,462 \\
\hline 4 & 68,9 & 62,0 & 634,454 & 1432,659 & 807,060 \\
5 & 68,9 & 124,1 & 661,028 & 2516,034 & 973,737 \\
6 & 68,9 & 186,1 & 693,648 & 3700,050 & 1158,217 \\
\hline 7 & 103,4 & 62,0 & 694,682 & 1132,709 & 979,930 \\
8 & 103,4 & 93,1 & 707,630 & 1523,434 & 1094,097 \\
9 & 103,4 & 186,1 & 710,209 & 2825,852 & 1378,686 \\
\hline \multicolumn{3}{c}{$\mathrm{RCS}(\mathrm{MPa})$} & 0,64 & 1,21 & 1,21 \\
\hline \multicolumn{3}{c}{ Eo (MPa) } & 409,082 & 978,473 & 415,162 \\
\hline
\end{tabular}

Sabe-se que o módulo de resiliência pode variar sensivelmente com alterações no estado de tensão. Para facilitar a interpretação dos resultados dos ensaios triaxiais dinâmicos, procurou-se estabelecer relações matemáticas entre valores de módulo de resiliência e os estados de tensão sob os quais foram determinados. As relações analisadas estão descritas em seguida, através das equações $4.1,4.2$ e 4.3.

$$
\begin{aligned}
& \mathrm{M}_{\mathrm{R}}=\mathrm{K}_{1} \cdot \sigma_{3}{ }^{\mathrm{K}_{2}} \\
& \mathrm{M}_{\mathrm{R}}=\mathrm{K}_{1} \cdot \sigma_{\mathrm{d}}^{\mathrm{K}_{2}} \\
& \mathrm{M}_{\mathrm{R}}=\mathrm{K}_{1} \cdot \sigma_{3}{ }^{\mathrm{K}_{2}} \cdot \sigma_{\mathrm{d}}{ }^{\mathrm{K}_{3}}
\end{aligned}
$$

onde:

$\mathrm{M}_{\mathrm{R}}$ : módulo de resiliência $(\mathrm{MPa})$;

$\sigma_{3}:$ tensão confinante $(\mathrm{kPa})$;

$\sigma_{\mathrm{d}}$ : tensão desvio $(\mathrm{kPa})$;

$K_{1}, K_{2}$, e $K_{3}$ : parâmetros de regressão.

A Tabela 4.9 apresenta os valores dos parâmetros de regressão determinados para cada uma das relações analisadas, bem como o valor do coeficiente de determinação $R^{2}$ correspondente. As regressões foram 
calculadas através do aplicativo STATISTICA 4.3, utilizando-se o módulo de resiliência como variável dependente, e $\sigma_{3}$ e $\sigma_{d}$ como variáveis independentes.

Tabela 4.9:Parâmetros de regressão e coeficientes de determinação dos modelos considerados para os resultados dos ensaios realizados nos corpos de prova 1,2 e 3.

\begin{tabular}{|c|c|c|c|c|c|}
\hline \multirow[t]{2}{*}{ Modelo } & \multicolumn{4}{|c|}{ Corpo de prova $1(7 \%$ - PN) } & \multirow[t]{2}{*}{ Eq. } \\
\hline & $\mathrm{K}_{1}$ & $\mathrm{~K}_{2}$ & $\mathrm{~K}_{3}$ & $\mathrm{R}^{2}$ & \\
\hline $\mathrm{M}_{\mathrm{R}}=\mathrm{K}_{1} \cdot \sigma_{3}^{\mathrm{K}_{2}}$ & 411,285 & 0,1149 & - & 0,59 & 4.1 \\
\hline $\mathrm{M}_{\mathrm{R}}=\mathrm{K}_{1} \cdot \sigma_{\mathrm{d}}^{\mathrm{K}_{2}}$ & 433,322 & 0,0948 & - & 0,61 & 4.2 \\
\hline $\mathrm{M}_{\mathrm{R}}=\mathrm{K}_{1} \cdot \sigma_{3}^{\mathrm{K}_{2}} \cdot{\sigma_{\mathrm{d}}}^{\mathrm{K}_{3}}$ & 361,528 & 0,0764 & 0,0645 & 0,80 & 4.3 \\
\hline \multirow[t]{2}{*}{ Modelo } & \multicolumn{4}{|c|}{ Corpo de prova 2 ( $15 \%$ - PN) } & Eq. \\
\hline & $\mathrm{K}_{1}$ & $\mathrm{~K}_{2}$ & $\mathrm{~K}_{3}$ & $\mathrm{R}^{2}$ & \\
\hline$M_{R}=K_{1} \cdot \sigma_{3}{ }^{K_{2}}$ & 514,975 & 0,3108 & - & 0,095 & 4.1 \\
\hline $\mathrm{M}_{\mathrm{R}}=\mathrm{K}_{1} \cdot \sigma_{\mathrm{d}}^{\mathrm{K}_{2}}$ & 33,180 & 0,8798 & - & 0,92 & 4.2 \\
\hline $\mathrm{M}_{\mathrm{R}}=\mathrm{K}_{1} \cdot \sigma_{3}{ }^{\mathrm{K}_{2}} \cdot \sigma_{\mathrm{d}}^{\mathrm{K}_{3}}$ & 54,914 & $-0,2374$ & 0,9849 & 0,95 & 4.3 \\
\hline \multirow[t]{2}{*}{ Modelo } & \multicolumn{4}{|c|}{ Corpo de prova $3(7 \%$ - PI) } & Eq. \\
\hline & $\mathrm{K}_{1}$ & $\mathrm{~K}_{2}$ & $\mathrm{~K}_{3}$ & $\mathrm{R}^{2}$ & \\
\hline $\mathrm{M}_{\mathrm{R}}=\mathrm{K}_{1} \cdot \sigma_{3}^{\mathrm{K}_{2}}$ & 431,776 & 0,2057 & - & 0,23 & 4.1 \\
\hline $\mathrm{M}_{\mathrm{R}}=\mathrm{K}_{1} \cdot \sigma_{\mathrm{d}}^{\mathrm{K}_{2}}$ & 264,834 & 0,2983 & - & 0,74 & 4.2 \\
\hline $\mathrm{M}_{\mathrm{R}}=\mathrm{K}_{1} \cdot \sigma_{3}^{\mathrm{K}_{2}} \cdot \sigma_{\mathrm{d}}^{\mathrm{K}_{3}}$ & 236,935 & 0,0442 & 0,2822 & 0,75 & 4.3 \\
\hline
\end{tabular}

Analisando-se e comparando-se os valores assumidos pelos parâmetros de regressão em cada uma das equações, pode-se afirmar que as influências de $\sigma_{3}$ e $\sigma_{d}$ no módulo de resiliência da mistura de fosfogesso e $7 \%$ de cimento, compactado sob a energia do Proctor normal, são equivalentes. Ainda sob a energia normal, a mistura contendo $15 \%$ de cimento teve 0 valor do módulo de resiliência influenciado predominantemente pela tensão desvio. O mesmo comportamento foi observado para a mistura com $7 \%$ de cimento compactada na energia do Proctor intermediário. Conclui-se portanto, que apenas a primeira mistura apresenta um comportamento assemelhado ao dos materiais granulares, visto que são estes os materiais mais sensíveis a variações da tensão principal menor. As Figuras 4.33, 4.34 e 4.35 mostram a representação gráfica da equação 4.1, respectivamente para os corpos de prova 1, 2 e 3. 
Para estes mesmo corpos de prova, as Figuras 4.36, 4.37 e 4.38 mostram a representação gráfica da equação 4.2. O destaque dado aos modelos representados por estas equações advém do fato de permitirem uma fácil visualização dos resultados e de serem muito utilizados neste tipo de análise.

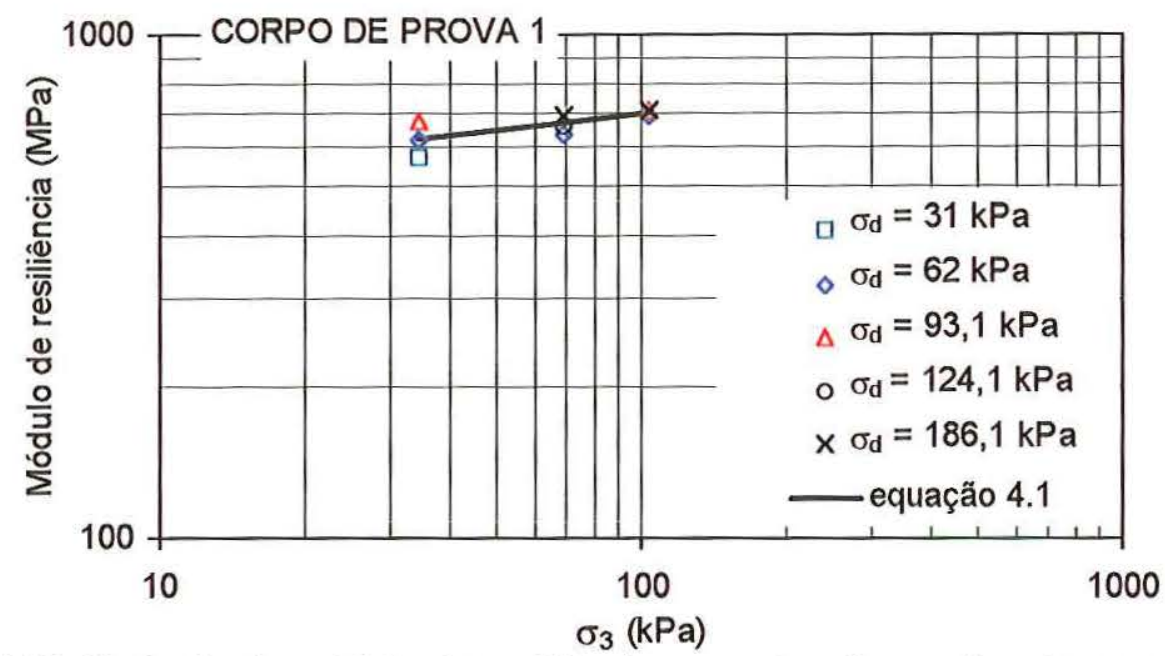

Figura 4.33: Variação do módulo de resiliência com a tensão confinante para o corpo de prova 1. Valores observados e reta de regressão.

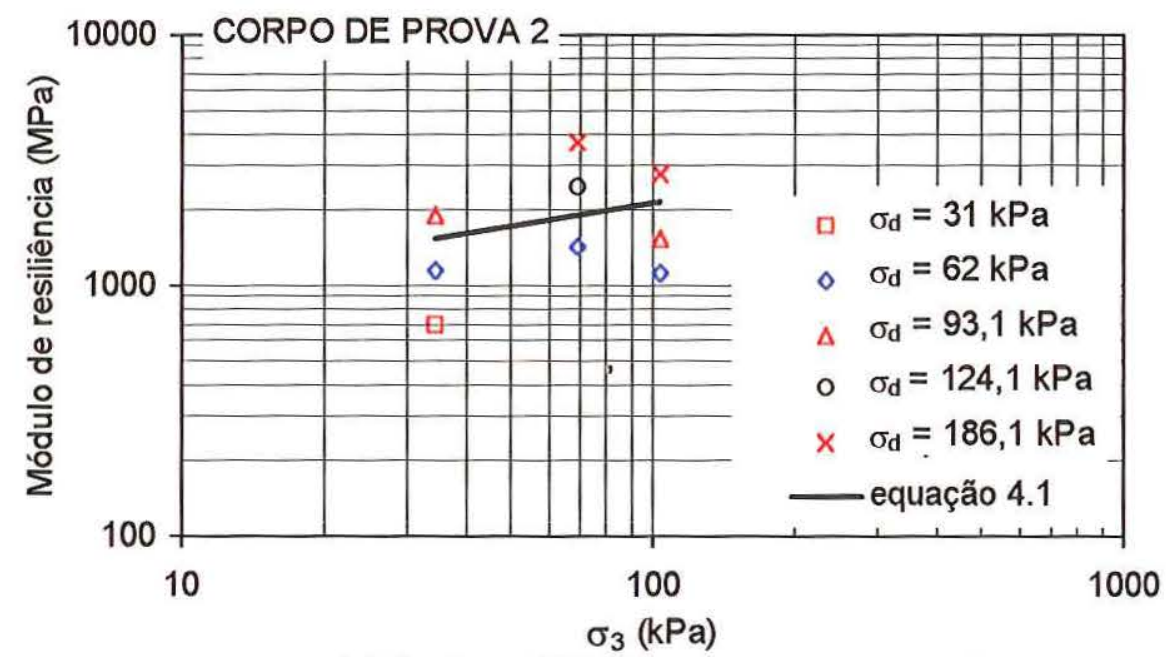

Figura 4. 34: Variação do módulo de resiliência com a tensão confinante para o corpo de prova 2. Valores observados e reta de regressão. 


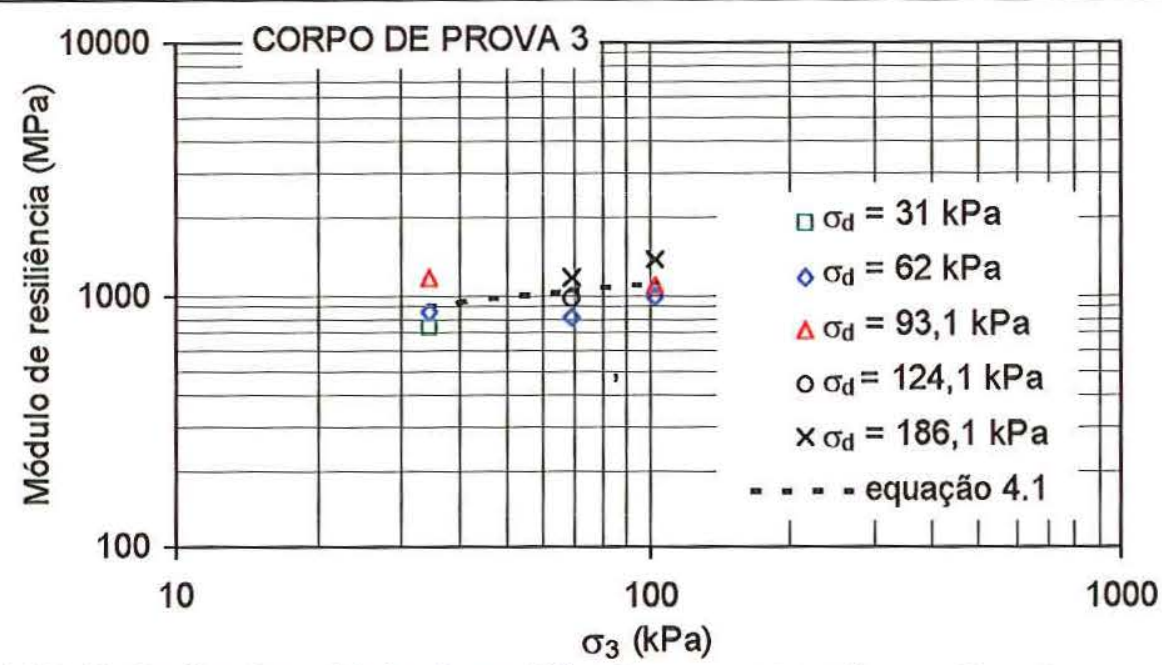

Figura 4.35: Variação do módulo de resiliência com a tensão confinante para o corpo de prova 3. Valores observados e reta de regressão.

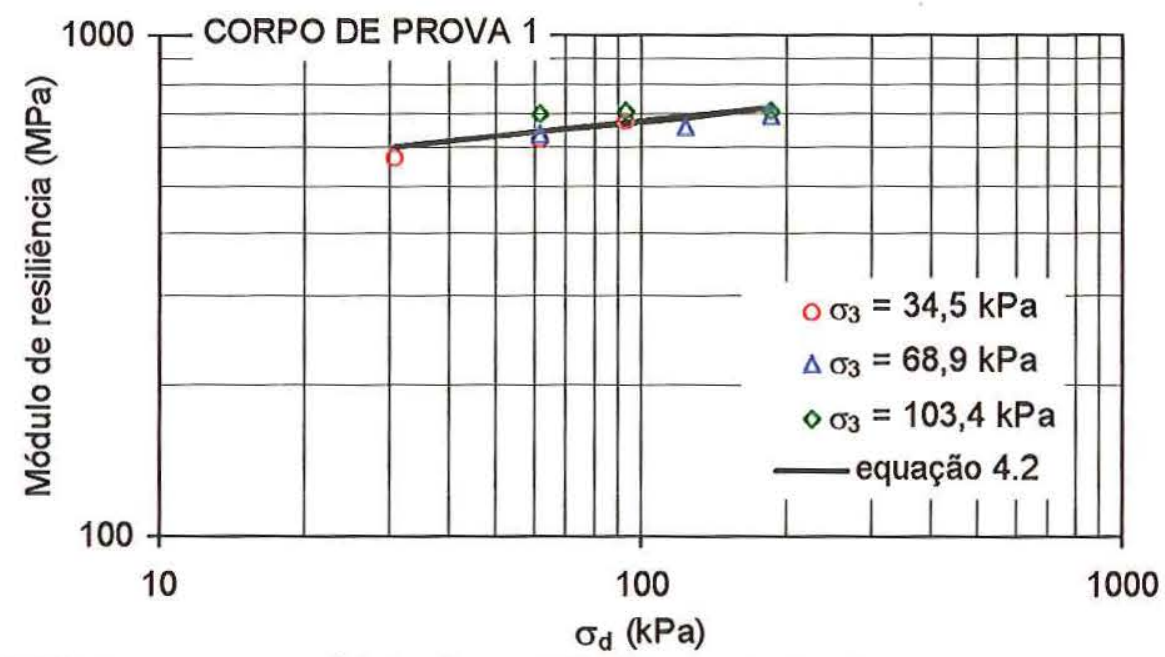

Figura 4.36: Variação do módulo de resiliência com a tensão desvio para o corpo de prova 1. Valores observados e reta de regressão.

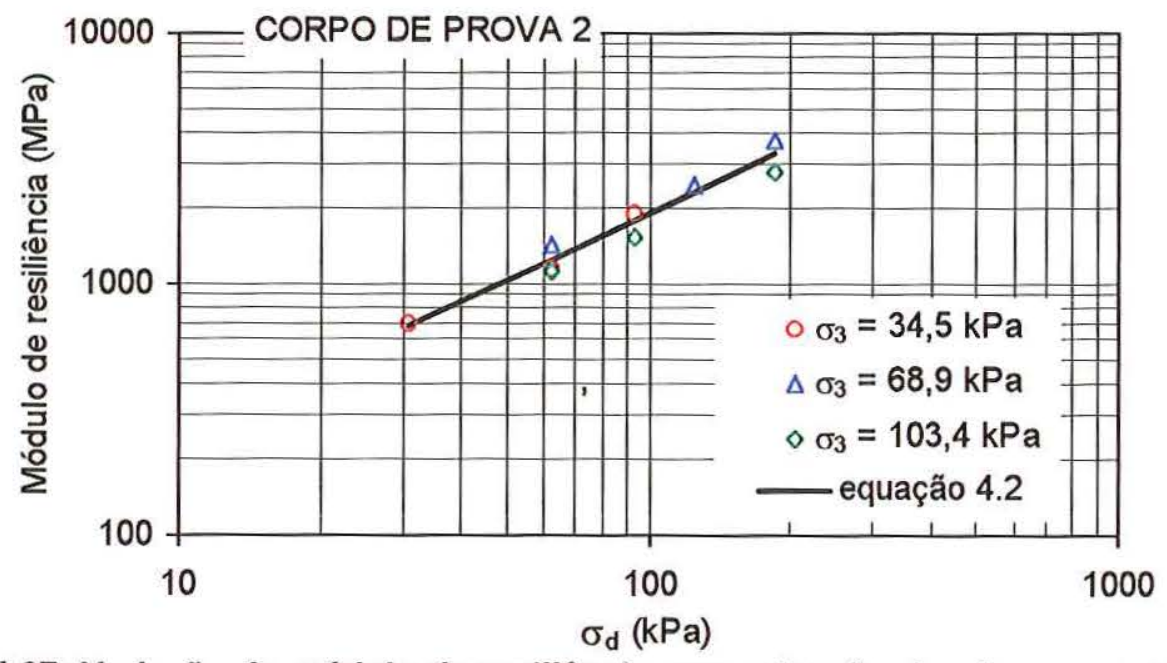

Figura 4.37: Variação do módulo de resiliência com a tensão desvio para o corpo de prova 2. Valores observados e reta de regressão. 


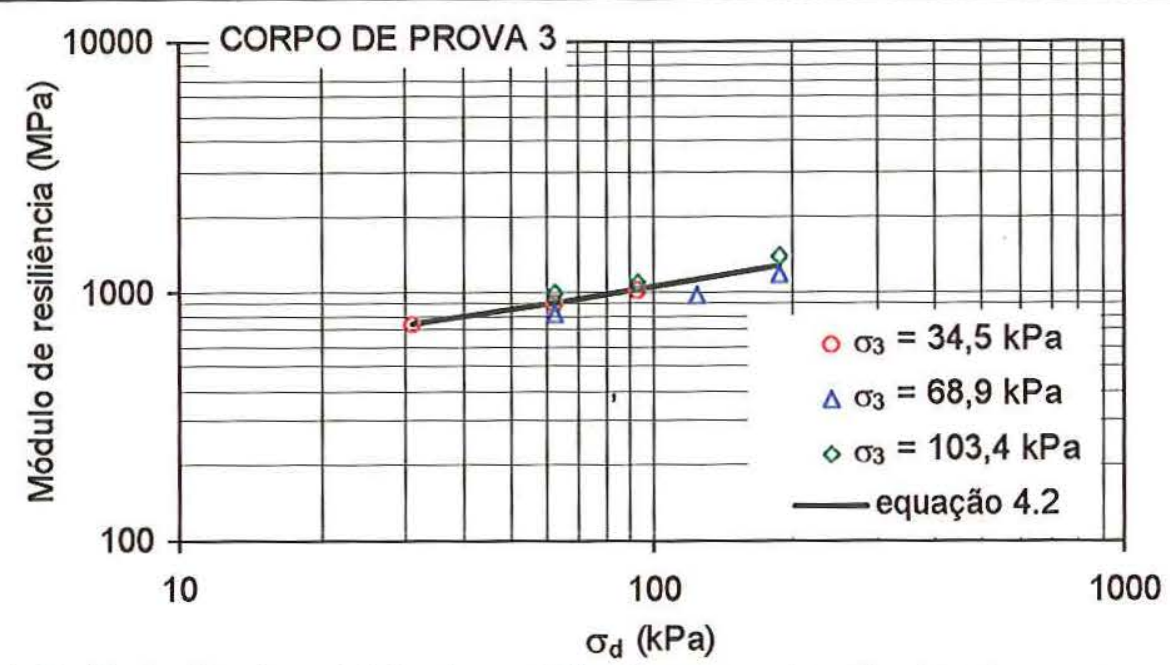

Figura 4.38: Variação do módulo de resiliência com a tensão desvio para o corpo de prova 3. Valores observados e reta de regressão.

A Figura 4.39 apresenta conjuntamente a variação do módulo de resiliência com a tensão desvio para os 3 corpos de prova ensaiados.

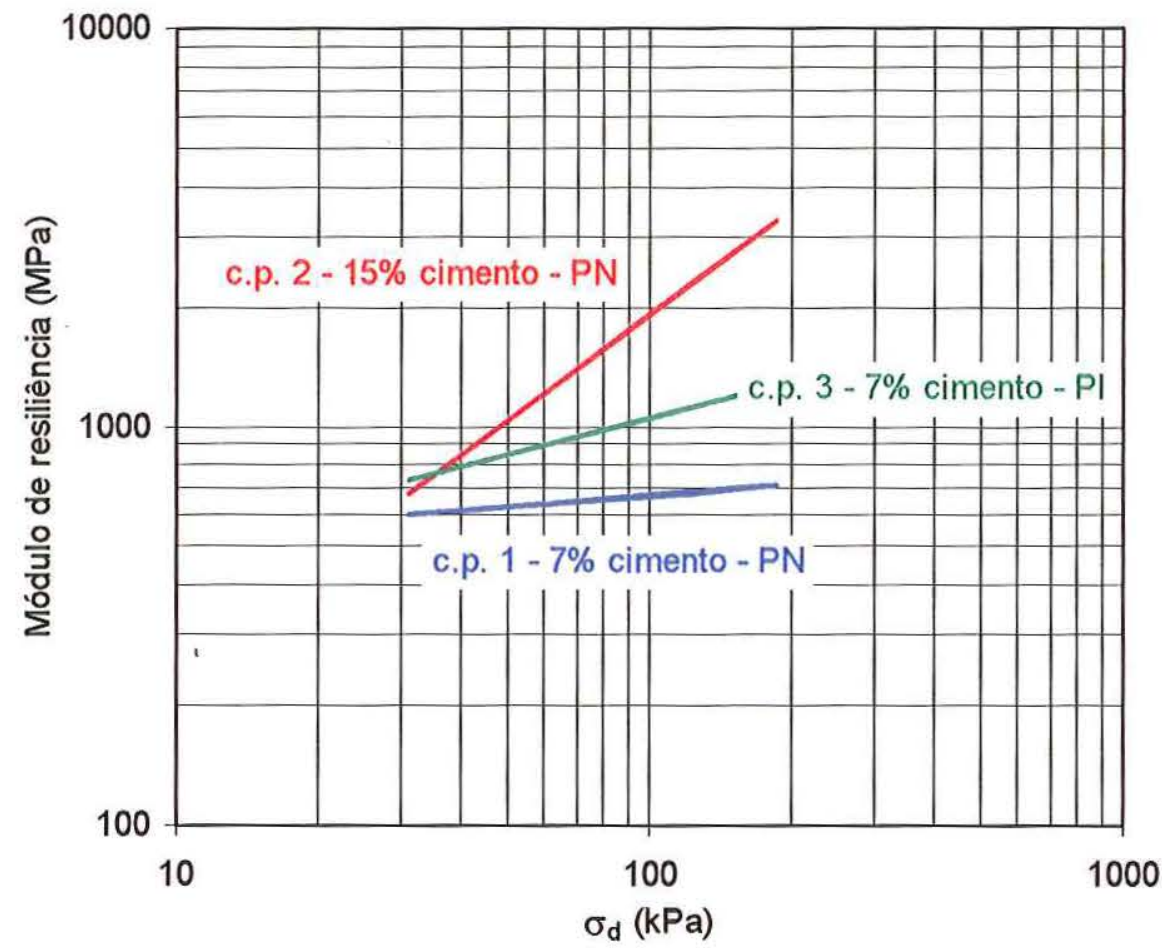

Figura 4.39: Variação do módulo de resiliência com a tensão desvio para os corpos de prova 1,2 e 3.

Observando-se os valores apresentados na Tabela 4.8 e a Figura 4.39, pode-se concluir que tanto o aumento da energia de compactação, 
como o aumento do teor de cimento na mistura promovem o crescimento do módulo de resiliência. Este crescimento situa-se nos intervalos de $27 \%$ a $94,1 \%$, e $22,8 \%$ a $433,4 \%$, respectivamente, para as variações da energia de compactação e do teor de cimento.

É interessante comparar os valores de módulo de resiliência obtidos nesta pesquisa com os determinados por GERRITY (1994) apresentados na Tabela 2.10. Este pesquisador encontrou para misturas de fosfogesso e $12 \%$ de cimento, após 7 dias de cura, valores de módulo de resiliência de 238 $\mathrm{MPa}$ e $2331 \mathrm{MPa}$, respectivamente para as energias de compactação normal e modificada, não tendo sido possível identificar o nível de tensão usado na determinação do módulo de resiliência. Apesar da discrepância entre os teores de cimento adotados nos dois estudos, pode-se afirmar, que para a energia normal, visto que obteve-se os valores mínimos de módulo de resiliência iguais a $568 \mathrm{MPa}$ e $698 \mathrm{MPa}$, respectivamente para $7 \%$ e $15 \%$ de cimento, que as misturas compostas com o fosfogesso estudado são menos deformáveis que aquelas ensaiadas por GERRITY (1994). Quanto ao módulo de resiliência obtido para corpos de prova compactados na energia modificada, não foi possível estabelecer uma comparação pois o presente estudo não contempla este nível de energia.

Finalmente, comparando-se o módulo de resiliência observado para as misturas de fosfogesso e cimento com o de outros materiais utilizados na composição de bases de pavimentos, conclui-se que apesar de sensivelmente menor que o apresentado por misturas de solo-cimento, é equivalente e até maior, que o de algumas bases granulares de bom desempenho.

Os resultados dos ensaios de compressão simples realizados no equipamento triaxial dinâmico utilizando corpos de prova na proporção $1: 2$, no caso $5 \mathrm{~cm} \times 10 \mathrm{~cm}$, permitem que se estabeleça uma avaliação preliminar do efeito de ter-se ensaiado corpos de prova de dimensões reduzidas, $5 \mathrm{~cm}$ 
X $5 \mathrm{~cm}$, no restante da pesquisa. A Tabela 4.10 apresenta a resistência à compressão simples e o módulo tangente inicial determinados a partir de corpos de prova nas proporções 1:1 e 1:2.

Tabela 4.10: Comparação entre os resultados de resistência à compressão simples (RCS) e módulo tangente inicial (Eo) para corpos de prova com dimensões diferentes.

\begin{tabular}{cccccccc}
\hline Energia de & Teor de & \multicolumn{4}{c}{ Corpo de prova } & \multicolumn{2}{c}{ Diferença percentual } \\
\cline { 3 - 8 } compactação & cimento & \multicolumn{2}{c}{$5 \times 5^{*(1)}$} & \multicolumn{2}{c}{$5 \times 10^{*(2)}$} & \multicolumn{2}{c}{$(2-1) /(1)$} \\
\cline { 3 - 8 } & & RCS & Eo & RCS & Eo & RCS & Eo \\
& & $(\mathrm{MPa})$ & $(\mathrm{MPa})$ & $(\mathrm{MPa})$ & $(\mathrm{MPa})$ & & \\
\hline Normal & 7 & 0,85 & 443,20 & 0,64 & 409,08 & $-24,71 \%$ & $-7,70 \%$ \\
Normal & 15 & 1,49 & 559,02 & 1,21 & 978,47 & $-18,79 \%$ & $75,03 \%$ \\
Intermediária & 7 & 1,53 & 508,27 & 1,21 & 415,16 & $-20,92 \%$ & $-18,32 \%$ \\
\hline
\end{tabular}

*diâmetro $(\mathrm{cm}) \times$ altura $(\mathrm{cm})$

Observa-se pelos resultados apresentados na Tabela 4.10 que os valores de resistência obtidos a partir de corpos de prova de dimensões 5 $\mathrm{cm} \times 5 \mathrm{~cm}$ são aproximadamente $21 \%$ superiores aos fornecidos pelos corpos de prova de dimensões $5 \mathrm{~cm} \times 10 \mathrm{~cm}$. Quanto ao módulo tangente inicial, excetuando-se a grande diferença observada para o corpo de prova 2, que poderia ser creditada a algum problema de ensaio, os valores de Eo determinados para corpos de prova de dimensões $5 \mathrm{~cm} \times 5 \mathrm{~cm}$ são aproximadamente $13 \%$ superiores aos obtidos através dos corpos de prova de dimensões $5 \mathrm{~cm} \times 10 \mathrm{~cm}$. Uma conclusão mais segura a respeito da influência das dimensões dos corpos de prova nos resultados exige a realização de um número maior de ensaios com corpos de prova na proporção 1:2 e que seja utilizada a mesma prensa em que se ensaiou os corpos de prova de $5 \mathrm{~cm} \times 5 \mathrm{~cm}$. 


\subsection{INTRODUÇÃO}

O objetivo deste trabalho foi avaliar o efeito da adição de cimento ao fosfogesso, tendo em vista o comportamento da mistura depois de compactada, em termos de resistência à compressão simples e deformabilidade.

Todas as conclusões estão vinculadas ao universo em estudo e considerando-se os resultados obtidos, pode-se estabelecer as conclusões e sugestões seguintes.

\subsection{CONCLUSÕES}

Para a determinação da umidade das misturas, verificou-se que, em estufa com ventilação forçada, a temperatura de $40^{\circ} \mathrm{C}$ mantida por 24 horas é suficiente para a secagem do material e não interfere com a água molecular.

A compactação das misturas de fosfogesso e cimento deve ser feita sem a reutilização do material.

Verificou-se que a acidez do fosfogesso, medido pelo $\mathrm{pH}$, exerce forte influência sobre a resistência à compressão simples das misturas. Quanto menor o pH do fosfogesso menores são as resistência obtidas. 
A tentativa de neutralização do fosfogesso com $\circ \mathrm{NaOH}$ não foi eficiente para elevar significativamente os valores da resistência à compressão simples.

A adição de quantidades crescentes de cimento ao fosfogesso conduz a um aumento nos valores de massa específica seca máxima. Quanto à umidade ótima, ela parece não ser muito afetada pelo teor de cimento.

A adição do cimento ao fosfogesso di-hidratado foi eficiente para a estabilização do material, tornando as misturas assim constituídas, estáveis frente a ação da água.

A adição de cimento, propiciou ao fosfogesso di-hidratado resistências mais elevadas do que as obtidas para o fosfogesso di-hidratado na sua condição natural.

Quantidades crescentes de cimento conduzem a ganhos crescentes de resistência.

As resistências para misturas com $10 \%$ de cimento são, em média, $25 \%$ maiores do que as resistências para misturas com $7 \%$ de cimento, independente do período de cura. As misturas com $12 \%$ e $15 \%$ de cimento são, em média, $39 \%$ e $64 \%$, respectivamente, maiores do que as resistências observadas para misturas com $7 \%$ de cimento. Essa constatação se repete para as duas energias de compactação e para ensaios realizados sem imersão e após imersão e água.

O período de cura após a compactação mostrou ter importante efeito sobre o ganho de resistência das misturas. Verificou-se um maior gradiente de crescimento da resistência para períodos até 14 dias. Nesse intervalo, as misturas, em média, alcançaram $79 \%$ da resistência obtida aos 84 dias. Aos 3 dias, as misturas alcançaram, em média, $27 \%$ da resistência aos 84 dias e aos 7 dias, alcançaram, em média, $65 \%$ de resistência aos 84 dias. 
O aumento da energia de compactação promoveu um ganho significativo de resistência. Misturas compactadas na energia intermediária apresentaram uma resistência $66 \%$ a $91 \%$ maiores que misturas compactadas na energia normal.

A resistência à compressão simples, para misturas ensaiadas após imersão em água por 4 horas, foram, em média, $8 \%$ menores do que as resistências observadas para misturas ensaiadas sem imersão prévia, independente do teor de cimento e do tempo de cura.

A resistência à compressão simples parece não sofrer uma influência significativa da umidade de compactação, variando pouco para teores em torno da umidade ótima. Não foi possível identificar um padrão único de variação que traduzisse o comportamento da resistência em função da variação da umidade de compactação.

A variação do módulo tangente inicial com o crescimento do teor de cimento é positiva e aproximadamente linear com o aumento do teor de cimento.

Observou-se que os valores de módulo tangente inicial aumentam com o período de cura. Essa situação verifica-se para todos os teores de cimento, para as duas energias de compactação e para as duas condições de ensaio. Da mesma forma que o observado para a resistência à compressão simples, constatou-se também um maior gradiente de crescimento do Eo até 14 dias de cura.

O aumento da energia de compactação implicou num aumento dos valores de Eo para todas as misturas de fosfogesso e cimento e para todos os períodos de cura. Entretanto, esse aumento não foi tão significativo quanto o observado para a resistência à compressão simples, variando de $4 \%$ a $17 \%$, enquanto a resistência varia de $66 \%$ a $91 \%$. 
Para o Eo, assim como foi observado para a resistência à compressão simples, os corpos de prova ensaiados após imersão em água apresentaram valores menores, se comparados aos resultados obtidos para corpos de prova ensaiados sem imersão. A redução nos valores de Eo variou em função da energia de compactação: para energia normal os valores de Eo foram, em média, 3,2\% menores do que os valores de Eo em condições não imersas; já para a energia intermediária, os valores são, em média, 5,2\% menores. Assim, o efeito da água é menos sensível no caso da deformabilidade, visto que a resistência diminui devido à imersão, em média $8,0 \%$ para as duas energias de compactação.

O Eo não sofre uma influência significativa da umidade de compactação, variando pouco para teores em torno da umidade ótima e não sendo possível identificar um padrão para esta variação.

Verificou-se através dos resultados dos ensaios triaxiais dinâmicos que, tanto o aumento da energia de compactação, quanto o aumento do teor de cimento na mistura promovem o crescimento do módulo de resiliência.

A comparação do módulo de resiliência observado para as misturas de fosfogesso e cimento com o de outros materiais de uso comum na construção de bases de pavimentos, permitiu concluir que, apesar de sensivelmente menor que o apresentado por misturas de solo-cimento, é equivalente e até maior, que o de algumas bases granulares de bom desempenho.

Do ponto de vista de resistência e deformabilidade, as misturas de fosfogesso e cimento possuem atributos que as qualificam como materiais possíveis de serem utilizados na construção rodoviária. 


\subsection{SUGESTŐES E RECOMENDAÇŐES PARA TRABALHOS FUTUROS}

Realizar estudos sobre a morfologia do fosfogesso, que conforme descrito na revisão bibliográfica, pode influir significativamente nos valores de resistência das misturas.

Avaliar a influência da dimensão e forma dos corpos de prova sobre a resistência à compressão simples e deformabilidade das misturas de fosfogesso e cimento.

Variar o tipo de cimento, focado no teor de $\mathrm{C}_{3} \mathrm{~A}$, usado para estabilização do fosfogesso, que conforme exposto na revisão bibliográfica, pode influir sobre a resistência à compressão simples e deformabilidade das misturas.

Estender o período de cura para além de 84 dias, permitindo que se avalie o problema da formação de cristais de etringita, e consequentemente, expansibilidade, sobre a resistência à compressão simples e deformabilidade.

Realizar ensaios de microscopia para se verificar a formação ou não da etringita nas misturas.

Ampliar as situações analisadas sob condições de carregamento dinâmico.

Avaliar o comportamento das misturas de fosfogesso e cimento frente a ação erosiva da água.

Avaliar o comportamento das misturas de fosfogesso e cimento em campo, através da construção de trechos experimentais com constante monitoramento. 


\section{REFERÊNCIAS BIBLIOGRÁFICAS}

ANDERSON, N. R. (1986). Gypsum aggregate - a viable commercial venture. In: PROCEEDINGS OF THE SECOND INTERNATIONAL SYMPOSIUM ON PHOSPHOGYPSUM, Miami, Florida, December, 1986. V. II, p.329-354.

ANDRIEX, P.; BIVERT, B. e DRON, R. (1978). Utilisation du phosphogypse en assises de chaussée. Bulletin de liaison des laboratoires des ponts et chaussées, Le phosphogypse: utilisation d'un sous-produit industriel en technique routière, número spécial VII, p. 54-68.

- ASSOCIAÇÃO BRASILEIRA DE NORMAS TÉCNICAS (1992) NBR 12253Solo-cimento - Dosagem para emprego como camada de pavimento, Rio de Janeiro.

AUSTIN, R. D. (1980). Sulfur from gypsum: laboratory, bench-scale, and pilot-plant studies. In: PROCEEDINGS OF THE INTERNATIONAL SYMPOSIUM ON PHOSPHOGYPSUM, Lake Buena Vista, Florida, 5-7 November, 1980. p. 307-323.

BARBOSA, D. A. (1980). Rochas fosfáticas brasileiras. Tecnologia de Fertilizantes Fosfatados. Centro de estudos de fertilizantes. Instituto de Pesquisas Tecnológicas do Estado de São Paulo - IPT. v. 9, 1980. p, 95-122.

BERETKA, J. (1990). The current state of utilization of phosphogypsum in Australia. In: PROCEEDINGS OF THE THIRD INTERNATIONAL SYMPOSIUM ON PHOSPHOGYPSUM, Orlando, Florida, December, 1990. v. 2, p. 394-401. 
BERISH, C. W. (1990). Potential environmental hazards of phosphogypsum storage in central Florida. In: PROCEEDINGS OF THE THIRD INTERNATIONAL SYMPOSIUM ON PHOSPHOGYPSUM, Orlando, Florida, December, 1990. V. I, p. 1-29.

BROWN, T. e BERETKA, J. (1990). Phosphogypsum as a raw material in the manufacturing of plaster products. . In: PROCEEDINGS OF THE THIRD INTERNATIONAL SYMPOSIUM ON PHOSPHOGYPSUM, Orlando, Florida, December, 1990. p. 437-445.

CHANG, W. C. e CHANG, W. F. (1988). Stabilization of phosphogypsum with epoxy. In: PROCEEDINGS OF THE SECOND INTERNATIONAL SYMPOSIUM ON PHOSPHOGYPSUM, Miami, Florida, December, 1986. V. II, p.287-300.

CHANG, W. F. (1988). A demonstration project: roller compacted concrete utilizing phosphogypsum. University of Miami/Florida Institute of Phosphate Research. (Final Report).

CHANG, W. F. (1990). Roller compacted concrete utilizing phosphogypsum. In: PROCEEDINGS OF THE THIRD INTERNATIONAL SYMPOSIUM ON PHOSPHOGYPSUM, Orlando, Florida, December, 1990. v.II, p. 623-631.

CHANG, W. F. e MANTELL, M. I. (1990). Engineering properties and construction applications of phosphogypsum. University of Miami press, Coral Gables, Florida, 203 p.

CHANG, W. F., CHIN, D. A. e HO, R. (1989). Phosphogypsum for secondary road construction. University of Miami/Florida Institute of Phosphate Research. (Final Report).

CHIN, D. A. (1988). The impact of a phosphogypsum roadway on local groundwater quality - a case study. . In: PROCEEDINGS OF THE SECOND INTERNATIONAL SYMPOSIUM ON PHOSPHOGYPSUM, Miami, Florida, December, 1986. V. I, p.35-60. 
COLLINNS, R. K. (1980). Phosphogypsum in Canada. In: PROCEEDINGS OF THE INTERNATIONAL SYMPOSIUM ON PHOSPHOGYPSUM, Lake Buena Vista, Florida, 5-7 November, 1980. p. 583-.596

COLOMBEL, J. H. (1978). Utilisation du phosphogypse en assises traitèes aux liants hydrauliques. Bulletin de liaison des laboratoires des ponts et chaussées, Le phosphogypse: utilisation d'un sous-produit industriel en technique routière, número spécial VII, p. 16-43.

DRUMM, E. C.; BOATENG-POKU, Y. e PIERCE, T. J. (1990). Estimation of subgrade resilient modulus from standard tests. Journal of Geotechnical Engineering, v.116,n. 5, p.774-89, may.

FERGUSON, F. (1988). Phosphogypsum - An overview. In: PROCEEDINGS OF THE SECOND INTERNATIONAL SYMPOSIUM ON PHOSPHOGYPSUM, Miami, Florida, December, 1986. V. I, p.117-130.

FIGUEROA, J. L.; ZHOU, L. e CHANG, W. F. (1987). Use of phosphate mining waste in secondary road construction. Transportation Research Record, 1106, p. 59-64.

FOXWORTHY, P. T.; NADIMPALLI, R. S.; SEALS, R. K. (1996). Phosphogypsum slag aggregate-based asphaltic concrete mixes. Journal of Transportation Engineering, v. 122, n. 4, July/August, p.300307, 1996.

GADALLA, A. M.; SAYLAK, D. e LINDNER, A. L. (1990).Comparison of strength development in waste industrial gypsum produced by the hemihydrate and dihydrate processes. Journal of the American Ceramic Society, v. 73, n. 8, p. 2255-2260.

GERRITY, D. M., METCALF, J. B. e SEALS, R. K. (1994). Estimating the design life of a prototype cement-stabilized phosphogypsum pavement. Transportation Research Record, 1440, Jul, p. 21-26, 1995.

GREGORY, C. A.; SAYLAK,D e LEDBETTER,W. B. (1984). The use of byproduct phosphogypsum for road bases and subbases. Transportation Research Record, 998, p. 47-52. 
HO, R. K. (1990). Pavement evaluation of two gypsum stabilized county roads. In: PROCEEDINGS OF THE THIRD INTERNATIONAL SYMPOSIUM ON PHOSPHOGYPSUM, Orlando, Florida, December, 1990. p. 602-622.

HO, R. K. H.;WILLIAMS, R. W.; COGDILL, L. L. e CHANG, W. F. (1988). Columbia county experimental road. In: PROCEEDINGS OF THE SECOND INTERNATIONAL SYMPOSIUM ON PHOSPHOGYPSUM, Miami, Florida, January, 1988. V. II, p. 397-416.

ISO 5725. Precision of test methods - Determination of repeatability and reproducibility for a standard test method by inter-laboratory tests. Second edition. 1986.

JAMES, A. C. (1996). Assessment of doses and risks from uses of waste product phosphogypsum in agriculture and road construction. Presented at the PHOSPHOGYPSUM FACT-FINDING FORUM, Tallahassee, Florida, December 7,1995.

JOHNSON, J. R.; TRAUB, R. J. (1996). Risk estimates for uses of phosphogypsum. Battele Pacific Northwest Laboratories/Florida Institute of Phosphate Research. (Final Report).

KENLEY, W. C. e CHANG, W. F. (1988). Polk county experimental road. In: PROCEEDINGS OF THE SECOND INTERNATIONAL SYMPOSIUM ON PHOSPHOGYPSUM, Miami, Florida, January, 1988. V. II, p.353360 .

KOULOHERIS, A. P. (1980).Chemical nature of phosphogypsum as produced by various wet process phosphoric acid processes. In: PROCEEDINGS OF THE INTERNATIONAL SYMPOSIUM ON PHOSPHOGYPSUM, Lake Buena Vista, Florida, 5-7 November, 1980. p. 7-34.

LINDEKEN, C. L. (1980). Radiological considerations of phosphogypsum utilization in agriculture. In: PROCEEDINGS OF THE INTERNATIONAL SYMPOSIUM ON PHOSPHOGYPSUM, Lake Buena Vista, Florida, 5-7 November, 1980. p. 401-414. 
LLOYD, G. M. (1985). Phosphogypsum: A review of the Florida Institute of Phosphate Research Programs to Develop Uses for Phosphogypsum. FLORIDA INSTITUTE OF PHOSPHATE RESEARCH, December, 1985.

M 3-61 DER-SP. Determinação da densidade real da fração de solos pelo picnômetro de $500 \mathrm{ml}$.

M 5-61 DER-SP. Determinação do limite e índice de plasticidade de solos.

M 6-61 DER-SP. Análise granulométrica de solos por peneiração e sedimentação (Processo do densímetro).

MACCARINI, M. (1991a) Estudos de Aproveitamento de Rejeitos Poluentes do Sul de Santa Catarina para a Pavimentação. 25a Reunião anual de pavimentação, ABPV, São Paulo, pp.443-451.

MACCARINI, M. (1991b) Propriedades Física, Química e Mecânica do Fosfogesso da Industria Carboquímica Catarinense. Simpósio sobre barragens de rejeitos e disposição de resíduos - REGEO'91, Rio de Janeiro, pp.147-157.

MANGIN, S. (1978a). Généralités. Bulletin de liaison des laboratoires des ponts et chaussées, Le phosphogypse: utilisation d'un sous-produit industriel en technique routière, número spécial VII, p. 7-13.

MANGIN, S. (1978b), LE PHOSPHOGYPSE: Utilisation d'un sous produit industriel en technique routière. capitulo IV.

MISHRA, U. N. (1980). Use of phosphogypsum in reclamation of sodic soils in India. In: PROCEEDINGS OF THE INTERNATIONAL SYMPOSIUM ON PHOSPHOGYPSUM, Lake Buena Vista, Florida, 5-7 November, 1980. p. 223-231.

NANNI, A. e CHANG, W. F. (1989). Phosphogypsum-based roller compacted concrete. Concrete International: design and Construction. v. 11, $\mathrm{n}^{\circ} 11$, Nov 1989, p. 48-53.

NIFONG, G. D. e HARRIS, J. K. (1993).Environmental monitoring of Polk and Columbia counties experimental phosphogypsum roads. Florida Institute of phosphate research. (Final Report). 
ONG, S.; METCALF, J.B.; SEALS, R. K. e TAHA, R. (1994). Unconfined compressive strength of various cement-stabilized phosphogypsum mixes. Transportation Research Record, 1424, P. 20-24.

ORTIZ, J. A. (1997). Estudo de misturas de solo e fosfogesso com vistas a sua utilização em rodovias. São Carlos.179 p. Dissertação (Mestrado) Escola de Engenharia de são Carlos, Universidade de São Paulo.

OSAKI, F. (1991). Calagem \& adubação. Campinas, São Paulo/Instituto Brasileiro de Ensino Agrícola. Cap.1, p.172-182.

PEIXOTO, A. S. P.; FABBRI, G. T. F. e NOGUEIRA, J. B. (1996). Uma avaliação da repetibilidade dos parâmetros que compõem a classificação MCT. $8^{\circ}$ Congresso brasileiro de geologia de engenharia, Rio de Janeiro, set/96.

-PITTA, M. R. (1997). Fatos básicos sobre o solo-cimento. Boletim técnico da ABCP, São Paulo, 1998.

PRESSINOTTI, A. F. (1982). Aproveitamento do gesso natural e gesso residual da produção de ácido fosfórico. INSTITUTO DE PESQUISAS TECNOLÓGICAS DO ESTADO DE SÃO PAULO - IPT, PESQUISA \& DESENVOLVIMENTO, n. 13, São Paulo, 1982.

PUIATTI, D. e VIGEA, G. (1978). Accotement expérimental en phosphogypse sur la RN 28 près de Neufchâtel-en-Bray. Bulletin de liaison des laboratoires des ponts et chaussées, Le phosphogypse: utilisation d'un sous-produit industriel en technique routière, número spécial VII, p. 132-140.

PULITI, P. (1998). FOSFERTIL aumenta a produção. O Estado de São Paulo, São Paulo, 14 abr. Economia-Negócios., p.B10.

ROESSLER, C. E. (1990). Radon emanation from roads constructed with phosphogypsum aggregates. In: PROCEEDINGS OF THE THIRD INTERNATIONAL SYMPOSIUM ON PHOSPHOGYPSUM, Orlando, Florida, December, 1990. p. 30-43. 
RUIZ, C. L. (1964). Presentación y comentatio sobre los diagramas Shell 1963 para el diseño de pavimentos flexibles. DVBA, Miniterio de Obras Publicas, La Plata Argentina.

RUSSEL, J. B. (1982). Química geral. Ed MacGraw-Hill do Brasil Ltda.

SAYLAK, D.; TAHA, R. e LITTLE, D. N. (1988). Recommended procedure for sample preparation and testing stabilized gypsum mixtures. In: PROCEEDINGS OF THE SECOND INTERNATIONAL SYMPOSIUM ON PHOSPHOGYPSUM, Miami, Florida, December, 1986. V. II, p.187208.

SCHAEFFNER, M. (1978). Premiers résultats relatifs aux conditions de stockage et d'utilisation du phophogypse dans les remblais routiers.. Bulletin de liaison des laboratoires des ponts et chaussées, Le phosphogypse: utilisation d'un sous-produit industriel en technique routière, número spécial VII, p. 54-68.

SILVA JR., A. F. (1980). Rochas fosfáticas brasileiras. Tecnologia de Fertilizantes Fosfatados. Centro de estudos de fertilizantes. Instituto de Pesquisas Tecnológicas do Estado de São Paulo - IPT. v. 9, 1980. p, 31-52.

SUMMER, M. E.; FEY, M. V. e FARINA, P.W. (1988). Amelioration of acid subsoils with phosphogypsum. In: PROCEEDINGS OF THE SECOND INTERNATIONAL SYMPOSIUM ON PHOSPHOGYPSUM, Miami, Florida, December, 1986. V. I, p. 211-229.

TAHA, R. e SEALS, R. (1991).Phosphogypsum literature review. (Report $n^{\circ}$ I-90-4).

TAHA, R. e SEALS, R. (1992). Engineering properties of phosphogypsumbased slag aggregate. Transportation Research Record, 1345, p. 106112, 1992.

TAHA, R.; SEALS, R. K.; TITTLEBAUM, M. E.; THORNSBERRY, W. e HOUSTON, J. T. (1992). Use of by-product phosphogypsum in road construction. Transportation Research Record, 1345, p. 28-35. 
TAHA, R.; SEALS, R.; TITTLEBAUM, M.; SAYLAK, D. (1995). Environmental Characteristics of by-product gypsum. Transportation Research Record, 1486, Jul, p. 21-26, 1995.

TAYLOR, B. F. (1988). The bacterial conversion of phosphogypsum into element sulfur. In: PROCEEDINGS OF THE SECOND INTERNATIONAL SYMPOSIUM ON PHOSPHOGYPSUM, Miami, Florida, December, 1986. V. II, p.159-163.

TREFLER, M. WU, X. e MEDORA, R. P. (1988). Radon emanation from building materials. In: PROCEEDINGS OF THE SECOND INTERNATIONAL SYMPOSIUM ON PHOSPHOGYPSUM, Miami, Florida, December, 1986. V. I, p.25-34.

TRICHÊS, G. e MACCARINI M. (1988) Misturas Fosfogesso/Cinza para Construção Rodoviária - Estudos Preliminares. 23a Reunião anual de pavimentação, ABPV, Florianópolis, pp. 311-329.

VAIDERGORIN, E. I.(1988). Características dos cimentos portland: uma abordagem química. In: TECNOLOGIA DE EDIFICAÇÕES, ed. PINI. São Paulo. p. 19-22.

WALSH, P. J. (1990). Radon daughter risks associated with phosphogypsum. In: PROCEEDINGS OF THE THIRD INTERNATIONAL SYMPOSIUM ON PHOSPHOGYPSUM, Orlando, Florida, December, 1990. p. 44-63.

WHEELOCK, T. D. (1980). Desulfurization of phosphogypsum. In: PROCEEDINGS OF THE INTERNATIONAL SYMPOSIUM ON PHOSPHOGYPSUM, Lake Buena Vista, Florida, 5-7 November, 1980. p. 325-342. 


\section{ANEXO A - CURVAS DE COMPACTAÇÃO E VALORES DE RESISTÊNCIA Á COMPRESSÃO SIMPLES PARA MISTURAS DE FOSFOGESSO E CIMENTO.}

As Figuras de A.1 a A.18 ilustram as curvas de compactação e os valores de resistência à compressão simples para cada corpo de prova moldado no ensaio de compactação. As Figuras de A.1 a A.8 correspondem aos ensaios realizados com o fosfogesso $A$, e as Figuras de A.9 a A.18 correspondem aos ensaios realizados com o fosfogesso B. As Figuras apresentam em conjunto a curva de compactação e os resultados correspondentes ao ensaio compressão simples para cada uma das misturas de fosfogesso e cimento estudadas, sendo que, as curvas representadas com as cores vermelha e azul indicam, respectivamente, ensaios de compressão simples em condições não imersas e imersas. A curva representada com a cor preta indica a curva de compactação. 


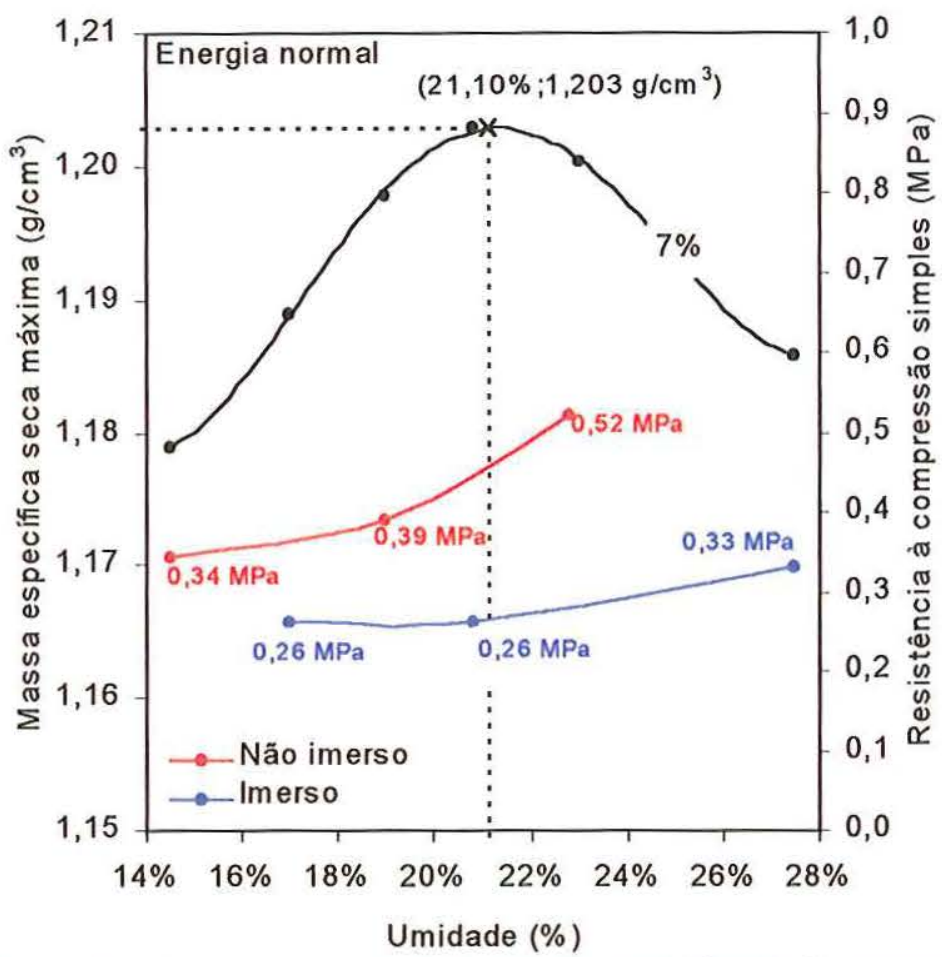

Figura A.1: Curva de compactação e valores de resistência à compressão simples para corpos de prova compostos com fosfogesso A e $7 \%$ de cimento compactados na energia normal.

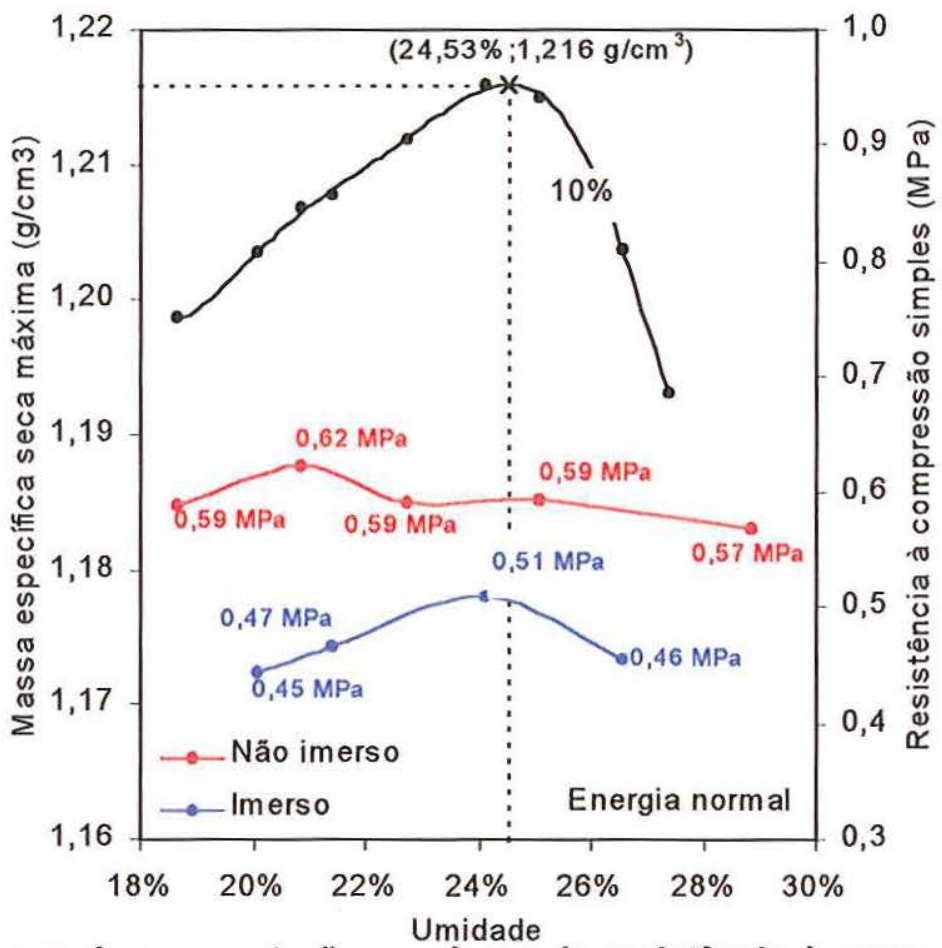

Figura A.2: Curva de compactação e valores de resistência à compressão simples para corpos de prova compostos com fosfogesso A e $10 \%$ de cimento compactados na energia normal. 


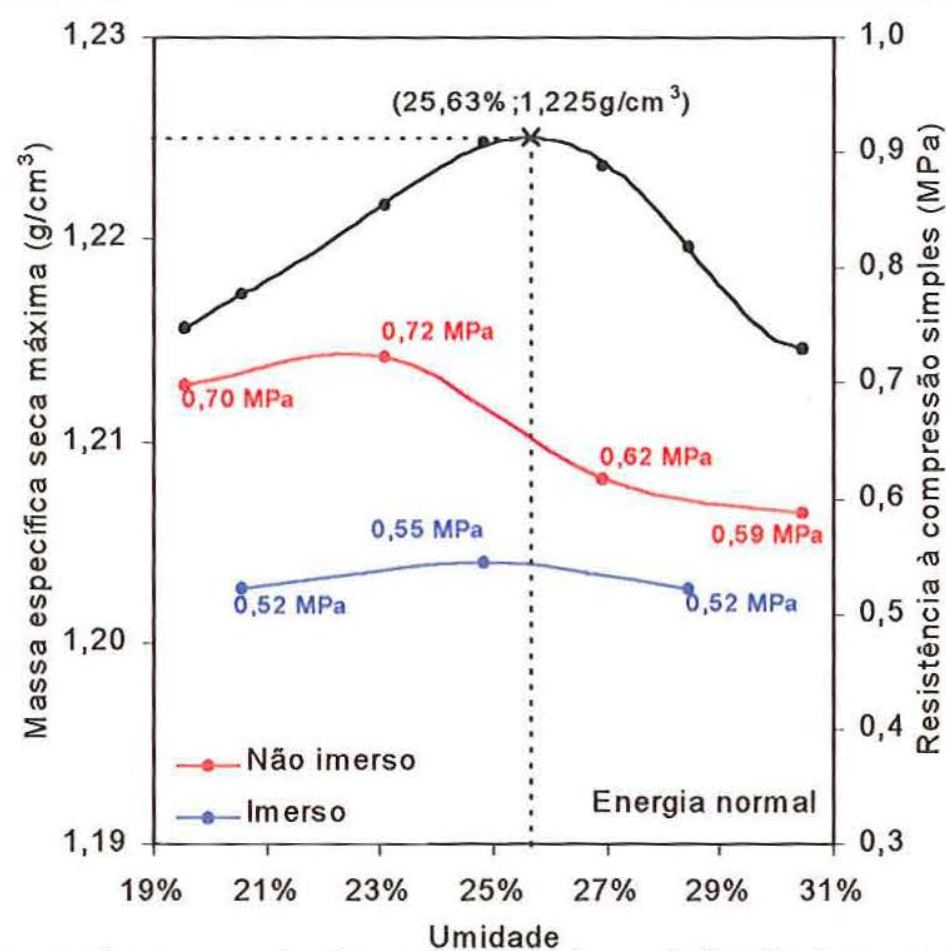

Figura A.3: Curva de compactação e valores de resistência à compressão simples para corpos de prova compostos com fosfogesso $A$ e $12 \%$ de cimento compactados na energia normal.

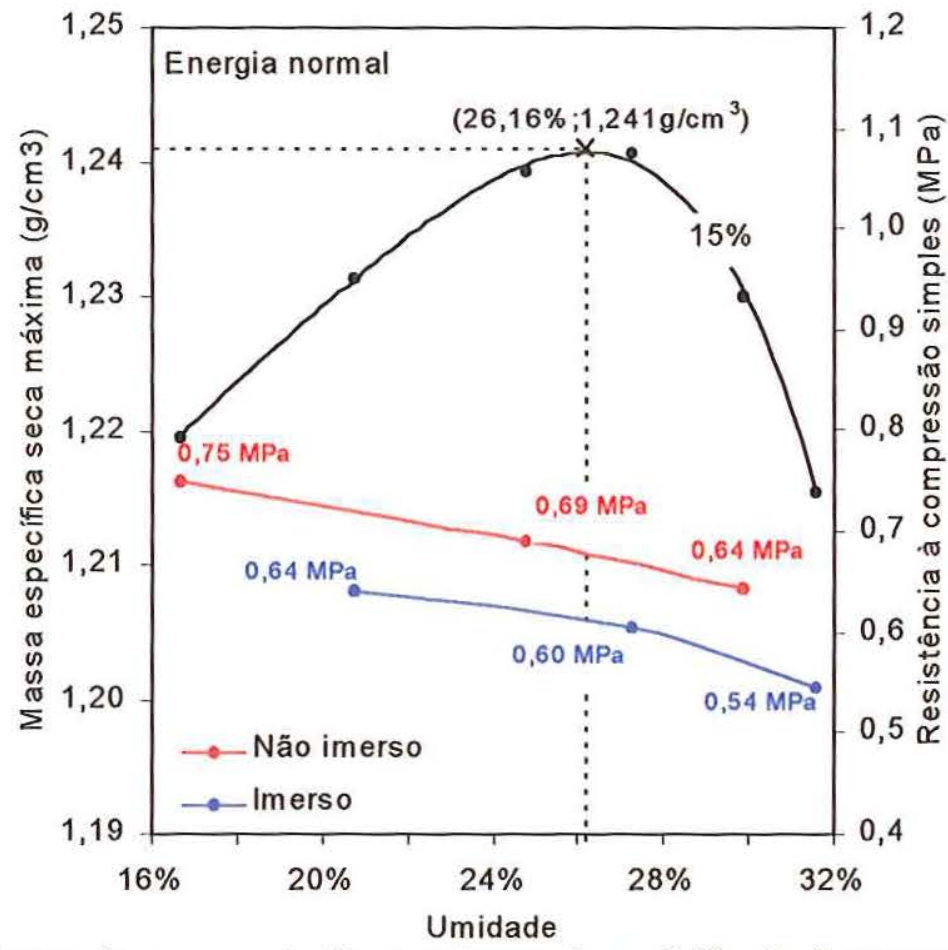

Figura A.4: Curva de compactação e valores de resistência à compressão simples para corpos de prova compostos com fosfogesso $A$ e $15 \%$ de cimento compactados na energia normal. 


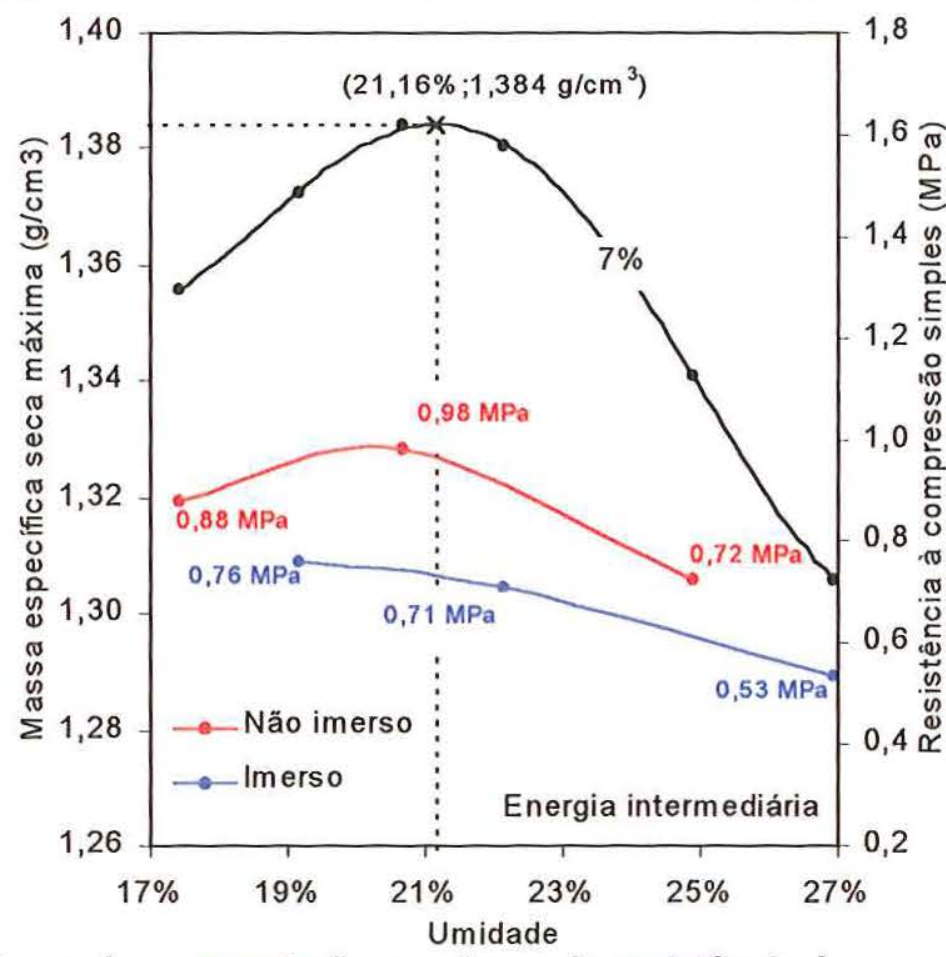

Figura A.5: Curva de compactação e valores de resistência à compressão simples para corpos de prova compostos com fosfogesso $A$ e $7 \%$ de cimento compactados na energia intermediária.

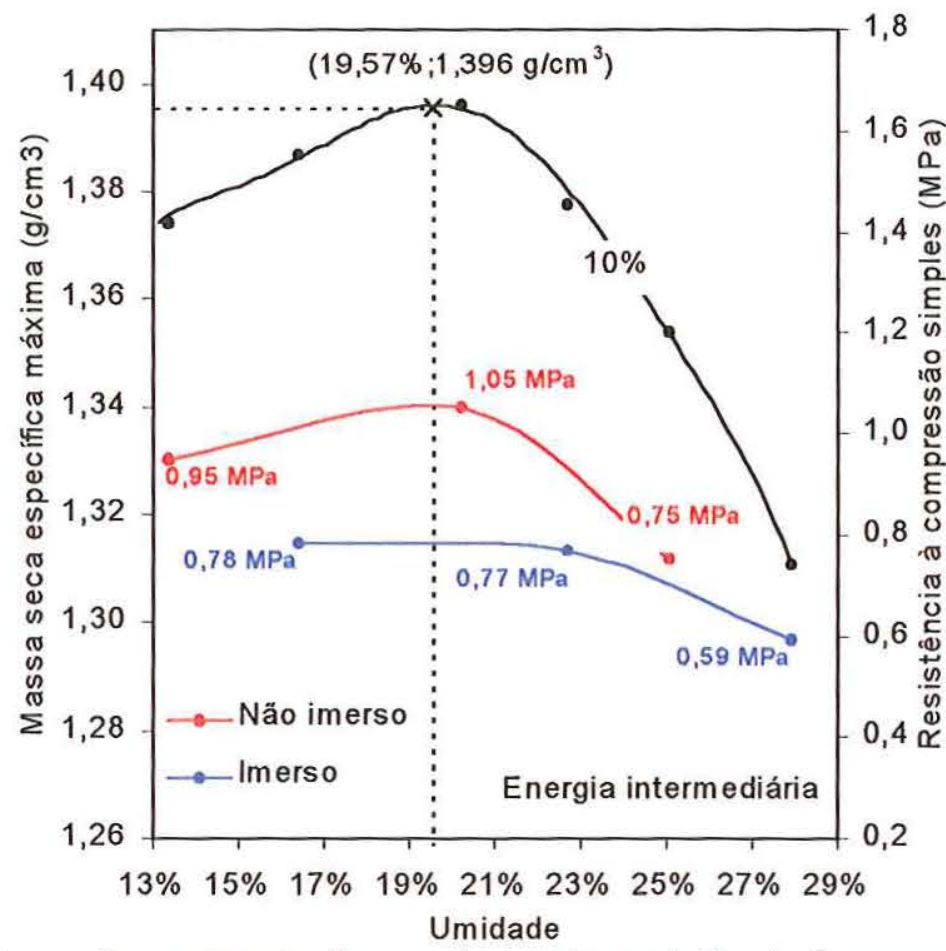

Figura A.6: Curva de compactação e valores de resistência à compressão simples para corpos de prova compostos com fosfogesso $A$ e $10 \%$ de cimento compactados na energia intermediária. 


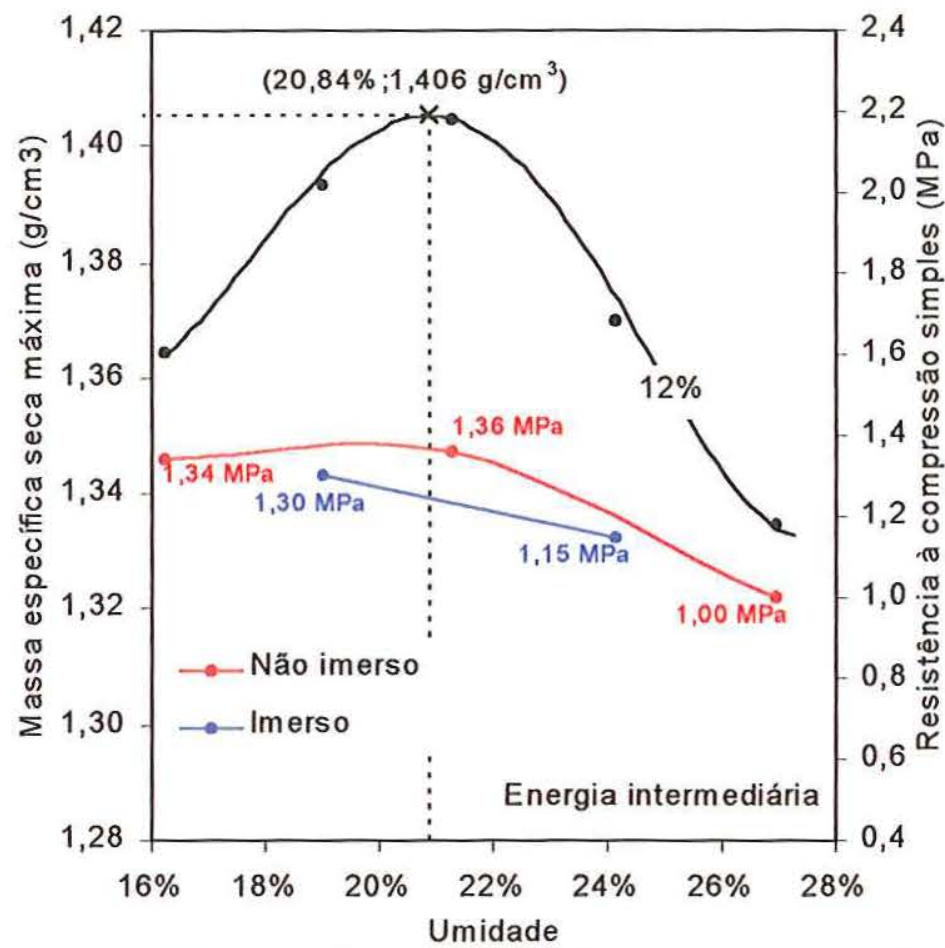

Figura A.7: Curva de compactação e valores de resistência à compressão simples para corpos de prova compostos com fosfogesso A e $12 \%$ de cimento compactados na energia intermediária.

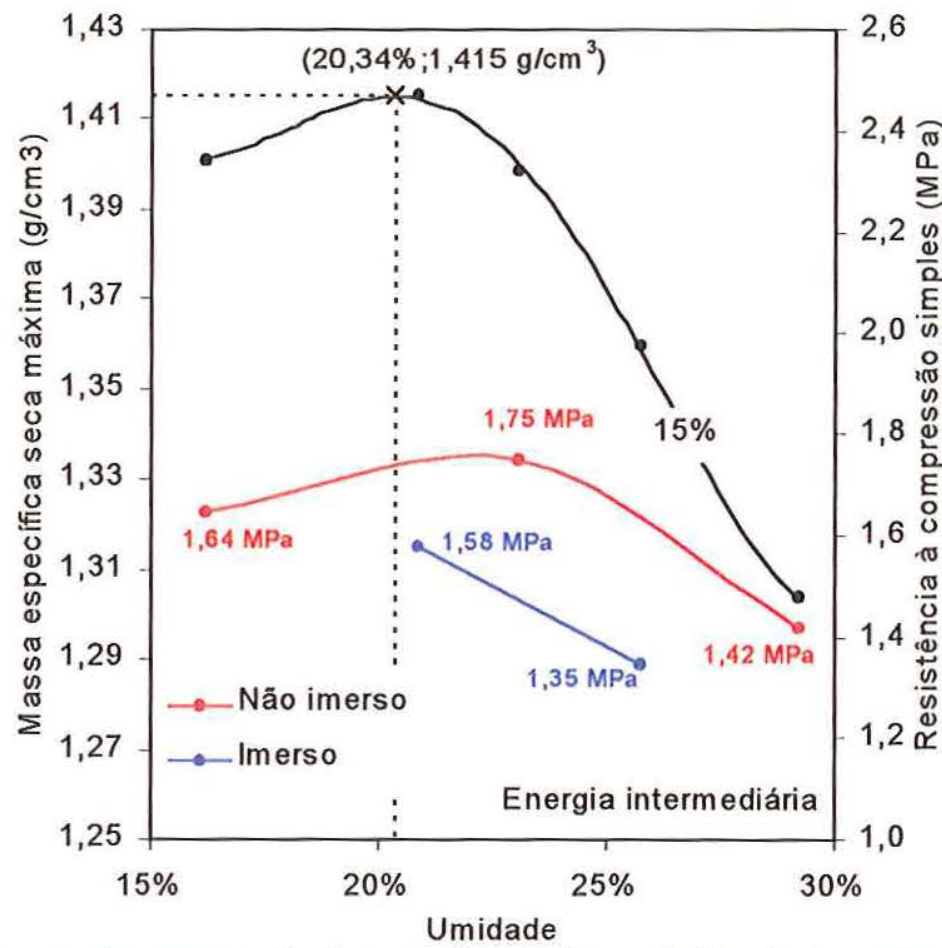

Figura A.8: Curva de compactação e valores de resistência à compressão simples para corpos de prova compostos com fosfogesso A e $15 \%$ de cimento compactados na energia intermediária. 


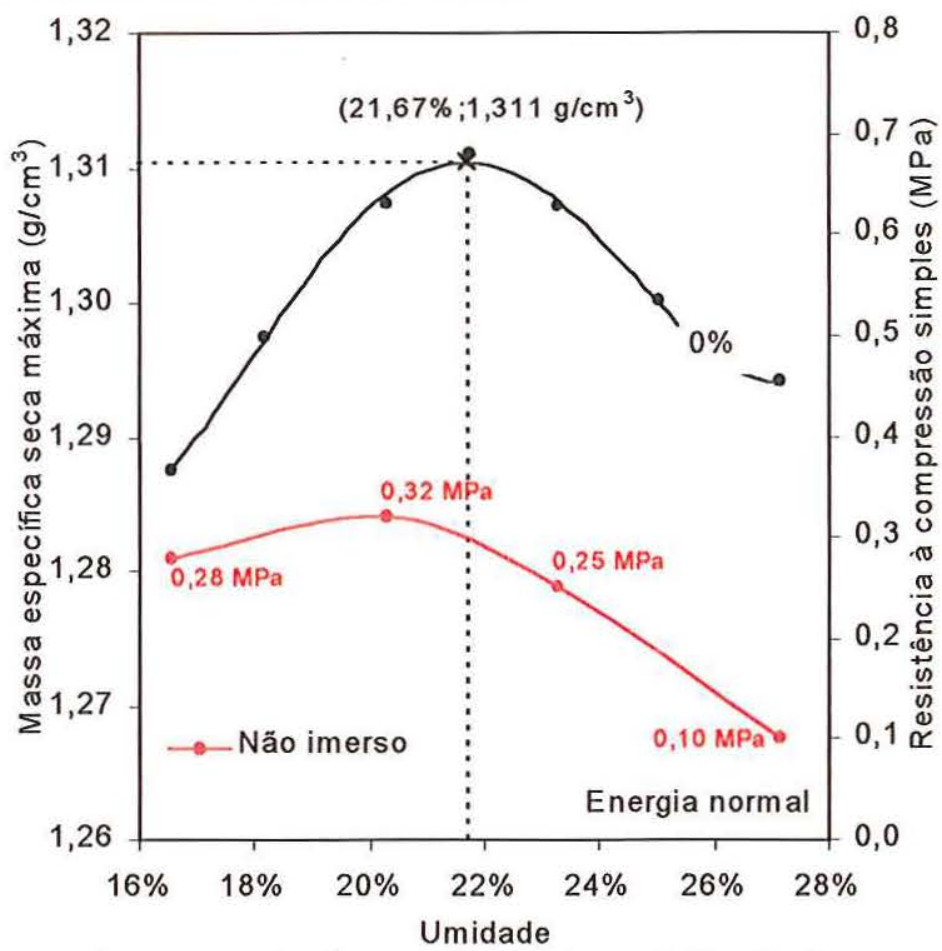

Figura A.9: Curva de compactação e valores de resistência à compressão simples para corpos de prova compostos com fosfogesso B e $0 \%$ de cimento compactados na energia normal.

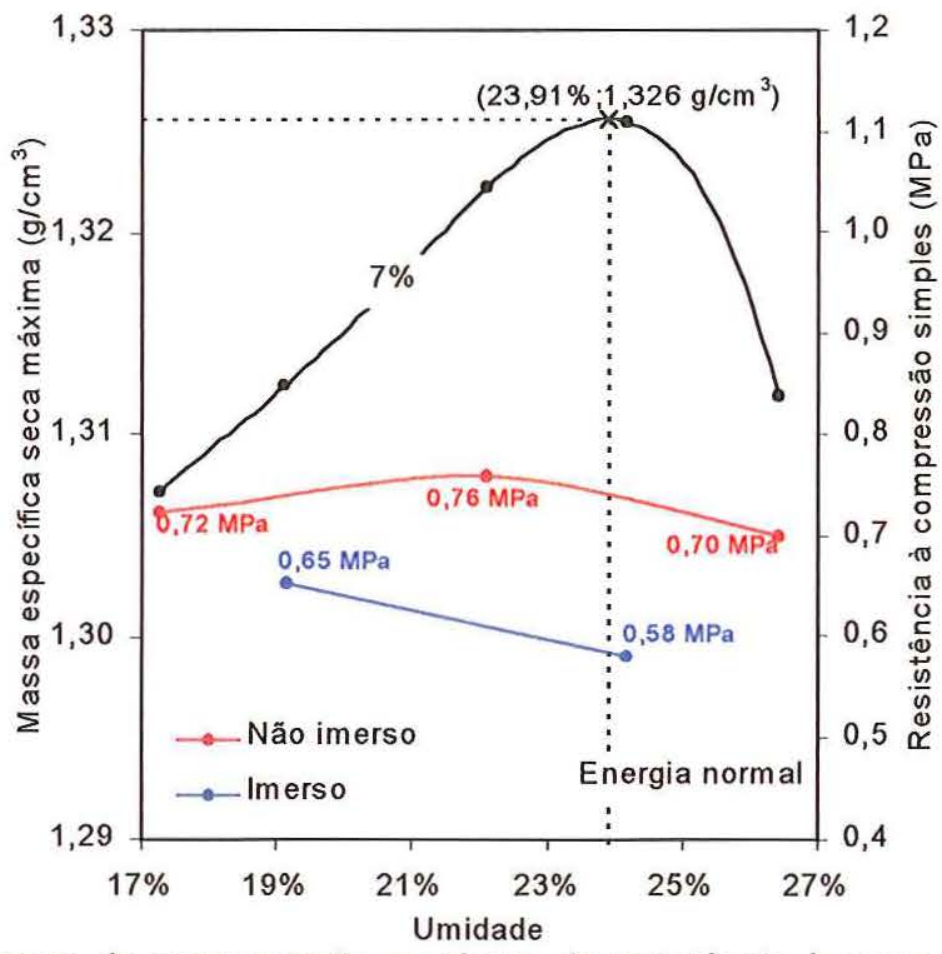

Figura A.10: Curva de compactação e valores de resistência à compressão simples para corpos de prova compostos com fosfogesso B e $7 \%$ de cimento compactados na energia normal. 
Página 147

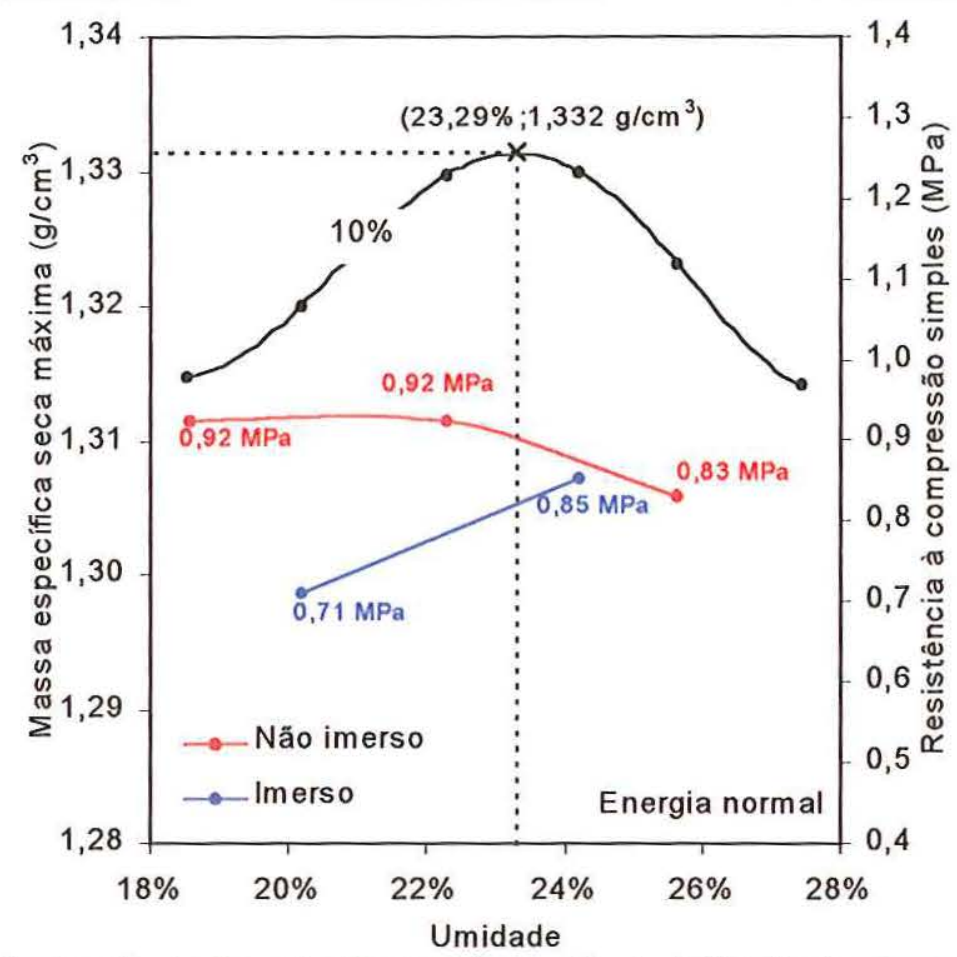

Figura A.11: Curva de compactação e valores de resistência à compressão simples para corpos de prova compostos com fosfogesso B e $10 \%$ de cimento compactados na energia normal.

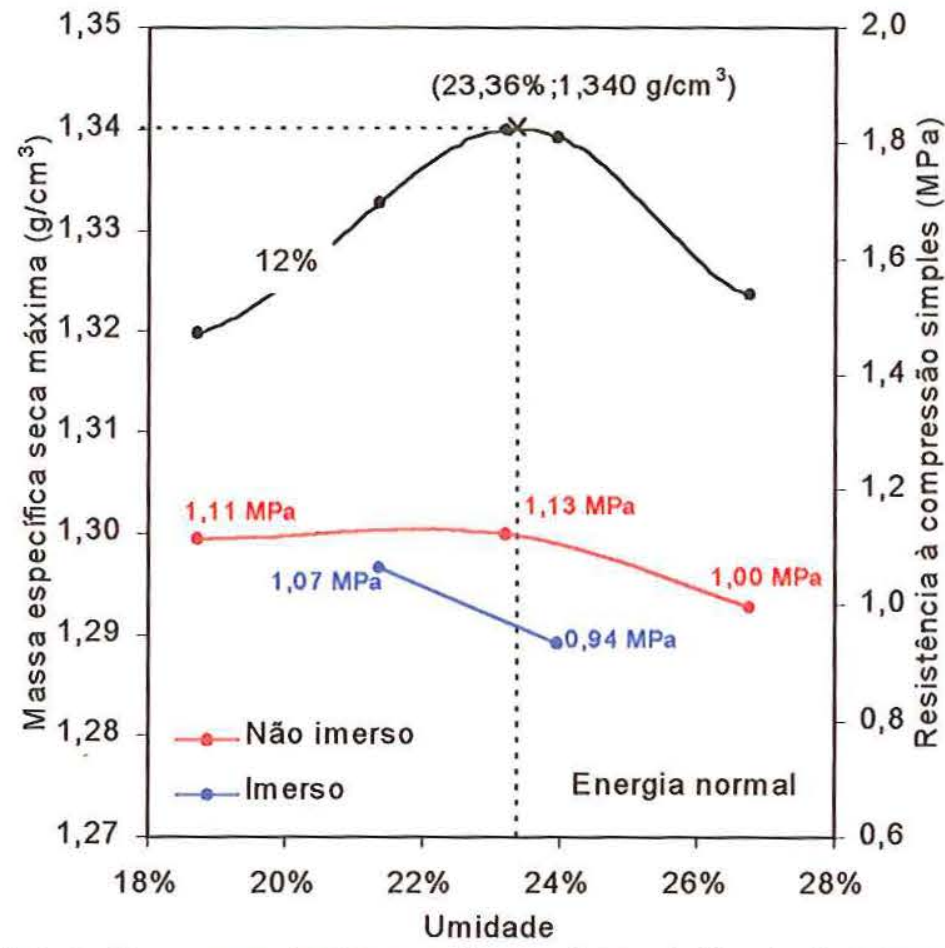

Figura A.12: Curva de compactação e valores de resistência à compressão simples para corpos de prova compostos com fosfogesso B e $12 \%$ de cimento compactados na energia normal. 


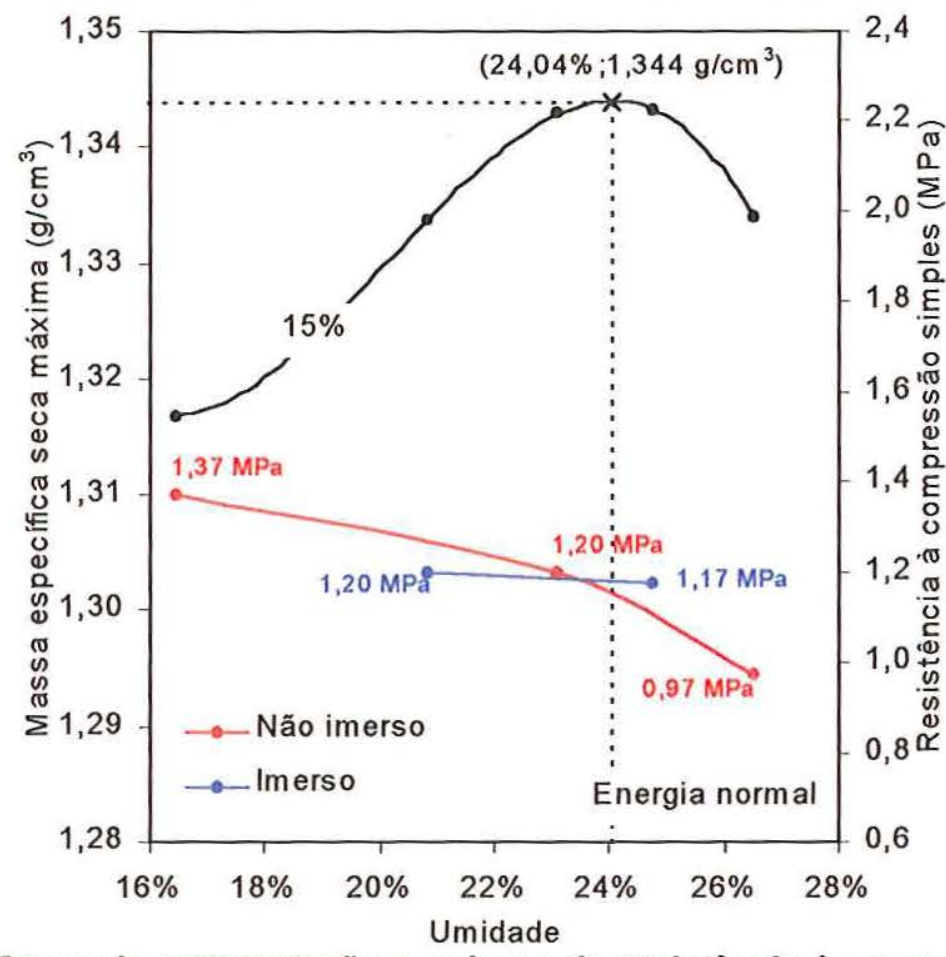

Figura A.13: Curva de compactação e valores de resistência à compressão simples para corpos de prova compostos com fosfogesso B e $15 \%$ de cimento compactados na energia normal.

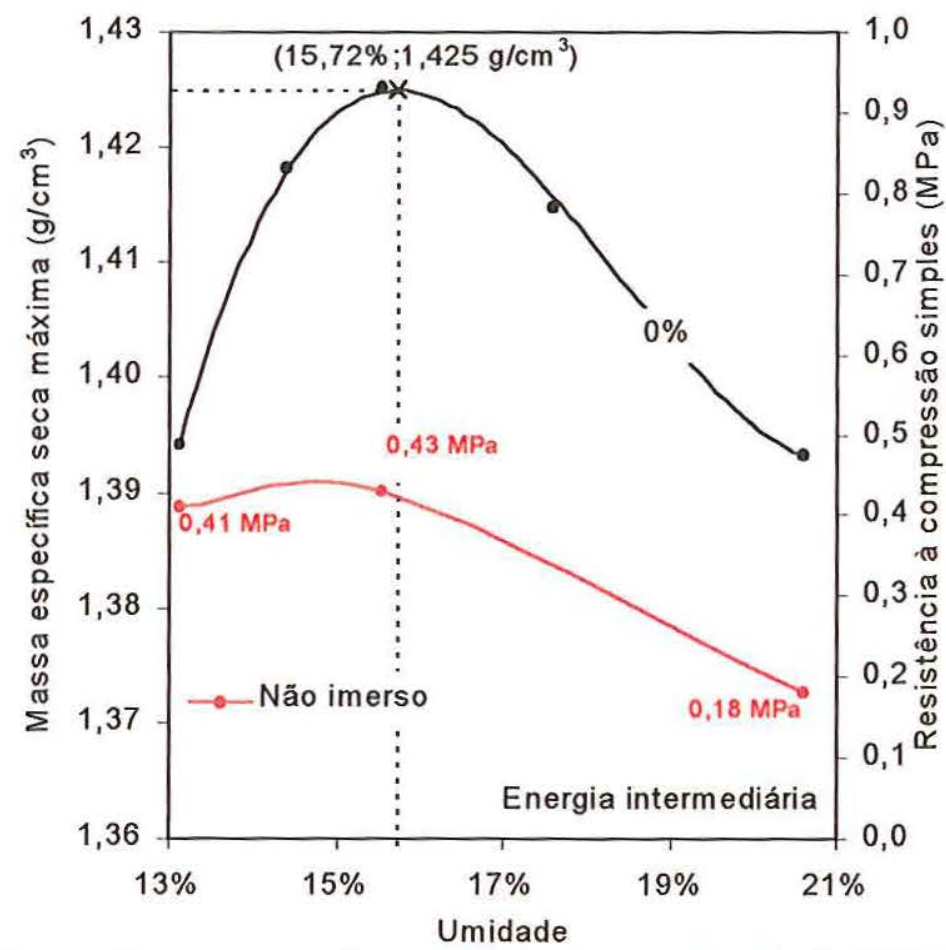

Figura A.14: Curva de compactação e valores de resistência à compressão simples para corpos de prova compostos com fosfogesso B e $0 \%$ de cimento compactados na energia intermediária. 


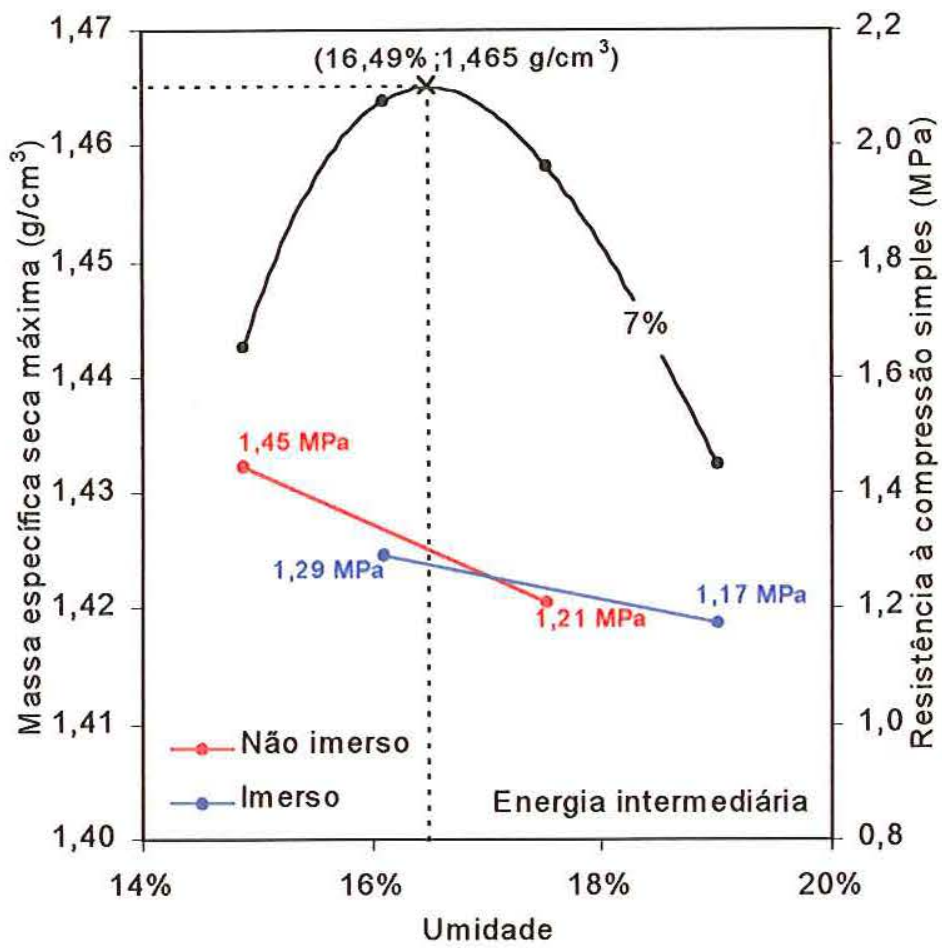

Figura A.15: Curva de compactação e valores de resistência à compressão simples para corpos de prova compostos com fosfogesso B e $7 \%$ de cimento compactados na energia intermediária.

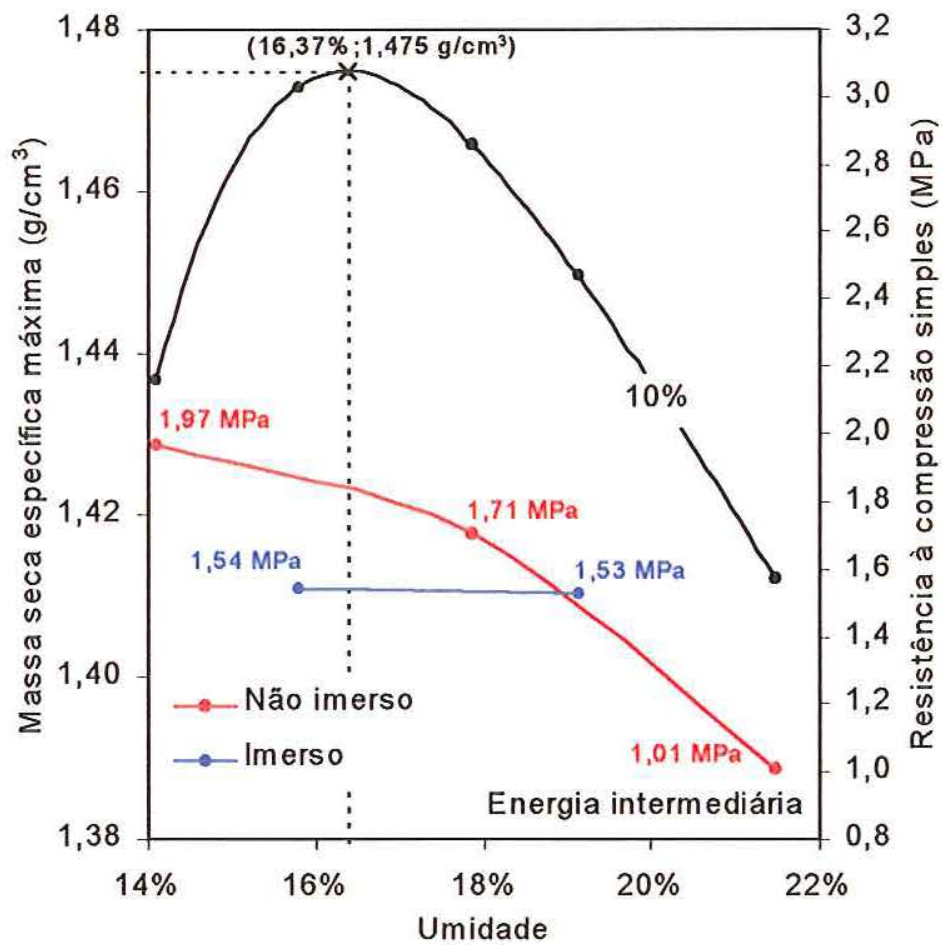

Figura A.16: Curva de compactação e valores de resistência à compressão simples para corpos de prova compostos com fosfogesso B e $10 \%$ de cimento compactados na energia intermediária. 


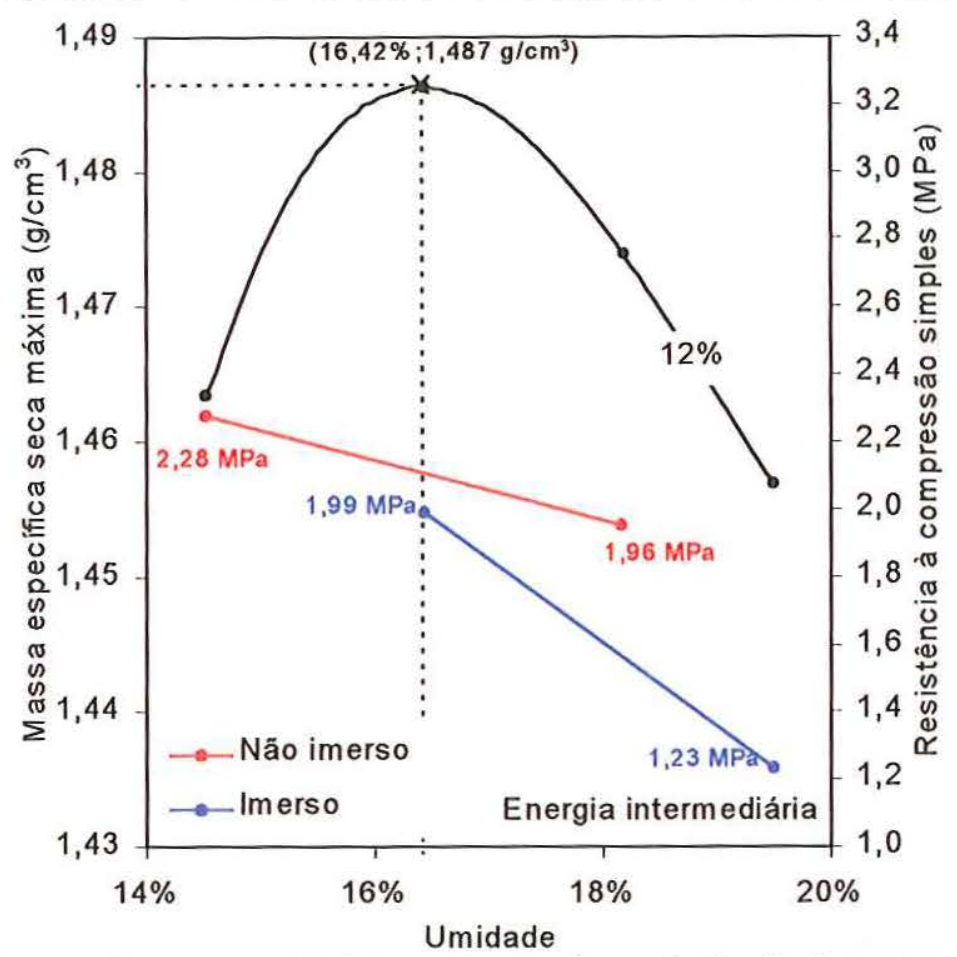

Figura A.17: Curva de compactação e valores de resistência à compressão simples para corpos de prova compostos com fosfogesso B e $12 \%$ de cimento compactados na energia intermediária.

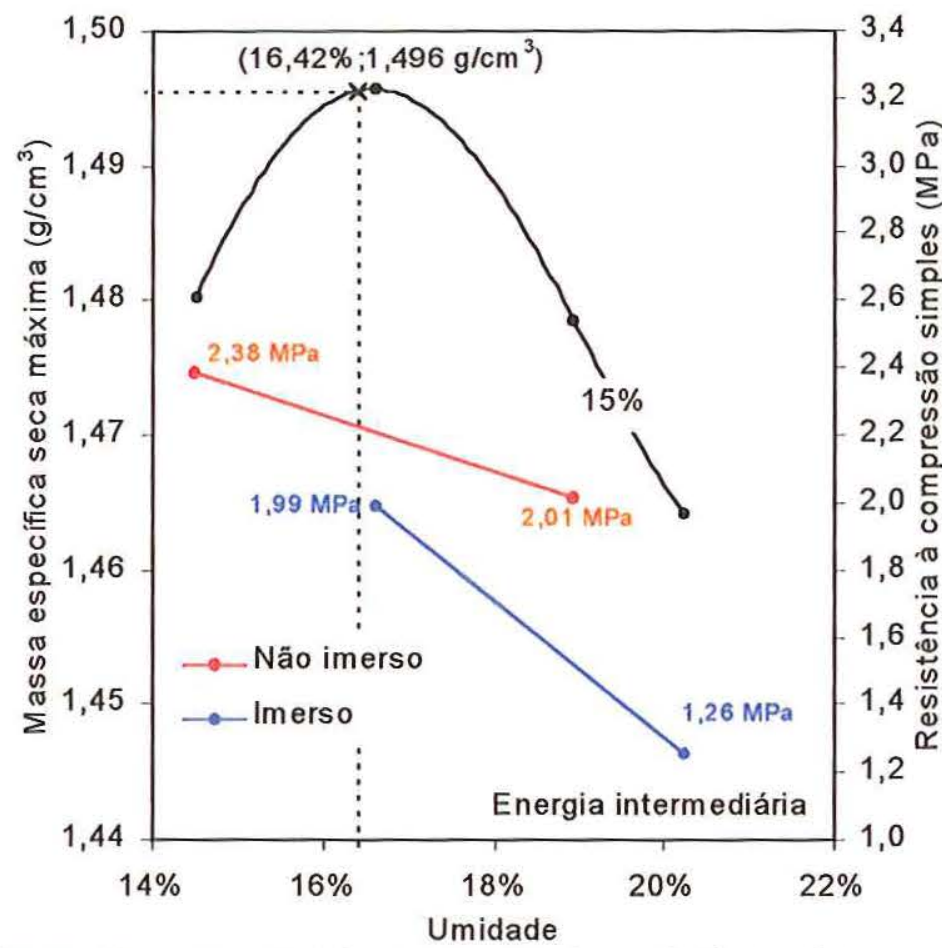

Figura A.18 Curva de compactação e valores de resistência à compressão simples para corpos de prova compostos com fosfogesso B e $15 \%$ de cimento compactados na energia intermediária. 


\section{ANEXO B - VALORES DE RESISTÊNCIA A COMPRESSÃO SIMPLES OBTIDOS DE CORPOS DE PROVA COMPACTADOS COM AS ENERGIAS NORMAL E INTERMEDIÁRIA, E ENSAIADOS COM IMERSÃO E SEM IMERSÃO PRÉVIA}

Apresentam-se nas Tabelas de B.1 a B.4 os valores de resistência à compressão simples para todos os corpos de prova ensaiados na etapa definitiva de estudos. Esse valores estão separados em função da energia de compactação, da condição de ensaio, do período de cura, e do teor de cimento. Além dos valores de resistência para as trincas de corpos de prova, apresentam-se a média dos valores, o desvio padrão, e o coeficiente de variação, este último definido como a relação entre o desvio padrão e média das resistência. 
Tabela B.1: Valores de resistência à compressão simples para corpos de prova ensaiados sem imersão prévia e compactados na energia normal.

\begin{tabular}{|c|c|c|c|c|c|c|c|c|c|c|}
\hline \multirow{3}{*}{$\begin{array}{l}\text { Período } \\
\text { de } \\
\text { cura }\end{array}$} & \multirow{3}{*}{$\begin{array}{c}\text { Teor } \\
\text { de } \\
\text { cimento }\end{array}$} & \multirow{3}{*}{\multicolumn{2}{|c|}{$\begin{array}{c}\text { Umidade } \\
\text { de } \\
\text { compactação }\end{array}$}} & \multirow{3}{*}{$\begin{array}{c}\text { Massa } \\
\text { específica } \\
\text { seca } \\
\text { máxima } \\
(\text { média) } \\
\left(\mathrm{g} / \mathrm{cm}^{3}\right)\end{array}$} & \multicolumn{6}{|c|}{ Resistência à compressão simples (MPa) } \\
\hline & & & & & \multicolumn{3}{|c|}{ c.p. } & \multirow[t]{2}{*}{ Média } & \multirow{2}{*}{$\begin{array}{l}\text { Desvio } \\
\text { padrão }\end{array}$} & \multirow{2}{*}{$\begin{array}{c}\text { Coeficiente } \\
\text { de } \\
\text { variação }\end{array}$} \\
\hline & & & & & 1 & 2 & 3 & & & \\
\hline \multirow{4}{*}{3 dias } & $7 \%$ & $\mathrm{w}_{0}$ & 22,7 & 1,29 & 0,31 & - & - & - & - & - \\
\hline & $10 \%$ & $\mathrm{w}_{0}$ & 23,3 & 1,29 & 0,40 & - & - & - & - & - \\
\hline & $12 \%$ & $\mathrm{w}_{0}$ & 23,2 & 1,30 & 0,51 & - & - & - & - & - \\
\hline & $15 \%$ & $w_{0}$ & 23,8 & 1,31 & 0,57 & - & - & - & - & - \\
\hline \multirow{8}{*}{7 dias } & $7 \%$ & $w_{0}$ & 22,1 & 1,29 & 0,87 & 0,84 & 0,85 & 0,85 & 0,02 & $1,99 \%$ \\
\hline & \multirow{3}{*}{$10 \%$} & $\mathrm{w}_{0}-2 \%$ & 21,2 & 1,30 & 1,10 & 1,04 & 1,04 & 1,06 & 0,04 & $3,52 \%$ \\
\hline & & $\mathrm{w}_{0}$ & 23,0 & 1,32 & 1,08 & 1,06 & 1,03 & 1,06 & 0,02 & $2,31 \%$ \\
\hline & & $w_{0}+2 \%$ & 25,2 & 1,30 & 1,07 & 1,08 & 1,01 & 1,05 & 0,04 & $3,70 \%$ \\
\hline & $12 \%$ & $w_{0}$ & 22,2 & 1,30 & 1,26 & 1,29 & 1,26 & 1,27 & 0,02 & $1,28 \%$ \\
\hline & \multirow{3}{*}{$15 \%$} & $w_{0}-2 \%$ & 20,9 & 1,29 & 1,55 & 1,54 & 1,52 & 1,54 & 0,02 & $1,04 \%$ \\
\hline & & $w_{0}$ & 23,4 & 1,30 & 1,54 & 1,44 & 1,48 & 1,49 & 0,05 & $3,66 \%$ \\
\hline & & $w_{0}+2 \%$ & 25,3 & 1,31 & 1,53 & 1,50 & 1,51 & 1,51 & 0,01 & $0,85 \%$ \\
\hline \multirow{4}{*}{14 dias } & $7 \%$ & $w_{0}$ & 23,0 & 1,30 & 1,12 & 1,05 & 1,06 & 1,08 & 0,04 & $3,65 \%$ \\
\hline & $10 \%$ & $w_{0}$ & 22,7 & 1,29 & 1,38 & 1,29 & 1,29 & 1,32 & 0,05 & $3,97 \%$ \\
\hline & $12 \%$ & $w_{0}$ & 22,0 & 1,30 & 1,48 & 1,48 & 1,51 & 1,49 & 0,02 & $1,01 \%$ \\
\hline & $15 \%$ & $w_{0}$ & 22,3 & 1,31 & 1,74 & 1,79 & 1,83 & 1,78 & 0,05 & $2,56 \%$ \\
\hline \multirow{8}{*}{28 dias } & $7 \%$ & $w_{0}$ & 23,9 & 1,28 & 1,21 & 1,21 & 1,15 & 1,19 & 0,04 & $3,00 \%$ \\
\hline & \multirow{3}{*}{$10 \%$} & $w_{0}-2 \%$ & 21,6 & 1,28 & 1,42 & 1,37 & 1,40 & 1,40 & 0,03 & $1,87 \%$ \\
\hline & & $w_{0}$ & 23,5 & 1,28 & 1,42 & 1,51 & 1,45 & 1,46 & 0,05 & $3,21 \%$ \\
\hline & & $w_{0}+2 \%$ & 25,6 & 1,28 & 1,48 & 1,42 & 1,39 & 1,43 & 0,04 & $2,95 \%$ \\
\hline & $12 \%$ & $W_{0}$ & 23,6 & 1,28 & 1,59 & 1,62 & 1,59 & 1,60 & 0,02 & $1,22 \%$ \\
\hline & \multirow{3}{*}{$15 \%$} & $W_{0}-2 \%$ & 20,7 & 1,29 & 1,93 & 1,90 & 1,92 & 1,92 & 0,02 & $0,88 \%$ \\
\hline & & $w_{0}$ & 23,6 & 1,30 & 1,90 & 1,97 & 1,93 & 1,93 & 0,03 & $1,64 \%$ \\
\hline & & $w_{0}+2 \%$ & 24,9 & 1,29 & 1,90 & 1,77 & 1,99 & 1,89 & 0,11 & $5,68 \%$ \\
\hline \multirow{8}{*}{84 dias } & $7 \%$ & $w_{0}$ & 22,2 & 1,29 & 1,43 & 1,36 & 1,41 & 1,40 & 0,04 & $2,69 \%$ \\
\hline & \multirow{3}{*}{$10 \%$} & $W_{0}-2 \%$ & 20,6 & 1,28 & 1,70 & 1,63 & 1,69 & 1,67 & 0,04 & $2,14 \%$ \\
\hline & & $w_{0}$ & 22,7 & 1,29 & 1,92 & 1,80 & 1,64 & 1,79 & 0,14 & $8,01 \%$ \\
\hline & & $w_{0}+2 \%$ & 25,1 & 1,29 & 1,83 & 1,77 & 1,68 & 1,76 & 0,07 & $4,13 \%$ \\
\hline & $12 \%$ & $w_{0}$ & 22,1 & 1,29 & 1,93 & 1,92 & 1,86 & 1,90 & 0,04 & $2,04 \%$ \\
\hline & \multirow{3}{*}{$15 \%$} & $w_{0}-2 \%$ & 20,8 & 1,29 & 1,99 & 2,11 & 2,08 & 2,06 & 0,06 & $3,09 \%$ \\
\hline & & $w_{0}$ & 23,4 & 1,29 & 2,20 & 2,17 & 2,07 & 2,14 & 0,07 & $3,15 \%$ \\
\hline & & $w_{0}+2 \%$ & 25,5 & 1,29 & 2,11 & 2,16 & 2,10 & 2,12 & 0,03 & $1,56 \%$ \\
\hline
\end{tabular}


Tabela B.2: Valores de resistência à compressão simples para corpos de prova ensaiados com imersão prévia e compactados na energia normal.

\begin{tabular}{|c|c|c|c|c|c|c|c|c|c|c|}
\hline \multirow{3}{*}{$\begin{array}{c}\text { Período } \\
\text { de } \\
\text { cura } \\
\text { (dias) }\end{array}$} & \multirow{3}{*}{$\begin{array}{c}\text { Teor } \\
\text { de } \\
\text { cimento } \\
(\%)\end{array}$} & \multirow{3}{*}{\multicolumn{2}{|c|}{$\begin{array}{c}\text { Umidade } \\
\text { de } \\
\text { compactação } \\
(\%)\end{array}$}} & \multirow{3}{*}{$\begin{array}{c}\text { Massa } \\
\text { específica } \\
\text { seca } \\
\text { máxima } \\
\text { (média) } \\
\left(\mathrm{g} / \mathrm{cm}^{3}\right)\end{array}$} & \multicolumn{6}{|c|}{ Resistência à compressão simples (MPa) } \\
\hline & & & & & \multicolumn{3}{|c|}{ c.p. } & \multirow[t]{2}{*}{ Média } & \multirow{2}{*}{$\begin{array}{l}\text { Desvio } \\
\text { Padrão }\end{array}$} & \multirow{2}{*}{$\begin{array}{c}\text { Coeficiente } \\
\text { de } \\
\text { variação }\end{array}$} \\
\hline & & & & & 4 & 5 & 6 & & & \\
\hline \multirow{4}{*}{3 dias } & $7 \%$ & $\mathrm{w}_{\mathrm{o}}$ & 22,7 & 1,29 & 0,20 & - & - & - & - & - \\
\hline & $10 \%$ & $w_{0}$ & 23,3 & 1,30 & 0,25 & - & - & - & - & - \\
\hline & $12 \%$ & $w_{0}$ & 23,2 & 1,30 & 0,33 & - & - & - & - & - \\
\hline & $15 \%$ & $W_{0}$ & 23,8 & 1,31 & 0,37 & - & - & - & - & - \\
\hline \multirow{8}{*}{7 dias } & $7 \%$ & $w_{0}$ & 22,1 & 1,29 & 0,74 & 0,81 & 0,75 & 0,77 & 0,04 & $4,72 \%$ \\
\hline & \multirow{3}{*}{$10 \%$} & $w_{0}-2 \%$ & 21,2 & 1,30 & 0,97 & 0,96 & 0,93 & 0,96 & 0,02 & $2,19 \%$ \\
\hline & & $w_{0}$ & 23,0 & 1,32 & 0,99 & 0,95 & 0,93 & 0,96 & 0,03 & $3,20 \%$ \\
\hline & & $\mathrm{w}_{0}+2 \%$ & 25,2 & 1,30 & 1,01 & 0,95 & 0,92 & 0,96 & 0,05 & $4,84 \%$ \\
\hline & $12 \%$ & $w_{0}$ & 22,2 & 1,30 & 1,21 & 1,16 & 1,20 & 1,19 & 0,03 & $2,24 \%$ \\
\hline & \multirow{3}{*}{$15 \%$} & $w_{0}-2 \%$ & 20,9 & 1,29 & 1,50 & 1,44 & 1,44 & 1,46 & 0,04 & $2,60 \%$ \\
\hline & & $w_{0}$ & 23,4 & 1,30 & 1,38 & 1,39 & 1,38 & 1,38 & 0,01 & $0,54 \%$ \\
\hline & & $w_{0}+2 \%$ & 25,3 & 1,31 & 1,45 & 1,36 & 1,40 & 1,40 & 0,04 & $3,14 \%$ \\
\hline \multirow{4}{*}{14 dias } & $7 \%$ & $w_{0}$ & 23,0 & 1,30 & 0,98 & 1,00 & 0,95 & 0,98 & 0,03 & $2,60 \%$ \\
\hline & $10 \%$ & $w_{0}$ & 22,7 & 1,29 & 1,19 & 1,16 & 1,14 & 1,16 & 0,02 & $1,96 \%$ \\
\hline & $12 \%$ & $w_{0}$ & 22,0 & 1,30 & 1,41 & 1,43 & 1,43 & 1,42 & 0,01 & $0,81 \%$ \\
\hline & $15 \%$ & $w_{0}$ & 22,3 & 1,31 & 1,70 & 1,73 & 1,72 & 1,72 & 0,01 & $0,68 \%$ \\
\hline \multirow{8}{*}{28 dias } & $7 \%$ & $w_{0}$ & 23,9 & 1,28 & 1,03 & 1,09 & 1,05 & 1,06 & 0,03 & $2,89 \%$ \\
\hline & \multirow{3}{*}{$10 \%$} & $w_{0}-2 \%$ & 21,6 & 1,28 & 1,19 & 1,28 & 1,30 & 1,26 & 0,06 & $4,80 \%$ \\
\hline & & $w_{0}$ & 23,5 & 1,28 & 1,30 & 1,34 & 1,32 & 1,32 & 0,02 & $1,39 \%$ \\
\hline & & $\mathrm{w}_{0}+2 \%$ & 25,6 & 1,28 & 1,25 & 1,25 & 1,32 & 1,28 & 0,04 & $3,33 \%$ \\
\hline & $12 \%$ & $w_{0}$ & 23,6 & 1,28 & 1,54 & 1,48 & 1,51 & 1,51 & 0,03 & $1,99 \%$ \\
\hline & \multirow{3}{*}{$15 \%$} & $w_{0}-2 \%$ & 20,7 & 1,29 & 1,75 & 1,86 & 1,80 & 1,80 & 0,05 & $3,00 \%$ \\
\hline & & $w_{0}$ & 23,6 & 1,30 & 1,86 & 1,83 & 1,73 & 1,81 & 0,06 & $3,53 \%$ \\
\hline & & $w_{0}+2 \%$ & 24,9 & 1,29 & 1,76 & 1,75 & 1,74 & 1,75 & 0,01 & $0,47 \%$ \\
\hline \multirow{8}{*}{84 dias. } & $7 \%$ & $w_{0}$ & 22,2 & 1,29 & 1,24 & 1,29 & 1,28 & 1,27 & 0,02 & $1,94 \%$ \\
\hline & \multirow{3}{*}{$10 \%$} & $w_{0}-2 \%$ & 20,6 & 1,28 & 1,51 & 1,47 & 1,51 & 1,50 & 0,03 & $1,85 \%$ \\
\hline & & $w_{0}$ & 22,7 & 1,29 & 1,64 & 1,63 & 1,59 & 1,62 & 0,02 & $1,47 \%$ \\
\hline & & $w_{0}+2 \%$ & 25,1 & 1,29 & 1,62 & 1,61 & 1,66 & 1,63 & 0,02 & $1,49 \%$ \\
\hline & $12 \%$ & $w_{0}$ & 22,1 & 1,29 & 1,87 & 1,80 & 1,77 & 1,81 & 0,05 & $2,81 \%$ \\
\hline & \multirow{3}{*}{$15 \%$} & $W_{0}-2 \%$ & 20,8 & 1,29 & 1,95 & 1,96 & 1,97 & 1,96 & 0,01 & $0,49 \%$ \\
\hline & & $w_{0}$ & 23,4 & 1,29 & 1,90 & 1,97 & 2,05 & 1,97 & 0,08 & $3,89 \%$ \\
\hline & & $w_{0}+2 \%$ & 25,5 & 1,29 & 1,94 & 1,98 & 2,09 & 2,00 & 0,07 & $3,69 \%$ \\
\hline
\end{tabular}


Tabela B.3: Valores de resistência à compressão simples para corpos de prova ensaiados sem imersão prévia e compactados na energia intermediária.

\begin{tabular}{|c|c|c|c|c|c|c|c|c|c|c|}
\hline \multirow{3}{*}{$\begin{array}{l}\text { Período } \\
\text { de } \\
\text { cura } \\
\text { (dias) }\end{array}$} & \multirow{3}{*}{$\begin{array}{c}\text { Teor } \\
\text { de } \\
\text { cimento } \\
(\%)\end{array}$} & \multirow{3}{*}{\multicolumn{2}{|c|}{$\begin{array}{c}\text { Umidade } \\
\text { de } \\
\text { compactação } \\
(\%)\end{array}$}} & \multirow{3}{*}{$\begin{array}{l}\text { Massa } \\
\text { específica } \\
\text { seca } \\
\text { máxima } \\
\text { (média) } \\
\left(\mathrm{g} / \mathrm{cm}^{3}\right)\end{array}$} & \multicolumn{6}{|c|}{ Resistência à compressão simples (MPa) } \\
\hline & & & & & & c.p. & & Média & Desvio & Coeficiente \\
\hline & & & & & 1 & 2 & 3 & & Padrão & $\begin{array}{c}\text { de } \\
\text { variação }\end{array}$ \\
\hline \multirow{4}{*}{3 dias } & $7 \%$ & $\mathrm{w}_{\mathrm{o}}$ & 15,7 & 1,40 & 0,77 & - & - & - & - & - \\
\hline & $10 \%$ & $w_{0}$ & 16,3 & 1,40 & 0,79 & - & - & - & - & - \\
\hline & $12 \%$ & $w_{0}$ & 16,6 & 1,41 & 0,94 & - & - & - & - & - \\
\hline & $15 \%$ & $w_{0}$ & 15,9 & 1,41 & 1,14 & - & - & - & - & - \\
\hline \multirow{8}{*}{7 dias } & \multirow{3}{*}{$7 \%$} & $W_{0}-2 \%$ & 13,8 & 1,41 & 1,56 & 1,53 & 1,55 & 1,55 & 0,02 & $1,11 \%$ \\
\hline & & $w_{0}$ & 16,4 & 1,41 & 1,54 & 1,51 & 1,54 & 1,53 & 0,02 & $1,17 \%$ \\
\hline & & $w_{0}+2 \%$ & 17,5 & 1,41 & 1,56 & 1,56 & & 1,56 & 0,00 & $0,23 \%$ \\
\hline & \multirow{3}{*}{$10 \%$} & $w_{0}-2 \%$ & 14,2 & 1,44 & 1,99 & 1,95 & 2,06 & 2,00 & 0,056 & $2,81 \%$ \\
\hline & & $w_{0}$ & 15,7 & 1,43 & 1,89 & 1,89 & 1,90 & 1,90 & 0,006 & $0,33 \%$ \\
\hline & & $w_{0}+2 \%$ & 17,5 & 1,44 & 1,98 & 1,89 & 1,90 & 1,92 & 0,047 & $2,47 \%$ \\
\hline & $12 \%$ & $w_{0}$ & 15,2 & 1,44 & 2,21 & 2,13 & 2,04 & 2,12 & 0,084 & $3,93 \%$ \\
\hline & $15 \%$ & $w_{0}$ & 15,1 & 1,43 & 2,67 & 2,67 & 2,52 & 2,62 & 0,082 & $3,13 \%$ \\
\hline \multirow{4}{*}{14 dias } & $7 \%$ & $w_{0}$ & 16,3 & 1,43 & 2,08 & 2,08 & 2,02 & 2,06 & 0,03 & $1,70 \%$ \\
\hline & $10 \%$ & $w_{0}$ & 16,3 & 1,42 & 2,41 & 2,46 & 2,40 & 2,42 & 0,03 & $1,39 \%$ \\
\hline & $12 \%$ & $w_{0}$ & 16,3 & 1,42 & 2,67 & 2,52 & 2,51 & 2,57 & 0,09 & $3,57 \%$ \\
\hline & $15 \%$ & $w_{0}$ & 16,2 & 1,42 & 3,13 & 2,97 & 3,05 & 3,05 & 0,08 & $2,57 \%$ \\
\hline \multirow{8}{*}{28 dias } & \multirow{3}{*}{$7 \%$} & $w_{0}-2 \%$ & 15,1 & 1,41 & 2,18 & 2,03 & 2,20 & 2,14 & 0,09 & $4,40 \%$ \\
\hline & & $w_{0}$ & 17,2 & 1,41 & 2,17 & 2,23 & 2,18 & 2,19 & 0,03 & $1,47 \%$ \\
\hline & & $w_{0}+2 \%$ & 19,1 & 1,41 & 2,17 & 2,15 & 2,07 & 2,13 & 0,05 & $2,38 \%$ \\
\hline & \multirow{3}{*}{$10 \%$} & $\mathrm{w}_{0}-2 \%$ & 13,9 & 1,42 & 2,43 & 2,57 & 2,67 & 2,56 & 0,12 & $4,72 \%$ \\
\hline & & $w_{0}$ & 16,2 & 1,43 & 2,66 & 2,64 & 2,61 & 2,64 & 0,03 & $0,95 \%$ \\
\hline & & $w_{0}+2 \%$ & 18,4 & 1,44 & 2,58 & 2,61 & 2,64 & 2,61 & 0,03 & $1,15 \%$ \\
\hline & $12 \%$ & $w_{0}$ & 17,2 & 1,42 & 2,95 & 2,74 & 2,79 & 2,84 & 0,15 & $5,25 \%$ \\
\hline & $15 \%$ & $w_{0}$ & 17,4 & 1,42 & 3,36 & 3,29 & 3,36 & 3,33 & 0,04 & $1,16 \%$ \\
\hline \multirow{8}{*}{84 dias } & \multirow{3}{*}{$7 \%$} & $w_{0}-2 \%$ & 14,6 & 1,43 & 1,33 & 2,28 & 2,49 & 2,39 & 0,14 & $6,02 \%$ \\
\hline & & $\mathrm{w}_{0}$ & 16,3 & 1,43 & 2,30 & 2,35 & 2,34 & 2,33 & 0,03 & $1,14 \%$ \\
\hline & & $w_{0}+2 \%$ & 18,2 & 1,43 & 2,50 & 2,45 & 2,40 & 2,45 & 0,05 & $1,92 \%$ \\
\hline & \multirow{3}{*}{$10 \%$} & $W_{0}-2 \%$ & 14,0 & 1,43 & 3,00 & 3,03 & 2,90 & 2,98 & 0,07 & $2,30 \%$ \\
\hline & & $w_{0}$ & 16,2 & 1,45 & 3,03 & 3,10 & 2,97 & 3,03 & 0,07 & $2,26 \%$ \\
\hline & & $w_{0}+2 \%$ & 18,6 & 1,45 & 3,18 & 2,93 & 2,98 & 3,03 & 0,13 & $4,33 \%$ \\
\hline & $12 \%$ & $w_{0}$ & 16,4 & 1,45 & 3,44 & 3,39 & 3,42 & 3,41 & 0,03 & $0,77 \%$ \\
\hline & $15 \%$ & $w_{0}$ & 16,7 & 1,46 & 3,71 & 3,73 & 3,65 & 3,70 & 0,04 & $1,07 \%$ \\
\hline
\end{tabular}


Tabela B.4: Valores de resistência à compressão simples para corpos de prova ensaiados com imersão prévia e compactados na energia intermediária.

\begin{tabular}{|c|c|c|c|c|c|c|c|c|c|c|}
\hline \multirow{3}{*}{$\begin{array}{l}\text { Período } \\
\text { de } \\
\text { cura } \\
\text { (dias) }\end{array}$} & \multirow{3}{*}{$\begin{array}{c}\text { Teor } \\
\text { de } \\
\text { cimento } \\
(\%)\end{array}$} & \multirow{3}{*}{\multicolumn{2}{|c|}{$\begin{array}{c}\text { Umidade } \\
\text { de } \\
\text { compactação } \\
(\%)\end{array}$}} & \multirow{3}{*}{$\begin{array}{c}\text { Massa } \\
\text { específica } \\
\text { seca } \\
\text { máxima } \\
(\text { média) } \\
\left(\mathrm{g} / \mathrm{cm}^{3}\right)\end{array}$} & \multicolumn{6}{|c|}{ Resistência à compressão simples (MPa) } \\
\hline & & & & & \multicolumn{3}{|c|}{ c.p. } & \multirow[t]{2}{*}{ Média } & \multirow{2}{*}{$\begin{array}{l}\text { Desvio } \\
\text { padrão }\end{array}$} & \multirow{2}{*}{$\begin{array}{c}\text { Coeficiente } \\
\text { de } \\
\text { variação }\end{array}$} \\
\hline & & & & & 4 & 5 & 6 & & & \\
\hline \multirow{4}{*}{3 dias } & $7 \%$ & $w_{0}$ & 15,7 & 1,39 & 0,45 & - & - & - & - & - \\
\hline & $10 \%$ & $w_{0}$ & 16,3 & 1,40 & 0,56 & - & - & - & - & - \\
\hline & $12 \%$ & $w_{0}$ & 16,6 & 1,41 & 0,71 & - & - & - & - & - \\
\hline & $15 \%$ & $\mathrm{w}_{0}$ & 15,9 & 1,41 & 0,98 & - & - & - & - & - \\
\hline \multirow{8}{*}{7 dias } & \multirow{3}{*}{$7 \%$} & $W_{0}-2 \%$ & 13,8 & 1,41 & 1,37 & 1,36 & 1,39 & 1,37 & 0,015 & $1,09 \%$ \\
\hline & & $w_{0}$ & 16,4 & 1,41 & 1,39 & 1,40 & 1,36 & 1,39 & 0,021 & $1,50 \%$ \\
\hline & & $w_{0}+2 \%$ & 17,5 & 1,41 & 1,32 & 1,31 & 1,38 & 1,34 & 0,036 & $2,70 \%$ \\
\hline & \multirow{3}{*}{$10 \%$} & $\mathrm{w}_{0}-2 \%$ & 14,2 & 1,44 & 1,86 & 1,86 & 1,75 & 1,82 & 0,059 & $3,22 \%$ \\
\hline & & $\mathrm{w}_{0}$ & 15,7 & 1,43 & 1,81 & 1,72 & 1,78 & 1,77 & 0,046 & $2,58 \%$ \\
\hline & & $w_{0}+2 \%$ & 17,5 & 1,44 & 1,77 & 1,75 & 1,65 & 1,73 & 0,063 & $3,65 \%$ \\
\hline & $12 \%$ & $\mathrm{~W}_{0}$ & 15,2 & 1,44 & 1,97 & 1,89 & 1,84 & 1,90 & 0,09 & $4,70 \%$ \\
\hline & $15 \%$ & $w_{0}$ & 15,1 & 1,43 & 2,40 & 2,40 & 2,40 & 2,40 & 0,00 & $0,00 \%$ \\
\hline \multirow{4}{*}{14 dias } & $7 \%$ & $w_{0}$ & 16,3 & 1,43 & 1,79 & 1,82 & 1,73 & 1,78 & 0,04 & $2,41 \%$ \\
\hline & $10 \%$ & $w_{0}$ & 16,3 & 1,42 & 2,18 & 2,30 & 2,22 & 2,23 & 0,06 & $2,69 \%$ \\
\hline & $12 \%$ & $w_{0}$ & 16,3 & 1,42 & 2,56 & 2,34 & 2,26 & 2,39 & 0,15 & $6,40 \%$ \\
\hline & $15 \%$ & $w_{0}$ & 16,2 & 1,42 & 2,92 & 2,87 & 2,84 & 2,88 & 0,04 & $1,51 \%$ \\
\hline \multirow{8}{*}{28 dias } & \multirow{3}{*}{$7 \%$} & $\mathrm{w}_{0}-2 \%$ & 15,1 & 1,41 & 2,02 & 1,95 & 1,93 & 1,97 & 0,05 & $2,40 \%$ \\
\hline & & $w_{0}$ & 17,2 & 1,41 & 1,93 & 1,95 & 1,90 & 1,93 & 0,03 & $1,31 \%$ \\
\hline & & $\mathrm{w}_{0}+2 \%$ & 19,1 & 1,41 & 1,98 & 1,88 & 1,89 & 1,92 & 0,06 & $2,87 \%$ \\
\hline & \multirow{3}{*}{$10 \%$} & $\mathrm{w}_{0}-2 \%$ & 13,9 & 1,42 & 2,34 & 2,40 & 2,36 & 2,37 & 0,03 & $1,29 \%$ \\
\hline & & $w_{0}$ & 16,2 & 1,43 & 2,42 & 2,40 & 2,46 & 2,43 & 0,03 & $1,26 \%$ \\
\hline & & $w_{0}+2 \%$ & 18,4 & 1,44 & 2,39 & 2,45 & 2,40 & 2,41 & 0,03 & $1,33 \%$ \\
\hline & $12 \%$ & $w_{0}$ & 17,2 & 1,42 & 2,68 & 2,67 & 2,61 & 2,65 & 0,04 & $1,37 \%$ \\
\hline & $15 \%$ & $w_{0}$ & 17,4 & 1,42 & 3,25 & 3,24 & 3,26 & 3,25 & 0,01 & $0,28 \%$ \\
\hline \multirow{8}{*}{84 dias } & \multirow{3}{*}{$7 \%$} & $w_{0}-2 \%$ & 14,6 & 1,43 & 2,23 & 2,04 & 2,21 & 2,16 & 0,11 & $4,94 \%$ \\
\hline & & $w_{0}$ & 16,3 & 1,43 & 2,23 & 2,22 & 2,14 & 2,20 & 0,05 & $2,31 \%$ \\
\hline & & $\mathrm{w}_{0}+2 \%$ & 18,2 & 1,43 & 2,26 & 2,23 & 2,22 & 2,24 & 0,02 & $0,91 \%$ \\
\hline & \multirow{3}{*}{$10 \%$} & $w_{0}-2 \%$ & 14,0 & 1,43 & 2,64 & 2,59 & 2,71 & 2,64 & 0,06 & $2,28 \%$ \\
\hline & & $w_{0}$ & 16,2 & 1,45 & 2,73 & 2,93 & 2,90 & 2,85 & 0,11 & $3,83 \%$ \\
\hline & & $w_{0}+2 \%$ & 18,6 & 1,45 & 2,82 & 2,65 & 2,81 & 2,76 & 0,09 & $3,41 \%$ \\
\hline & $12 \%$ & $w_{0}$ & 16,4 & 1,45 & 2,79 & 3,13 & 3,04 & 2,99 & 0,18 & $5,87 \%$ \\
\hline & $15 \%$ & $w_{0}$ & 16,7 & 1,46 & 3,42 & 3,41 & 3,32 & 3,38 & 0,05 & $1,56 \%$ \\
\hline
\end{tabular}


ANEXO C - VALORES DE MÓDULO TANGENTE INICIAL (EO) OBTIDOS DE CORPOS DE PROVA COMPACTADOS COM AS ENERGIAS NORMAL E INTERMEDIÁRIA, E ENSAIADOS COM IMERSÃO E SEM IMERSÃO PRÉVIA

Apresentam-se nas Tabelas de C.1 a C.4 os valores de módulo tangente inicial para todos os corpos de prova ensaiados na etapa definitiva de estudos. Esse valores estão separados em função da energia de compactação, da condição de ensaio, do período de cura, e do teor de cimento. Os valores de umidade e massa específica seca são os mesmos apresentados nas Tabela B.1, B.2, B.3 e B.4 para as misturas correspondentes. 
Tabela C.1:Valores de módulo tangente inicial (Eo) para corpos de prova ensaiados sem imersão e compactados na energia normal.

\begin{tabular}{|c|c|c|c|c|c|c|c|c|c|}
\hline \multirow{3}{*}{$\begin{array}{l}\text { Período } \\
\text { de cura } \\
\text { (dias) }\end{array}$} & \multirow{3}{*}{$\begin{array}{l}\text { Teor de } \\
\text { cimento } \\
\text { (\%) }\end{array}$} & \multirow{3}{*}{\multicolumn{2}{|c|}{$\begin{array}{l}\text { Umidade de } \\
\text { compactação } \\
\text { (\%) }\end{array}$}} & \multicolumn{6}{|c|}{ Módulo tangente inicial $\left(\mathrm{E}_{0}\right)(\mathrm{MPa})$} \\
\hline & & & & \multicolumn{3}{|c|}{ c.p. } & \multirow[t]{2}{*}{ Média } & \multirow{2}{*}{$\begin{array}{l}\text { Desvio } \\
\text { padrão }\end{array}$} & \multirow{2}{*}{$\begin{array}{l}\text { Coeficiente } \\
\text { de variação }\end{array}$} \\
\hline & & & & 1 & 2 & 3 & & & \\
\hline \multirow{8}{*}{7 dias } & $7 \%$ & $w_{0}$ & 22,1 & 441,50 & 444,05 & 444,05 & 443,20 & 1,47 & $0,33 \%$ \\
\hline & \multirow{3}{*}{$10 \%$} & $\mathrm{w}_{0}-2 \%$ & 21,2 & 455,17 & 467,73 & 506,84 & 476,58 & 26,95 & $5,66 \%$ \\
\hline & & $\mathrm{W}_{0}$ & 23,0 & 503,20 & 479,16 & 464,04 & 482,13 & 19,75 & $4,10 \%$ \\
\hline & & $\mathrm{w}_{0}+2 \%$ & 25,2 & 484,50 & 445,28 & 472,37 & 467,38 & 20,08 & $4,30 \%$ \\
\hline & $12 \%$ & $w_{0}$ & 22,2 & 579,84 & 497,27 & 489,96 & 522,36 & 49,92 & $9,56 \%$ \\
\hline & \multirow{3}{*}{$15 \%$} & $w_{0}-2 \%$ & 20,9 & 540,54 & 512,22 & 575,37 & 542,71 & 31,63 & $5,83 \%$ \\
\hline & & $w_{0}$ & 23,4 & 572,41 & 555,86 & 548,79 & 559,02 & 12,12 & $2,17 \%$ \\
\hline & & $w_{0}+2 \%$ & 25,3 & 498,26 & 558,66 & 519,21 & 525,38 & 30,67 & $5,84 \%$ \\
\hline \multirow{4}{*}{14 dias } & $7 \%$ & $w_{0}$ & 23,0 & 561,80 & 586,51 & 518,13 & 555,48 & 34,62 & $6,23 \%$ \\
\hline & $10 \%$ & $w_{0}$ & 22,7 & 600,24 & 603,50 & 567,21 & 590,32 & 20,07 & $3,40 \%$ \\
\hline & $12 \%$ & $w_{0}$ & 22,0 & 601,32 & 618,43 & 648,93 & 622,89 & 24,12 & $3,87 \%$ \\
\hline & $15 \%$ & $w_{0}$ & 22,3 & 683,99 & 710,23 & 667,56 & 687,26 & 21,52 & $3,13 \%$ \\
\hline \multirow{8}{*}{28 dias } & $7 \%$ & $w_{0}$ & 23,9 & 511,77 & 618,43 & 595,24 & 606,83 & 56,10 & $9,24 \%$ \\
\hline & \multirow{3}{*}{$10 \%$} & $W_{0}-2 \%$ & 21,6 & 676,59 & 628,93 & 637,76 & 647,76 & 25,36 & $3,91 \%$ \\
\hline & & $w_{0}$ & 23,5 & 642,26 & 611,25 & 652,74 & 635,42 & 21,58 & $3,40 \%$ \\
\hline & & $\mathrm{w}_{0}+2 \%$ & 25,6 & 651,89 & 605,69 & 601,87 & 619,82 & 27,84 & $4,49 \%$ \\
\hline & $12 \%$ & $w_{0}$ & 23,6 & 667,11 & 686,81 & 650,20 & 668,04 & 18,33 & $2,74 \%$ \\
\hline & \multirow{3}{*}{$15 \%$} & $w_{0}-2 \%$ & 20,7 & 702,25 & 717,88 & 678,89 & 699,67 & 19,62 & $2,80 \%$ \\
\hline & & $\mathrm{w}_{0}$ & 23,6 & 708,22 & 698,32 & 713,27 & 706,60 & 7,60 & $1,08 \%$ \\
\hline & & $w_{0}+2 \%$ & 24,9 & 689,66 & 712,25 & 689,66 & 697,19 & 13,05 & $1,87 \%$ \\
\hline \multirow{8}{*}{84 dias } & $7 \%$ & $w_{0}$ & 22,2 & 706,21 & 637,76 & 697,84 & 680,60 & 37,34 & $5,49 \%$ \\
\hline & \multirow{3}{*}{$10 \%$} & $w_{0}-2 \%$ & 20,6 & 717,88 & 703,73 & 724,64 & 715,41 & 10,67 & $1,49 \%$ \\
\hline & & $w_{0}$ & 22,7 & 710,23 & 719,42 & 702,25 & 710,63 & 8,60 & $1,21 \%$ \\
\hline & & $w_{0}+2 \%$ & 25,1 & 725,16 & 706,21 & 709,22 & 713,53 & 10,18 & $1,43 \%$ \\
\hline & $12 \%$ & $w_{0}$ & 22,1 & 753,01 & 683,53 & 738,01 & 724,85 & 36,56 & $5,04 \%$ \\
\hline & \multirow{3}{*}{$15 \%$} & $w_{0}-2 \%$ & 20,8 & 727,80 & 724,64 & 741,84 & 731,43 & 9,16 & $1,25 \%$ \\
\hline & & $w_{0}$ & 23,4 & 745,71 & 738,01 & 748,50 & 744,07 & 5,44 & $0,73 \%$ \\
\hline & & $w_{0}+2 \%$ & 25,5 & 748,50 & 734,75 & 742,39 & 741,88 & 6,89 & $0,93 \%$ \\
\hline
\end{tabular}


Tabela C.2: Valores de módulo tangente inicial (Eo) para corpos de prova ensaiados sem imersão e compactados na energia normal.

\begin{tabular}{|c|c|c|c|c|c|c|c|c|c|}
\hline \multirow{3}{*}{$\begin{array}{l}\text { Período } \\
\text { de cura } \\
\text { (dias) }\end{array}$} & \multirow{3}{*}{$\begin{array}{l}\text { Teor de } \\
\text { cimento } \\
(\%)\end{array}$} & \multirow{3}{*}{\multicolumn{2}{|c|}{$\begin{array}{c}\text { Umidade de } \\
\text { compactação } \\
(\%)\end{array}$}} & \multicolumn{6}{|c|}{ Módulo tangente inicial (Eo) (MPa) } \\
\hline & & & & \multicolumn{3}{|c|}{ c.p. } & \multirow[t]{2}{*}{ Média } & \multirow{2}{*}{$\begin{array}{l}\text { Desvio } \\
\text { padrão }\end{array}$} & \multirow{2}{*}{$\begin{array}{l}\text { Coeficiente } \\
\text { de variação }\end{array}$} \\
\hline & & & & 4 & 5 & 6 & & & \\
\hline \multirow{8}{*}{7 dias } & $7 \%$ & $w_{0}$ & 22,1 & 464,92 & 438,17 & 395,41 & 432,84 & 35,06 & $8,10 \%$ \\
\hline & & $w_{0}-2 \%$ & 21,2 & 461,04 & 438,79 & 504,64 & 468,16 & 33,50 & $7,16 \%$ \\
\hline & $10 \%$ & $w_{0}$ & 23,0 & 475,29 & 466,85 & 473,04 & 471,73 & 4,37 & $0,93 \%$ \\
\hline & & $w_{0}+2 \%$ & 25,2 & 471,25 & 447,63 & 461,04 & 459,97 & 11,85 & $2,58 \%$ \\
\hline & $12 \%$ & $w_{0}$ & 22,2 & 516,80 & 513,08 & 498,41 & 509,43 & 9,73 & $1,91 \%$ \\
\hline & & $w_{0}-2 \%$ & 20,9 & 477,55 & 579,37 & 508,91 & 521,95 & 52,15 & $9,99 \%$ \\
\hline & $15 \%$ & $w_{0}$ & 23,4 & 532,77 & 543,77 & 557,72 & 544,75 & 12,51 & $2,30 \%$ \\
\hline & & $w_{0}+2 \%$ & 25,3 & 561,86 & 459,14 & 533,05 & 518,02 & 52,99 & $10,23 \%$ \\
\hline \multirow{4}{*}{14} & $7 \%$ & $w_{0}$ & 23,0 & 528,26 & 566,89 & 468,82 & 521,33 & 49,40 & $9,48 \%$ \\
\hline & $10 \%$ & $w_{0}$ & 22,7 & 565,93 & 583,77 & 552,18 & 567,29 & 15,84 & $2,79 \%$ \\
\hline & $12 \%$ & $w_{0}$ & 22,0 & 597,01 & 600,24 & 589,28 & 595,51 & 5,64 & $0,95 \%$ \\
\hline & $15 \%$ & $w_{0}$ & 22,3 & 683,99 & 664,01 & 657,46 & 668,49 & 13,82 & $2,07 \%$ \\
\hline \multirow{8}{*}{28 dias } & $7 \%$ & $w_{0}$ & 23,9 & 598,09 & 566,89 & 582,41 & 582,46 & 15,60 & $2,68 \%$ \\
\hline & & $\mathrm{w}_{0}-2 \%$ & 21,6 & 626,17 & 625,39 & 642,26 & 631,28 & 9,52 & $1,51 \%$ \\
\hline & $10 \%$ & $w_{0}$ & 23,5 & 611,62 & 607,53 & 614,25 & 611,13 & 3,38 & $0,55 \%$ \\
\hline & & $\mathrm{w}_{0}+2 \%$ & 25,6 & 614,63 & 605,33 & 602,41 & 607,45 & 6,38 & $1,05 \%$ \\
\hline & $12 \%$ & $w_{0}$ & 23,6 & 656,17 & 656,17 & 625,78 & 646,04 & 17,54 & $2,72 \%$ \\
\hline & & $w_{0}-2 \%$ & 20,7 & 695,89 & 644,75 & 694,93 & 678,52 & 29,26 & $4,31 \%$ \\
\hline & $15 \%$ & $\mathrm{~W}_{0}$ & 23,6 & 673,85 & 685,87 & 707,21 & 688,98 & 16,90 & $2,45 \%$ \\
\hline & & $w_{0}+2 \%$ & 24,9 & 703,23 & 687,76 & 693,48 & 694,82 & 7,83 & $1,13 \%$ \\
\hline \multirow{8}{*}{84 dias } & $7 \%$ & $w_{0}$ & 22,2 & 640,61 & 618,05 & 711,74 & 656,80 & 48,90 & $7,45 \%$ \\
\hline & & $w_{0}-2 \%$ & 20,6 & 708,22 & 687,29 & 711,24 & 702,25 & 13,04 & $1,86 \%$ \\
\hline & $10 \%$ & $w_{0}$ & 22,7 & 713,78 & 653,68 & 694,20 & 687,22 & 30,65 & $4,46 \%$ \\
\hline & & $w_{0}+2 \%$ & 25,1 & 704,23 & 696,38 & 699,30 & 699,97 & 3,97 & $0,57 \%$ \\
\hline & $12 \%$ & $W_{0}$ & 22,1 & 685,40 & 745,71 & 709,72 & 713,61 & 30,34 & $4,25 \%$ \\
\hline & & $W_{0}-2 \%$ & 20,8 & 709,22 & 696,38 & 688,23 & 697,94 & 10,58 & $1,52 \%$ \\
\hline & $15 \%$ & $w_{0}$ & 23,4 & 742,39 & 715,82 & 724,11 & 727,44 & 13,59 & $1,87 \%$ \\
\hline & & $w_{0}+2 \%$ & 25,5 & 709,22 & 728,33 & 714,29 & 717,28 & 9,90 & $1,38 \%$ \\
\hline
\end{tabular}


Tabela C.3: Valores de módulo tangente inicial (Eo) para corpos de prova ensaiados sem imersão e compactados na energia intermediária.

\begin{tabular}{|c|c|c|c|c|c|c|c|c|c|}
\hline \multirow{3}{*}{$\begin{array}{l}\text { Período } \\
\text { de cura } \\
\text { (dias) }\end{array}$} & \multirow{3}{*}{$\begin{array}{c}\text { Teor de } \\
\text { cimento } \\
(\%)\end{array}$} & \multirow{3}{*}{\multicolumn{2}{|c|}{$\begin{array}{c}\text { Umidade de } \\
\text { compactação } \\
\text { (\%) }\end{array}$}} & \multicolumn{6}{|c|}{ Módulo tangente inicial (Eo) (MPa) } \\
\hline & & & & \multicolumn{3}{|c|}{ c.p. } & \multirow[t]{2}{*}{ Média } & \multirow{2}{*}{$\begin{array}{l}\text { Desvio } \\
\text { padrão }\end{array}$} & \multirow{2}{*}{$\begin{array}{l}\text { Coeficiente } \\
\text { de variação }\end{array}$} \\
\hline & & & & 1 & 2 & 3 & & & \\
\hline \multirow{8}{*}{7 dias } & \multirow{3}{*}{$7 \%$} & $w_{0}-2 \%$ & 13,8 & 465,98 & 488,52 & 616,14 & 523,55 & 80,98 & $15,47 \%$ \\
\hline & & $w_{0}$ & 16,4 & 484,03 & 509,42 & 531,35 & 508,27 & 23,68 & $4,66 \%$ \\
\hline & & $\mathrm{w}_{0}+2 \%$ & 17,5 & 481,23 & 513,35 & & 497,29 & 22,71 & $4,57 \%$ \\
\hline & \multirow{3}{*}{$10 \%$} & $W_{0}-2 \%$ & 14,2 & 523,01 & 521,38 & 526,87 & 523,75 & 2,82 & $0,54 \%$ \\
\hline & & $w_{0}$ & 15,7 & 536,19 & 533,05 & 532,48 & 533,91 & 2,00 & $0,37 \%$ \\
\hline & & $\mathrm{w}_{\mathrm{o}}+2 \%$ & 17,5 & 527,15 & 530,22 & 528,26 & 528,54 & 1,56 & $0,29 \%$ \\
\hline & $12 \%$ & $w_{0}$ & 15,2 & 638,57 & 564,33 & 500,50 & 567,80 & 69,10 & $12,17 \%$ \\
\hline & $15 \%$ & $w_{0}$ & 15,1 & 560,54 & 613,50 & 655,31 & 609,78 & 47,49 & $7,79 \%$ \\
\hline \multirow{4}{*}{14} & $7 \%$ & $w_{0}$ & 16,3 & 641,44 & 653,59 & 660,07 & 651,70 & 9,46 & $1,45 \%$ \\
\hline & $10 \%$ & $\mathrm{w}_{0}$ & 16,3 & 694,44 & 637,35 & 704,23 & 678,67 & 36,12 & $5,32 \%$ \\
\hline & $12 \%$ & $W_{0}$ & 16,3 & 705,72 & 698,81 & 700,28 & 701,60 & 3,64 & $0,52 \%$ \\
\hline & $15 \%$ & $w_{0}$ & 16,2 & 708,22 & 736,92 & 728,86 & 724,67 & 14,81 & $2,04 \%$ \\
\hline \multirow{8}{*}{28 dias } & \multirow{3}{*}{$7 \%$} & $w_{0}-2 \%$ & 15,1 & 650,62 & 627,35 & 703,73 & 660,57 & 39,15 & $5,93 \%$ \\
\hline & & $w_{0}$ & 17,2 & 672,49 & 674,31 & 675,68 & 674,16 & 1,60 & $0,24 \%$ \\
\hline & & $w_{0}+2 \%$ & 19,1 & 607,53 & 718,39 & 701,75 & 675,89 & 59,78 & $8,84 \%$ \\
\hline & \multirow{3}{*}{$10 \%$} & $w_{0}-2 \%$ & 13,9 & 682,13 & 628,93 & 697,35 & 669,47 & 35,92 & $5,37 \%$ \\
\hline & & $w_{0}$ & 16,2 & 699,79 & 725,16 & 695,41 & 706,79 & 16,06 & $2,27 \%$ \\
\hline & & $w_{0}+2 \%$ & 18,4 & 679,81 & 676,13 & 665,78 & 673,91 & 7,28 & $1,08 \%$ \\
\hline & $12 \%$ & $w_{0}$ & 17,2 & 718,39 & 760,46 & 696,86 & 739,42 & 29,74 & $4,02 \%$ \\
\hline & $15 \%$ & $w_{0}$ & 17,4 & 741,84 & 762,20 & 745,16 & 749,73 & 10,92 & $1,46 \%$ \\
\hline \multirow{8}{*}{84 dias } & \multirow{3}{*}{$7 \%$} & $w_{0}-2 \%$ & 14,6 & & 702,26 & 663,74 & 683,00 & 27,24 & $3,99 \%$ \\
\hline & & $w_{0}$ & 16,3 & 703,73 & 707,71 & 704,23 & 705,22 & 2,17 & $0,31 \%$ \\
\hline & & $w_{0}+2 \%$ & 18,2 & 693,09 & 723,56 & 659,35 & 692,00 & 32,12 & $4,64 \%$ \\
\hline & \multirow{3}{*}{$10 \%$} & $w_{0}-2 \%$ & 14,0 & 710,23 & 679,35 & 798,08 & 729,22 & 61,60 & $8,45 \%$ \\
\hline & & $w_{0}$ & 16,2 & 741,29 & 745,71 & 747,38 & 744,80 & 3,15 & $0,42 \%$ \\
\hline & & $w_{0}+2 \%$ & 18,6 & 716,33 & 754,72 & 724,11 & 731,72 & 20,29 & $2,77 \%$ \\
\hline & $12 \%$ & $w_{0}$ & 16,4 & 786,16 & 816,99 & 738,55 & 780,57 & 39,52 & $5,06 \%$ \\
\hline & $15 \%$ & $w_{0}$ & 16,7 & 755,29 & 823,05 & 814,33 & 797,55 & 36,86 & $4,62 \%$ \\
\hline
\end{tabular}


Tabela C.4: Valores de módulo tangente inicial (Eo) para corpos de prova ensaiados com imersão e compactados na energia intermediária.

\begin{tabular}{|c|c|c|c|c|c|c|c|c|c|}
\hline \multirow{3}{*}{$\begin{array}{l}\text { Período } \\
\text { de cura } \\
\text { (dias) }\end{array}$} & \multirow{3}{*}{$\begin{array}{c}\text { Teor de } \\
\text { cimento } \\
\text { (\%) }\end{array}$} & \multirow{3}{*}{\multicolumn{2}{|c|}{$\begin{array}{l}\text { Umidade de } \\
\text { Compactação } \\
\text { (\%) }\end{array}$}} & \multicolumn{6}{|c|}{ Módulo tangente inicial (Eo) (MPa) } \\
\hline & & & & \multicolumn{3}{|c|}{ c.p. } & \multirow[t]{2}{*}{ Média } & \multirow{2}{*}{$\begin{array}{l}\text { Desvio } \\
\text { padrão }\end{array}$} & \multirow{2}{*}{$\begin{array}{l}\text { Coeficiente } \\
\text { de variação }\end{array}$} \\
\hline & & & & 4 & 5 & 6 & & & \\
\hline \multirow{8}{*}{7 dias } & \multirow{3}{*}{$7 \%$} & $w_{0}-2 \%$ & 13,8 & 465,98 & 499,50 & 496,77 & 487,42 & 18,61 & $3,82 \%$ \\
\hline & & $w_{0}$ & 16,4 & 482,16 & 481,70 & 504,03 & 489,30 & 12,76 & $2,61 \%$ \\
\hline & & $\mathrm{w}_{0}+2 \%$ & 17,5 & 485,44 & 479,39 & 476,64 & 480,49 & 4,50 & $0,94 \%$ \\
\hline & \multirow{3}{*}{$10 \%$} & $w_{0}-2 \%$ & 14,2 & 530,50 & 495,29 & 504,03 & 509,94 & 18,334 & $3,60 \%$ \\
\hline & & $w_{0}$ & 15,7 & 499,75 & 519,21 & 491,40 & 503,45 & 14,27 & $2,83 \%$ \\
\hline & & $\mathrm{w}_{0}+2 \%$ & 17,5 & 479,85 & 491,88 & 513,35 & 495,03 & 16,97 & $3,43 \%$ \\
\hline & $12 \%$ & $w_{0}$ & 15,2 & 528,54 & 564,02 & 542,01 & 535,27 & 9,52 & $1,78 \%$ \\
\hline & $15 \%$ & $w_{0}$ & 15,1 & 542,59 & 624,22 & 630,91 & 599,24 & 49,17 & $8,21 \%$ \\
\hline \multirow{4}{*}{14 dias } & $7 \%$ & $w_{0}$ & 16,3 & 633,71 & 649,35 & 629,33 & 637,46 & 10,53 & $1,65 \%$ \\
\hline & $10 \%$ & $w_{0}$ & 16,3 & 659,20 & 648,51 & 639,80 & 649,17 & 9,72 & $1,50 \%$ \\
\hline & $12 \%$ & $w_{0}$ & 16,3 & 665,78 & 659,63 & 665,78 & 663,73 & 3,55 & $0,53 \%$ \\
\hline & $15 \%$ & $w_{0}$ & 16,2 & 667,11 & 670,69 & 677,51 & 671,77 & 5,28 & $0,79 \%$ \\
\hline \multirow{8}{*}{28 dias } & \multirow{3}{*}{$7 \%$} & $w_{0}-2 \%$ & 15,1 & 629,33 & 657,03 & 632,07 &, 48 & 15,26 & $2,39 \%$ \\
\hline & & $w_{0}$ & 17,2 & 631,71 & 672,49 & 661,38 & 655,19 & 21,08 & $3,22 \%$ \\
\hline & & $w_{0}+2 \%$ & 19,1 & 640,45 & 678,10 & 650,58 & 656,38 & 19,49 & $2,97 \%$ \\
\hline & \multirow{3}{*}{$10 \%$} & $w_{0}-2 \%$ & 13,9 & 644,75 & 623,83 & 642,67 & 637,08 & 11,52 & $1,81 \%$ \\
\hline & & $w_{0}$ & 16,2 & 659,20 & 663,13 & 665,78 & 662,70 & 3,31 & $0,50 \%$ \\
\hline & & $\mathrm{w}_{0}+2 \%$ & 18,4 & 635,73 & 657,89 & 655,31 & 649,64 & 12,12 & $1,87 \%$ \\
\hline & $12 \%$ & $w_{0}$ & 17,2 & 688,23 & 697,35 & 679,35 & 688,31 & 9,00 & $1,31 \%$ \\
\hline & $15 \%$ & $w_{0}$ & 17,4 & 677,74 & 703,23 & 713,27 & 698,08 & 18,32 & $2,62 \%$ \\
\hline \multirow{8}{*}{84 dias } & \multirow{3}{*}{$7 \%$} & $w_{0}-2 \%$ & 14,6 & 652,74 & 657,03 & 677,78 & 662,52 & 13,39 & $2,02 \%$ \\
\hline & & $w_{0}$ & 16,3 & 673,40 & 664,89 & 673,85 & 670,72 & 5,05 & $0,75 \%$ \\
\hline & & $w_{0}+2 \%$ & 18,2 & 640,45 & 678,10 & 686,53 & 686,53 & 24,54 & $3,57 \%$ \\
\hline & \multirow{3}{*}{$10 \%$} & $w_{0}-2 \%$ & 14,0 & 698,32 & 673,40 & 674,76 & 682,16 & 14,01 & $2,05 \%$ \\
\hline & & $w_{0}$ & 16,2 & 698,81 & 709,72 & 704,23 & 704,25 & 5,46 & $0,77 \%$ \\
\hline & & $w_{0}+2 \%$ & 18,6 & 703,73 & 719,42 & 715,82 & 712,99 & 8,22 & $1,15 \%$ \\
\hline & $12 \%$ & $w_{0}$ & 16,4 & 740,19 & 719,94 & 710,73 & 723,62 & 15,07 & $2,08 \%$ \\
\hline & $15 \%$ & $w_{0}$ & 16,7 & 739,10 & 680,27 & 806,45 & 741,94 & 63,14 & $8,51 \%$ \\
\hline
\end{tabular}


Ensaios aplicados em materiais presumivelmente idênticos, sob circunstancias presumivelmente idênticas, não conduzem, de maneira geral, a resultados idênticos. Isso é atribuído a erros aleatórios inevitáveis e inerentes a todos os procedimentos de ensaios. Os fatores que influenciam os resultados dos ensaios não podem ser completamente controlados. $\mathrm{Na}$ interpretação dos resultados dos ensaios, essa variabilidade deve ser levada em conta (ISO 5725).

A preocupação com qualidade dos resultados obtidos nesta pesquisa motivou a realização do estudo de repetibilidade para verificar-se a consistência entre os valores obtidos para as trincas de corpos de prova. Segundo PEIXOTO (1996), a ISO 5725 permite que se avalie a qualidade dos ensaios através da repetibilidade.

A ISO 5725 define como valor de repetibilidade $r$, aquele abaixo do qual, a diferença absoluta entre 2 ou mais resultados obtidos nas condições impostas, tenha probabilidade de ocorrência de $95 \%$. O procedimento para cálculo da repetibilidade, adotado neste trabalho, foi apresentado por Peixoto (1996).

Adotou-se neste estudo um nível de confiança de $90 \%$. Das três relações existentes entre os valores de repetibilidade e as médias, adotou-se a que representa uma reta passando pela origem. 
Essa analise foi realizada apenas para a resistência à compressão simples, sendo que os corpos de prova descartados a partir daí não foram considerados para o Eo. Os resultados da análise de repetibilidade forneceram indicações para o descarte de um único corpo de prova, no caso o corpo de prova $1, \operatorname{com} 7 \%$ de cimento, curado por 84 dias e ensaiado sem imersão. Inicialmente, o coeficiente de variação apresentado pela trinca de corpos de prova foi $30,54 \%$. Após o descarte do corpo de prova 1 esse valor caiu para $6,02 \%$. 


\section{ANEXO E - RESULTADO DO ENSAIO TGA}

Este Anexo apresenta o resultado do ensaio TGA, realizado na Universidade Federal de São Carlos, para avaliação do comportamento do fosfogesso di-hidratado frente a variação da temperatura. Analisando-se a Figura E.1, apresentada na seqüência, observa-se que apenas temperaturas a partir de $90{ }^{\circ} \mathrm{C}$ iniciam o processo de desidratação do fosfogesso, com saída da água molecular. Portanto, a temperatura usada neste estudo, 40 ${ }^{\circ} \mathrm{C}$, não converte o fosfogesso di-hidratado em anidro. 

Sample: GESSO
Size: $\quad 7.7970 \mathrm{mg}$
Method: 10/250
TGA
File: C: GESSO.01
operator: DANI
Comment: ALUMINA 9OML/MIN N2
Run Date: 17-Jul-97 11: 22

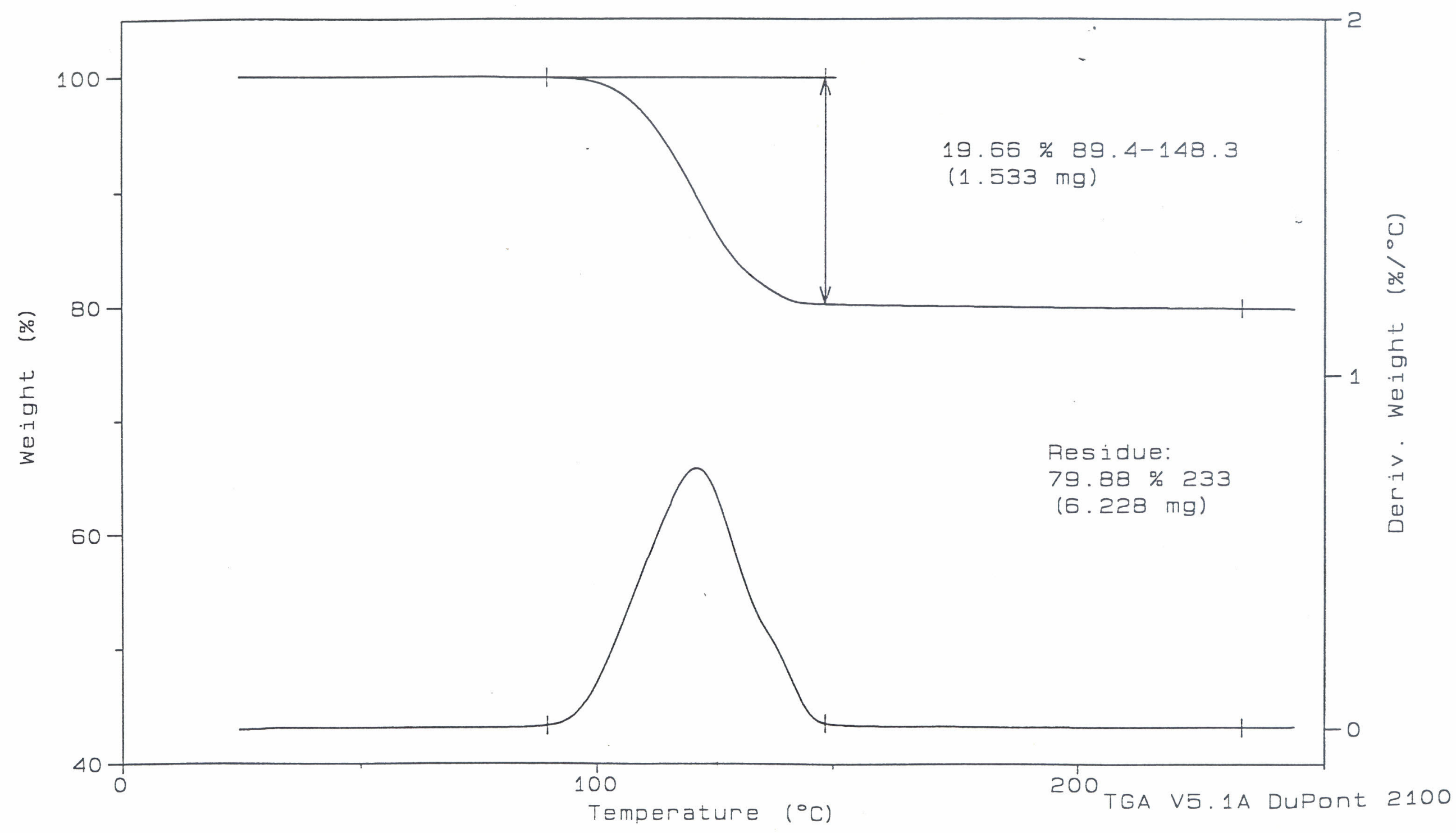

